\title{
Lead Exposures and Biological Responses in Military Weapons Systems: Aerosol Characteristics and Acute Lead Effects among U.S. Army Artillerymen - Final Report
}

by M.H. Bhattacharyya, J.H. Stebbings, D.P. Peterson, S.A. Johnson,"

R. Kumar," B.D. Goun, I. Janssen, and J.E. Trier

Biological and Medical Research Division,

Argonne National Laboratory, 9700 South Cass Avenue, Argonne, Illinois 60439

March 1993

Army Project No. 86PP6821

Supported by U.S. Army Medical Research and Development Command

Fort Detrick, Frederick, Maryland 21702:5012

Contracting Officer's Representative: Major David L. Parmer

U.S. Army Biomedical Research and Development Laboratory

Approved for public release; distribution unlimited

The findings in this report are not to be construed as an official Department of the Army position unless so designated by other authorized documents.

"Johnson and Kumar are affiliated with Argonne's Chemical Technology Division. 
Unclassified

SECUAITY CLASSIFICATION OF THIS PAGE

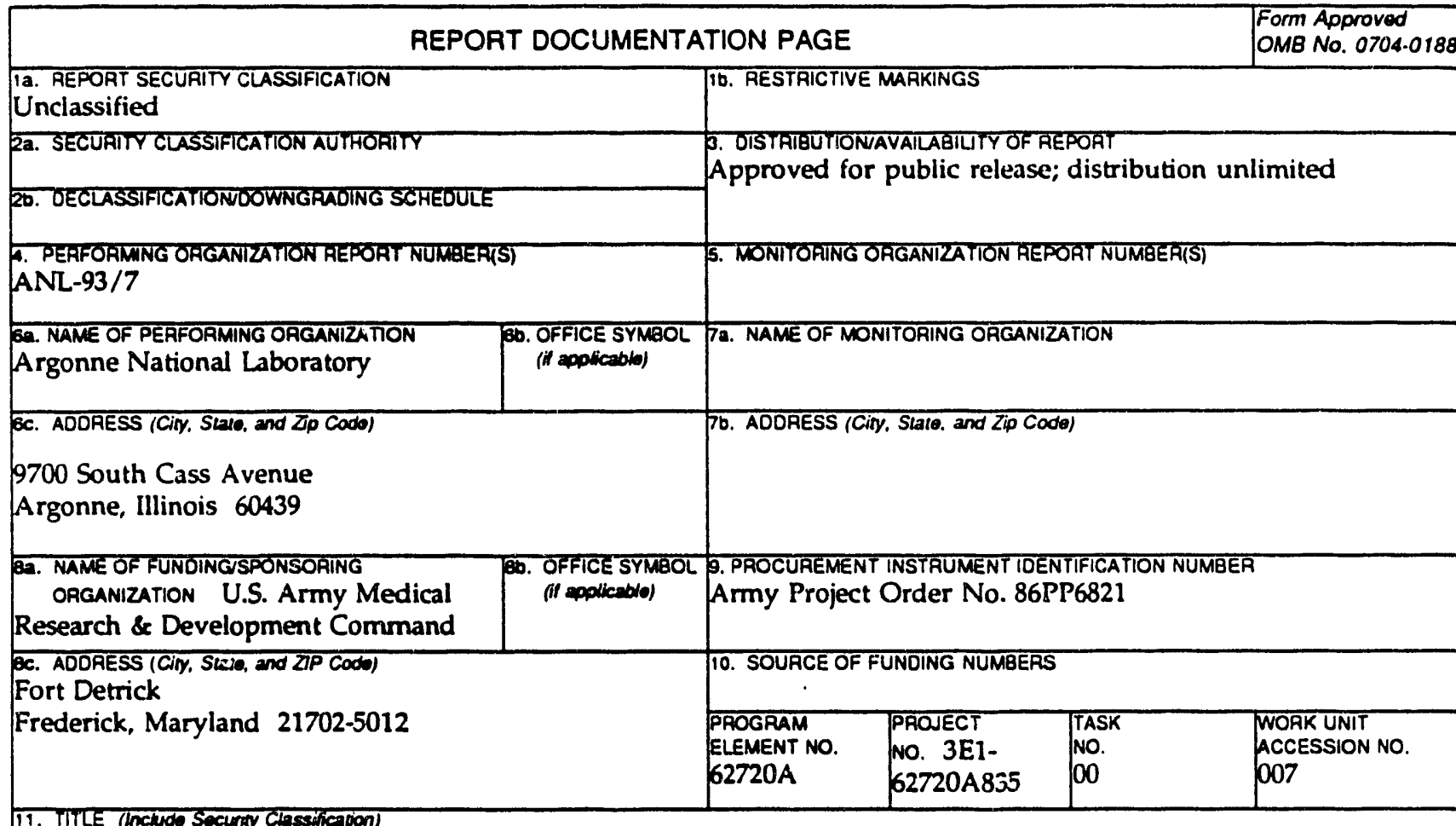

(U) Lead Exposures and Biological Responses in Military Weapons Systems

12. PERSONAL AUTHOAIS

M.H. Bhattacharyya, J.H. Stebbings, D.P. Peterson, S.A. Johnson, R. Kumar, B.C. Coun, I. Janssen, and J.E. Trier

13. TYPE OF AEPPAT 136. TIME COVERED

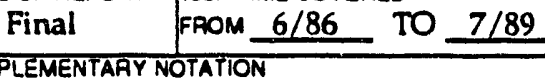

14. OATEOF REPOAT (YQAr, Month, Day)

1993, March

15. PAGE COUN

152

18. SUPPLEMENTAAY NOTATION
Subtitle: Aerosol Characteristics and Acute Lead Effects among U.S. Army Artillerymen - Final Report

\begin{tabular}{|c|c|c|c|}
\hline \multicolumn{3}{|c|}{ COSATICOOES } & 18. SUBUECT TERMS (Coninus on reverse il necesssary and idenify by block number) \\
\hline FIELD & GFOUP & SUE-GROUP & RA 3, lead aerosols, 8-in./M110 howitzer, 155-mm/M109A3 howitzer, \\
\hline 06 & 14 & & $\begin{array}{l}\text { hematocrit, nerve conduction velocity } \\
\text { theme erytnrocyte porpnymins, }\end{array}$ \\
\hline 06 & 11 & & \\
\hline
\end{tabular}

This study was to determine the concentration and chemical nature of lead $(\mathrm{Pb})$ aerosols produced during the firing of artillery and to determine the exposures and biological responses of crew members exposed to lead aerosols during such firing. The concentrations of lead-containing aerosols at crew positions depended on wind conditions, with higher concentrations when firing into a head wind. Aerosol concentrations were highest in the muzzle blast zone. Concentrations of lead in the blood of crew members rose during the first 12 days of exposure to elevated airborne lead concentrations and then leveled off. There was no rapid decrease in blood lead concentrations after completion of firing. Small decreases in hematocrit and small increases in free erythrocyte porphyrin were correlated with increasing exposure to airborne lead. These changes were reversed by seven weeks after firing. Changes in nerve conduction velocity had borderline statistical significance to airbome lead exposure. In measuring nerve conduction velocity, differences in skin temperature must be taken into account.

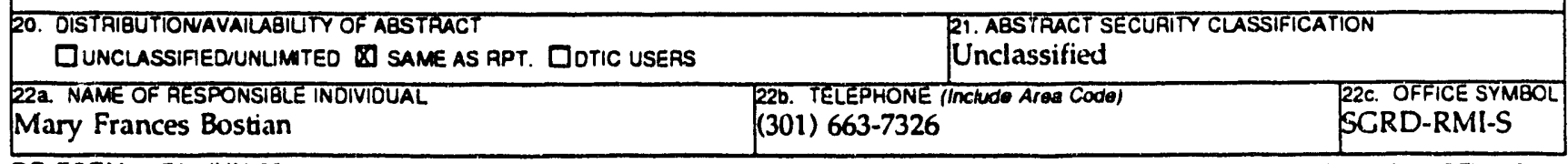

DD FORM 1473, JUN 86 SECURITY CLASSIFICATION OF THIS PAGE Unclassified 


\section{CONTENTS}

FOREWORD $\ldots \ldots \ldots \ldots \ldots \ldots \ldots \ldots \ldots \ldots \ldots \ldots \ldots \ldots \ldots \ldots \ldots \ldots$

ACKNOWLEDGMENTS $\ldots \ldots \ldots \ldots \ldots \ldots \ldots \ldots \ldots \ldots \ldots \ldots \ldots$

NOTATION $\ldots \ldots \ldots \ldots \ldots \ldots \ldots \ldots \ldots \ldots \ldots \ldots \ldots \ldots \ldots \ldots \ldots$

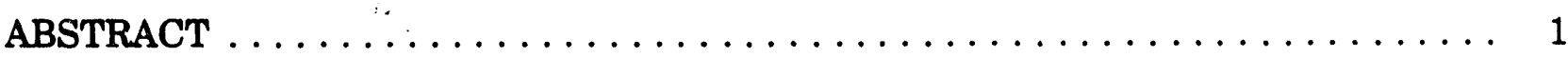

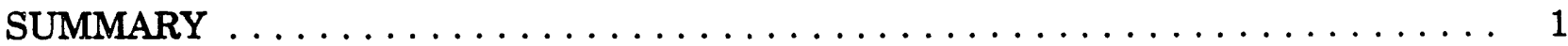

1 INTRODUCTION AND SCOPE $\ldots \ldots \ldots \ldots \ldots \ldots \ldots \ldots \ldots$

2 AEROSOL STUDIES $\ldots \ldots \ldots \ldots \ldots \ldots \ldots \ldots \ldots \ldots \ldots \ldots$

2.1 Methods $\ldots \ldots \ldots \ldots \ldots \ldots \ldots \ldots \ldots \ldots \ldots \ldots \ldots \ldots \ldots$

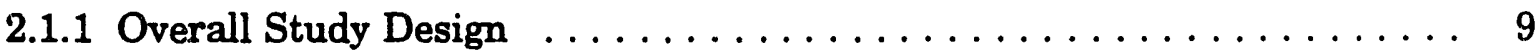

2.1.2 Instrumentation and Sampling Equipment . . . . . . . . . . 10

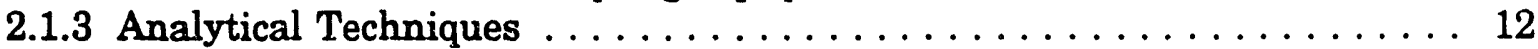

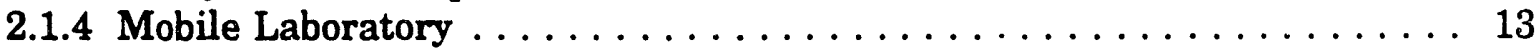

2.2 Field Studies of the 8 -in $/ \mathrm{M} 110$ Howitzer $\ldots \ldots \ldots \ldots \ldots \ldots \ldots$

2.3 Field Studies of the $155-\mathrm{mm} / \mathrm{M} 109 \mathrm{~A} 3$ Howitzers $\ldots \ldots \ldots \ldots \ldots \ldots$

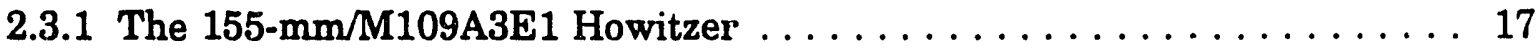

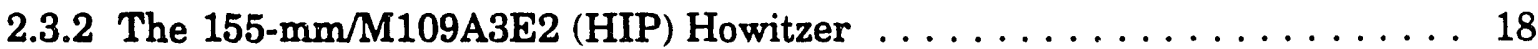

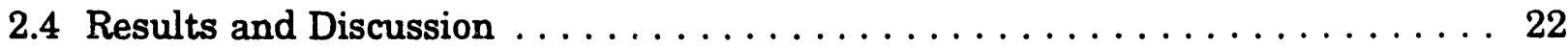

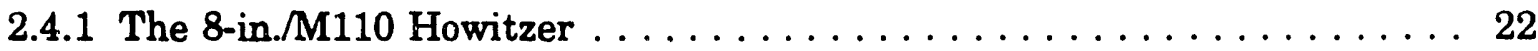

2.4.2 The $155-\mathrm{mm} / \mathrm{M} 109 \mathrm{A3}$ Howitzers $\ldots \ldots \ldots \ldots \ldots \ldots \ldots \ldots \ldots$

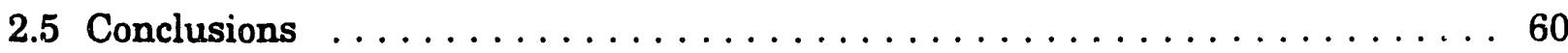

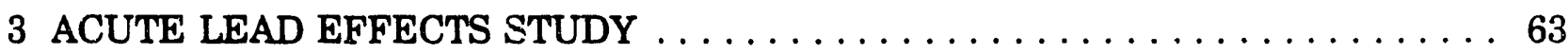

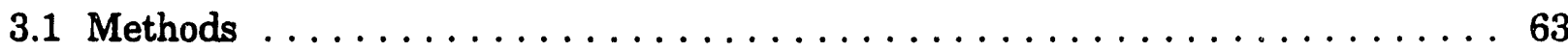

3.1.1 Overall Study Design $\ldots \ldots \ldots \ldots \ldots \ldots \ldots \ldots \ldots \ldots \ldots \ldots \ldots \ldots$

3.1 .2 Air Sampling . . . . . . . . . . . . . . . . . . . . . 64

3.1.3 Study Questionnaire . . . . . . . . . . . . . . . . 64

3.1 .4 Blood Sampling $\ldots \ldots \ldots \ldots \ldots \ldots \ldots \ldots \ldots \ldots \ldots \ldots$

3.1.5 Nerve Conduction Velocity Measurements . . . . . . . . . . . . 65

3.1 .6 Sample Analyses . . . . . . . . . . . . . . . . . . . 67

3.1.7 Dissolution of Aerosol Lead in Simulated Lung Fluid . . . . . . . . . . 68

3.1 .8 Statistical Analyses . . . . . . . . . . . . . . . . . 68

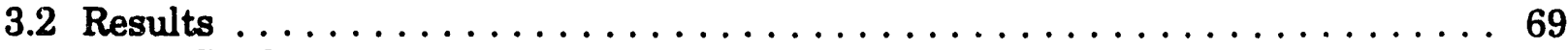

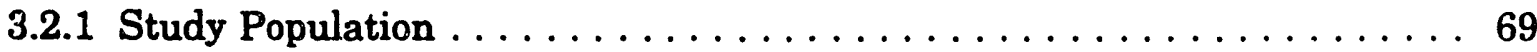

3.2.2 Air Lead and Blood Lead Concentrations . . . . . . . . . . . . . . 70

3.2.3 Relationship between Airborne Lead Exposures and

Blood Lead Responses . . . . . . . . . . . . . . . . . . . . 82

3.2.4 Hematocrit and Free Erythrocyte Porphyrin Concentrations . . . . . . . 84 


\section{CONTENTS (Cont.)}

3.2.5 Relationships between Air Lead Exposures and Changes in Hematocrit and FEP Concentrations $\ldots \ldots \ldots \ldots \ldots \ldots \ldots \ldots, 85$

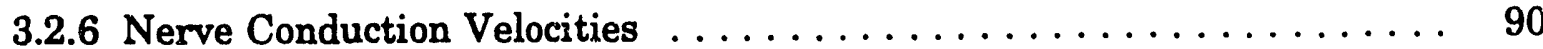

3.2.7 Dissolution of Aerosol Lead in Simulated Lung Fluid . . . . . . . . 98

3.3 Discussion .................................. 101

3.3.1 Study Population and Study Design $\ldots \ldots \ldots \ldots \ldots \ldots \ldots \ldots \ldots 1$

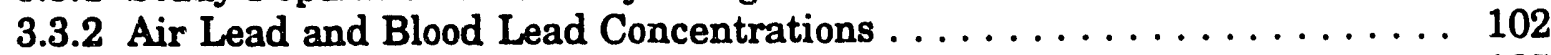

3.3.3 Relationship of Air Lead to Blood Lead . . . . . . . . . . . . . 105

3.3.4 Hematopoietic Response to Lead . . . . . . . . . . . . . . . 106

3.3.5 Peripheral Nervous System Response to Lead . . . . . . . . . . . . 107

3.3.6 Solubility Studies of the Lead Aerosol . . . . . . . . . . . . . 108

3.4 Conclusions $\ldots \ldots \ldots \ldots \ldots \ldots \ldots \ldots \ldots \ldots \ldots \ldots \ldots \ldots \ldots . \ldots \ldots$

4 RECOMMENDATIONS ........................... 111

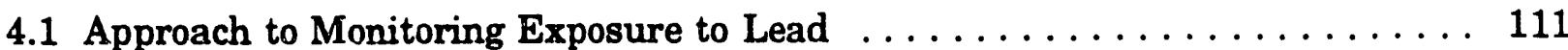

4.2 Recommendations for Research $\ldots \ldots \ldots \ldots \ldots \ldots \ldots \ldots \ldots \ldots \ldots \ldots$

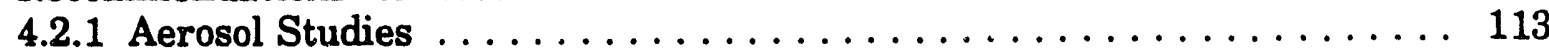

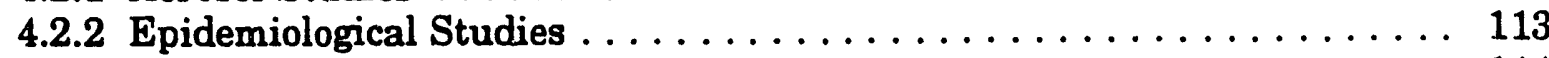

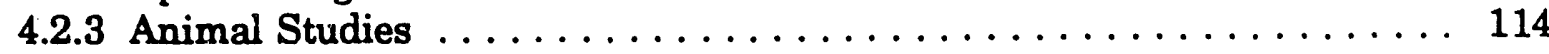

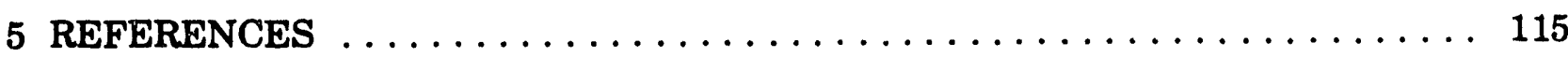

APPENDIX A: Individual Values of $\mathrm{PbA}, \mathrm{CuA}, \mathrm{PbB}$, Hematocrit, and FEP . . . . 119

APPENDIX B: Individual Values of Nerve Conduction Velocity and

Skin Temperature ....................... 127

DISTRIBUTION LIST $\ldots \ldots \ldots \ldots \ldots \ldots \ldots \ldots \ldots \ldots \ldots \ldots \ldots \ldots$

\section{FIGURES}

1 Diagram of 8-in./M110 howitzer with the positions of the filter samples and wind conditions at APG, February 10 and March 19-20, $1987 \ldots \ldots \ldots \ldots$

2 Diagram of 155-mm/M109A3E1 howitzer with positions of filter samples and wind conditions at YPG, August 19-20, 1987

3 Firing time line for August 19, 1987, at YPG for the 155-mm/M109A3E1 howitzer.

4 Firing time line for August 20, 1987, at YPG for the 155-mm/M109A3E1 howitzer. 


\section{FIGURES (Cont.)}

5 Diagram of 155-mm/M109A3E2 HIP howitzer with positions of filter samples and wind conditions at YPG from August 31 to September 2, $1988 \ldots \ldots \ldots \ldots 22$

6 a) Three howitzers in firing position at YPG; b) 8-in. howitzer firing at Fort Sill, showing muzzle blast aerosol; c) 8-in. howitzer in loading

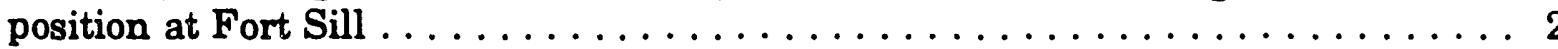

7 Particle size distribution from the firing of a single round from the

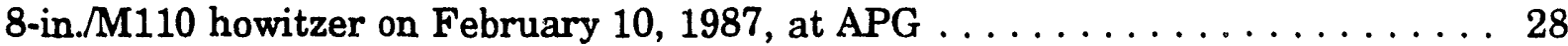

8 Climet Optical Particle Counter data from firing of the 8-in./M110 howitzer at APG on March 20,1987, using M188A1, zone 9, high-lead charges . . . . . . 29

9 Infrared spectra of breech aerosol and soil from APG compared with

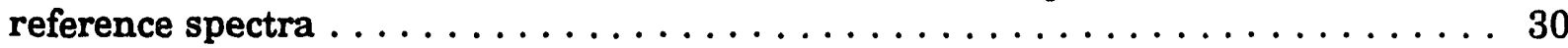

10 SEM images of aerosol from the 8-in./M110 howitzer firing M188A1 zone 9 charges at APG

11 EDX spectra for a) the 18- $\mu \mathrm{m}$ aluminate particle; b) the $3.5-\mu \mathrm{m}$

$\mathrm{Pb} / \mathrm{K}$ particle; and $\mathrm{c}$ ) the $0.6-\mu \mathrm{m} \mathrm{Pb} / \mathrm{K}$ particle shown in Figure 10

12 SEM images and EDX spectra of breech aerosol collected from the 8-in./M110 howitzer firing M188A1 zone 9 charges at APG . . . . . . . 33

13 SEM images and EDX spectra of muzzle blast aerosol collected from the 8-in./M110 howitzer firing M188A1 zone 9 charges at APG . . . . . . 35

14 Total sample weight per round fired vs. sample position and time of day. . . . . . 43

15 Weight of lead per round fired vs. sample position and time of day . . . . . . . . 44

16 SEM image and EDX spectra of aerosol from the muzzle blast of the $155-\mathrm{mm} / \mathrm{M} 109 \mathrm{~A} 3 \mathrm{E} 1 \mathrm{~h}$ owitzer at YPG on August $20,1987 \ldots \ldots \ldots \ldots . \ldots 45$

17 SEM images from the muzzle blast of the 155-mm/M109A3E2 HIP howitzer at YPG . . . . . . . . . . . . . . . . . . . . . 46

18 SEM image and EDX spectra of aerosol from the Gunner position of the 155-mm/M109A3E1 howitzer collected at YPG on August 20, $1987 \ldots \ldots \ldots \ldots 4$

19 SEM image and EDX spectrum of particle 3A from Fig. 18a . . . . . . . . . . 48

20 Climet Optical Particle Counter data from the 155-mm/M109A3E2 HIP howitzer at YPG on September 1, 1988 


\section{FIGURES (Cont.)}

21 Climet Optical Particle Counter data from the 155-mm/M109A3E2 HIP

howitzer at YPG on September $2,1988 \ldots \ldots \ldots \ldots \ldots \ldots \ldots \ldots \ldots \ldots . \ldots \ldots$

22 Time line for Fort Sill acute lead exposure study: 8-in. howitzer with CBS . . . 64

23 Characteristics of the study population $\ldots \ldots \ldots \ldots \ldots \ldots \ldots \ldots \ldots \ldots$

24 Time course of rise in blood lead concentration among five 2/18 FA

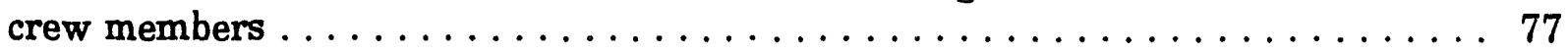

25 Firing course and lead values during the -CBS firing period for the

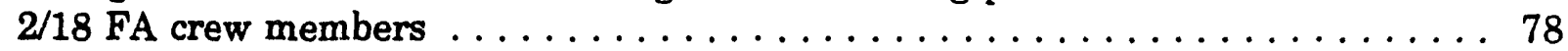

26 Firing course and lead values during the +CBS1 firing period for the

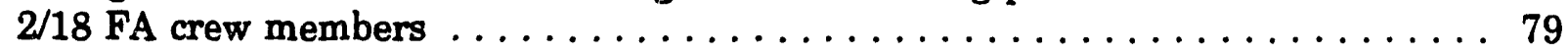

27 Firing course and lead values during the +CBS2 firing period for the

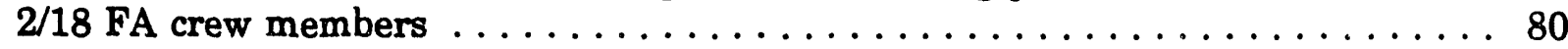

28 Firing course and lead values during the +CBS3 firing period for the

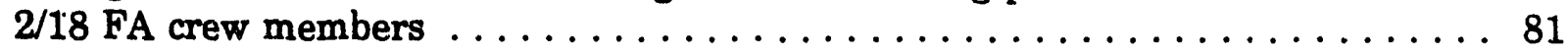

29 Relationship between acute air lead exposure and change in blood lead concentration from BL to + CBS3 $\ldots \ldots \ldots \ldots \ldots \ldots \ldots \ldots \ldots \ldots \ldots \ldots$

30 Relationship between cumulative air lead exposure and change in blood lead concentration from BL to DPE

31 Relationship between the change in hematocrit from BL to IPE and the change in blood lead concentration from BL to DPE

32 Relationship between the change in hematocrit from IPE to DPE and the change in blood lead concentration from BL to DPE

33 Relationship between the change in FEP concentration from BL to IPE and the change in blood lead concentration from BL to DPE .

34 Relationship between the change in FEP concentration from IPE to DPE and the change in blood lead concentration from BL to DPE

35 Change in peroneal nerve conduction velocity from IPE to DPE vs. the change in blood lead concentration from BL to DPE

36 Dissolution of lead nitrate and lead carbonate over time in $200 \mathrm{mM}$ acetate buffer, $\mathrm{pH} 4.8$ 


\section{FIGURES (Cont.)}

37 Dissolution of lead over time in $50 \mathrm{mM}$ acetate buffer, $\mathrm{pH} 4.8 \ldots \ldots 100$

38 Dissolution of a second lead sample over time in $50 \mathrm{mM}$ acetate

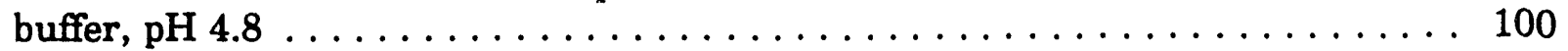

\section{TABLES}

1 Summary of testing schedule, weapons, charges, and propellants $\ldots \ldots \ldots$

2 Samples collected from firings of an 8-in./M110 howitzer at APG . . . . . . . 14

3 Samples and data taken at YPG during three days of firing the

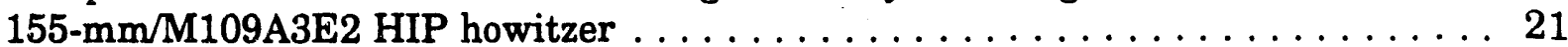

4 Data for the dichotomous impactor Teflo filter samples from the 8-in./M110 howitzer collected at APG on February 10, $1987 \ldots \ldots \ldots$. . . . . . 24

5 Lead and copper content of cellulose acetate filter samples collected at APG on February 10, 1987, in the CBS of the 8-in./M110 howitzer by using personal sampling pumps $\ldots \ldots \ldots \ldots \ldots$

6 Lead and copper content of the filter samples collected at various positions on the 8-in./M110 howitzer on March $19-20,1987 \ldots \ldots \ldots \ldots \ldots$

7 Analysis of smear tabs from the 8-in./M110 howitzer obtained on

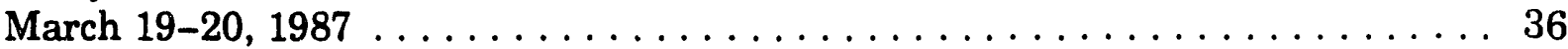

8 Sampling data and analysis of samples collected from the $155-\mathrm{mm} / \mathrm{M} 109 \mathrm{~A} 3 \mathrm{E} 1$ howitzer on August 19, $1987 \ldots \ldots \ldots \ldots \ldots \ldots \ldots \ldots$

9 Sampling data and analysis of samples collec $i$ ed from the 155-mm/M109A3E1 howitzer on August 20, $1987 \ldots \ldots \ldots \ldots \ldots \ldots \ldots \ldots$

10 Aerosol sampling data from August 31, 1988, at YPG during firing of the 155-mm/M109A3E2 HIP howitzer

11 Aerosol sampling data from September 1, 1988, at YPG during firing of the 155-mm/M109A3E2 HIP howitzer . . . . . . . . . . . . . . . . . . 50

12 Aerosol sampling data from September 2, 1988, at YPG during firing of the

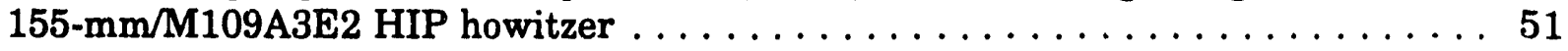

13 Data for aerosol samples collected at YPG from August 31 to September 2, 1988, during firing of the 155-mm/M109A3E2 HIP howitzer 


\section{TABLES (Cont.)}

14 Lead and copper content of samples collected by the Lundgren impactor from firings of the 155-mm/M109A3E2 HIP howitzer on

September 1-2, 1988

15 Results from samples collected during single-round firings of the 155-mm/M109A3E2 HIP howitzer on September 2, $1988 \ldots \ldots \ldots \ldots \ldots \ldots$

16 Mean $\mathrm{PbA}$ and $\mathrm{PbB}$ concentrations for artillerymen of $\mathrm{C}$ Battery, 4/4 FA . . . . 74

17 Mean $\mathrm{PbA}$ and $\mathrm{PbB}$ concentrations for artillerymen of $\mathrm{C}$ Battery, 2/18 FA . . . 75

18 Values of $\mathrm{PbB}$, hematocrit, and FEP before and after a series of firing exercises

19 Mean changes in values of $\mathrm{PbB}$, hematocrit, and FEP for three time intervals

20 Statistical analysis of relationships between lead exposure and change in hematocrit and FEP during three time intervals $\ldots \ldots \ldots \ldots \ldots \ldots$

21 Mean NCV before and after a series of firing exercises . . . . . . . . . . 91

22 Mean differences in NCV before and after a series of firing exercises $\ldots \ldots \ldots . \ldots 91$

23 Statistical analysis of the relationship between lead exposure and change in NCV during three time intervals

24 Mean NCV before and after a series of firing exercises temperature-adjusted data set $\ldots \ldots \ldots \ldots \ldots \ldots \ldots \ldots$

25 Mean differences in NCV before and after a series of firing exercises -

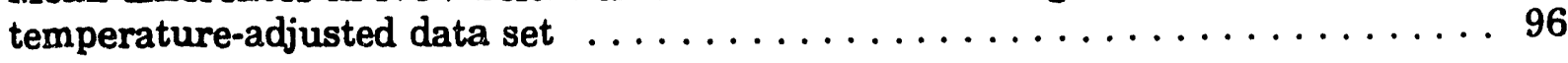

26 Statistical analysis of the relationship between lead exposure and change in NCV during three time intervals - temperature-adjusted data set

27 Effect of smoking on $\mathrm{PbB}$ response to $\mathrm{PbA}$ exposures among crew members firing the 8-in. howitzer 


\section{FOREWORD}

Opinions, interpretations, conclusions, and recommendations are those of the author and are not necessarily endorsed by the U.S. Army.

Where copyrighted material is quoted, permission has been obtained to use such material.

Where material from documents designated for limited distribution is quoted, permission has been obtained to use the material.

$x$ Citations of commercial organizations and trade names in this report do not constitute an official Department of the Army endorsement or approval of the products or services of these organizations.

In conducting research using animals, the investigator(s) adhered to the Guide for the Care and Use of Laboratory Animals, prepared by the Committee on Care and Use of Laboratory Animals of the Institute of Laboratory Animal Resources, National Research Council (NIH Publication No. 86-23, Revised 1985).

$x$ For the protection of human subjects, the investigator(s) have adhered to policies of applicable Federal Law 45CFR46.

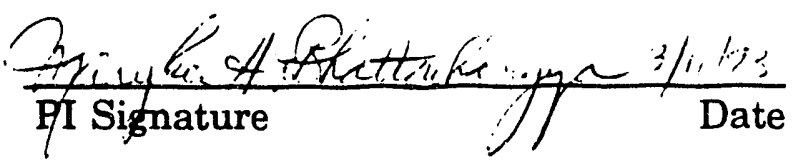




\section{ACKNOWLEDGMENTS}

The members of the Argonne research team give special thanks to Major David Parmer for his careful guidance and keen interest in all aspects of the acute lead effects study. We are indebted to Captain Paul Barron, Major Richard Bonney, Sergeant Newton Mills, and the crew members of the C Battery, 4/4 and 2/18 Field Artillery units at Fort Sill, Oklahoma, for their generous assistance and outstanding dedication to the study.

We express our appreciation to David Nadziejka for the special interest he showed in this report and the extra effort he invested in editing and managing its final publication.

Finally, thanks go to all study participants for the friendships and memories that their teamwork created. 


\section{NOTATION}

\section{Abbreviations}

$\begin{array}{ll}\text { AAS } & \text { atomic sosorption spectroscopy } \\ \text { ACGIH } & \text { Ameican Conference of Government Industrial Hygienists } \\ \text { a.d. } & \text { asrodynamic diameter } \\ \text { APG } & \text { Aberdeen Proving G'round } \\ \text { BL } & \text { baseline (before firing) } \\ \text { CBS } & \text { crew ballistic shelter (on 8-in./M110 howitzer) } \\ \text { DPE } & \text { delayed post-exposure }(6-7 \text { weeks after the end of firing) } \\ \text { EDX } & \text { energy-dispersive X-ray analysis } \\ \text { FA } & \text { field artillery } \\ \text { FEP } & \text { free erythrocyte porphyrin } \\ \text { HIP } & \text { Howitzer Improvement Program } \\ \text { IPE } & \text { immediate post-exposure (within one week of the end of firing) } \\ \text { LMS } & \text { liquid media sampler } \\ \text { MM } & \text { median motor nerve } \\ \text { MS } & \text { median sensory nerve } \\ \text { NCV } & \text { nerve conduction velocity } \\ \text { OPC } & \text { optical particle counter } \\ \text { OSHA } & \text { Occupational Safety and Health Administration } \\ \text { PbA } & \text { airborne lead } \\ \text { PbB } & \text { blood lead } \\ \text { PEL } & \text { permissible exposure limit } \\ \text { PM } & \text { peroneal motor nerve } \\ \text { SE } & \text { standard error } \\ \text { SEM } & \text { scanning electron microscope } \\ \text { SS } & \text { sural sensory nerve } \\ \text { TWA } & \text { time-weighted average } \\ \text { UM } & \text { ulnar motor nerve } \\ \text { UPASP } & \text { Universal Personal Air Sampling Pump } \\ \text { US } & \text { ulnar sensory nerve } \\ \text { YPG } & \text { Yuma Proving Ground } \\ & \end{array}$

\section{Units}

$\begin{array}{ll}{ }^{\circ} \mathrm{C} & \begin{array}{l}\text { degree Celsius } \\ \mathrm{cm}\end{array} \\ \mathrm{cm}^{-1} & \begin{array}{l}\text { centimeter } \\ \text { reciprocal centimeter } \\ \mathrm{dL}\end{array} \\ \mathrm{deciliter} \\ \mathrm{ft} & \text { foot } \\ \mathrm{g} & \text { gram } \\ \mathrm{h} & \text { hour } \\ \text { in. } & \text { inch } \\ \mathrm{L} & \text { liter } \\ \mu \mathrm{g} & \text { microgram } \\ \mu \mathrm{m} & \text { micrometer }\end{array}$




$\begin{array}{ll}\mathrm{m} & \text { meter } \\ \mathrm{mi} & \text { mile } \\ \mathrm{min} & \text { minute } \\ \mathrm{mL} & \text { milliliter } \\ \mathrm{mm} & \text { millimeter } \\ \mathrm{mM} & \text { millimolar } \\ \mathrm{ms} & \text { millisecond } \\ \mathrm{N} & \text { normal (solution concentration) } \\ \mathrm{oz} & \text { ounce } \\ \mathrm{s} & \text { second }\end{array}$

\section{Chemical Symbols}

$\begin{array}{ll}\mathrm{Al} & \text { aluminum } \\ \mathrm{Ca} & \text { calcium } \\ \mathrm{CO} & \text { carbon monoxide } \\ \mathrm{CO}_{2} & \text { carbon dioxide } \\ \mathrm{Cr} & \text { chromium } \\ \mathrm{Cu} & \text { copper } \\ \mathrm{Fe} & \text { iron } \\ \mathrm{HNO} & \text { nitric acid } \\ \mathrm{K} & \text { potassium } \\ \mathrm{KHCO} & \text { potassium bicarbonate } \\ \mathrm{K}_{2} \mathrm{SO}_{4} & \text { potassium sulfate } \\ \mathrm{Mg}_{4} & \text { magnesium } \\ \mathrm{NaHCO} & \text { sodium bicarbonate } \\ \mathrm{Pb} & \text { lead } \\ \mathrm{PbCO} & \text { lead carbonate } \\ \mathrm{Pb}\left(\mathrm{NO}_{3}\right)_{2} & \text { lead nitrate } \\ \mathrm{Si} & \text { silicon } \\ \mathrm{Ti} & \text { titanium } \\ \mathrm{TiO}_{2} & \text { titanium dioxide }\end{array}$




\title{
LEAD EXPOSURES AND BIOLOGICAL RESPONSES IN MILITARY WEAPONS SYSTEMS: AEROSOL CHARACTERISTICS AND ACUTE LEAD EFFECTS AMONG U.S. ARMY ARTHLERYMEN - FINAL REPORT
}

\author{
by
}

M.H. Bhattacharyya, J.H. Stebbings, D.P. Peterson, S.A. Johnson, R. Kumar, B.D. Goun, I. Janssen, and J.E. Trier

\begin{abstract}
This study was to determine the concentration and chemical nature of lead $(\mathrm{Pb})$ aerosols produced during the firing of artillery and to determine the exposures and biological responses of crew members exposed to lead aerosols during such firing. The concentrations of lead-containing aerosols at crew positions depended on wind conditions, with higher concentrations when firing into a head wind. Aerosol concentrations were highest in the muzzle blast zone. Concentraticns of lead in the blood of crew members rose during the first 12 days of exposure to elevated airborne lead concentrations and then leveled off. There was uo rapid decrease in blood lead concentrations after completion of firing. Small decreases in hematocrit and small increases in free erythrocyte porphyrin were correlated with increasing exposure to airborne lead. These changes were reversed by seven weeks after firing. Changes in nerve conduction velocity had borderline statistical significance to airborne lead exposure. In measuring nerve conduction velocity, differences in skin temperature must be taken into account.
\end{abstract}

SUMMARY

\section{AEROSOL STUDIES}

\section{8-in. Howitzer: Aerosol Characteristics}

- Particle concentrations were elevated for 1-2 $\mathrm{min}$ at the breech after firing.

- Breech aerosol produced a blackened filter and contained both large, irregular soil-like particles rich in silicon, aluminum, calcium, and iron, and roughly spherical, 0.5 - to 5 - $\mu \mathrm{m}$ particles rich in lead. 
- Resuspension of soil particles did not contribute significantly to the lead in breech or muzzle blast aerosols.

- Breech aerosol was typically 3-6\% lead by weight for high-lead charges.

- Muzzle blast aerosol produced a clean-looking filter and contained predominantly lead-rich spheres, also $0.5-5 \mu \mathrm{m}$ in size.

- Muzzle blast aerosols were typically $15-20 \%$ lead by weight for highlead charges.

- Besides lead, aerosols also contained potassium and titanium, and their infrared spectra were consistent with bicarbonate as the major aerosol anion.

\section{8-in. Howitzer: Air Lead Concentrations}

- Air lead (PbA) concentrations were low, 1-2 $\mu \mathrm{g} / \mathrm{m}^{3}$, at crew member positions when high-lead charges were fired with a tail wind.

- Air lead concentrations were high, $600 \mu \mathrm{\mu g} / \mathrm{m}^{3}$, at crew member positions when high-lead charges were fired with a light head wind, such that substantial portions of the muzzle blast aerosol came back on the men and exited from the breech when it was opened.

- Under given conditions of firing, air lead concentrations were essentially the same at all five crew member positions within the howitzer.

- Calculations showed that lead present in the muzzle blast aerosol could account for most of the $10 \mathrm{oz}$ of lead present in the charges.

- The muzzle blast aerosol was high in lead, $400-600 \mu \mathrm{gg} / \mathrm{m}^{3}$, even when crew member positions were low in lead concentration, $2 \mu \mathrm{g} / \mathrm{m}^{3}$, due to a tail wind.

- $\mathrm{Cu} / \mathrm{Pb}$ ratios were typically $0.3-0.7$, and air copper concentrations were $1-230 \mu \mathrm{g} / \mathrm{m}^{3}$, paralleling changes in air lead concentration.

\section{5-mm Howitzer: Aerosol Characteristics}

- Particle concentrations were elevated for 3-6 $\mathrm{min}$ at the breech after firing, longer than for the 8-in. howitzer.

- Breech aerosols appeared similar to 8-in. howitzer breech aerosols, containing carbonaceous material, soil-like particles, roughly spherical,

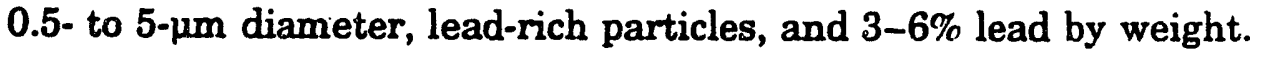


- Size fractionation results with a Lundgren impactor showed that 80-85\% of the lead in the aerosol at crew member positions was associated with particles less than $0.3 \mu \mathrm{m}$ in aerodynamic diameter. (Size fractionation results similar in reliability were not obtained for the 8-in. howitzer.)

- Muzzle blast aerosol appeared similar to the 8-in. howitzer muzzle blast aerosol, producing a clean-looking filter and containing predominantly lead-rich spheres, $0.5-5 \mu \mathrm{m}$ in diameter, $15-20 \%$ lead by weight.

- Study of higher magnification pictures of the muzzle blast aerosol by scanning electron microscopy revealed a lawn of tiny lead-rich particles corresponding to those identified by the size fractionation results.

- Less than $1 \%$ of the lead in the breech and muzzle blast aerosols was present as organic lead.

\section{5-mm Howitzer: Air Lead Concentrations}

- Air lead concentrations were $100-200 \mu \mathrm{g} / \mathrm{m}^{3}$ at crew member positions inside the cab during firing with either a head wind or a tail wind.

- The concentrations were essentially the same at all crew member positions.

- $\mathrm{Cu} / \mathrm{Pb}$ ratios typically ranged from 0.2 to 0.7 , with air copper concentrations of $25-100 \mu \mathrm{g} / \mathrm{m}^{3}$ at crew member positions, reaching $250 \mu \mathrm{g} / \mathrm{m}^{3}$ in the muzzle blast zone.

- Muzzle blast aerosol lead concentrations were $150-600 \mu \mathrm{g} / \mathrm{m}^{3}$ and were consistently higher than at crew member positions inside the cab.

\section{ACUTE LEAD EFFECTS STUDY}

\section{Air Lead Concentrations}

- Air lead $(\mathrm{PbA})$ concentrations were determined in the breathing zones of crew members who wore personal air sampling pumps while firing the 8-in. howitzer.

- Twenty-four-hour time-weighted average (TWA) $\mathrm{PbA}$ concentrations were $0.1-0.4 \mathrm{\mu g} / \mathrm{m}^{3}$ for crew members firing low-zone charges from the standard 8-in. howitzer without a crew ballistic shelter (CBS). 
- Twenty-four-hour TWA PbA concentrations were $2-30 \mu \mathrm{g} \mathrm{Pb} / \mathrm{m}^{3}$ for crew members firing high-lead charges from the 8-in. howitzer with CBS, with a mean 24-h TWA of $3 \mu \mathrm{g} / \mathrm{m}^{3}$ for the $4 / 4 \mathrm{FA}$ crew members and $11 \mu \mathrm{g} / \mathrm{m}^{3}$ for the $2 / 18 \mathrm{FA}$ crew members.

- Air lead concentrations were similar for all study participants on a given day of firing, unless it was clear that only one crew was operating due to malfunctioning of one of the weapons. In this case, $\mathrm{PbA}$ concentrations for the operating crew members were similar to one another, and $\mathrm{PbA}$ concentrations for the remaining crew members were clearly lower.

- Maximum PbA concentrations occurred for the 2/18 FA crew members on August 10, 1987, when 1- to 5-knot head winds were recorded throughout the period of firing. The mean TWA PbA for that day was about $60 \mu \mathrm{g} / \mathrm{m}^{3}$ for $\mathrm{PbA}$ values averaged over only the period of active firing (average 20 rounds per hour for $12 \mathrm{~h}$ ).

- The maximum PbA concentration obtained at Fort Sill was tenfold lower than the maximum TWA PbA concentration measured at Aberdeen Proving Ground under similar conditions of firing. A difference in elevation of the weapon during firing is believed to account for the large difference in maximum PbA concentrations observed. The lower concentrations obtained at Fort Sill with the highly elevated weapon are typical of conditions anticipated under battlefield conditions. The higher concentrations obtained at Aberdeen are typical of concentrations anticipated under weapon testing conditions when the weapon is often fired in the loading position.

\section{Blood Lead Concentrations}

- Mean blood lead $(\mathrm{PbB})$ concentrations were 5-6 $\mu \mathrm{g} / \mathrm{dL}$ at baseline (BL; before the start of firing) and were 8-11 $\mu \mathrm{g} / \mathrm{dL}$ immediately after the firing exercises (IPE). The maximum blood lead concentration among the crew members at the end of firing was $17 \mu \mathrm{g} / \mathrm{dL}$.

- Mean rises in $\mathrm{PbB}$ for individual crew members from $\mathrm{BL}$ to IPE were $1.0 \pm 0.5 \mu \mathrm{g} / \mathrm{dL}$ (mean $\pm \mathrm{SE}, n=16$ ) for crew members of the $4 / 4 \mathrm{FA}$ unit and $6.9 \pm 0.7 \mu \mathrm{g} / \mathrm{dL}(n=17)$ for crew members of the more highly exposed 2/18 FA unit.

- $\mathrm{PbB}$ concentrations rose to the greatest extent during the first 12 days of the firing exercises for crew members of the $2 / 18 \mathrm{FA}$ unit, after which the concentrations maintained a mean plateau value of $10-11 \mu \mathrm{g} / \mathrm{dL}$ in 
spite of continued exposure to high $\mathrm{PbA}$ concentrations compared to earlier in the firing exercises.

- For crew members of the 4/4 FA unit, $\mathrm{PbB}$ concentrations fell by $1.9 \pm 0.5 \mu \mathrm{g} / \mathrm{dL}$ (mean $\pm \mathrm{SE}, n=15$ ) from IPE to the delayed sampling time (DPE) seven weeks later, leaving these crew members at a blood lead concentration at DPE that was slightly lower than at BL.

- For crew members of the 2/18 FA unit, $\mathrm{PbB}$ concentrations did not fall significantly from IPE to $\mathrm{DPE}(\triangle \mathrm{PbB}=-1.2 \pm 0.6$, mean $\pm \mathrm{SE}, n=14$, $p=0.08$ ). Consequently at DPE, the $2 / 18 \mathrm{FA}$ crew members maintained a 5.4- $\mu \mathrm{g} / \mathrm{dL}$ rise in $\mathrm{PbB}$ over their $\mathrm{BL}$ values.

\section{Relationship between Air Lead Exposures and Blood Lead Responses}

- The change in PbB from baseline to the DPE sampling time (6-7 weeks after the end of firing) for each crew member showed a significant relationship to cumulative air lead exposure $(\triangle \mathrm{PbB}=0.061$ [cumulative $\left.\mathrm{PbA}]-1.87 ; \mathrm{R}^{2}=0.84, \mathrm{~F}=135, p=0.0001, n=28\right)$.

- The change in $\mathrm{PbB}$ from baseline to the +CBS3 sampling time on August 11, 1987, for each crew member of the 2/18 FA unit also showed a significant relationship to $\mathrm{PbA}$ concentration on the highest day of exposure, August $10,1987\left(\triangle \mathrm{PbB}=0.10 \mathrm{PbA}+3.55 ; \mathrm{R}^{2}=0.35, \mathrm{~F}=4.85\right.$, $p=0.03, n=11$ ).

- The slope of the $\mathrm{PbB}$ vs. $\mathrm{PbA}$ regression line for the August 10 exposures is about tenfold lower than values of $\triangle \mathrm{PbB} / \triangle \mathrm{PhA}$ obtained from studies of humans environmentally exposed to $\mathrm{PbA}$ concentrations of 0.2-10 $\mu \mathrm{g} / \mathrm{m}^{3}$ and from an experimental study of humans continuously exposed to either 3.2 or $10 \mu \mathrm{g} / \mathrm{m}^{3}$ (as lead oxide).

- If a mean 24-h TWA PbA ( \pm SE) for the entire period of +CBS high-lead firing is calculated for each FA unit $\left(2.1 \pm n .6 \mu \mathrm{g} / \mathrm{m}^{3}\right.$ for 11 days of exposure for the $4 / 4$ FA unit and $7.9 \pm 2.3 \mu \mathrm{g} / \mathrm{m}^{3}$ for 16 days of exposure for the 2/18 FA unit), then the 2/18 exposures cansed an increase in $\mathrm{PbB}$ similar to the value of $1 \mu \mathrm{g} \mathrm{Pb} / \mathrm{dL}$ of blood for each 24-h TWA exposure to $1 \mu \mathrm{g} \mathrm{Pb} / \mathrm{m}^{3}$ of air obtained from many other studies of low-level lead exposures in humans.

\section{Hematopoietic Responses to Lead Exposure}

- Hematocrit (Hct) and free erythrocyte porphyrin (FEP) concentrations were determined in each crew member at the BL, IPE, and DPE time points. 


\section{Changes from BL to IPE}

- Hematocrit and FEP concentrations did not change significantly during the six weeks from BL to IPE for crew members of the 4/4 FA unit: $43.7 \%$ vs. $44.0 \%$ hematocrit and 19.0 vs. $18.2 \mu \mathrm{g} \mathrm{FEP} \mathrm{per} \mathrm{dL} \mathrm{blood} \mathrm{at} \mathrm{the}$ BL vs. IPE time points, respectively.

- In contrast, small but significant changes in hematocrit and FEP concentration occurred from BL to IPE for crew members of the more highly lead-exposed $2 / 18$ FA unit: $46.0 \%$ vs. $44.9 \%$ at BL vs. IPE for hematocrit, with a statistically significant mean decrease of $1.47 \pm 0.63 \%$ (mean $\pm \mathrm{SE}, n=17$ ), and 18.9 vs. $21.8 \mu \mathrm{g}$ FEP per dL blood at BL vs. IPE, with a statistically significant mean increase of $2.22 \pm 0.65 \mu \mathrm{g} / \mathrm{dL}$ $(n=18)$.

- Considering data from both units, there was a significant inverse relationship between changes in hematocrit from $B L$ to IPE and changes in $\mathrm{PbB}$ from BL to DPE ( $\triangle \mathrm{Hct}=-0.33 \triangle \mathrm{PbB}+0.12 ; \mathrm{R}^{2}=0.23, \mathrm{~F}=7.94$, $p=0.009, n=28$ ).

- Considering data from both FA units, there was a significant direct relationship between changes in FEP concentration from BL to IPE and changes in $\mathrm{PbB}$ from $\mathrm{BL}$ to $\mathrm{DPE}\left(\triangle \mathrm{FEP}=0.29 \triangle \mathrm{PbB}-0.02 ; \mathrm{R}^{2}=0.14\right.$, $\mathrm{F}=4.50, p=0.04, n=30$ ).

\section{Changes from IPE to DPE}

- From IPE to 6-7 weeks later at DPE, during which time additional firing of high-lead charges was insignificant compared to the BL to IPE period, small but significant increases in hematocrit occurred for crew members of both FA units: $1.46 \%$ and $1.93 \%$ hematocrit increases for the 4/4 and 2/18 FA crew members, respectively.

- Considering data from both FA units, there was a direct relationship between changes in hematocrit from IPE to DPE and changes in $\mathrm{PbB}$ from BL to DPE that was borderline in significance $(\triangle H c t=0.20 \triangle \mathrm{PbB}$ $+1.16 ; \mathrm{R}^{2}=0.12, \mathrm{~F}=3.41, p=0.08, n=28$ ).

- From IPE to DPE, no significant change in FEP concentration occurred among crew members of the 4/4 FA unit, while a significant decrease of $5.45 \pm 0.62 \mu \mathrm{g} / \mathrm{dL}$ (mean $\pm \mathrm{SE}, n=15$ ) occurred for the $2 / 18 \mathrm{crew}$ members.

- Considering data from both FA units, there was a significant inverse relationship between changes in FEP concentration from IPE to DPE 
and changes in $\mathrm{PbB}$ from $\mathrm{BL}$ to $\mathrm{DPE}\left(\triangle \mathrm{FEP}=-0.82 \triangle \mathrm{PbB}+0.05 ; \mathrm{R}^{2}=\right.$ $0.39, \mathrm{~F}=17.32, p=0.0003, n=29$ ).

\section{Peripheral Nervous System Response to Lead Exposure}

- Conduction velocities of three motor nerves (median, ulnar, and peroneal) and three sensory nerves (median, ulnar, and sural) were measured at the BL, IPE, and DPE time points in each crew member.

- Mean values of nerve conduction velocity (NCV) had standard error values that were only $2 \%$ of the mean $(0.5-1.4 \mathrm{~m} / \mathrm{s})$, indicating that very small changes in NCV, in the range of 3-5 m/s, could be measured with our technique.

- Without adjusting the data set for differences in skin temperature, the NCV in one nerve, the peroneal motor nerve, decreased significantly from IPE to DPE in crew members of the $2 / 18 \mathrm{FA}(3.76 \mathrm{~m} / \mathrm{s}$ mean decrease) and showed no change among crew members of the 4/4 FA.

- For the latter data set, there was an inverse relationship between the change in peroneal motor NCV from IPE to DPE and the change in PbB from BL to DPE that approached statistical significance $(p=0.08$, $\mathrm{R}^{2}=0.11, n=29$ ).

- After adjusting the data set for differences in skin temperature, NCV values at baseline for the $2 / 18 \mathrm{FA}$ crew members increased more than other values in the data set, because there were more persons with slightly low skin temperatures in this group than in any other. As a result, the temperature-adjusted data set showed a greater number of decreases in NCV from baseline for the $2 / 18$ crew members than prior to temperature adjustment. These additional decreases, dependent as they are on temperature adjustment, are not very convincing. 


\section{INTRODUCTION AND SCOPE}

The U.S. Army Environmental Hygiene Agency has determined through field measurements that military personnel are exposed by inhalation to lead aerosols during the firing of armored vehicle weapons. A review of military exposure data suggests that the circumstances of military exposure to lead aerosols (sporadic, potentially high levels) differ enough from the circumstances of civilian industrial exposures (continuous, predominantly low levels) that military protection standards may need to be formulated differently from those recommended for industry. Military concerns also differ from civilian concerns in that both training and combat conditions need to be considered. Because significantly more lead is present in new, long-range charges and because a cab or crew ballistic shelter (CBS), which can confine exhaust gases, is present on armored vehicles firing these charges, an evaluation is needed of the lead exposure hazard to crew members firing long-range charges from within a cab or a CBS.

The program reported here has two parts, an aerosol study and an acute lead effects study. The objectives of the program were to (1) determine the concentration and chemical nature of the lead aerosols generated during firing of armored vehicle weapons, (2) determine exposures and biological responses of crew members exposed to airborne lead during weapons fire, and (3) based on the results, recommend an approach to monitoring weapons-related exposures to lead and predict potential responses to lead in crew members under combat conditions and in career artillerymen.

Originally, we had planned to focus the lead aerosol production and emission studies on the 155-mm/M109A3 howitzer, the new weapon being developed under the Howitzer Improvement Program (HIP). In addition, it was anticipated that some comparative studies on other weapons, such as the 8-in. $/ \mathrm{M} 110$ howitzer, the $105-\mathrm{mm}$ tank gun, and the $120-\mathrm{mm}$ tank gun, would be conducted on a limited basis. However, because of slippage in the availability of the 155-mm/M109A3 and an early opportunity for testing the 8-in./M110 at the Aberdeen Proving Ground, an extensive testing program was conducted on the 8-in./M110. No lead aerosol emission studies were conducted on the $105-\mathrm{mm}$ and the $120-\mathrm{mm}$ tanks guns.

It had also been anticipated that the aerosol studies would be conducted using a firing protocol specifically designed to supply the needed data. However, nearly all of the measurements were conducted strictly nonintrusively during tests conducted primarily for purposes other than aerosol characterization. In spite of these conditions, a considerable number of useful and important insights into the weapons aerosols were obtained.

The acute lead effects study involved measuring personal air lead exposures in 45 crew members firing high-lead charges from the 8-in. howitzer with crew ballistic shelter. Potential responses to lead exposure determined were blood lead concentration, hematocrit, free erythrocyte porphyrin, and nerve conduction velocities for three motor and three sensory nerves. 


\section{AEROSOL STUDIES}

\subsection{METHODS}

\subsubsection{Overall Study Design}

The major objectives of the aerosol studies were (1) to determine the concentrations of airborne lead at the crew positions for the different weapons, (2) to identify the physical and chemical characteristics of the lead aerosol, (3) to determine if any organic lead compounds are present, and (4) to assess the significance of resuspended lead for the exposure of crew to lead aerosol. Since lead $(\mathrm{Pb})$ is added to the propellant as a decoppering agent, the copper $(\mathrm{Cu})$ content of the emission aerosol was examined throughout the study. Field measurements were made at the Aberdeen Proving Ground (APG), Maryland, and at Yuma Proving Ground (YPG), Arizona. Table 1 presents a summary of the testing schedule, weapons, charges, and propellants used in this study.

TABLE 1 Summary of testing schedule, weapons, charges, and propellants

\begin{tabular}{|c|c|c|c|c|c|c|c|c|}
\hline & & & & & & & Content & 1021 \\
\hline Date & Weapon & Location & $\begin{array}{l}\text { Rounds } \\
\text { Fired }\end{array}$ & Charge & Zone & $\begin{array}{l}\text { Propel- } \\
\text { lane }\end{array}$ & $P b^{d}$ & $\mathrm{TiO}_{2}$ \\
\hline $2 / 10 / 87$ & $8-\mathrm{in.} / \mathrm{M} 110$ & APG & 3 & M2 & 7 & M1 & Note b & - \\
\hline $2 / 10 / 87$ & $8-\ln . / M 110$ & APG & 2 & MI8RAL & 9 & $M 3\lfloor A \perp$ & 10.25 & 4.3 \\
\hline $3 / 19 / 87$ & $8-\mathrm{in} . / \mathrm{M} 110$ & APG & 30 & M18BAI & 9 & M3 $1 A \perp$ & 10.25 & 4.3 \\
\hline $3 / 20 / 87$ & $8-\ln . / M 110$ & APG & 82 & MI8BAL & 9 & $M 3 \perp A \perp$ & 10.25 & 4.3 \\
\hline $8 / 19 / 87$ & $\begin{array}{l}155-\mathrm{mm} / \\
\text { M109A3E1 }\end{array}$ & YPG & 120 & $M 203 A 1$ & 8 & $M 31 A 1$ & 5.5 & 17.5 \\
\hline $8 / 20 / 87$ & $\begin{array}{l}155-\mathrm{mm} / \\
\text { M109A3E1 }\end{array}$ & YPG & 21 & M119A2 & 7 & MG & 0 & - \\
\hline $8 / 20 / 87$ & $\begin{array}{l}155-\mathrm{mm} / \\
\text { M109A3E1 }\end{array}$ & YPG & 44 & M203A1 & 8 & $M 3|A|$ & 5.5 & 17.5 \\
\hline $8 / 31 / 88$ & $\begin{array}{l}155-\mathrm{mm} / \\
M 109 A 3 \mathrm{E} 2 \text { HIP }\end{array}$ & YPG & 12 & $M 203 \mathrm{Al}$ & 8 & M3 $1 A 1$ & 5.5 & 17.5 \\
\hline $9 / 01 / 88$ & $\begin{array}{l}155-\mathrm{mm} / \\
\text { M109A3E2 HIP }\end{array}$ & YPG & 11 & M203A1 & 8 & $M 31 A 1$ & 5.5 & 17.5 \\
\hline $9 / 02 / 88$ & $\begin{array}{l}155-\mathrm{mm} / \\
\text { M109A3E2 HIP }\end{array}$ & YPG & 14 & M203A1 & 8 & $M 31 A 1$ & 5.5 & 17.5 \\
\hline
\end{tabular}

a Lead foil except as noted.

b $18 \mathrm{PbCO}_{3}$. 


\subsubsection{Instrumentation and Sampling Equipment}

The instrumentation and aerosol sampling equipment consisted of optical particle counters, filters, impactors, carbon monoxide $(\mathrm{CO})$ and carbon dioxide $\left(\mathrm{CO}_{2}\right)$ analyzers, impingers, sorption tubes, and a portable weather station to record wind speed, wind direction, and temperature.

Optical Particle Counter. A Climet model CI-225 (Climet Instruments Co., Redlands, California) optical particle counter (OPC) was used to measure the size distribution of the particles. This unit operates at a flow rate of $7 \mathrm{~L} / \mathrm{min}$ and provides particle counts in each of eight size ranges: $0.3-0.5,0.5-0.7,0.7-1,1-2,2-3,3-5,5-10$, and $10-20 \mu \mathrm{m}$. The associated multi-channel analyzer (Climet model CI-210) was operated with a time resolution of $8 \mathrm{~s}$ to provide a continuous record of the particle size distribution during periods of firing. For the studies on the 8-in./M110 howitzer at APG, the inlet for the OPC was positioned over the breech, while for the studies on the $155-\mathrm{mm} / \mathrm{M} 109 \mathrm{~A} 3$ howitzer at YPG, the inlet was located in the breathing zone for the Gunner position.

Filters and Personal Air Sampling Pumps. Several different types of filters were used in this study. One type was the ultrathin polytetrafluoroethylene Teflo ${ }^{\mathrm{TM}}$ membrane filter (Gelman Science Inc., Ann Arbor, Michigan). The 2- $\mu \mathrm{m}$ pore size filters were chosen because they are extremely thin $(25 \mu \mathrm{m})$, have high air flow rate capacity, and provide 99.99\% retention of $0.3-\mu \mathrm{m}$ and larger aerosol particles. A special advantage of the Teflo filters in our studies is that the particles collected can be analyzed directly on the filter by infrared spectroscopy without any additional sample preparation. Moreover, these filters are not affected by humidity, so that accurate weights can be obtained to determine sample loadings. Both $37-\mathrm{mm}$ and $47-\mathrm{mm}$ diameter filters were used in appropriate filter holders.

For determinations of the derosol concentrations in the breathing zones of the crew, Universal Personal Air Sampling Pumps (UPASP; model 224-PCXR7, SKC Inc., Eighty Four, Pennsylvania) were used with cassette filters. These constant-flow pumps have a time modulation feature which allows them to be operated for extended periods, making them especially suitable for use in the acute lead effects studies conducted at Fort Sill (see Section 3). The pumps have an adjustable flow rate of 0.1-5.0 L/min. Depending on the usage, the flow rate was calibrated at $1.0,2.0$, or $4.0 \mathrm{~L} / \mathrm{min}$.

The filters used with the UPASP were factory-loaded, 37-mm diameter type MAWP037AO (matched-weight) and type MAWP037AM (single filter) cellulose acetate 0.8- $\mu \mathrm{m}$ pore size cassette filters (Millipore Corp., Bedford, Massachusetts). The matchedweight filters have two filters of the same weight preloaded into the cassettes, so the clean (second) filter can be used as tare to determine the weight of the sample collected on the front filter. 
High-Volume Filters. Two different types of high-volume samplers were used to obtain greater quantities of aerosol samples for analysis. One type of sampler, model CF-903 (Hi-Q Environmental Products Co., La Jolla, California) had a variable flow rate of $0.2-\left(.8 \mathrm{~m}^{3} / \mathrm{min}\right.$. The other sampler, model TFIA (Staplex Co., Brooklyn, New York) sampled the aerosol at flow rates approaching $2 \mathrm{~m}^{3} / \mathrm{min}$. Either sampler could be fitted with 4-in. diameter circular or 8- $\times 10$-in. rectangular filter sheets. These portable high-volume (hi-vol) samplers were used mainly as back-up collectors in case inadequate amounts of sample were collected on the lower flow rate devices. Since adequate material was collected in all cases with the lower flow rate units, most of the high-volume (hi-vol) filters were not analyzed.

Impactors. Several different kinds of impactors were used in these studies to collect size-classified samples of aerosol particles.

The Automatic Dichotomous Sampler (model 245, Sierra Instruments Inc., Carmel Valley, California) virtual impactor was used to collect the aerosol as two size fractions, greater than or less than 2.5- $\mu \mathrm{m}$ aerodynamic diameter (a.d.), on $47-\mathrm{mm}$ filters. This sampler operates at an air flow rate of $17 \mathrm{~L} / \mathrm{min}$. This unit was used only at APG for studies on the 8-in./M110 howitzer. The collection module of the dichotomous sampler is too large to be mounted inside the weapon, so it was located on the ground close to the right rear side of the weapon. The inlet for the sampler was located directly above the breech.

The Lundgren impactor (model 4220, Sierra Instruments Inc., Carmel Valley, California) was used to collect samples in the Assistant Gunner's position of the 155-mm/M109A3E2 HIP howitzer at YPG. This impactor provides size and time resolution while sampling the air at a flow rate of $100 \mathrm{~L} / \mathrm{min}$. It separates the collected particles into size fractions of greater than $10 \mu \mathrm{m}, 3-10 \mu \mathrm{m}, 1-3 \mu \mathrm{m}$, and $0.3-1 \mu \mathrm{m}$. Particles smaller than $0.3 \mu \mathrm{m}$ are collected on an after-filter. The particles are collected on Mylar films mounted on rotatable drums. The first two stages of the impactor have a thin coating of silicone grease on them to prevent bounce of the larger particles.

Gas Analyzers. A continuous carbon monoxide analyzer (model Binos 4.2, LeyboldHereaus, East Syracuse, New York) was used during the final field study of the 155-mm/M109A3E2 HIP at YPG. A $\mathrm{CO}_{2}$ monitor was also installed, but the unit malfunctioned when the first round was fired and therefore no $\mathrm{CO}_{2}$ data were obtained.

Impingers. To determine whether any vapor phase or organic lead was generated during the weapons firing, a liquid media sampler (LMS) from Industrial Hygiene Specialties (Columbus, Ohio) was used in conjunction with the UPASP by placing it after the filter. The LMS consists of a glass tube with hydrophobic filter material at either end. The hydrophobic nature of the filters allows a solution to be contained within the tube while the sampled air stream is bubbled through it; we used a $10 \%$ nitric acid $\left(\mathrm{HNO}_{3}\right)$ solution with an air flow rate of $500 \mathrm{~mL} / \mathrm{min}$. The $\mathrm{HNO}_{3}$ solution was subsequently analyzed for its lead content by atomic absorption spectroscopy (AAS). The LMS tubes were cleaned with $3 \mathrm{~N} \mathrm{HNO}_{3}$ prior to use. 
Sorption Tubes. In addition to the liquid impingers, sorption tubes with three different solid sorption media were also used. If the LMS sample showed the presence of organic lead, the samples in the solid-media sorption tubes could be used to identify the specific compounds using gas chromatography. Charcoal, Tenax, and XAD2 (SKC Inc., Eighty Four, Pennsylvania) were used as the solid sorbents. These tubes were also used with the UPASP. Each of the sorption tubes was preceded with one of the standard 37-mm filter cartridges. The sealed glass tubes were cracked open just before use and sealed with plastic caps as soon as possible after collection.

Miscellaneous. Surface soil samples were collected at the different sites. The soil was sifted through a 100-mesh sieve to remove particles larger than $150 \mu \mathrm{m}$ on the assumption that such large particles would not be susceptible to resuspension by the firing blast.

Smear samples of deposits on weapon surfaces were also collected. Generally, a marked-off area of about $160 \mathrm{~cm}^{2}$ was wiped as clean as possible with dry smear tabs. These smear tabs were of low-ash, acid-hardened paper (SKC\#225-24; SKC Inc., Eighty Four, Pennsylvania) designed for the collection of samples from surfaces. The used tabs were sealed in clean vials. Successive wipings were made to determine the effectiveness of the cleaning method. After samples of the original deposits were taken, the marked-off area was cleaned more thoroughly with acetone. Another series of smear tabs was then used to verify the cleanliness of the area. Then, after the day's firing was completed, the marked area was again cleaned with a series of smear tabs to measure the accumulation.

\subsubsection{Analytical Techniques}

Because of the variety of sampling methods used for this study, several different analytical techniques were employed to supply chemical, physical, and morphological information on the collected samples. Atomic absorption spectroscopy was used to determine the lead and copper content, with lower limits of detection for this set of samples at $0.2 \mu \mathrm{g}$ for lead and $0.6 \mu \mathrm{g}$ for copper.

Fourier-transform infrared spectroscopy (IR) was used for the chemical characterization of the aerosol size fractions collected on the Teflo filters or on the internal reflection elements (IREs). These analyses were carried out using direct absorbance spectroscopy or attenuated total internal reflectance (ATR) on a Digilab model FTS-14 (Bio-Rad, Digilab Division, Cambridge, Massachusetts) spectrophotometer. Samples on IREs were analyzed using a $4 \times$ beam condenser (model 4 XTBC, Harrick Scientific Corp., Ossining, New York). In most cases, 100 scans were co-added using $8 \mathrm{~cm}^{-1}$ resolution over the range of 400 to $3900 \mathrm{~cm}^{-1}$.

A scanning electron microscope (JEOL JSM-35U; Jeol USA Inc., Peabody, Massachusetts) with an Ortec EEDS-II energy-dispersive X-ray attachment (SEM/EDX.) was used to obtain photomicrographs of the collected particles and to conduct elemental analysis 
of individual particles. The Teflo filters were prepared for SEM/EDX by sputtering a thin layer of gold on them to make them electrically conductive.

Powder X-ray diffraction was used on select samples with a 1.14.6-mm-diameter camera (Debye-Scherrer, Phillips Corp., Mahwah, New Jersey) to verify the interpretations from the infrared spectroscopic analyses.

Gravimetric analyses were used to determine the mass of sample and the fraction of lead in it. The Teflo filters used in the different collection techniques were weighed before and after collection using a Mettler electronic microbalance model ME-22 (Mettler Instrument Corp., Hightstown, New Jersey). These weights also allowed the total air loadings to be determined.

Millipore matched-weight, type AA, cellulose acetate, 37-mm-diameter filters in preloaded monitor cartridges (Millipore Corp., Bedford, Massachusetts) were used extensively for the samples collected using the UPASP. The "matched-weight" designation indicates that there are two filters in each cartridge; the sample is collected on the front filter while the second filter remains clean and can be used as the "blank" or tare weight to determine the amount of sample collected. One can then determine the amount of material other than lead and copper that is in the collected sample.

Optical microscopy was generally used to visually examine the collected aerosol samples. Most of the samples were first examined with a low magnification stereo zoom microscope (model M-7, Wild-Heerburgg Instruments Inc., Farmingdale, New York). A higher magnification instrument (model Ultraphot II, Zeiss, Germany) was used if deemed necessary.

\subsubsection{Mobile Laboratory}

We equipped a motor home as a mobile laboratory for the field work to characterize the lead emissions from the firing of the weapons. The equipment on-board the motor home included all the aerosol sampling devices (filters, air sampling pumps, impactors), the optical particle counter, the gas analyzers, sorption equipment, the electronic microbalance, a portable optical microscope, tape recorders (to facilitate note-taking), and the portable weather station. The motor home also had an electrical generator which was used on occasion to provide power for equipment operation in the field.

\subsection{FIELD STUDIES OF THE 8-IN/M110 HOWITZER}

Table 2 summarizes the samples obtained at APG. Emissions from the 8-in./M110 howitzer were monitored during test firing of the weapon at APG on February 10, 1987 (five rounds fired), and on March 19 and 20, 1987 (112 rounds fired). The firings were conducted at the ballistic range known as "Old Ant Hill." This weapon had the CBS installed on it at the time of test. 
TABLE 2 Samples collected from firings of an 8-indM110 howitzer at APG

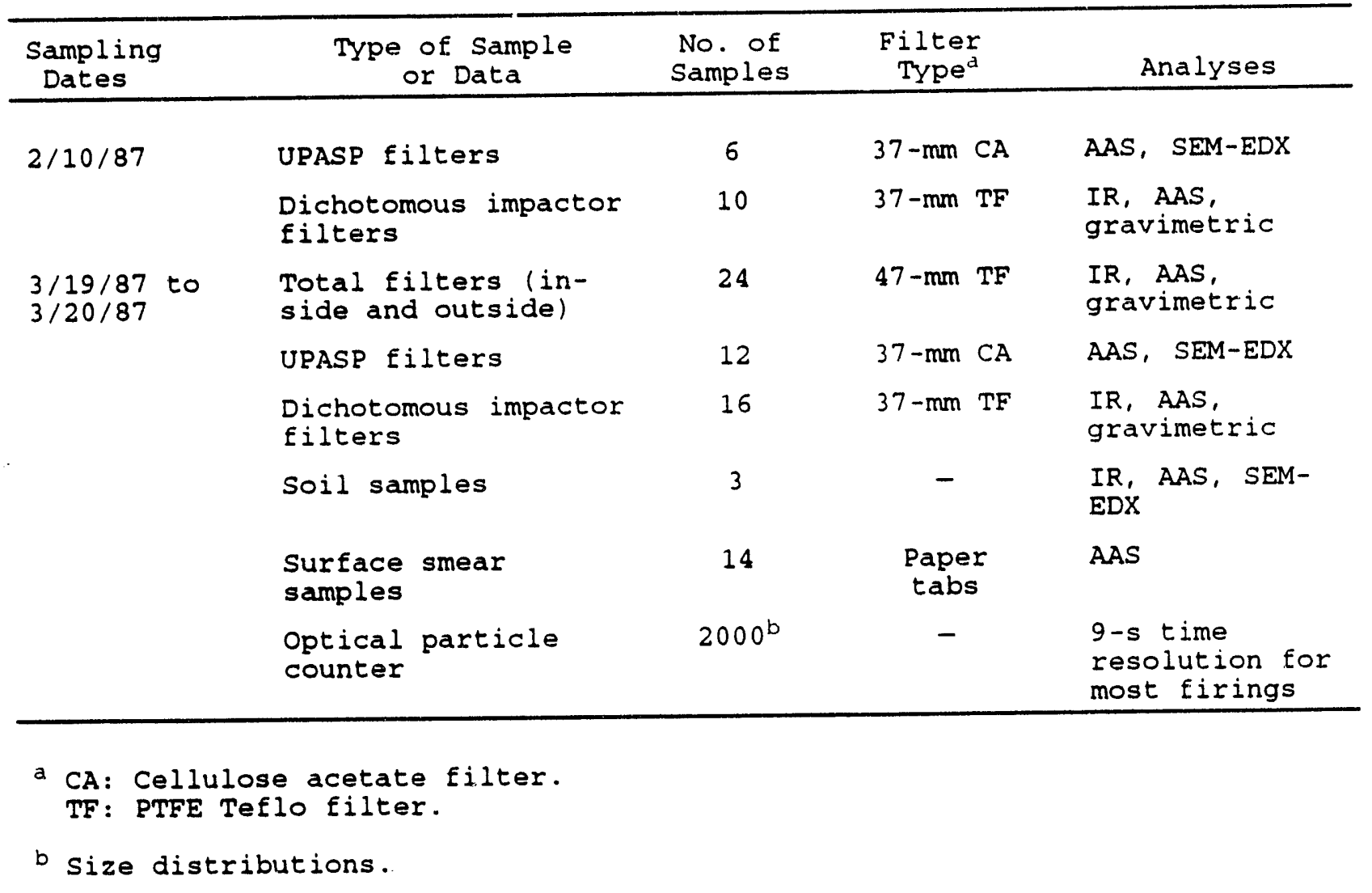

The sampling locations are shown schematically in Fig. 1. For these measurements the inlet for the dichotomous impactor was located just above the breech. Also at the breech were three $37-\mathrm{mm}$ cellulose acetate filters in cartridges connected to three separate UPASPs, each set to a different flow rate, since we did not know what particle loading to expect. The inlet hose for the optical particle counter was also located just above the breech, with the counter itself placed on the ground next to the weapon. The control and readout for the OPC were located in the motor home stationed behind a concrete bunker. In addition, three other UPASPs with 37-min cartridge filters were located so as to collect particle samples in the breathing zones of the Gunner position on the left side of the CBS, and the Assistant Gunner and Loader 2 positions (right side of the CBS).

Soil samples from around the weapon were collected at the APG firing site for analysis of their lead and copper content by AAS. Three samples of surface soil were collected from under the muzzle area of the gun.

Paper smear tabs (SKC Inc., Eight Four, Pennsylvania) were used to collect samples of deposited emissions from ari area of about $160 \mathrm{~cm}^{2}$ (approximately $25 \mathrm{in} .^{2}$ ) on the right wall of the CBS. All "hands checks" were done by first cleaning the hands of the person handling the tabs and then thoroughly wiping the hands with the smear tabs. All tabs were 


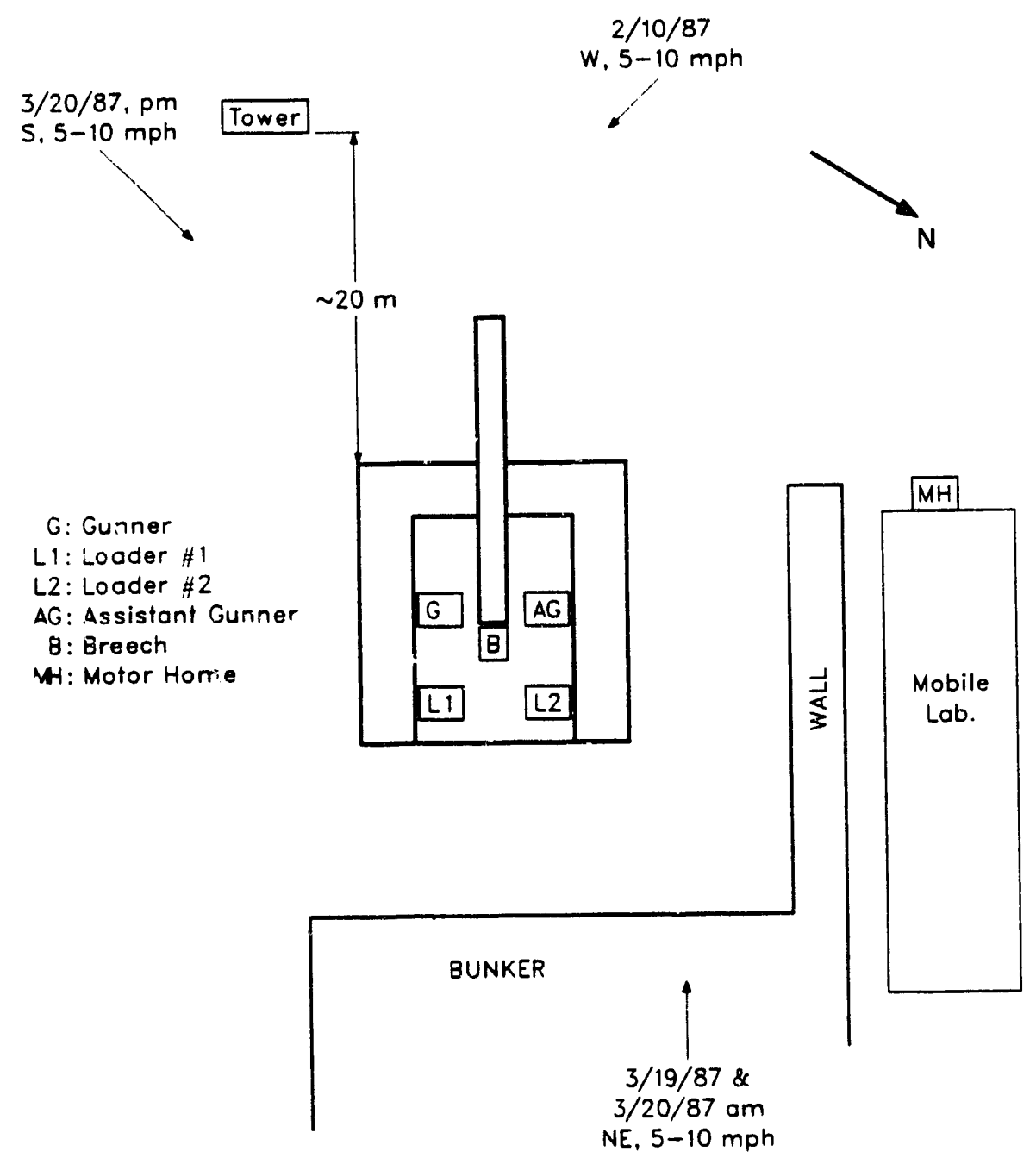

FIGURE 1 Niagram of 8-in $/ M 110$ howitzer with the positions of the filter samples and wind conditions at $\mathbf{A P G}$, February 10 and March 19-20, 1987

placed in precleaned vials for subsequent AAS. The designated wall area of the CBS was delineated with tape borders. Four consecutive cleanings of the accumulated material were done with individual tabs to determine the "pretest accumulation." The area was then scrubbed with methanol and allowed to dry. The area was then wiped three consecutive times to check on cleanliness. At the end of each day of firing, the designated area was wiped two times on March 19 and three times on March 20. These results are discussed later in this report.

The five rounds for which aerosol samples were collected on February 10, 1987, were fired between 1430 and 1500 hours. The first three rounds used zone 7 charges, which contain 1 oz each of lead carbonate $\left(\mathrm{PbCO}_{3}\right)$ and potassium sulfate $\left(\mathrm{K}_{2} \mathrm{SO}_{4}\right)$. The last two rounds used zone 9 charges, which contain 10.25 oz of lead foil and 1 oz of $\mathrm{K}_{2} \mathrm{SO}_{4}$. The gun was fired to the southwest into Chesapeake Bay; throughout the firing period the wind was 
from the west at $2.2-4.4 \mathrm{~m} / \mathrm{s}(5-10 \mathrm{mi} / \mathrm{h})$. The gun was fired at the barrel elevation at which it is loaded. All hatches were kept closed throughout the firing. Because of the wind direction, copious fumes vented into the CBS when the breech was opened. The fumes from round \#4 were so heavy that some of the crew could not even be seen for several seconds; the crew evacuated the CBS at that time. A delay of about 15 min occurred between rounds \#4 and \#5 due to a problem with the loader. The problem persisted, and the firing was suspended for the day after round \#5. The fumes from round \#5 itself mostly bled out of the barrel tip because the breech was not opened after the firing.

During the second firing sequence on March 19-20, 1987, 30 rounds were fired on the 19th, and 82 rounds were fired on the 20th. The wind was from the rear of the weapon (northeast) on March 19 and the morning of March 20; the wind shifted to forward of the weapon (south) at midday on the 20th. The wind shift occurred during the lunch break between the firing of rounds $\# 50$ and $\# 51$.

The first two rounds fired on the 19th used zone 7 charges; the remaining 100 rounds

all used zone 9 charges. On the 19th, firing started at about 1330 hours and proceeded at a fairly constant rate until about 1500 hours. During this period of $1.5 \mathrm{~h}$, the rounds were fired at an average rate of about one round every $3 \mathrm{~min}$. On the $20 \mathrm{th}$, firing started at about 0920 hours and continued until about 1145 hours, when there was a break for lunch. During this 2-h, 25-min period, 50 rounds were fired, again giving an average of about one round every $3 \mathrm{~min}$. However, if the 10-min delay between rounds \#4 and \#5 and another 40-min delay between rounds \#20 and \#21 is subtracted, the firing rate was one round in under 2 min. During the afternoon firing of 32 rounds between 1340 hours and 1450 hours, the average firing rate was one round in just over $2 \mathrm{~min}$.

Between rounds \#35 and \#36, at about 1110 hours, a filter sampler was set up on the tower to the left front of the gun. This was done to collect samples in the direct range of the muzzle blast plume. The first "tower" sampler was left on until about 1256 hours, about an hour after the 50th round was fired. At that time, another filter cartridge was put in place and the pump turned on again, even though the afternoon firing did not start until about 1340 hours. This second tower sample was allowed to collect through the 70th round at about 1410 hours. By that time, the wind shift was such that the muzzle blast plume was blowing away from the filter on the tower, back around the end of the mobile laboratory which was located behind the concrete wall on the right side of the weapon. Therefore, the sampler was moved from the tower to the end of the motor home. In this position, the third tower sample was collected for rounds \#71 through \#82.

Originally, $\mathrm{CO}$ and $\mathrm{CO}_{2}$ were to be monitored by APG personnel, but because of the delayed schedule, this was not possible.

\subsection{FIELD STUDIES OF THE 155-mm/M109A3 HOWITZERS}

Emissions from the firing of the 155-mm/M109A3 howitzers were sampled at YPG on August 19 and 20, 1987, and again a year later from August 31 to September 2, 1988. 
However, the weapons tested during the two time periods were different models. The unit used for the testing on August 19 and 20, 1987, was a current version, M109A3E1 (Cobra). The unit used for the testing on August 31 to September 2, 1988, was the upgraded version, M109A3E2, the HIP weapon. The cab (turret) on the HIP weapon is much larger than that on the Cobra.

\subsubsection{The 155-mm/M109A3E1 Howitzer}

During the first two-day period, August 19-20, 1987, aerosol samples were collected with tcn UPASPs, five located inside the cab of the test $155-\mathrm{mm} / \mathrm{M} 109 \mathrm{~A} 3 \mathrm{E} 1 \mathrm{howitzer}$ and five located outside of the weapon. These pumps were located in the positions identified in Fig. 2. The sampling was conducted at the KOFA Range at Gun Position \#12, also known as the "Rocket Pad." All firings during the two days were toward the east, with the gun fired at the loading elevation of 431 mils. All hatches except the main rear hatch were closed during firing. The main rear hatch was kept open for loading purposes. The ventilation blower was not used at any time. Firings were by lanyard, except in a few cases when electronic ignition was used.

The muzzle brake on the test weapon directed the blast rearward from the muzzle at about $45^{\circ}$ angles on either side of the gun. Distinct oval areas were scoured down to hardpacked soil on either side of the gun in this blast zone. (This differed from the 8-in./M110 howitzer [tested earlier at APG], which had a muzzle brake which directed the blast out at a $90^{\circ}$ angle from the barrel.) The left and right outside samplers were located at the rear edges of these zones. The weapon also had a bore evacuator which seemed to work effectively.

The test site was wetted down each day before firing in the morning and again during lunch break. This wetting down, however, instead of limiting the resuspension of dust, often caused a bigger problem than would have occurred without the wetting. Even though the area was heavily soaked by the water truck, the majority of the ground surface dried quickly in the low humidity and high temperature of Yuma, leaving behind numerous puddles. Thus, the dust was still present, and to compound the problem, the puddles created liquid spray at each firing.

All ten UPASPs were fitted with $1.8 \mathrm{~m}$ of tubing which allowed the pumps to be secured safely out of the way. The pump units were placed in closed "bubble pack" bags to reduce the shock. This worked well, since there were only a few problems with the pumps even though some were placed directly in the blast zone. The inlets for five filters inside the weapon were mounted as close to the breathing zones of the five crew members as possible without interfering with their movement. The outside filters were mounted about $0.5 \mathrm{~m}$ above ground on wooden stakes, with the excess tubing coiled and the pumps attached to the base of the stakes. Filter cartridges were used as blanks at several locations. This was done by simply fastening the blank cartridge next to the sample cartridge and opening the inlet side at the time the pumps were turned on. The blanks were processed through the entire analytical procedure in a manner identical to that of the regular samples. 


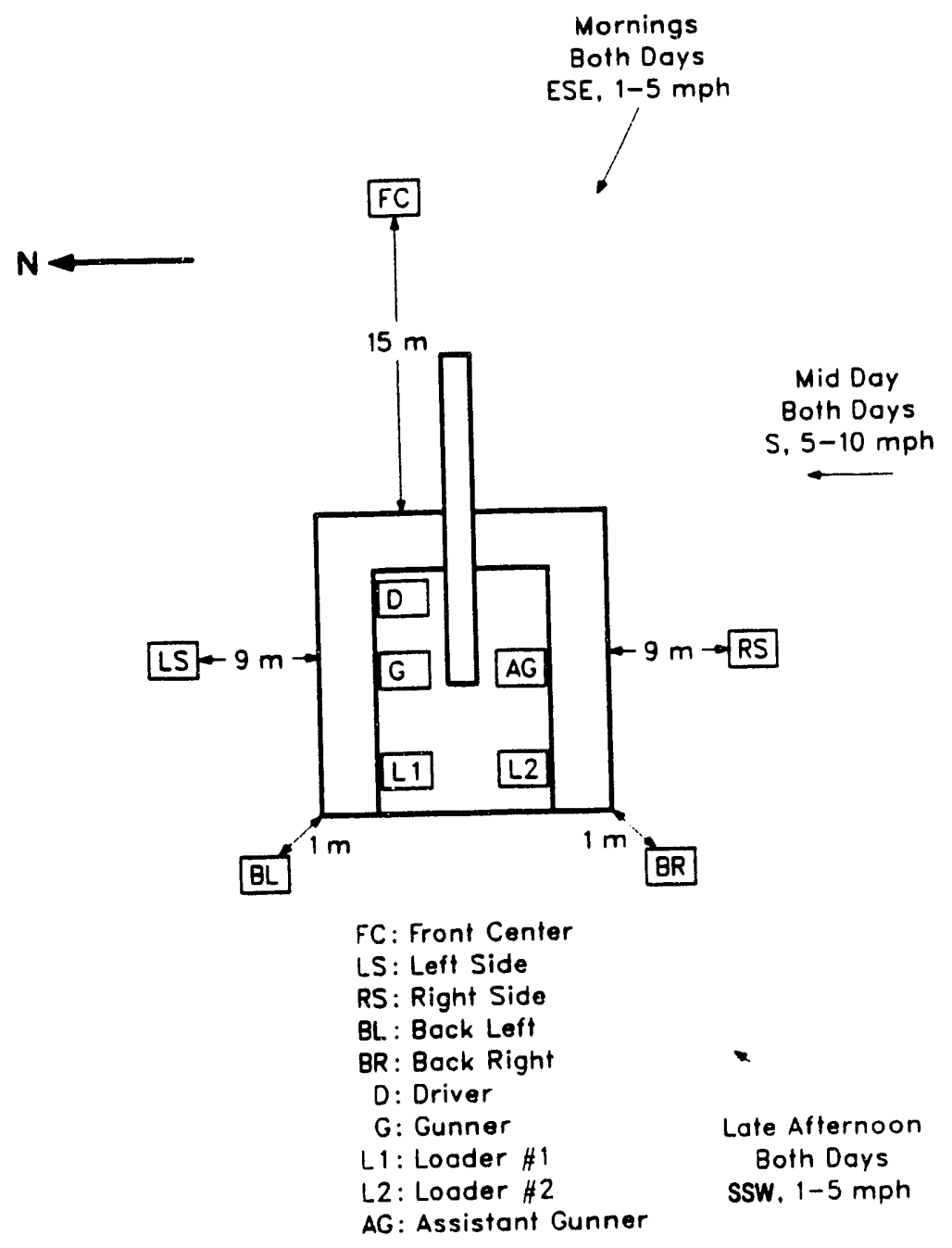

FIGURE 2 Diagram of 155-mm/M109A3E1 howitzer with positions of filter samples and wind conditions at YPG, August 19-20, 1987

Initially, the intent was to collect separate sets of samples for the morning and afternoon firing sessions of each day. This was done, but some filters were changed at other times to take advantage of specific circumstances. The collection periods for each of the filter samples relative to the firing time line are shown in Figs. 3 and 4.

\subsubsection{The 155-mm/M109A3E2 (HIP) Howitzer}

The lead aerosol sampling was much more comprehensive for the second set of tests, which were on the 155-mm/M109A3E2 HIP howitzer. Table 3 presents a list of the various sampling methods and a count of how many samples were collected on each of the days at YPG. When a set is listed, it includes from three to five separate samples for different size cuts or different sample media. Also, a list of the analysis methods for each type of sample 


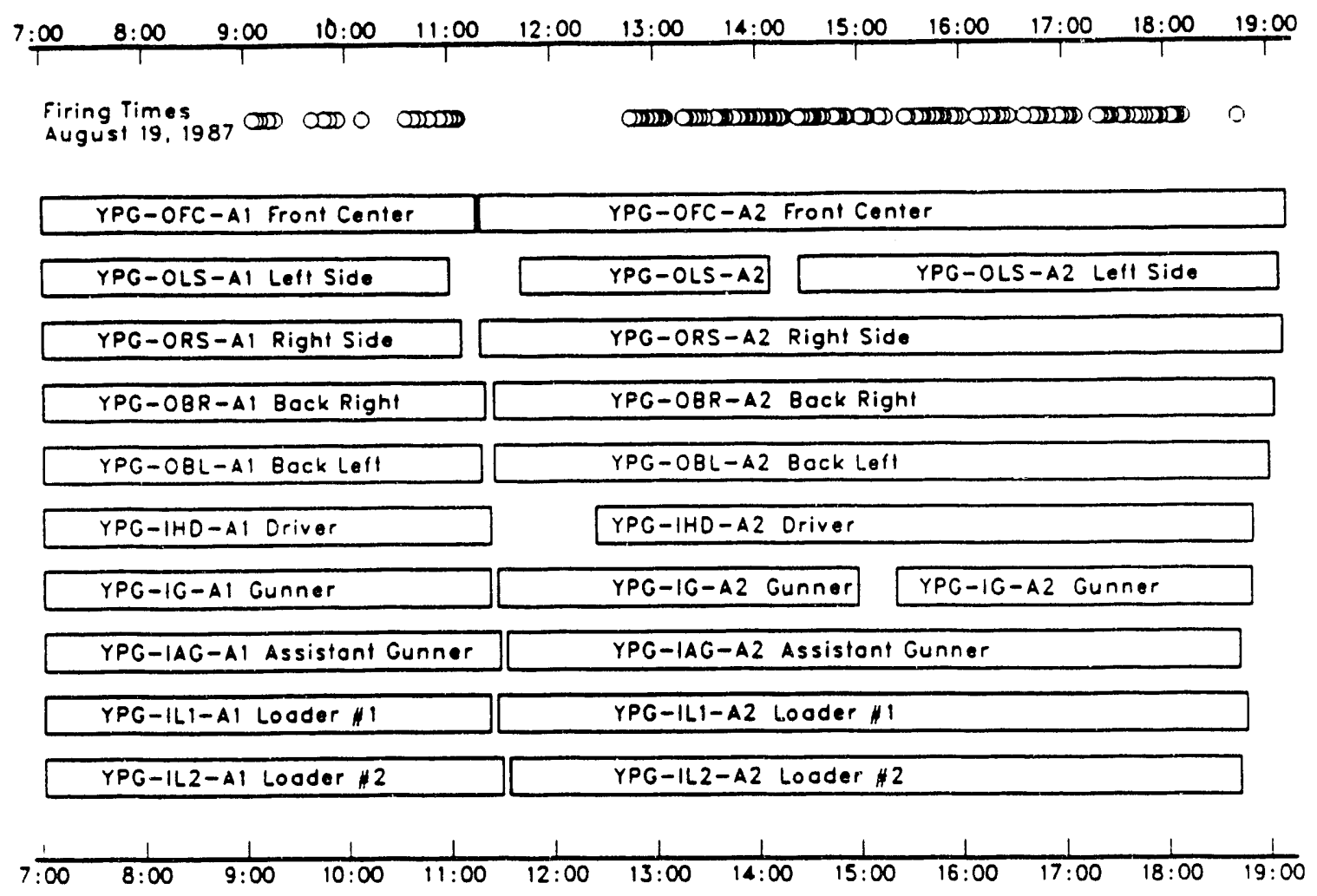

FIGURE 3 Firing time line for August 19, 1987, at YPG for the 155-mm/M109A3E1 howitzer. Bars represent sampling periods, with filter ID and location within each bar. Circles represent firing of M203A1 charges (a total of 120 rounds).

is included. In addition to the 10 UPASPs deployed as before, a Lundgren size-fractionating cascade impactor, sorption tubes, impingers, the optical particle counter, gas analyzers, and the weather station were also used. The sorption tube and impinger (LMS) samples were taken at the Assistant Gunner position. An LMS was also located outside at the left-center position (Fig. 5). Three soil surface samples were also taken. Sampling covered the entire period of the weapon firing each day with 12,11, and 11 rounds fired on August 31, September 1, and September 2, 1988, respectively (all charges were M203A1; see Table 1). On September 2, the last three rounds (rounds 12-14) were individually sampled.

The wind direction and speed for the different collection periods were WSW at $2.3 \mathrm{~m} / \mathrm{s}(6 \mathrm{mi} / \mathrm{h})$ on August 31; WSW at $1.8-2.3 \mathrm{~m} / \mathrm{s}(4-6 \mathrm{mi} / \mathrm{h})$ on September 1; and $\mathrm{E}$ at $5.4 \mathrm{~m} / \mathrm{s}(12 \mathrm{mi} / \mathrm{h})$ for rounds $\# 1-11$ and $E N E$ at $3.6 \mathrm{~m} / \mathrm{s}(8 \mathrm{mi} / \mathrm{h})$ for rounds $\# 12-14$ on September 2. These wind directions are shown in Fig. 5. All firing during the three days of collection had an azimuth of $70^{\circ}$ ENE. Gun elevation was 550 mils, 750 mils, and 950 mils on August 31, September 1, and September 2, respectively. All hatches except the main rear hatch were closed during firing. Ventilation fans were not operated and firings were accomplished by electronic ignition. 

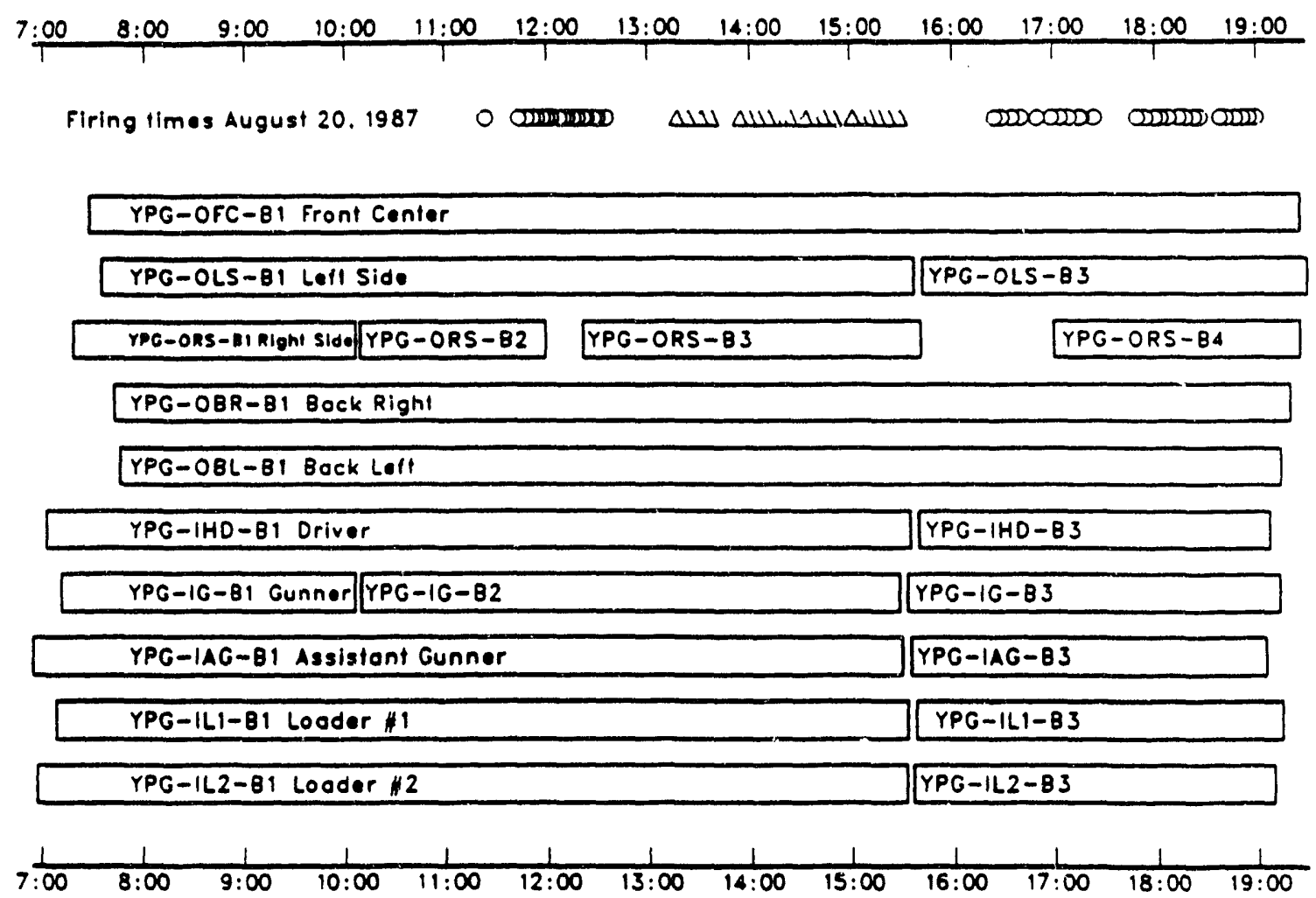

FIGURE 4 Firing time line for August 20, 1987, at YPG for the 155-mm/M109A3E1 howitzer. Bars represent sampling periods, with filter ID and location within each bar. Circles represent firing of M203A1 charges; triangles represent firing of M119A2 charges.

As opposed to the first sampling session, when only one weapon was being fired at the test site, during this second session three different $155-\mathrm{mm}$ howitzers were fired each day: these were the M198 field piece, the M109A3E1 Cobra, and the M109A3E2 HIP weapon. Figure 6a is a photograph showing the three howitzers and their relative locations during the session. Data and sample collection for the chemical and physical characterization of the lead-containing aerosol were, for the most part, limited to the period during which the HIP weapon was fired using the high-lead-content M203A1 propellant.

On the last day of firing, we requested an important change from the firing table schedule. The request was that the HIP weapon be fired first, rather than last, of the three guns. Since the weather patterns are quite consistent at YPG, with the wind shifting from the east in the morning, through the south during mid-day, to the west in the afternoon, we wanted to have information collected under different wind directions. This request was granted, and indeed we did get a full period with the wind from an easterly direction for comparison with the data from the two other days when the wind was westerly. 
TABLE 3 Samples and data taken at YPG during three days of firing the 155-mm/M109A3E2 HIP howitzer

\begin{tabular}{|c|c|c|c|c|}
\hline \multirow{2}{*}{$\begin{array}{c}\text { Type of Sample } \\
\text { or Data }\end{array}$} & \multicolumn{3}{|c|}{ Number of Samples collected } & \multirow[b]{2}{*}{ Analyses } \\
\hline & $8 / 31 / 88$ & $9 / 1 / 88$ & $9 / 2 / 88$ & \\
\hline $\begin{array}{l}\text { Matched-weight } \\
\text { filters (inside) }\end{array}$ & 5 & 8 & 20 & $\begin{array}{l}\text { AAS, gravimetric, } \\
\text { SEM-EDX }\end{array}$ \\
\hline $\begin{array}{l}\text { Matched-weight } \\
\text { filters (outside) }\end{array}$ & 5 & 6 & 22 & $\begin{array}{l}\text { AAS, gravimetric, } \\
\text { SEM-EDX }\end{array}$ \\
\hline $\begin{array}{l}\text { Hi-vol filters } \\
\text { (inside) }\end{array}$ & 1 & 1 & 1 & $\begin{array}{l}\text { Ion chromatography, } \\
\text { Raman microprobe }\end{array}$ \\
\hline $\begin{array}{l}\text { Hi-vol filters } \\
\text { (outside) }\end{array}$ & 1 & 1 & 1 & $\begin{array}{l}\text { Ion chromatography, } \\
\text { Raman microprobe }\end{array}$ \\
\hline $\begin{array}{l}\text { Lundgren impactor } \\
\text { (inside) }\end{array}$ & 1 set & 1 set & 1 set & AAS, IR, other \\
\hline $\begin{array}{l}\text { Lundgren impactor } \\
\text { (outside) }\end{array}$ & 1 set & 1 set & 1 set & AAs, IR, other \\
\hline $\begin{array}{l}\text { Sorption tubes, } \\
3 \text { types (inside) }\end{array}$ & - & 1 set & 1 set & $\begin{array}{l}\text { Gas chromatography/ } \\
\text { mass spectrometry }\end{array}$ \\
\hline $\begin{array}{l}\text { Liquid media } \\
\text { samplers (inside) }\end{array}$ & 1 & 1 & 1 & AAS \\
\hline $\begin{array}{l}\text { Liquid media } \\
\text { samplers (outside) }\end{array}$ & 1 & 1 & 1 & AAS \\
\hline $\begin{array}{l}\text { Optical particle } \\
\text { counter (inside) }\end{array}$ & Néarly & $\begin{array}{l}\text { continuous } \\
\text { firing }\end{array}$ & during & - \\
\hline Co monitor & Continu & dous during & firing & On-line co analysis \\
\hline $\begin{array}{l}\text { Wind speed } \\
\text { and direction }\end{array}$ & & Continuous & & Real time \\
\hline Soil samples & - & - & 3 & AAS \\
\hline
\end{tabular}

It had been decided during the planning of the study that the sample collection would be integrated over the entire firing period on any given day because of the limited number of rounds of the high-lead-content propellant to be used. It was also felt, however, that data from the firing of single rounds would also be useful. Therefore, it had been requested that some additional rounds be fired at the end of the regular firing scenario to collect some single-round data. As it turned out, sample collection went so well, and we felt confident enough that adequate data and samples were collected, that it was suggested that the last three rounds of the regular firing scenario be used for single round samples. This was done with only slight delays in the firing schedule and with some very useful and significant results. 


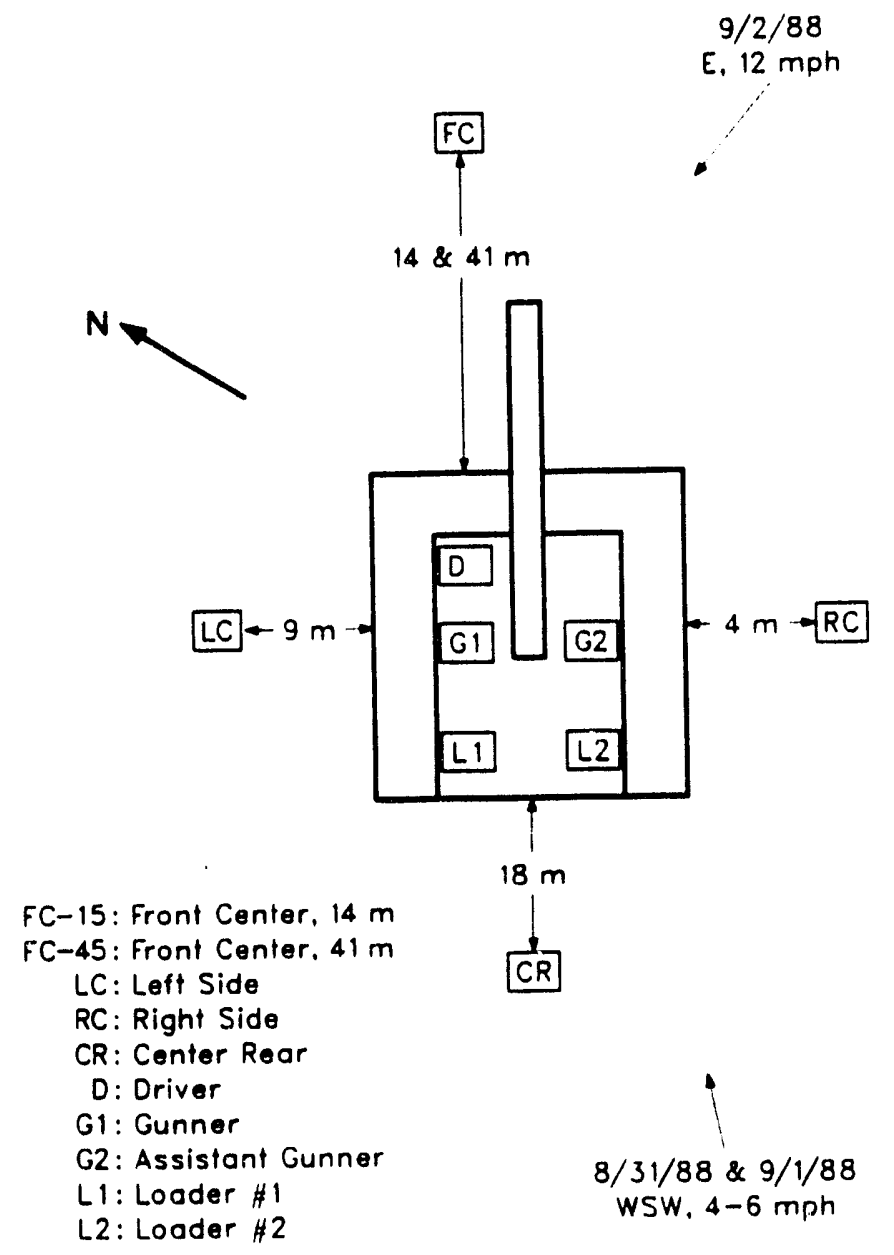

FIGURE 5 Diagram of 155-mm/M109A3E2 HIP howitzer with positions of filter samples and wind conditions at YPG from August 31 to

September 2, 1988

\subsection{RESULTS AND DISCUSSION}

\subsubsection{The 8-indM110 Howitzer}

Sampling conditions, sampling time, filter loading, and the lead and copper contents (as determined by AAS) for the dichotomous impactor samples collected at APG on February 10,1987, are shown in Table 4. Among these samples, the highest lead content was found in the coarse filter sample collected during the firing of rounds \#4 and \#5 (sample DI-APG-C4), the total lead concentration approaching $3 \%$ by weight. These results indicate that a significant portion of the lead aerosol was associated with particles larger than $2.5 \mu \mathrm{m}$ a.d. 
a)
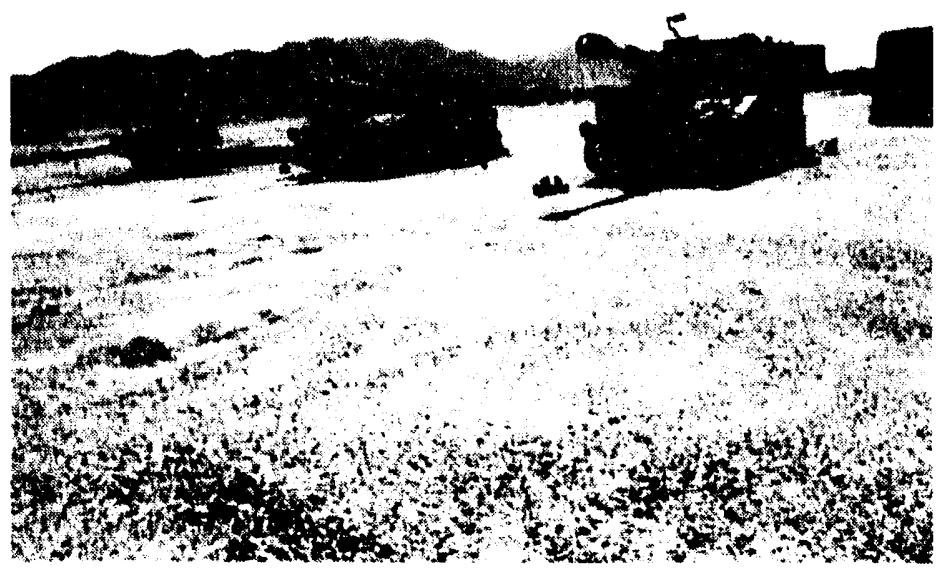

b)

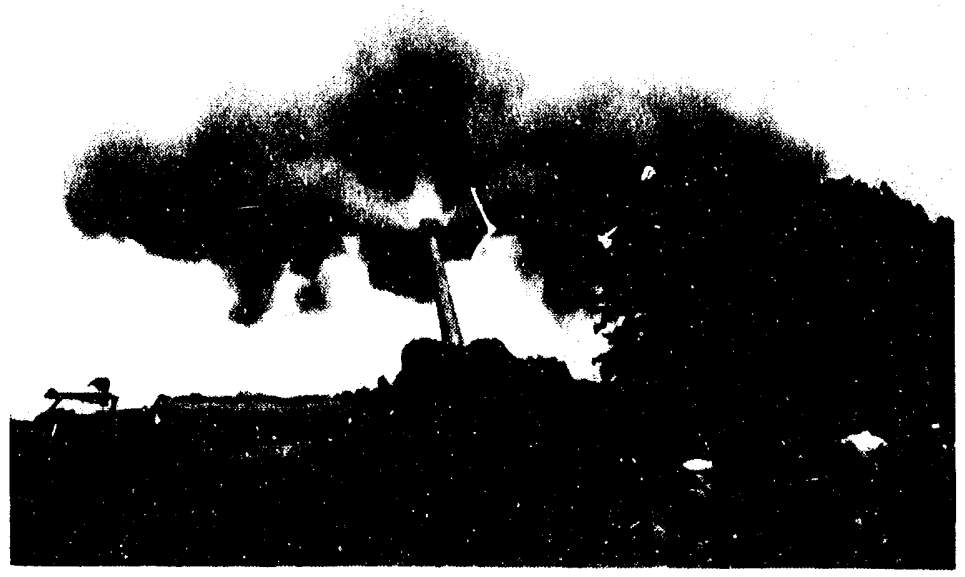

c)

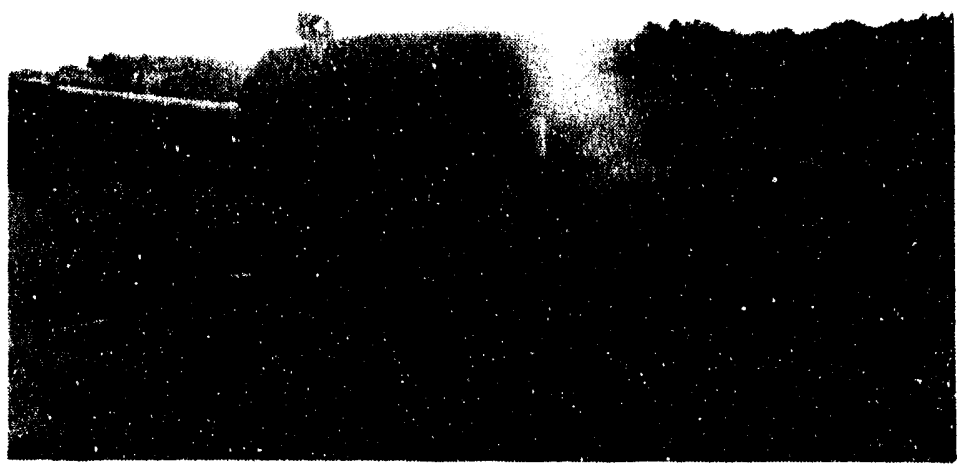

FIGURE 6 a) Three howitzers in firing position at YPG; b) 8-in. howitzer firing at Fort Sill, showing muzzle blast aerosol; c) 8-in. howitzer in loading position at Fort Sill 
TABLE 4 Data for the dichotomous impactor Teflo filter samples from the 8-in./M110 howitzer collected at APG on February 10, 1987

\begin{tabular}{|c|c|c|c|c|c|}
\hline \multirow[b]{2}{*}{ Sample $I D^{a}$} & \multirow[b]{2}{*}{ Conditions } & \multirow[b]{2}{*}{$\begin{array}{l}\text { Approx. } \\
\text { Collection } \\
\text { Time (min) } \\
\end{array}$} & \multicolumn{3}{|c|}{ Collected Sample ( $\mu \mathrm{g})$} \\
\hline & & & $\begin{array}{c}\text { Total } \\
\text { Weight }\end{array}$ & $\begin{array}{c}\text { Total } \\
\mathrm{Pb}^{\mathrm{b}}\end{array}$ & $\begin{array}{l}\text { Total } \\
\mathrm{Cu}^{\mathrm{b}}\end{array}$ \\
\hline $\begin{array}{l}\text { DI - APG-F2 } \\
\text { DI-APG-C2 }\end{array}$ & $\begin{array}{l}\text { Prefiring } \\
\text { background }\end{array}$ & 120 & $\begin{array}{r}83 \\
116\end{array}$ & $\begin{array}{l}0.525 \\
0.770\end{array}$ & $\begin{array}{l}0.020 \\
0.030\end{array}$ \\
\hline $\begin{array}{l}D I-A P G-F 3 \\
D I-A P G-C 3\end{array}$ & $\begin{array}{l}\text { Rounds } 1,2, \\
\text { and } 3 \\
\text { (al1 zone } 7 \text { ) }\end{array}$ & 8 & $\begin{array}{r}1316 \\
331\end{array}$ & $\begin{array}{l}1.220 \\
1.020\end{array}$ & $\begin{array}{l}0.720 \\
0.280\end{array}$ \\
\hline $\begin{array}{l}D I-A P G-F 4 \\
D I-A P G-C 4\end{array}$ & $\begin{array}{l}\text { Rounds } 4 \\
\text { and } 5 \\
\text { (both zone 9) }\end{array}$ & 25 & $\begin{array}{l}447 \\
159\end{array}$ & $\begin{array}{l}2.190 \\
4.660\end{array}$ & $\begin{array}{l}0.220 \\
0.730\end{array}$ \\
\hline $\begin{array}{l}\text { DI-APG-F5 } \\
\text { DI-APG-C } 5\end{array}$ & $\begin{array}{l}\text { Postfiring } \\
\text { background }\end{array}$ & 10 & $\begin{array}{l}19 \\
16\end{array}$ & $\begin{array}{l}0.295 \\
0.885\end{array}$ & $\begin{array}{l}0.040 \\
0.040\end{array}$ \\
\hline $\begin{array}{l}D I-A P G-F 7 \\
D I-A P G-C 6\end{array}$ & $\begin{array}{l}\text { Blank } \\
\text { "unused" } \\
\text { filters }\end{array}$ & 0 & $\begin{array}{l}16 \\
16\end{array}$ & $\begin{array}{l}0.730 \\
0.760\end{array}$ & $\begin{array}{l}0.040 \\
0.030\end{array}$ \\
\hline$I-A N L-00$ & $\begin{array}{l}\text { Blank "not } \\
\text { handled" } \\
\text { filters" }\end{array}$ & $N A^{d}$ & NA & $<0.1$ & $<0.03$ \\
\hline
\end{tabular}

a DI-APG-Fn = Fine particles (less than $2.5 \mu \mathrm{m}$ aerodynamic diameter). DI-APG-Cn = Coarse particles (greater than $2.5 \mu \mathrm{m}$ aerodynamic diameter).

b From AAS.

c "Unused" filters were in filter cartridge during firing but were not put in place for aerosol collection. The "not handled" filter was taken directly from the original box ind not handled except for analysis.

d $N A=$ not applicable.

The dichotomous impactor samples, however, are believed to be contaminated. For example, appreciable amounts of lead were found on the "background" and "unused" filters, but no accompanying copper was detected. This indicates that there was lead contamination of these filters with "non-emission" lead, since all "emission" samples contained significant amounts of copper as well. The likely reason for this contamination was that in the dichotomous impactor sampler, all the filter sets are mounted in a large circular plate which is then sealed within the device. Under the field conditions prevalent in this study, it was not possible to load the clean filters without introducing some dust into the unit. Further, each firing caused some resuspension and cross-contamination of the filters within the instrument. Some of the filters were even knocked out of position and damaged. Because of these problems, use of the dichotomous impactor was discontinued for subsequent sampling. 
Even though the amounts of lead and copper given in Table 4 may be incorrect, these values are high enough above the background and contamination levels that they can still be of use, at least to show trends.

The lead and copper content of the filter samples collected with the UPASPs from various positions in the weapon's cab are shown in Table 5. These data show that the lead contents of samples collected at $4 \mathrm{~L} / \mathrm{min}$ were similar at the breech and Gunner positions and were somewhat higher at the Assistant Gunner position. In addition, the lead content of the breech sample collected at $2.0 \mathrm{~L} / \mathrm{min}$ was approximately one-half that of the breech sample collected at $4.0 \mathrm{~L} / \mathrm{min}$. These data indicate that the UPASP filters, which were not removed from the cartridges until the time of AAS, were not contaminated by lead during handling and that the sampling was reliable at these flow rates.

Table 6 presents the results from the AAS analysis of the filters collected with the UPASPs at APG on March 19-20, 1987. The most striking feature in these results is the large difference in the air lead loading between the first four samples and the rest listed in the table. This is due to a shift in the wind direction. The wind was from the rear of the weapon (northeast) on March 19th (rounds 1-30) and the morning of the 20th (rounds 1-50), but shifted to forward of the weapon (south) by mid-day on the 20th (see Fig. 1). For the afternoon sampling (rounds 51-82), we had placed a filter on the tower but later moved it to the rear of the motor home. The high air lead levels at the tower and the motor home indicate that a significant portion of the lead is ejected from the muzzle with the blast and that this ejection is probably a much greater source of lead emissions than the breech. Note that the high air lead concentration at the Tower-1 sample position $\left(381 \mu \mathrm{g} / \mathrm{m}^{3}\right.$, rounds 36-50) was obtained in range of the muzzle blast even under tail wind conditions that resulted in low air lead concentrations at the breech $\left(1-2 \mu \mathrm{g} / \mathrm{m}^{3}\right.$, rounds $\left.1-50\right)$, again indicating the importance of the muzzle blast as a source of lead emissions during firing.

Figure 7 shows an example of the data obtained with the OPC for observing the aerosol generated during a single firing. The figure shows the volumetric size distribution of the particles at a time resolution of approximately $9 \mathrm{~s}$. Throughout all of the testing, the OPC was operated on a continuous basis using the 9-s time resolution during all firing periods. Many thousands of plots of this type were generated. These data were transformed into the more useful plot shown in Fig. 8. The 18 plots shown in Fig. 7 cover a time period of about $2 \mathrm{~min}$. This particular set was from the last of the five rounds fired on February 10 , 1987. Since the crew knew that they would not fire any more that day, they were slow to open the breech after firing the last round, so most of the fumes bled out from the tip of the barrel.

The changes in the aerosol caused by the firing of a series of rounds are shown in Fig. 8. This figure shows the particle counts in the smallest and largest size ranges and in the two middle ranges designated in the legend. Thus, the generation and decay of the different size ranges of particles can be followed relative to each other. The omitted ranges have somewhat lower values but follow closely the two mid-size ranges which are plotted. 
TABLE 5 Lead and copper content of cellulose acetate filter samples collected at APG on February 10, 1987, in the CBS of the 8-in./M110 howitzer by using personal sampling pumps ${ }^{a}$

\begin{tabular}{|c|c|c|c|c|}
\hline \multirow[b]{2}{*}{$\begin{array}{l}\text { Filter } \\
\text { ID }\end{array}$} & \multirow[b]{2}{*}{ Position } & \multirow[b]{2}{*}{$\begin{array}{l}\text { Flow Rate } \\
(\mathrm{L} / \mathrm{min})\end{array}$} & \multicolumn{2}{|c|}{$\begin{array}{c}\text { Element Content of Sample } \\
(\mu \mathrm{g})\end{array}$} \\
\hline & & & $\mathrm{Pb}$ & $\mathrm{Cu}$ \\
\hline S1A & Breech & 4.0 & 2.28 & 0.85 \\
\hline $\mathrm{S} 2 \mathrm{~A}$ & Breech & 3.0 & Note $b$ & Note $b$ \\
\hline$S 3 A$ & Breech & 2.0 & 1.30 & 0.34 \\
\hline $\mathrm{D} 2 \mathrm{~A}$ & $\begin{array}{l}\text { Gunner } \\
\text { (front) }\end{array}$ & 3.9 & 2.09 & 0.72 \\
\hline D3A & $\begin{array}{l}\text { Asst. gunner } \\
\text { (front) }\end{array}$ & 3.8 & 3.72 & 0.56 \\
\hline DIA & $\begin{array}{l}\text { Asst. gunner } \\
\text { (back) }\end{array}$ & $1.5^{\mathrm{C}}$ & 0.21 & $\mathrm{ND}^{\mathrm{d}}$ \\
\hline Note e & - & - & ND & 0.03 \\
\hline
\end{tabular}

a Wind was from the west (forward of weapon) at 5-10 mi/h. All samples were collected continuously for $2-3 \mathrm{~h}$.

b Used for SEM/EDX.

c Flow stopped at unknown time.

${ }^{d}$ ND $=$ not detectable.

e Blank filter, not handled. This filter was taken directly from its original box and not handled except for analysis.

The OPC does not provide information on the chemical compositions of the aerosol. The firing times are shown by the asterisks. Results show that the large and mid-size particles rose and fell in concentration over a period of approximately $1 \mathrm{~min}$ after each firing.

Examples of infrared spectra obtained from the aerosol collected on the coarse and fine filters of the dichotomous impactor sampling at the breech are shown in Fig. 9. These samples, fine fraction DI-APG-F3 and coarse fraction DI-APG-C3, were collected during the firing of three zone 7 charges on February 10, 1987, and are representative of the many infrared spectra taken of emission samples from both weapons. Also shown on Fig. 9 are the infrared spectra of one of the APG soil samples and of sodium bicarbonate $\left(\mathrm{NaHCO}_{3}\right)$. The asterisks on the top three spectra in Fig. 9 identify the infrared absorption bands from published spectra of $\mathrm{NaHCO}_{3}$ that are common to all three spectra. Because potassium is the most likely cation present in the emissions, the compound in the aerosol particles is assumed to be potassium bicarbonate $\left(\mathrm{KHCO}_{3}\right)$. However, for comparison of these infrared 
TABLE 6 Lead and copper content of the filter samples collected at various positions on the 8-in JM110 howitzer on March 19-20, 1987

\begin{tabular}{|c|c|c|c|c|c|c|c|}
\hline \multirow{2}{*}{$\begin{array}{l}\text { Date/ } \\
\text { Rounds }\end{array}$} & \multirow{2}{*}{$\begin{array}{c}\text { Flicer } \\
\text { ID/Location }\end{array}$} & \multirow{2}{*}{$\begin{array}{l}\text { Sampling } \\
\text { Timeb } \\
\text { (min) }\end{array}$} & \multicolumn{2}{|c|}{$\begin{array}{c}\text { Total Element } \\
\text { in Samp } 1 e^{c} \\
(\mu g)\end{array}$} & \multicolumn{2}{|c|}{$\begin{array}{c}\text { AIr Loading } \\
\left(\mu g / \mathrm{m}^{3}\right)\end{array}$} & \multirow{2}{*}{$\begin{array}{l}\text { Rupl: } \\
\text { Racis: }\end{array}$} \\
\hline & & & $\mathrm{Pb}$ & $\mathrm{Cu}$ & $\mathrm{Pb}$ & $\mathrm{Cu}$ & \\
\hline \multicolumn{8}{|l|}{$3 / 19 / 87$} \\
\hline $1-30 \quad(30)$ & S1A (breech) & 278 & 12.85 & 5.4 & $12^{\mathrm{d}}$ & 5 & 0.42 \\
\hline $1-30(30)$ & S3A (Gunner) & 278 & 15.2 & 5.2 & $15^{d}$ & 5 & 0.34 \\
\hline \multicolumn{8}{|l|}{$3 / 20 / 97^{\circ}$} \\
\hline $1-50 \quad(50)$ & SlB (breech) & 283 & 2.22 & 1.6 & $2^{d, f}$ & 1 & 0.72 \\
\hline $1-50 \quad(50)$ & S3B (Gunner) & 285 & 1.47 & 1.5 & $L^{d, f}$ & 1 & 1.02 \\
\hline $36-50(15)$ & $\begin{array}{l}\text { Tower } 1 \\
\text { (front left) }\end{array}$ & 105 & 160 & 34.0 & $381^{\mathrm{d}, \mathrm{t}}$ & $B 1$ & 0.21 \\
\hline $51-82 \quad(32)$ & sic (breech) & 87 & 200 & 76.0 & $574^{9}$ & 218 & 0.38 \\
\hline $51-82(32)$ & s3c (Gunner) & 87 & 210 & 80.0 & $603^{9}$ & 230 & 0.38 \\
\hline $51-70 \quad(20)$ & $\begin{array}{l}\text { Tower } 2 \\
\text { (front left) }\end{array}$ & 81 & 100 & 26.0 & $309^{9}$ & 92 & 0.26 \\
\hline $71-82(12)$ & $\begin{array}{l}\text { Tower } 3 \\
\text { (mocor home) }\end{array}$ & 41 & 80 & 38.0 & $488^{9}$ & 232 & 0.48 \\
\hline - & $\begin{array}{l}\text { Exposed blank } \\
\text { (breech) }\end{array}$ & 0 & 50.10 & $\leq 0.10$ & - & - & - \\
\hline - & $\begin{array}{l}\text { No flow blank } \\
\text { (breech) }\end{array}$ & 0 & $N D^{h}$ & 50.10 & - & - & - \\
\hline - & Wet ash blank & - & ND & ND & - & - & - \\
\hline
\end{tabular}

a The number of rounds fired during the collection period is in parentheses.

b Flow rate for all samples was $4 \mathrm{~L} / \mathrm{min}$.

c Determined by AAS.

d WInd was from the NE (rear of weapon) at $5-20 \mathrm{mi} / \mathrm{h}$ during collection.

- Eighcy-two zone 9 charges were $f 1$ red (numbereu 1 to 82 ).

f Fllters S1B, S3B, and Tower 1 all included collection during rounds 36-50. However, the cower sample was the only one in the range of the muzzle blast showing high PbA levels.

$g$ Wind was from the south (forward of weapon) at $5-20 \mathrm{mi} / \mathrm{h}$ for rounds $51-82$.

n NO = not detectable. 

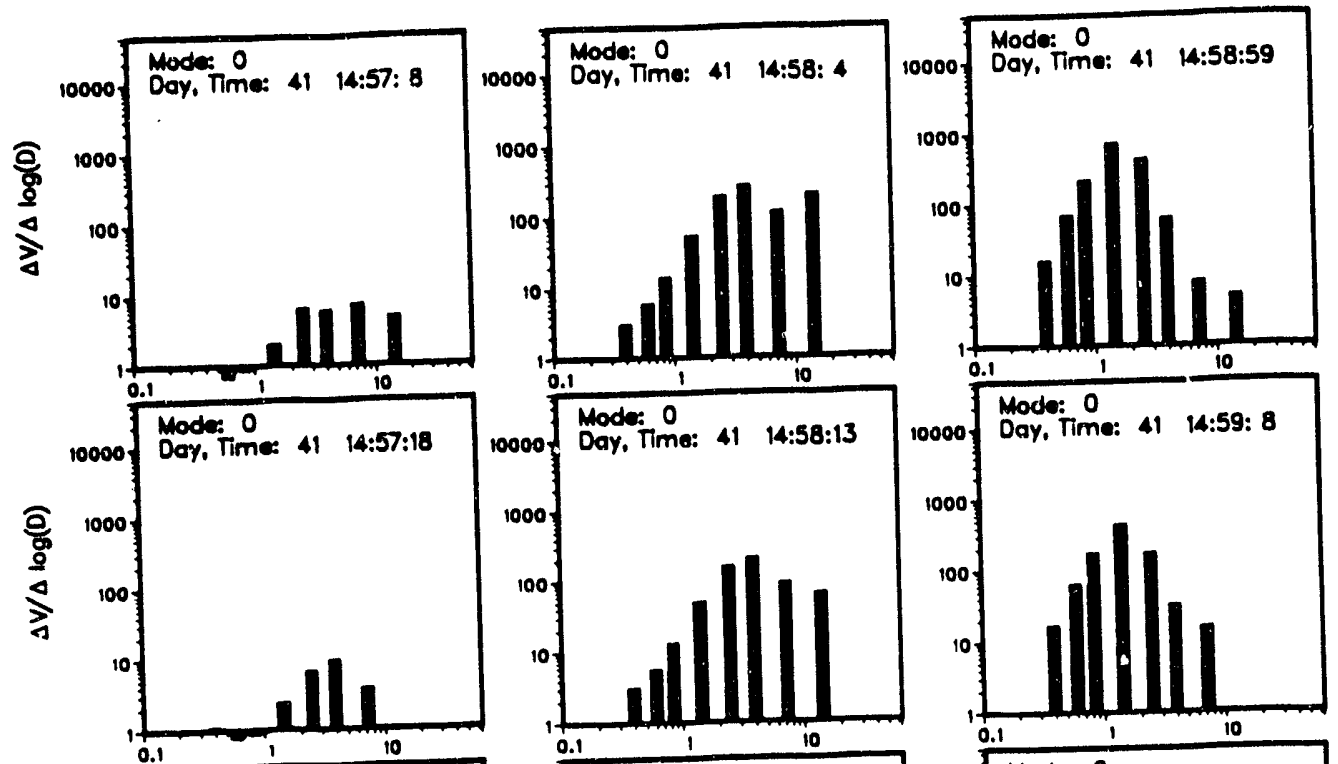

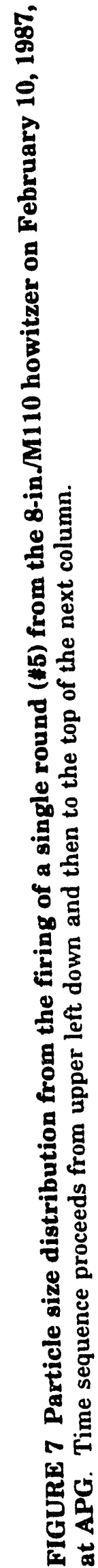
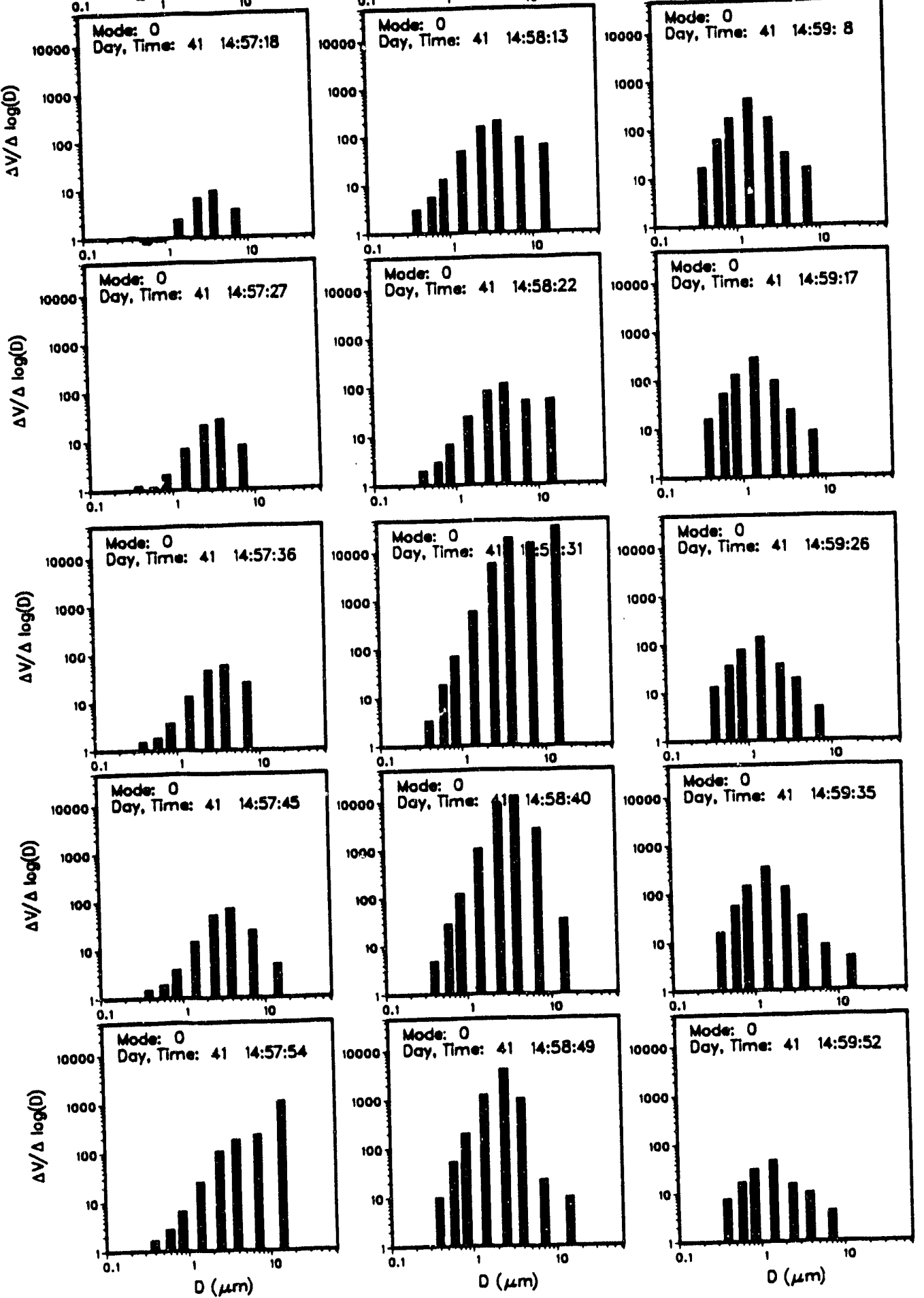


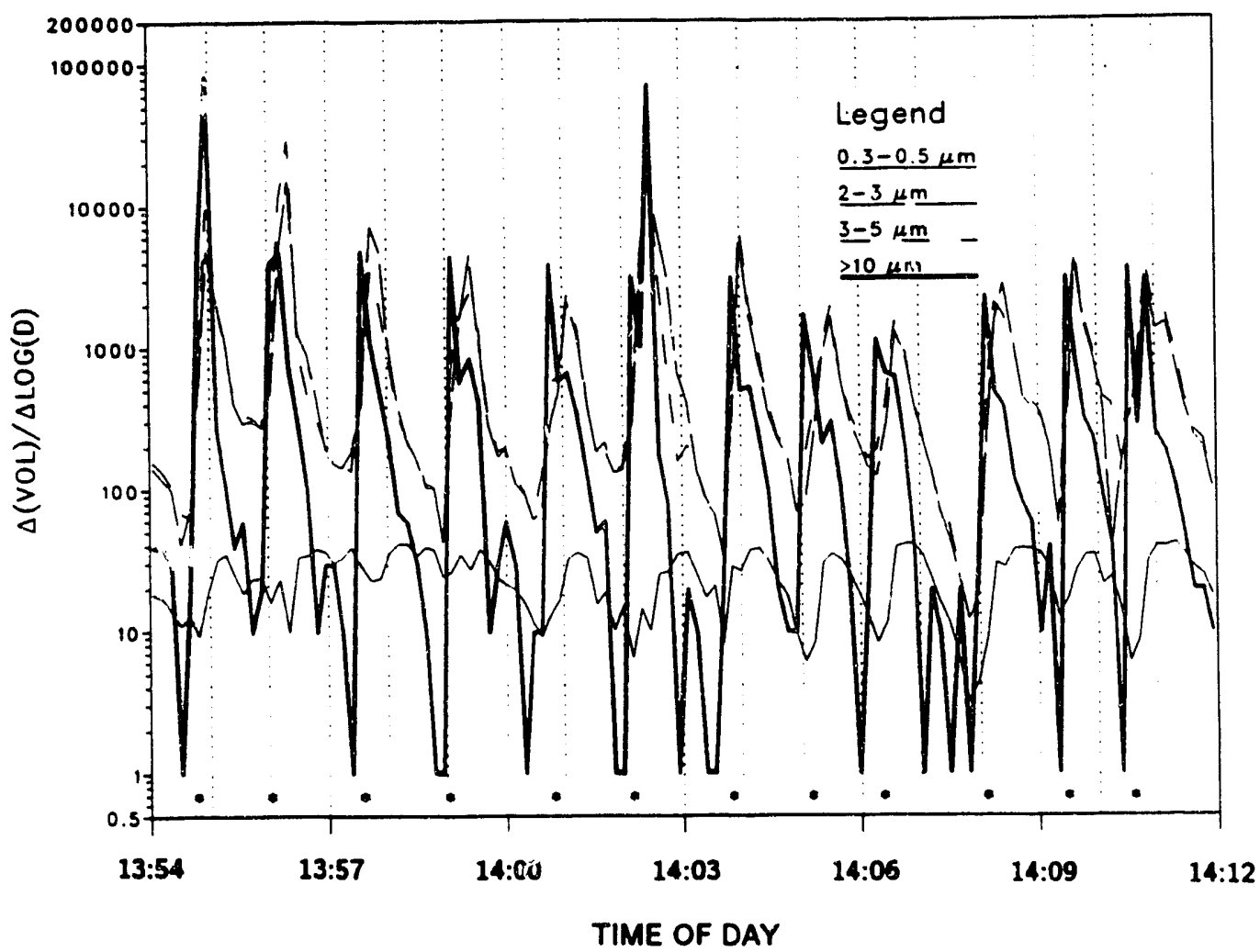

FIGURE 8 Climet Optical Particle Counter data from firing of the 8-in $\sqrt{M 110}$ howitzer at APG on March 20, 1987, using M188A1, zone 9, high-lead charges. Asterisks indicate time of firing. For clarity, only four of the eight size ranges are plotted.

spectra, the cation does not affect the bicarbonate absorption band structure. The spectrum of the APG soil sample shows mainly silica, as expected from soil. About 26 dichotomous impactor samples and 24 total filters were analyzed using infrared spectroscopy. No leadcontaining compounds were specifically identified with infrared spectroscopy in any of the samples.

A filter sample of aerisol from the breech following the firing of high-lead propellant was examined by SEM and EDX. At 1000x, the sample revealed a variegated distribution of particles having a wide range of shapes and sizes. The EDX analysis of selected particles in the 5-20 $\mu \mathrm{m}$ size range showed that the majority of the particles were aluminates and aluminosilicates originating from the soil at the test site. A number of particles rich in iron ( $\mathrm{Fe}$ ) and chromium $(\mathrm{Cr})$ were also found; these are believed to have originated from structural materials. Measurements with EDX were also made in the backscatter electron imaging mode, which accentuates the X-ray images of particles containing elements of the higher atomic numbers, e.g., lead. Scans in the backscatter mode at 1000x and 5000x revealed a widely distributed array of nearly circular bright spots corresponding to particles in the 


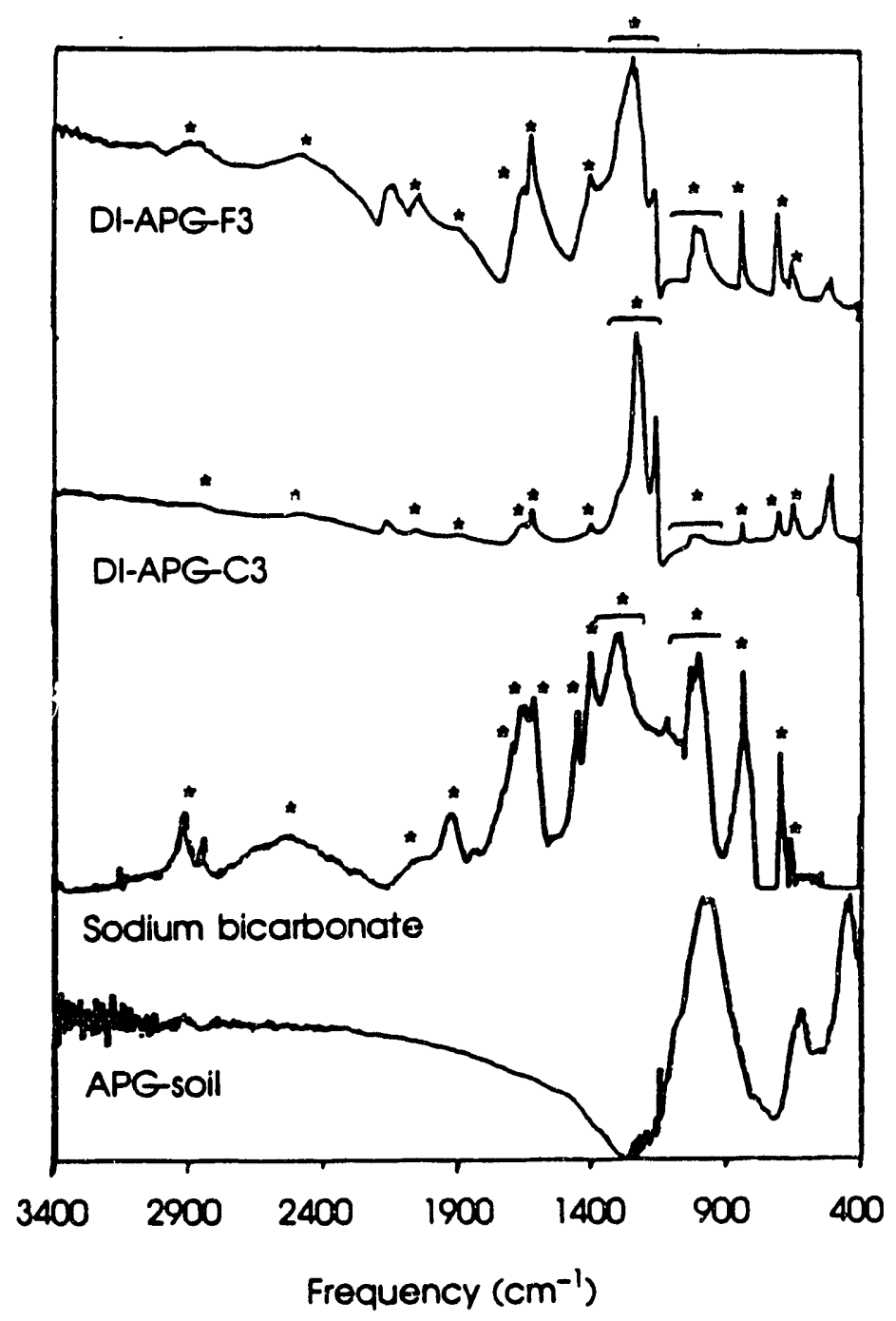

FIGURE 9 Infrared spectra of breech aerosol and soil from APG compared with reference specira. Asterisks indicate absorption bands from published spectra of $\mathrm{NaHCO}_{3}$ that are common to all of the spectra.

$0.5-5 \mu \mathrm{m}$ range. The major metallic elements in these particles were lead and potassium. These are also the two principal metallic ingredients in most charges, usually introduced as lead foil or $\mathrm{PbCO}_{3}$ (or both) for lead and as $\mathrm{K}_{2} \mathrm{SO}_{4}$ for potassium.

Overall, 30 sections of different filters were mounted for analysis by SEM/EDX. On each section, several fields of view were examined and about 150 photomicrographs were taken with corresponding EDX plots. Typical SEM photomicrographs are shown in Figs. 10a and b. Figure 10a shows an 18- $\mu \mathrm{m}$ aluminate particle and a nearby $3.5-\mu \mathrm{m} \mathrm{Pb} / \mathrm{K}$ particle at 1000x. Note the relative brightness of the two particles and the sphericity of the $\mathrm{Pb} / \mathrm{K}$ 


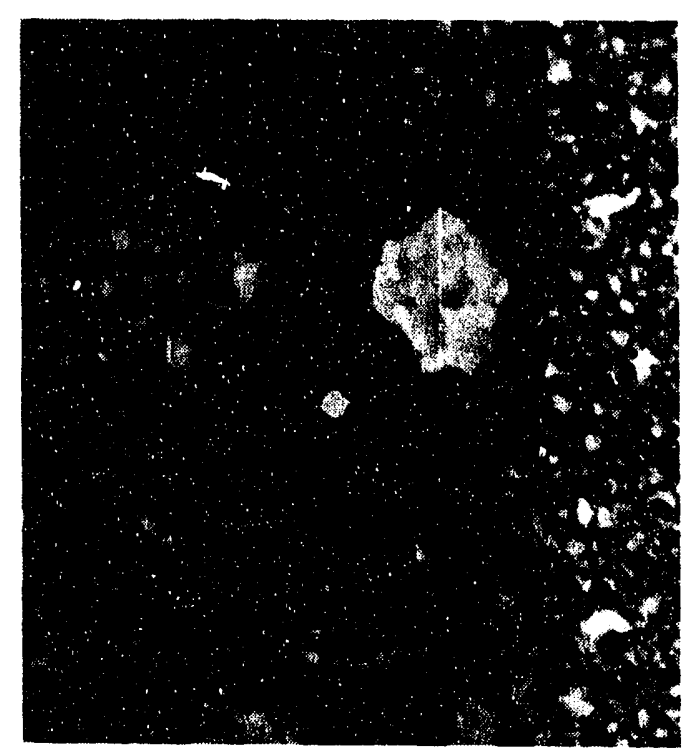

a) A 3.5- $\mu \mathrm{m} \mathrm{Pb} / \mathrm{K}$ particle (bright spot at center) and an 18- $\mu \mathrm{m}$ aluminate particle (large particle in upper right quadrant)

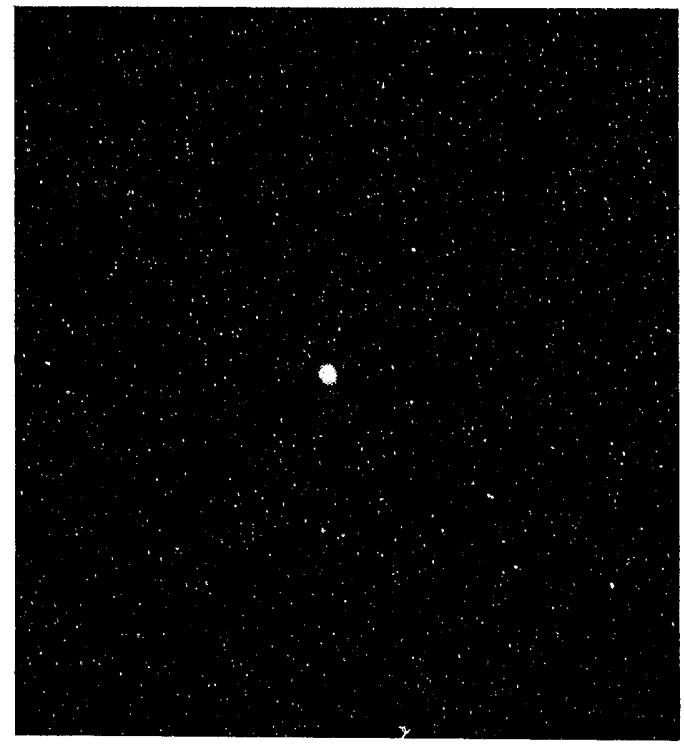

b) A 0.6- $\mu \mathrm{m} \mathrm{Pb} / \mathrm{K}$ particle (bright spot in center)

\section{FIGURE 10 SEM images of aerosol from the 8-in.M110 howitzer firing M188A1 zone 9} charges at APG

particle. Figure 10b shows the image of a $0.6-\mu \mathrm{m} \mathrm{Pb} / \mathrm{K}$ particle. The EDX spectra of the three particles highlighted in Figs. 10a and $b$ are shown in Fig. 11a, b, and c. The composition of the $\mathrm{Pb} / \mathrm{K}$ particles and their identity with the constituent metallic elements, including copper, in the propellant confirm that these particles are formed from combustion of the propellant. The aerosol from the breech seems to be largely composed of a complex lead/potassium bicarbonate salt, with the lead concentrated in the particle size range between 0.5-5.0 $\mu \mathrm{m}$ a.d. These SEM results support the relatively high concen-tration of lead found in the coarse-particle fraction (larger than $2.5 \mu \mathrm{m}$ ) for zone 9 charges (see Table 4).

Samples S1C from the breech area, Fig. 12) and S3C (from the Gunner position, not shown) each contained a heavy deposit of particles with two distinctly different compositions from the firing of high-lead charges. Particles of one type existed in a wide range of sizes and irregular shapes and contained primarily silicon ( $\mathrm{Si}$ ), aluminum (Al), calcium (Ca), magnesium $(\mathrm{Mg})$, and iron, with little of the high atomic number elements. The other type of particles had a more regular shape (usually spherical), and contained high levels of the heavier elements (lead, potassium, silicon, or titanium) which show up brighter in the backscatter mode. Analysis of these particles by DEX revealed that lead, potassium, and in some cases titanium (Ti) were the major elemental constituents, along with varying amounts of silicon. Qualitative examination of the photomicrographs of the second type of particles showed that of the total particle sample, the major fraction consisted of particles containing 


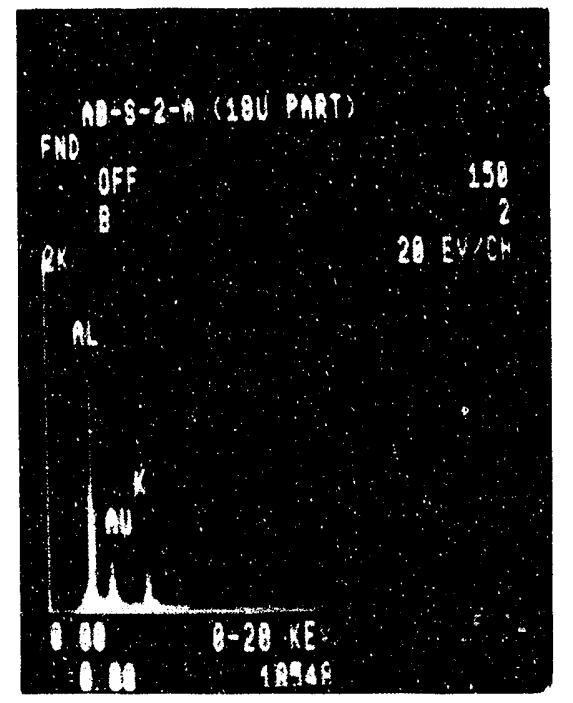

a

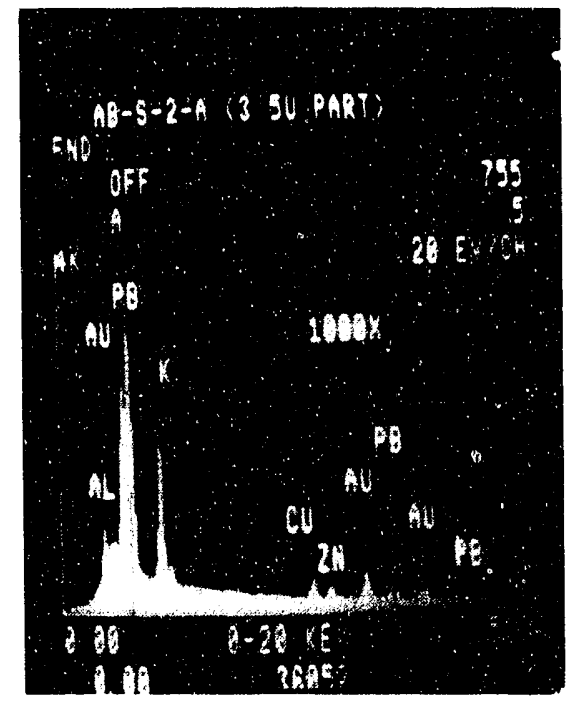

b

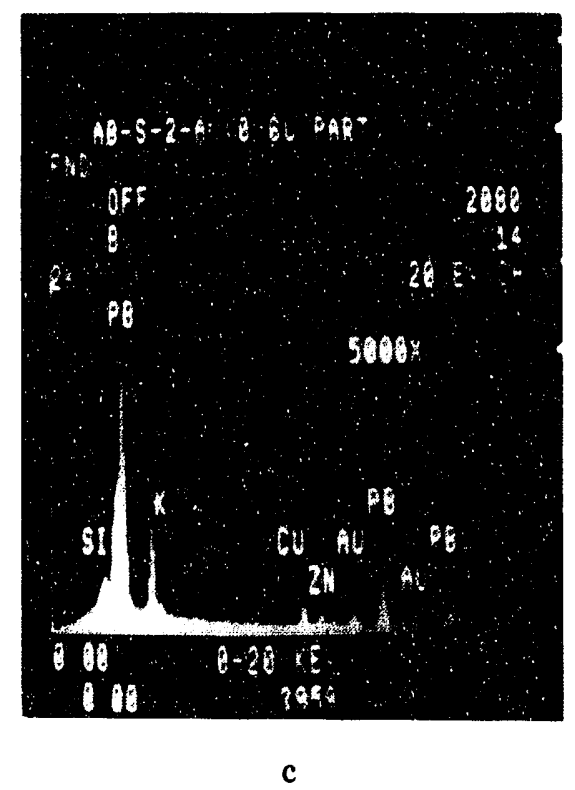

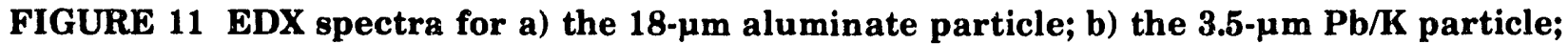
and $\mathrm{c}$ ) the 0.6- $\mu \mathrm{m} \mathrm{Pb} / \mathrm{K}$ particle shown in Figure 10 


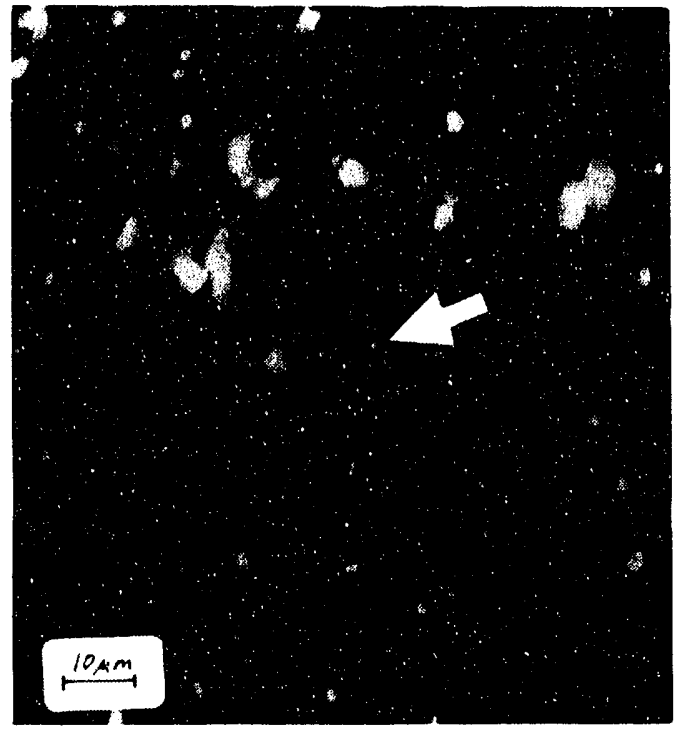

a) BEI mode showing particles with high-Z atoms

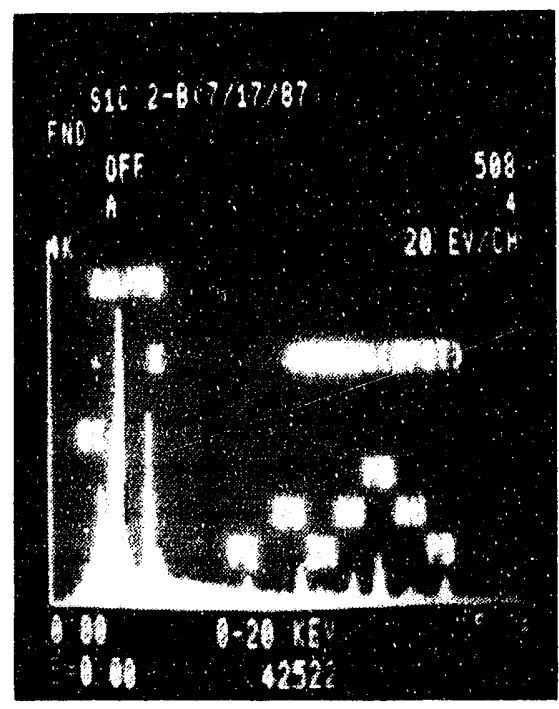

c) EDX results showing high lead content of the small particle shown by the arrow in Fig. 12a

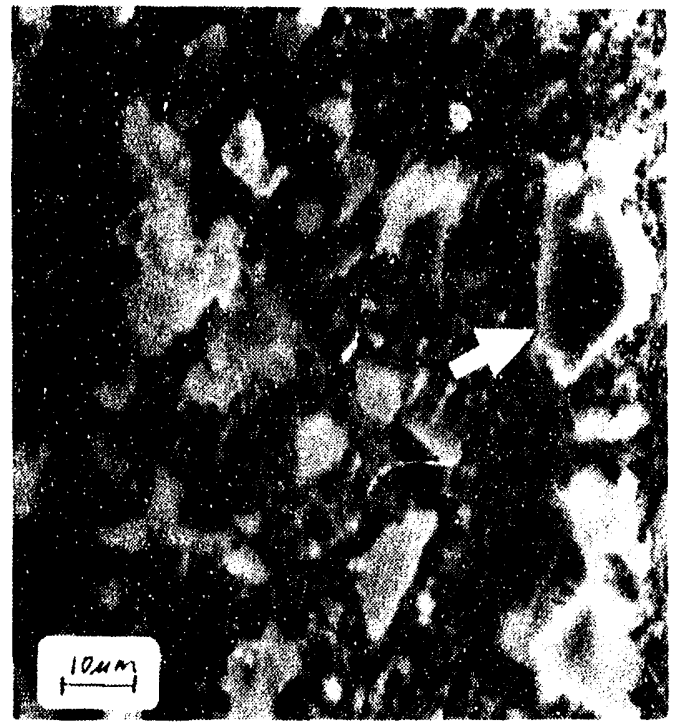

b) SEM mode showing all particles

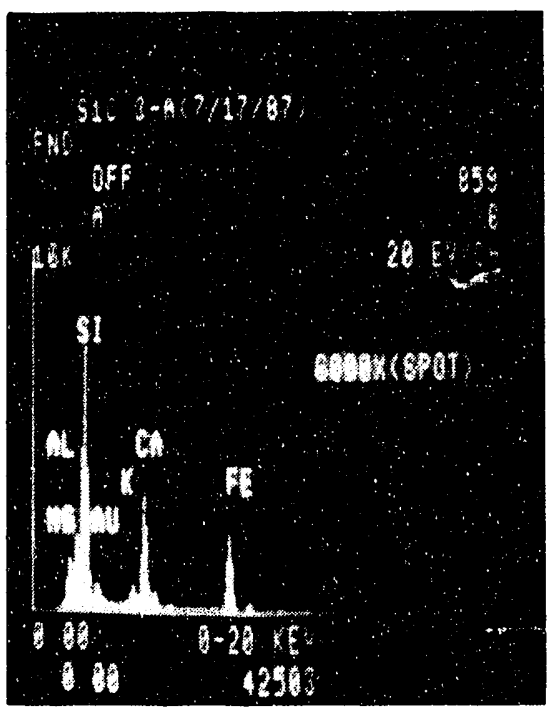

d) EDX results showing soil-like composition of the large particle shown by the arrow in Fig. $12 \mathrm{~b}$

FIGURE 12 SEM images and EDX spectra of breech aerosol collected from the 8-in./M110 howitzer firing M188A1 zone 9 charges at APG 
lead. These lead-containing particles ranged in size from less than $1 \mu \mathrm{m}$ to about $10 \mu \mathrm{m}$ in diameter. The first type of particles is believed to originate mainly from soil and other debris on the floor and walls of the howitzer cab, while the second type of particles is believed to arise from the propellant. Many of the soil/debris particles were "decorated" with lead on their edges and surfaces. Thus lead was the dominant metallic element in each of the two samples, S1C and S3C.

During the course of the aerosol studies several attempts were made to use powder X-ray diffraction as one of the instrumental methods to help elucidate the chemical composition of the aerosol. The technique did not work as well as expected because the filter material tended to mask the lines, and it was difficult to get adequate samples off of the filters to get good X-ray patterns. Therefore, the only materials unambiguously identified were the soil type chemicals. However, during the process of preparing the final report, we went back to take another look at the diffraction patterns from some of the samples. This was done because new and better diffraction pattern data had been acquired in the ensuing period.

On one of the samples, the diffraction patterns identified two lead-containing compounds. The sample was one collected at APG on March 20,1987, from the Gunner position of the 8-in./M110 and designated S3C. The X-ray diffraction analysis was carried out on particles from two separate areas of the filter. Both areas contained alpha-SiO $\mathrm{S}_{2}$, as expected for soil particles, but also, both areas contained some potassium lead carbonate hydroxide, $\mathrm{KPb}_{2}\left(\mathrm{CO}_{3}\right)_{2} \mathrm{OH}$. Another lead-containing phase was also detected but only in the one area near the center of the filter. This material was tentatively identified as ammonium lead copper nitrate, $\left(\mathrm{NH}_{4}\right)_{2} \mathrm{PbCu}\left(\mathrm{NO}_{2}\right)_{6}$.

Samples Tower 1 (front left of gun) and Tower 3 (right rear of gun) were much the same with regard to particle size distribution and composition after firing high-lead charges. Figure 13 shows a representative SEM field of view from the Tower 3 sample, which is also presented in backscatter mode with EDX results for one of the small spherical particles. These samples contained a much smaller fraction of the non- $\mathrm{Pb}$ soil/debris particles than was found on S1C and S3C. Instead, the particulate matter on these filters was mainly the spherical lead-rich type, with potassium and in some cases titanium as major co-constituents. In these tower samples, a majority of the particles contained lead, and about half of these paricles were $1 \mu \mathrm{m}$ or less in diameter.

Soil samples were collected from the Old Ant Hill firing site at APG and analyzed for lead and copper by AAS. Three samples of surface soil collected from under the muzzle area of the gun showed an average of $777 \mu \mathrm{g} \mathrm{Pb} / \mathrm{g}$ soil and $588 \mu \mathrm{g} \mathrm{Cu} / \mathrm{g}$ soil.

The results of analyses of the smear samples collected from the wall of the cab are given in Table 7. The firing history and previous cleaning of the weapon are unknown, so the values for the "pre-test accumulation" give only a point of reference for comparison of the other values. This set does indicate that four dry wipings did not remove all of the lead and copper. The methanol wash, on the other hand, was effective (values for "after cleaning 


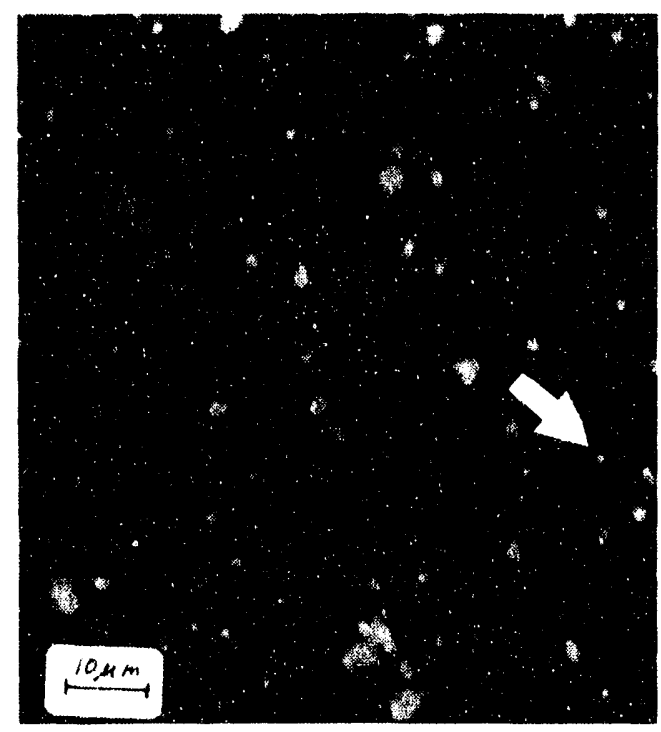

a) BEI mode showing particles with high-Z atoms

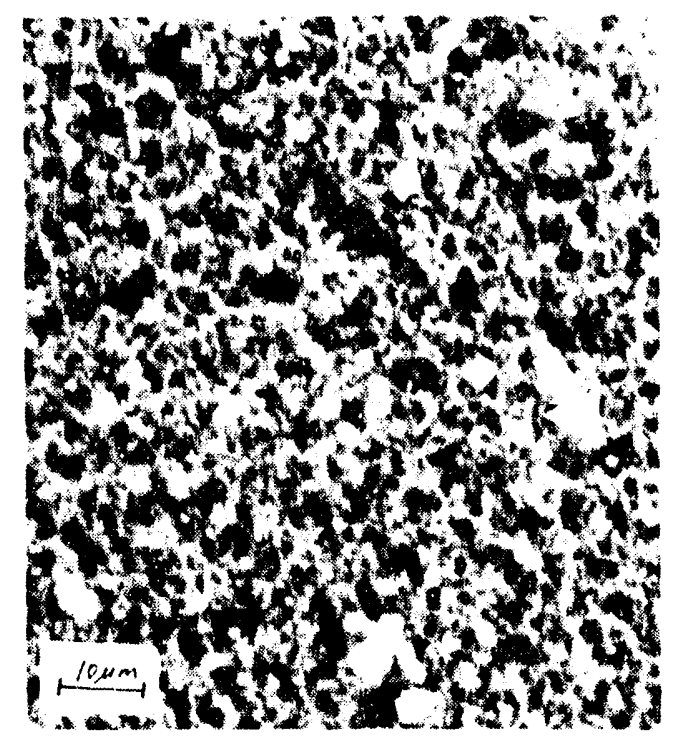

b) SEM mode showing all particles

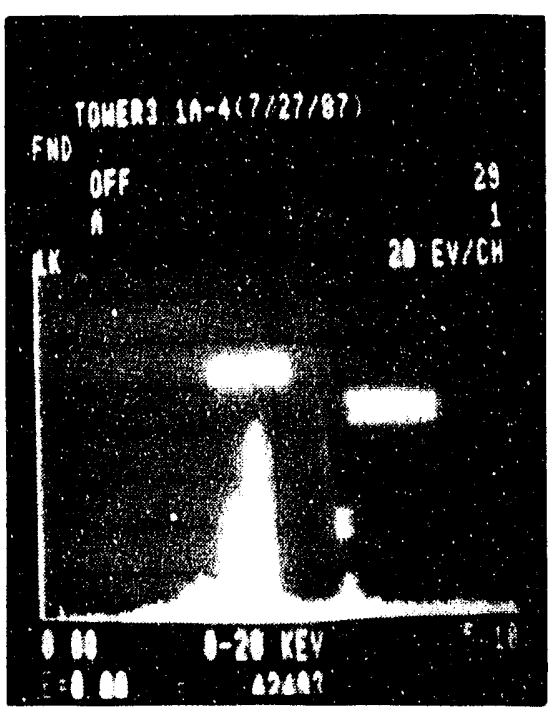

c) EDX results (low energy range) showing a prominent lead peak for the small particle shown by the arrows in Fig. 13a and b

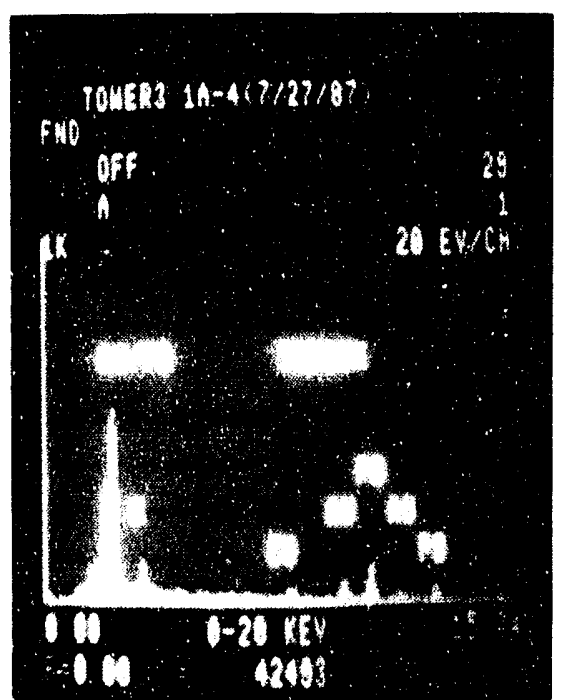

d) EDX results (broad energy range) showing multiple prominent lead peaks for the small particle shown by the arrows in Fig. 13a and b

FIGURE 13 SEM images and EDX spectra of muzzle blast aerosol collected from the 8-in./M110 howitzer firing M188A1 zone 9 charges at APG 
TABLE 7 Analysis of smear tabs from the 8-in $/$ M1 10 howitzer obtained on March 19-20, 1987

\begin{tabular}{|c|c|c|c|}
\hline Smear No. & $\begin{array}{c}\mathrm{Pb} \\
(\mu \mathrm{g})\end{array}$ & $\begin{array}{c}\mathrm{Cu} \\
(\mu \mathrm{g}) \\
\end{array}$ & $\begin{array}{l}\mathrm{Cu} / \mathrm{Pb} \\
\mathrm{Ratio}\end{array}$ \\
\hline \multicolumn{4}{|l|}{ Hand check } \\
\hline 1 & 0.04 & 0.10 & 2.5 \\
\hline 2 & 0.02 & 0.06 & 3.0 \\
\hline 3 & 0.02 & 0.06 & 3.0 \\
\hline 4 & 0.01 & 0.04 & 4.0 \\
\hline \multicolumn{4}{|l|}{$\begin{array}{l}\text { Pre-test } \\
\text { accumulation }\end{array}$} \\
\hline 1 & 0.52 & 0.23 & 0.44 \\
\hline 2 & 0.42 & 0.18 & 0.43 \\
\hline 3 & 0.39 & 0.20 & 0.51 \\
\hline 4 & 0.33 & 0.22 & 0.66 \\
\hline \multicolumn{4}{|l|}{$\begin{array}{l}\text { After cleaning } \\
\text { surface }\end{array}$} \\
\hline 1 & 0.03 & 0.10 & 3.3 \\
\hline 2 & 0.04 & 0.08 & 2.0 \\
\hline 3 & 0.05 & 0.08 & 1.6 \\
\hline \multicolumn{4}{|c|}{$\begin{array}{l}\text { After firing } \\
(30 \text { rounds, } 3 / 19 / 87)\end{array}$} \\
\hline 1 & 0.22 & 0.18 & 0.82 \\
\hline 2 & 0.10 & 0.12 & 1.20 \\
\hline \multicolumn{4}{|c|}{$\begin{array}{l}\text { After firing } \\
(82 \text { rounds, } 3 / 20 / 87)\end{array}$} \\
\hline 1 & 0.58 & 0.32 & 0.55 \\
\hline 2 & 0.20 & 0.14 & 0.70 \\
\hline 3 & 0.14 & 0.13 & 0.92 \\
\hline
\end{tabular}

a See Section 2.2 .

surface"). The values for copper indicate that it was not removed from the surface at the same rate or in the same way as the lead. This could mean that the copper is not in the same particles as the lead or that there is some other source of copper, such as the paint on the cab wall. Since tne copper does not seem to wipe off at the same rate as the lead, the copper-to-lead ratios appear distorted towards higher values with successive smears. As seen in Table 7, the lead values for the hands check, although quite low, could still be detected.

For the deposit accumulated during the firing, the lead values total $0.32 \mu \mathrm{g}$ and $0.92 \mu \mathrm{g} \mathrm{Pb}$ for the approximately $160-\mathrm{cm}^{2}$ defined area on the $19 \mathrm{th}$ and $20 \mathrm{th}$, respectively. Dividing the total lead deposited by the number of rounds fired each day gives values of $0.0107 \mu \mathrm{g}$ and $0.0112 \mu \mathrm{g} \mathrm{Pb}$ deposited per round each day. These two values, the first 
averaged over 30 rounds and the second averaged over 82 rounds, are very close to each other. Thus, the lead deposition appears to be linearly accumulative with the number of rounds fired at a rate of approximately $3.4 \mu \mathrm{g} \mathrm{Pb} / \mathrm{m}^{2}$ per round.

An observation which should be kept in mind is that three very distinct types of aerosol are generated from the firing of the howitzers. These are a blue-white smoke which bled from the breech or the muzzle after firing, the surface dust raised by the blast and shock wave, and the visible and invisible emissions from the blast itself, the latter being expelled from the muzzle at high speed at the instant of firing (see Fig. 6b). The invisible emissions are probably gaseous but will have a particulate component resulting from condensation as the gases cool.

A rough calculation was made using an approximate muzzle blast volume obtained from observation of the plume. The dispersal of $156 \mathrm{~g} \mathrm{(5.5} \mathrm{oz)} \mathrm{of} \mathrm{lead} \mathrm{in} \mathrm{the} \mathrm{zone} 8$ (M203A1) propellant into a cube of the atmosphere $50 \mathrm{~m}$ on a side $\left(125,000 \mathrm{~m}^{3}\right.$ ) yields an air lead ( $\left.\mathrm{PbA}\right)$ concentration of $1248 \mu \mathrm{g} / \mathrm{m}^{3}$. This value approximated some of our measured time-weighted average (TWA) values for $\mathrm{PbA}$ outside the cab (see Table 6), indicating that the muzzle blast aerosol can account for much of the lead present in the propellant. Note that the M188A1, zone 9 charge for the 8.in./M110 howitzer contains about twice as much lead, $290 \mathrm{~g}(10.25 \mathrm{oz})$ per charge (see Table 1).

Air copper concentrations ranged from a low of $1 \mu \mathrm{g} / \mathrm{m}^{3}$ to a high of $232 \mu \mathrm{g} / \mathrm{m}^{3}$ during the firing of high-lead charges from the 8-in./M110 howitzer (see Table 6). Air copper concentrations were, in general, lower than those for lead, with $\mathrm{Cu} / \mathrm{Pb}$ ratios ranging from 0.21 to 1.02 .

\subsubsection{The 155-mm/M109A3 Howitzers}

Since the two field trips to YPG for characterizing the emissions from the firing of the 155-mm/M109A3 howitzer were conducted more than a year apart and on two different types of weapons, and since the second trip involved a much more comprehensive sampling protocol than the first, the results from the two field studies are presented separately.

The 155-mm/M109A3E1 Howitzer, August 19-20, 1987. The filter samples collected and the results of the AAS and gravimetric analyses are summarized for the two days in Tables 8 and 9, respectively. Perhaps the most significant information from these tables is that the lead and copper values for the samples collected outside the weapon are as high as, or in some cases much higher than, the values for samples collected inside the cab. This reinforces the limited data from our earlier work at APG for the 8-in./M110 howitzer. The set of samples from the afternoon of August 19, 1987, designated "A2," is the easiest set to examine since all filters have similar collection times, which include the firing of 100 rounds with the M203 propellant. Also, it is a continuous sampling period of nearly $8 \mathrm{~h}$. 


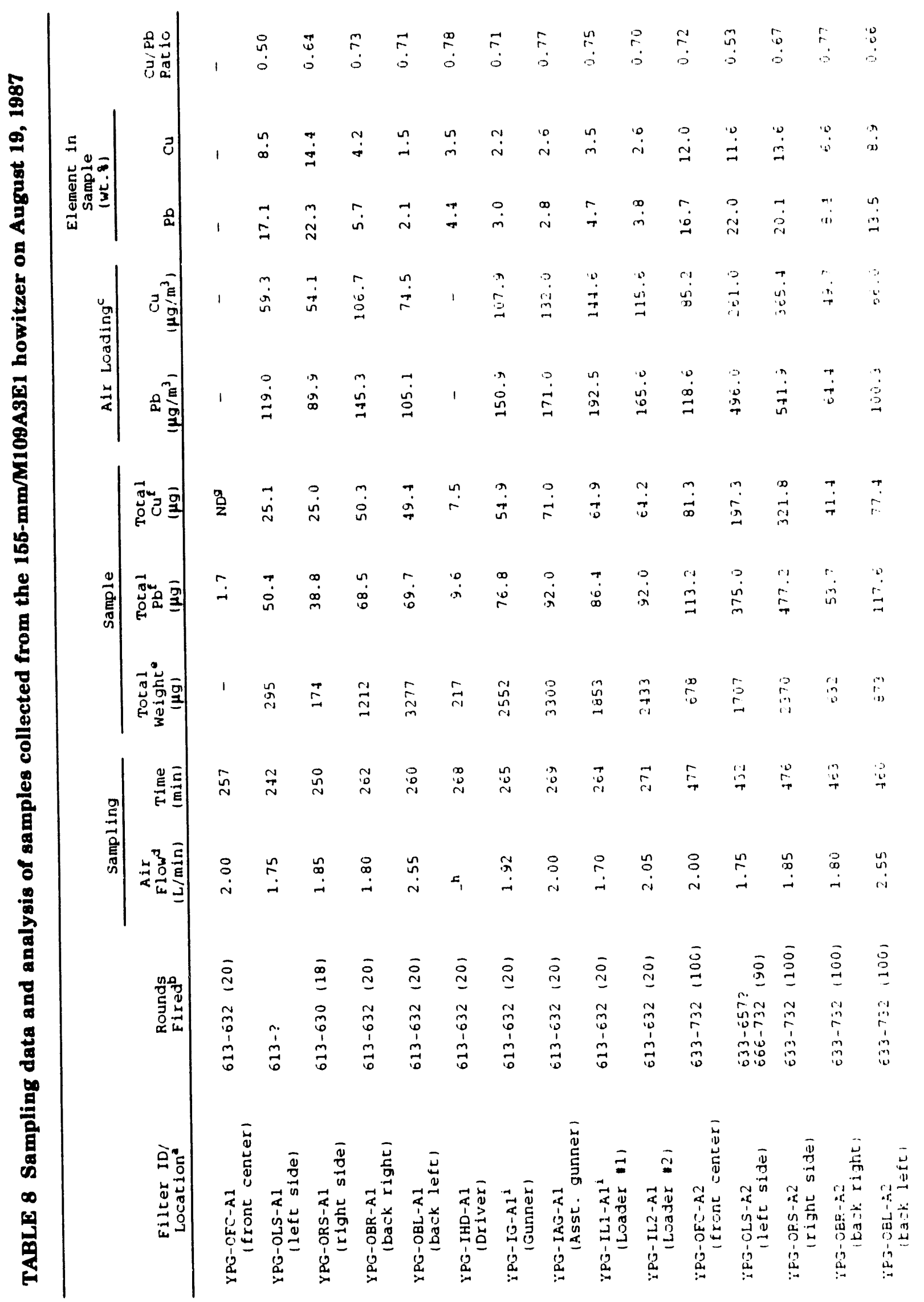




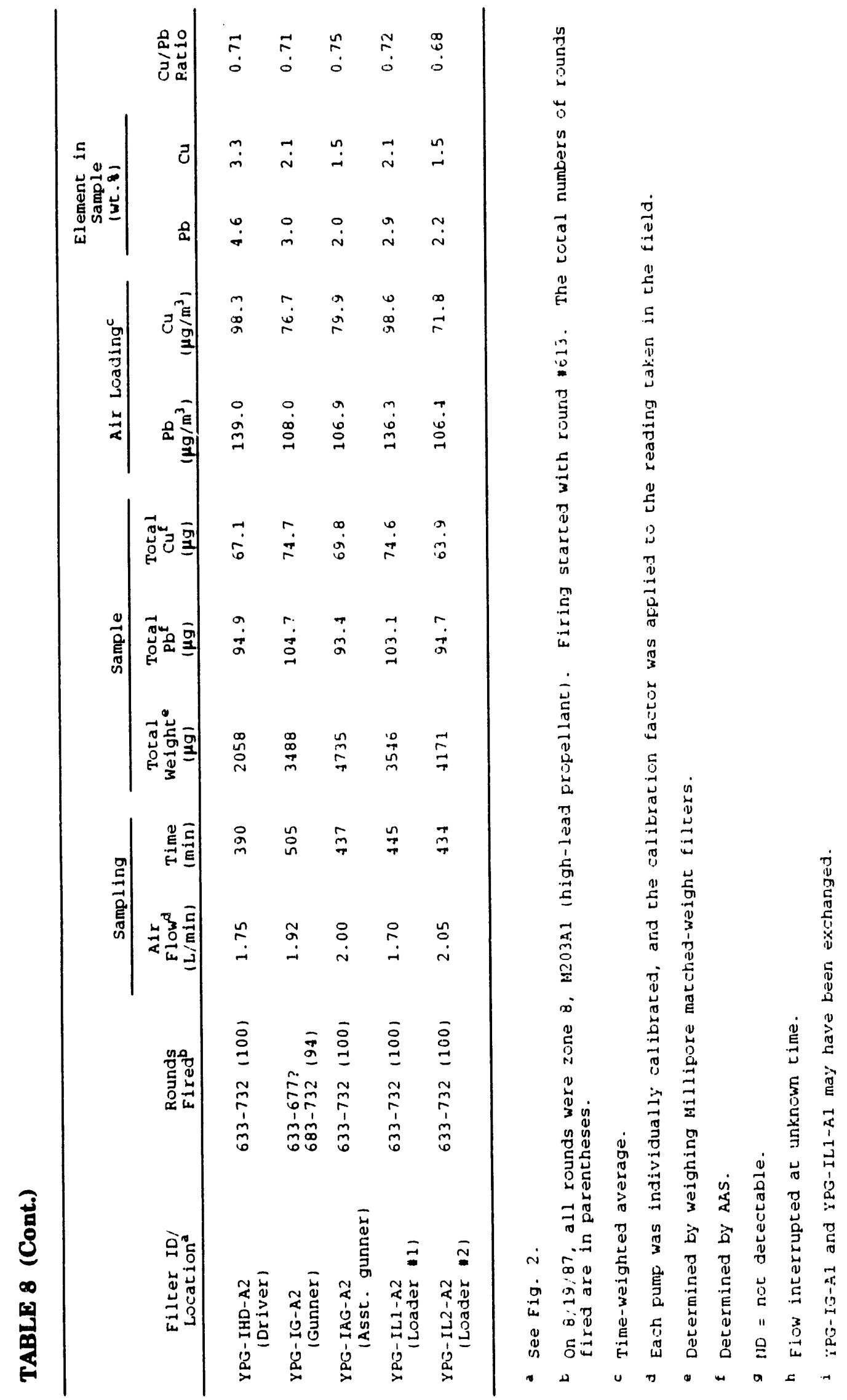




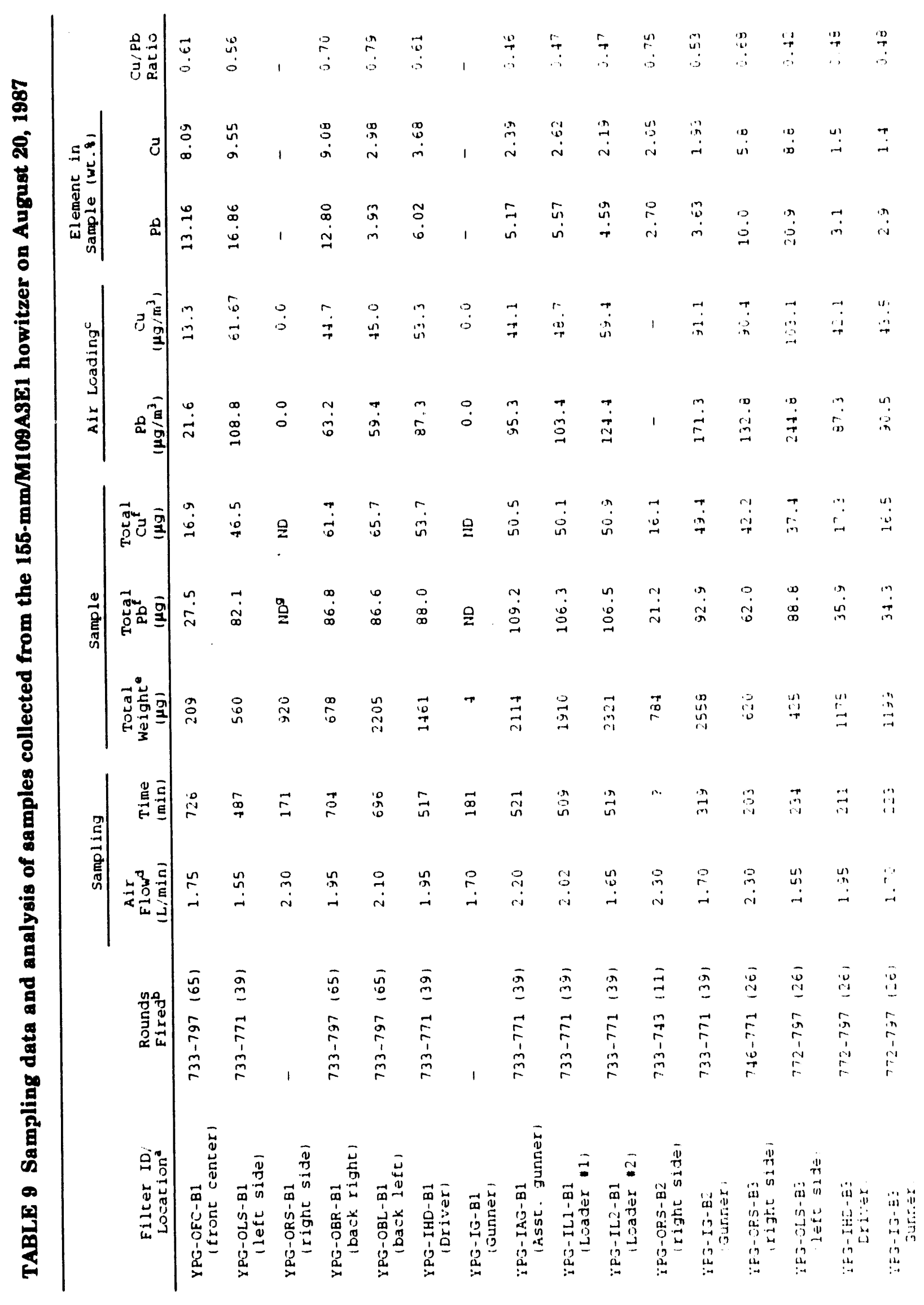




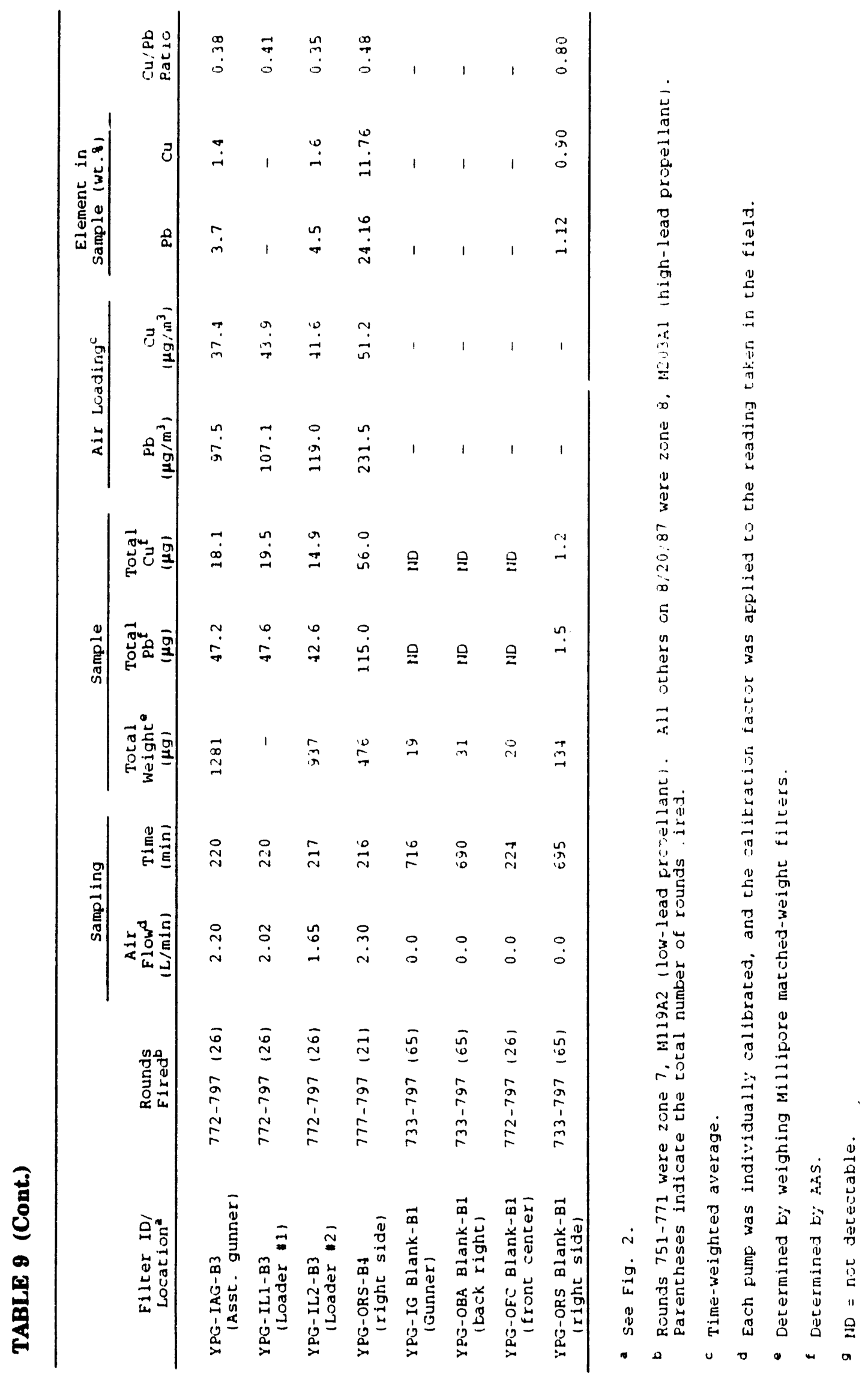


In the A2 set, the TWA for lead varied from about $100 \mu \mathrm{g} / \mathrm{m}^{3}$ to over $500 \mu \mathrm{gg} / \mathrm{m}^{3}$ for the right outside sample, compared to the Occupational Safety and Health Administration's (OSHA) permissible exposure limit (PEL) for lead of $50 \mu \mathrm{g} / \mathrm{m}^{3}$ over an 8 -h period. Interestingly, the weight fraction of lead for all of the outside samples in this and the other sets was much higher than that for the inside samples. The outside front center (OFC) filter was visually the cleanest of all of the samples, and even though it was directly in front of the barrel, it did not seem to get much, if any, resuspended dust since the blast was directed rearward. However, the OFC-A2 filter had a significant amount of sample and a high percentage of lead in the sample. This is an indication that the lead is probably not associated with only the visible smoke plume or resuspended dust; rather, it is invisible and spread throughout the general area outside the weapon from the muzzle blast. Moreover, this results in higher lead concentrations outside than inside the weapon. The blank filters had nondetectable or negligible lead and copper.

Figures 14 and 15 show the total sample weight and aerosol lead, respectively, on a per-round basis for the firings on August 19 and 20,1987. The data are divided into morning and afternoon firing periods. The most striking feature of the plot of sample weight is the relatively high values for the morning of the 19th. This is at least partially explained by the southeast wind during the morning, which tended to blow the dust from the firing around the weapon and conceivably swirl it in the open back hatch. The inside howitzer driver (IHD) position was probably too isolated to be exposed to this dust. The outside back right (OBR) position would receive some of this dust, and the outside back left (OBL), being the most downwind position, would receive the most.

Figure 15 reveals a more dramatic and probably more significant feature of the emission aerosol. First there is a striking difference between the three sets from the outside forward sample positions (outside front center, OFC; outside left side, OLS; outside right side, ORS), and the samples collected inside the weapon. However, the two sets of samples collected on either side of the rear hatch (outside back right, OBR; outside back left, OBL) are similar to the samples from inside. For the inside, the samples from the mornings of both days are significantly higher in the average lead content per round. This can be explained in two different ways but both explanations use the wind direction as the dominant variable. One explanation would be that the morning wind from the southeast tends to blow more of the residual fumes back down the barrel and into the cab. These fumes are then exhausted through the open rear hatch where they are collected by the two samplers on either side of the weapon. This seems plausible except that the bore evacuator seemed to be operating effectively, since a distinct plume was emitted from the tip of the barrel after each firing. The other explanation is that the wind from the right front (southeast) in the morning carried the heavily lead-laden effluent from the blast back around the weapon where the air swirled around the rear of the gun, where the two back samplers were located, and into the hatch to be collected by the inside samplers. The values for the side and front sample positions are generally higher in the afternoon, which is reasonable if the afternoon wind, from the south and southwest, was blowing the emissions from the muzzle blast back over these positions after the firing. Since the results from APG indicated that the lead concentration is higher in the outside emissions, this explanation seems to have merit. 


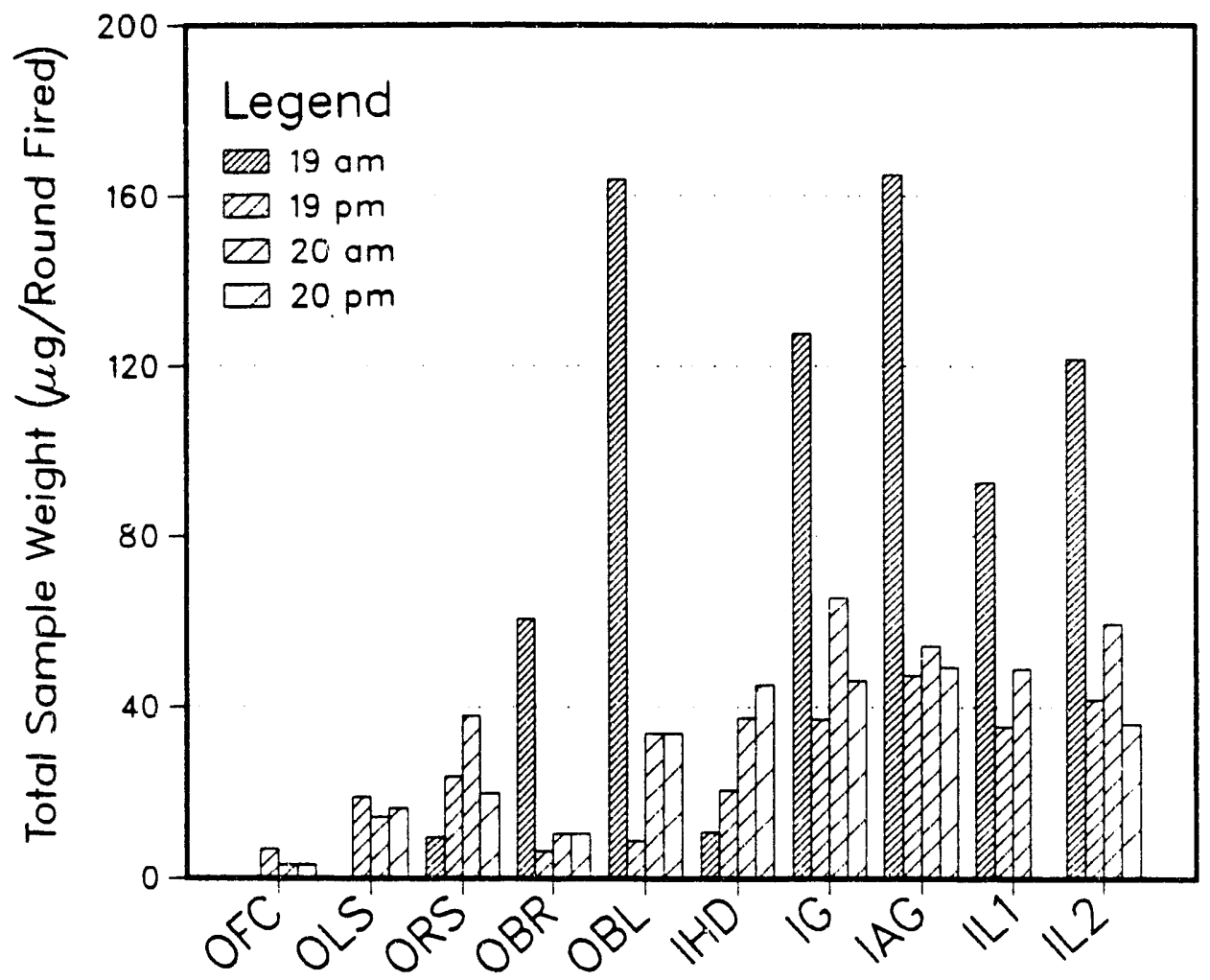

FIGURE 14 Total sample weight per round fired vs. sample position and time of day. Aerosol samples were collected during firing of the 155-mm/M109A3E1 howitzer at YPG on August 19-20, 1987.

OFC, outside front center; OLS, outside left side; ORS, outside right side; OBL, outside back left; IHD, inside howitzer driver; IG, inside Gunner; LAG, inside Assistant Gunner; IL1, inside Loader 1 (left side); IL2, inside Loader 2 (right side).

Figure 16a is an SEM photomicrograph obtained from the sample YPG-ORS-B4, collested outside on the right side in the muzzle blast area of the howitzer at YPG on August 20, 1987. The granular background in the photograph is tize filter material, while most of the collected particles are spheres of various sizes. The EDX analysis for two of the spherical particles is also presented in Fig. 16. The analyses show that the combustion products are distinctly spherical, with a higher concentration of lead in the smaller spheres and a higher concentration of titanium in the larger spheres. The titanium is derived from the titanium oxide wax used as a wear-reducing agent in the propellant. Soil particles have the expected irregular shape, as in Fig. 16a, particle 1B, with silicon and calcium as components. The samiples from the muzzle blast zones consisted almost exclusively of the spherical combustion products, containing as much as $24 \%$ lead by weight. This result is from the AAS and gravimetric analysis of YPG-ORS-B4 as presented in Table 9. The $\mathrm{Cu} / \mathrm{Pb}$ ratio for this sample was 0.48 . 


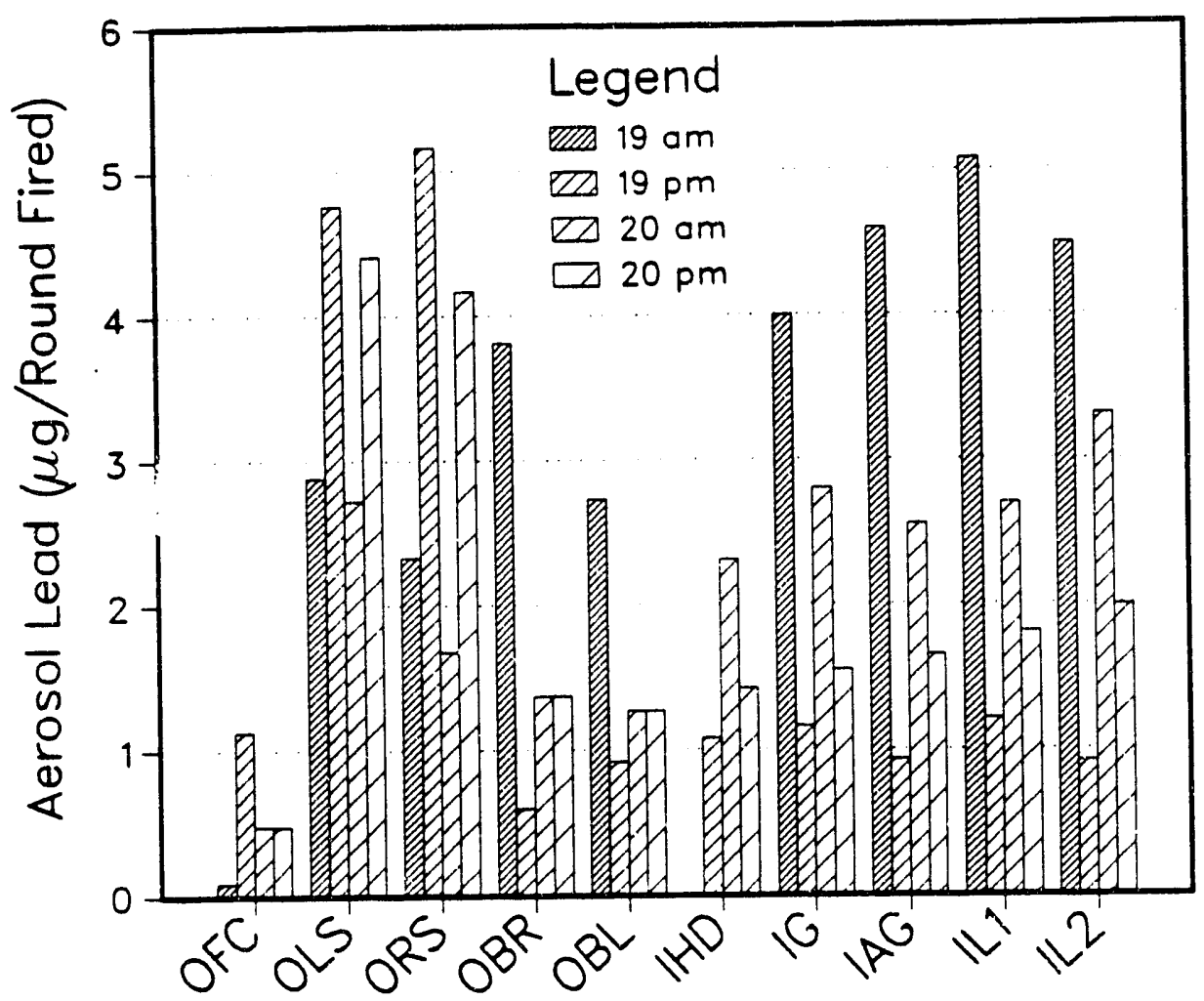

FIGURE 15 Weight of lead per round fired vs. sample position and time of day. Aerosol samples were collected during firing of the 155-mm/M109A3E1 howitzer at YPG on August 19-20, 1987 (see Fig. 14 caption for abbreviations).

Results of SEM/EDX support the view that the lead aerosols from the 8-in. and 155 -mm howitzers differ significantly in particle size. For the aerosol from the 8-in./M110 howitzer, roughly spherical particles in the size range $0.5-5 \mu \mathrm{m}$ in diameter were easily visible by SEM and backscatter analysis and were found to be rich in lead by EDX, consistent with the data from the samples collected using the dichotomous impactor (see Table 4). The pair of samples from the high-lead charges (rounds 4 and 5 , zone 9 ) indicate that $68 \%$ of the lead was in particles larger than $2.5 \mu \mathrm{m}$ a.d. and only $32 \%$ of the lead was in particles less than 2.5 um a.d.

In contrast, for the aerosol from the $155-\mathrm{mm} / \mathrm{M} 109 \mathrm{~A} 3 \mathrm{E} 1$, particles in the size range 0.5 to $5 \mu \mathrm{m}$ contained less lead when analyzed in the backscatter mode. A "lead map" of the muzzle blast aerosol from the $155-\mathrm{mm} / \mathrm{M} 109 \mathrm{~A} 3 \mathrm{E} 2 \mathrm{HIP}$ weapon showed a lawn of tiny lead particles on the filter, with some larger, spherical particles apparently coated with the tiny lead particles (Fig. 17). These data support the view that, for both the 155-mm/M109A3E1 and the $155-\mathrm{mm} / \mathrm{M} 109 \mathrm{~A} 3 \mathrm{E} 2 \mathrm{HIP}$ weapons, most of the aerosol lead is on particles of $0.3 \mu \mathrm{m}$ or smaller. It is not clear whether the difference in lead particle size is due to the difference in weapons or to a difference in the composition of the propellants used. 


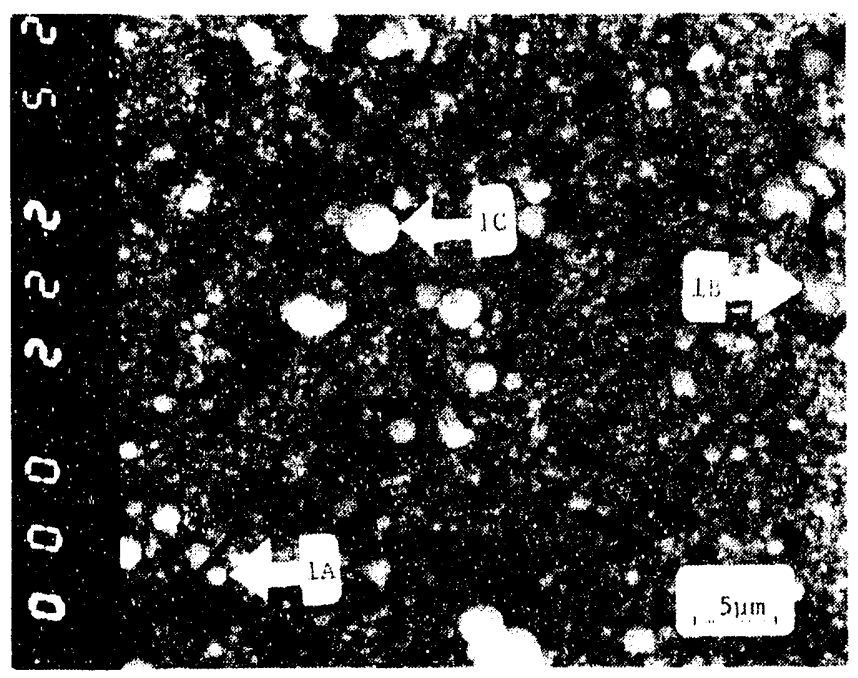

a) SEM image of muzzle blast aerosol

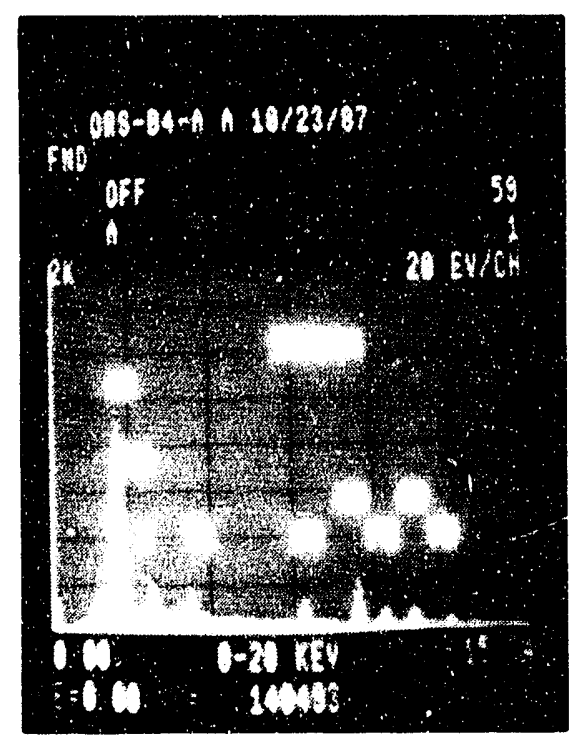

b) EDX results for particle $1 \mathrm{~A}$

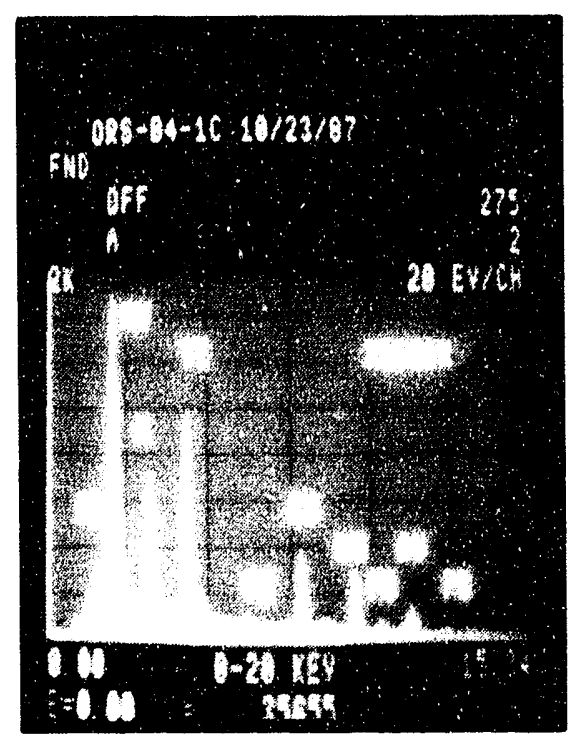

c) EDX results for particle $1 \mathrm{C}$

FIGURE 16 SEM image and EDX spectra of aerosol from the muzzle blast of the 155-mm/M109A3E1 howitzer at YPG on August 20, 1987 


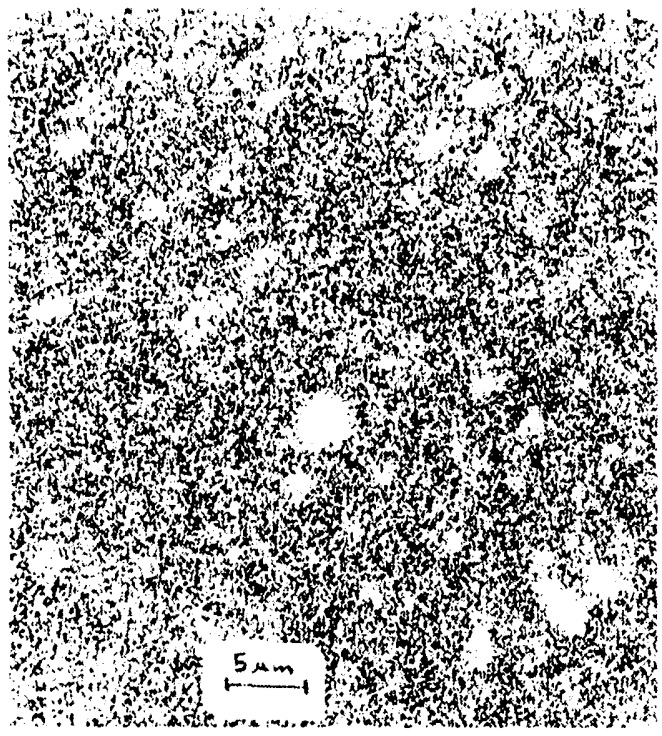

a) "Lead map" showing a lawn of tiny lead-containing particles

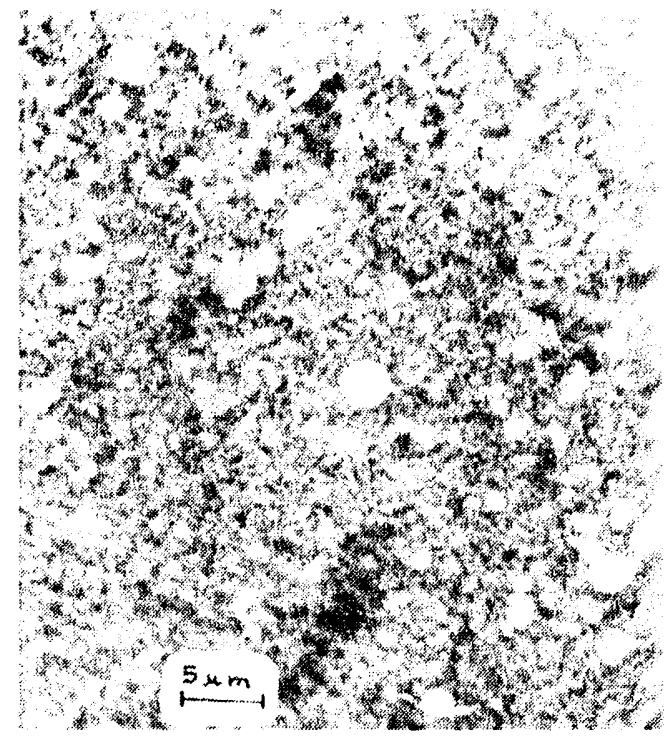

b) SEM image of muzzle blast aerosol

FIGURE 17 SEM images from the muzzle blast of the 155-mm/M109A3E2 HIP howitzer at YPG

Figure 18 is an SEM photomicrograph of a sample from the Gunner position inside the howitzer collected on August 20,1987, and the EDX analysis of two of the particles. In Fig. 18a, the spherical combustion product particles are also quite evident, but there are, in addition, numerous irregularly shaped large and small particles assumed to be soil particles. Of the irregular particles, there are two types: one particle (3C) is large, solid, and crystalline, and the other (3B) is an agglomeration of small crystals. The EDX analyses show silicon and calcium as the major constituents of particle $3 \mathrm{C}$, indicating that it is a soil particle with no measurable lead. Particle 3B, the agglomerated particle, contains silicon, calcium, and some titanium, but again no lead. This seems to indicate an agglomeration of soil particles held together with residue of the titanium oxide wax. Particle 3A is shown at a higher magnification in Fig. 19, mainly to highlight the nearly perfect sphericity of the particle. The EDX analysis shows titanium, lead, silicon, and calcium. The soil constituents (silicon and calcium) may be from nearby particles or from surface contamination of the sphere.

Soil samples from the Rocket Pad firing site at YPG were analyzed for their lead content. Samples were collected from three different areas, front center, right side, and rear. These samples contained 156.0, 85.2, and $55.5 \mu \mathrm{g} \mathrm{Pb} / \mathrm{g}$ of soil, respectively. The average for the three YPG locations is $98.9 \mu \mathrm{g} \mathrm{Pb} / \mathrm{g}$ soil compared to $777 \mu \mathrm{g} \mathrm{Pb} / \mathrm{g}$ soil from our results at the Old Ant Hill site at APG and $3000 \mu \mathrm{g} \mathrm{Pb/g}$ soil from another APG soil analysis. Putting these results in term of percentages, the YPG soil was $0.01 \% \mathrm{~Pb}$, and the APG soil, from our analysis, was $0.08 \% \mathrm{~Pb}$. Contaminated soil in urban areas ranges from 100 to $10,000 \mu \mathrm{g} \mathrm{Pb} / \mathrm{g}$ 


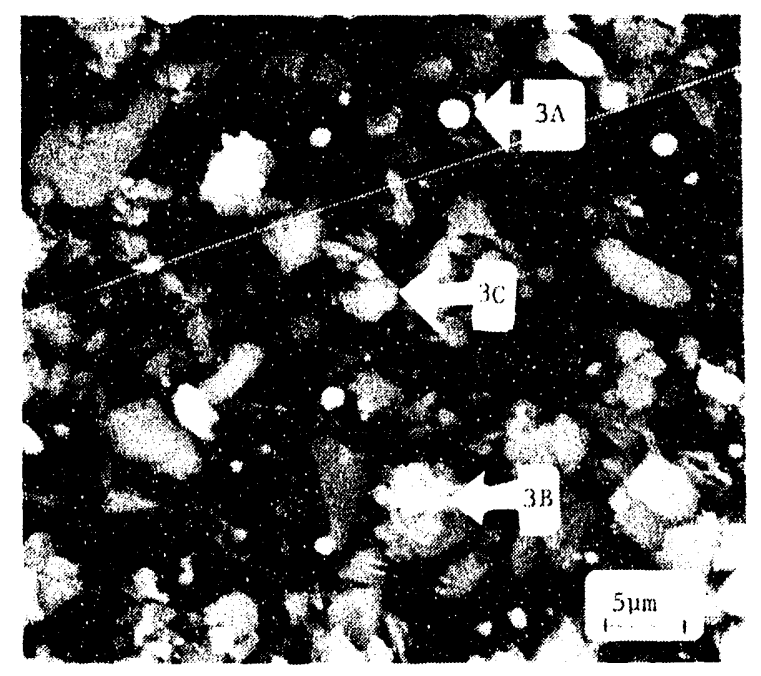

a) Backscatter image of particles from the Gunner position

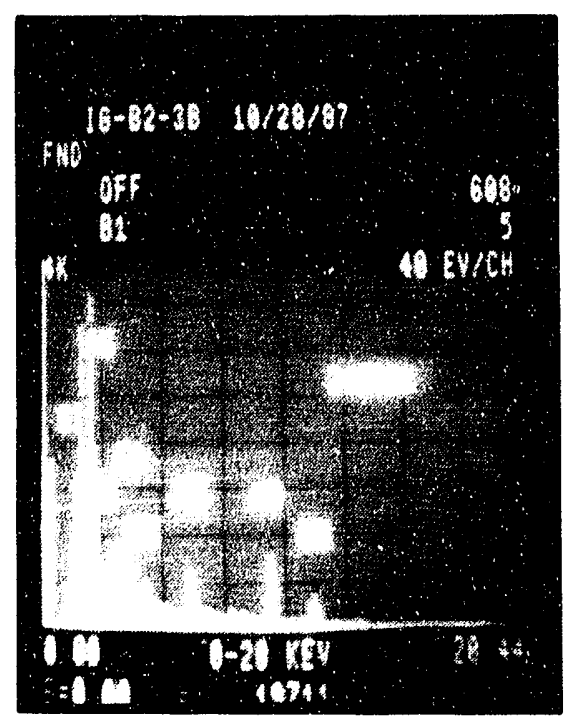

b) EDX results for particle $3 \mathrm{~B}$

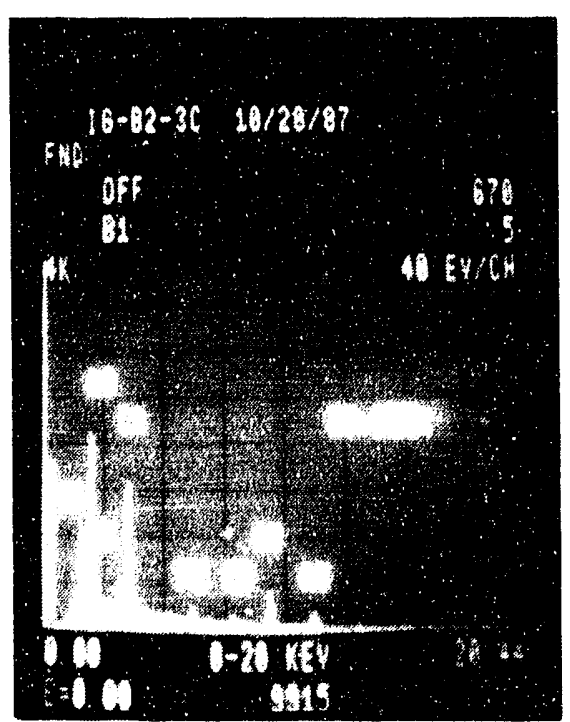

c) EDX results for particle $3 \mathrm{C}$

FIGURE 18 SEM image and EDX spectra of aerosol from the Gunner position of the 155-mm/M109A3E1 howitzer collected at YPG on August 20, 1987 

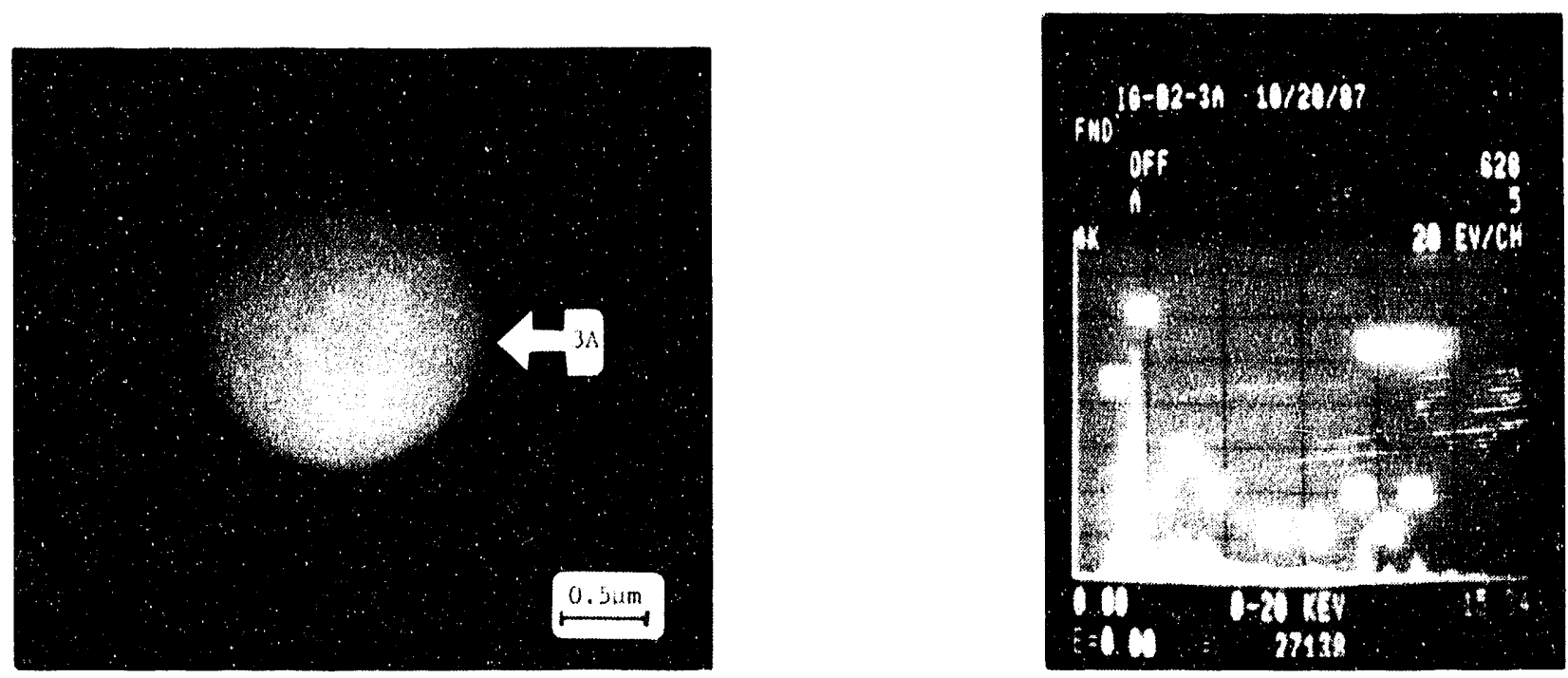

FIGURE 19 SEM image (left) and EDX spectrum (right) of particle 3A from Fig. 18a

soil (Bo86). These low values for the percentage of lead in soil demonstrate that lead in resuspended soil did not contribute significantly to the lead in the aerosol sampled during firing.

The 155-mm/M109A3E2 HIP Weapon, August 31-September 2, 1988. Tables 10,11, and 12 present data collected from the array of ten UPASPs for the three days of measurement. The mean TWA PbA concentration inside the cab was $142 \pm 31 \mu \mathrm{g} / \mathrm{m}^{3}$ (mean $\pm \mathrm{SE}$ ). The highest concentrations of $\mathrm{Pb}$ were found outside of the weapon in the blast zone (right side, left side). At these positions, the TWA PbA concentrations were 427--627 $\mathrm{\mu g} / \mathrm{m}^{3}$. At the samplers located at a distance downwind from the weapon (filters designated OFC), TWA PbA concentrations were $76-94 \mu \mathrm{g} / \mathrm{m}^{3}$ at $14 \mathrm{~m}$ and $22-30 \mu \mathrm{g} / \mathrm{m}^{3}$ at $41 \mathrm{~m}$ on August 31 and September 1, 1988. No lead was detectable in the upwind OFC samples collected on September 2, on which day there was a $5.4 \mathrm{~m} / \mathrm{s}(12 \mathrm{mi} / \mathrm{h})$ head wind. Thus, elevated $\mathrm{PbA}$ concentrations can be expected $41 \mathrm{~m}$ or more downwind of the weapon; conversely, upwind positions as close as $14 \mathrm{~m}$ from the weapon may have no $\mathrm{PbA}$ concentrations when the wind is blowing at $5.4 \mathrm{~m} / \mathrm{s}(12 \mathrm{mi} / \mathrm{h})$ or more.

Samples from the M109A3E2 HIP weapon collected at YPG in 1988 showed lower $\mathrm{Cu} / \mathrm{Pb}$ ratios than did samples from the M109A3E1 collected at YPG on August 19, 1987 (see Table 8). The $\mathrm{Cu} / \mathrm{Pb}$ ratios for the HIP weapon averaged $0.18 \pm 0.05$ (mean \pm standard deviation) for inside samples with adequate material collected and $0.39 \pm 0.08$ for samples collected outside of the weapon. Weapons aerosols collected from an M109A3E1 howitzer at YPG (August 19, 1987) had mean $\mathrm{Cu} / \mathrm{Pb}$ ratios of $0.73 \pm 0.04$ and $0.66 \pm 0.09$ for samples collected inside and outside, respectively. The reason for this difference in the $\mathrm{Cu} / \mathrm{Pb}$ ratio for the two weapons is unknown. 


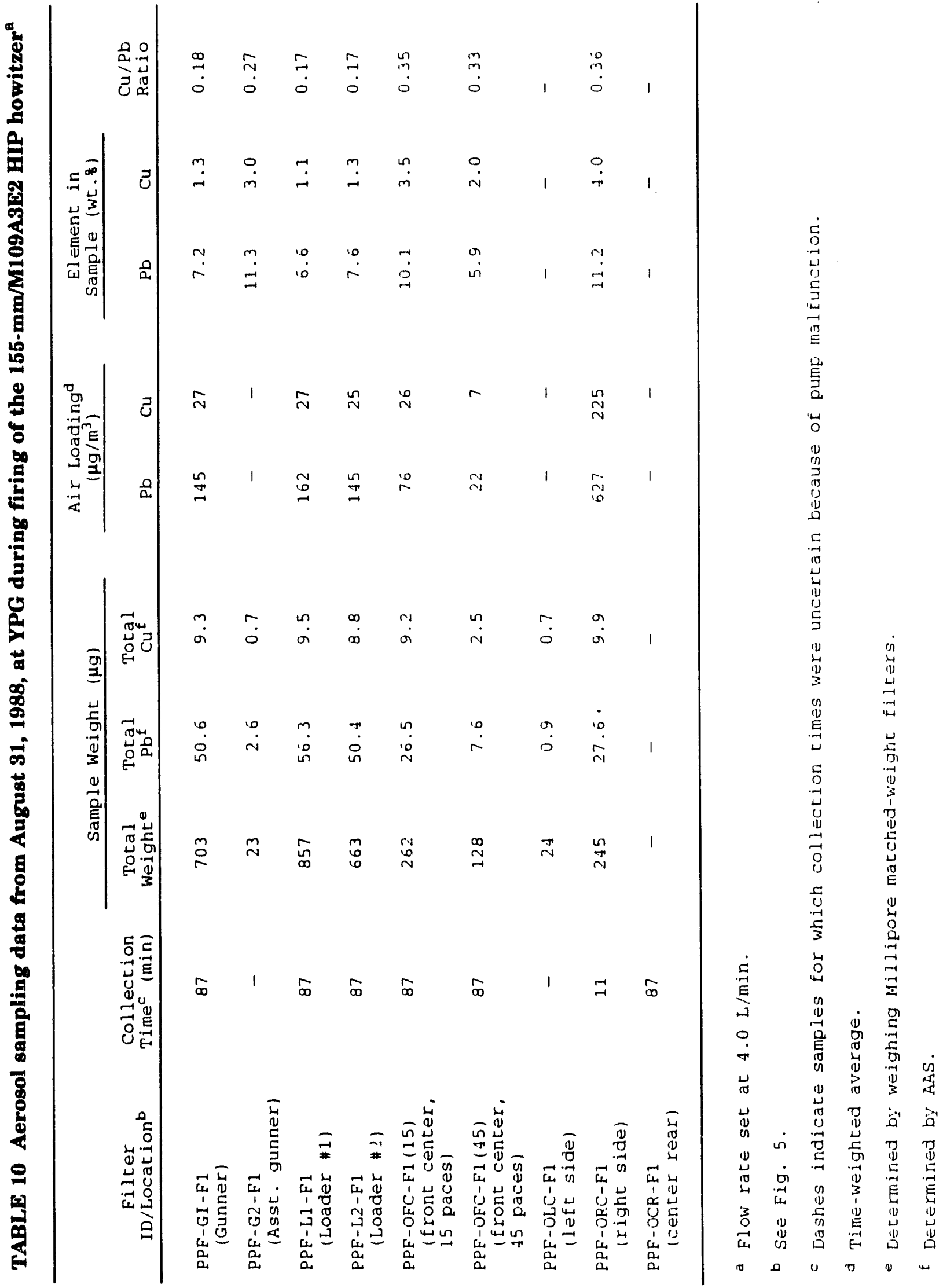




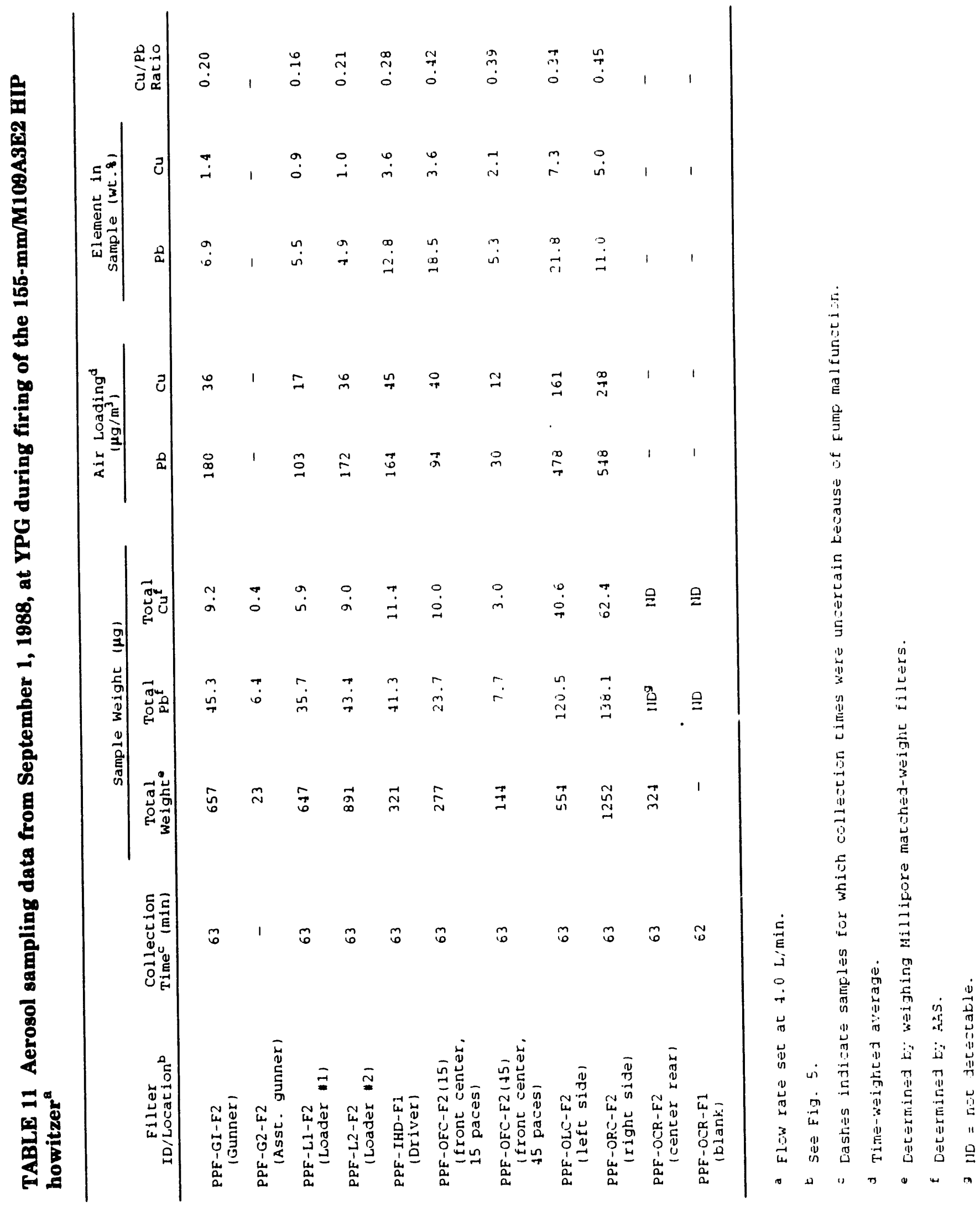




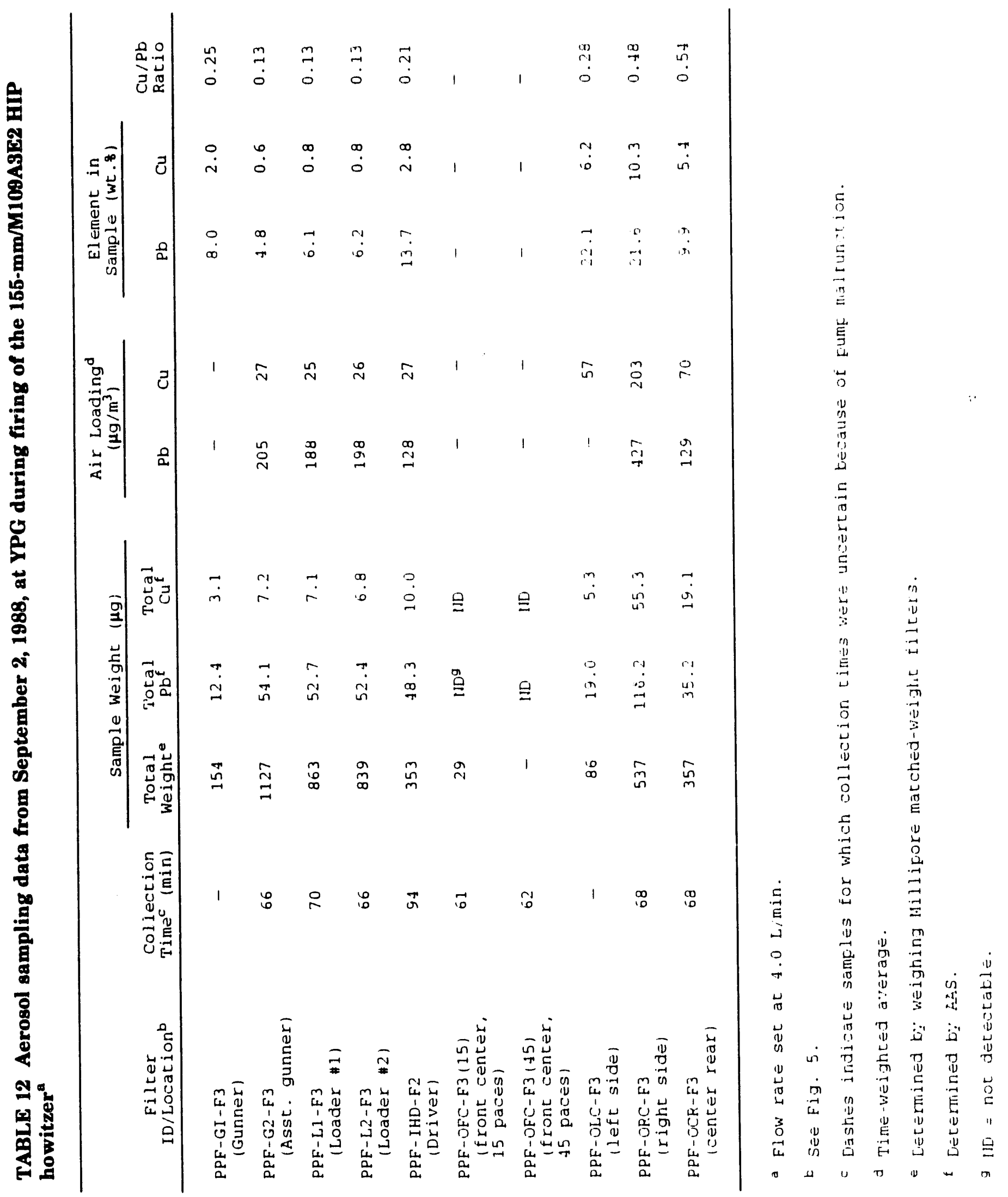


Overall, the TWA PbA concentrations at YPG on August 31 through September 2, 1988, for the HIP howitzer were similar to those measured on August 19, 1987, at YPG during firing of the M109A3E1 howitzer. Mean TWA PbA values inside the HIP weapon were $151 \pm 10 \mu \mathrm{g} / \mathrm{m}^{3}$ (mean $\pm \mathrm{SE}$ ) and $155 \pm 35 \mu \mathrm{g} / \mathrm{m}^{3}$ on August 31 and September 1,1988 , respectively, when the wind was from the rear of the weapon. On September 2, 1988, the mean TWA PbA inside the HIP weapon was $180 \pm 35 \mu \mathrm{g} / \mathrm{m}^{3}$ when the wind was from the front of the weapon. Changes in wind direction and speed that occurred in our study, therefore, had little influence on TWA $\mathrm{PbA}$ values inside the cab.

Results of measurements with the OPC are shown in Figs. 20 and 21 for the rounds fired on September 1 and 2, 1988, respectively. (No OPC results are available for August 31, 1988, due to a malfunction of the instrument caused by the shock from the blast.) The ordinates in Figs. 20 and 21 are a function of the volume of the particles in a given size range plotted on a logarithmic scale. The firing times are indicated by the asterisks. These plots show the rise and decay of the different size particles relative to each other. The largest particles have the highest peak volume but they then decay faster than the mid-size particles. The peak for the largest size range is consistently earlier than the peak for the other sizes; in most cases, the largest particles also show a second peak (or shoulder) more closely corresponding to the peaks for the other size ranges. The particles in the next to largest size range (5.0-10.0 $\mu \mathrm{m}$ ) also have an early peak, but the particles below $3.0 \mu \mathrm{m}$ do not have the early, sharp peak. The initial peak is possibly from the resuspension of large particles due to the initial mechanical shock, while the second peak is from the weapon exhaust aerosol. Figures 20 and 21 show that the larger particle volume increases by several orders of magnitude after each firing, while the volume for the smallest particles remains low and fairly constant.

There is, however, a very noticeable difference in the decay time of the mid-range sized particles between the 8-in./M110 howitzer, Fig. 8, and the 155-mm/M109A3E2 howitzer, Figs. 20a and $b$ and 21a, b, and c. By visual comparison of the plots, it can be seen that, for a decay of two orders of magnitude, the times were $1 \mathrm{~min}$ or less for the 8-in./M110 howitzer, while for the 155-mm/M109A3E2 howitzer, the decay time was 3-6 min. This difference probably arises from the very different configuration of the cab vs. that of the CBS.

The results from the LMS and sorption tube prefilters and the liquid media are summarized in Table 13. This table lists the sampling conditions, lead and copper measurements and ratio, and the percentage of the total lead from the sampled air that was collected either on the filter (LMSx-Fn) or in the liquid media (LMSx-Ln) of the samplers. The prefilters of the LMSs contained 94.2-99.7\% of the lead collected from the sampled air; only $0.3-5.8 \%$ of the (possibly organic) lead was found in the $\mathrm{HNO}_{3}$ of the LMSs. In the samples collected inside of the cab (LMSI-Fn samples), the fraction of lead found in the $\mathrm{HNO}_{3}$ was less than $1 \%$ of the total.

The highest amount of lead found in the liquid of the LMS samples occurred on September 2,1988 , when $5.8 \%$ of the total lead collected was in the liquid of the left outside 
a)

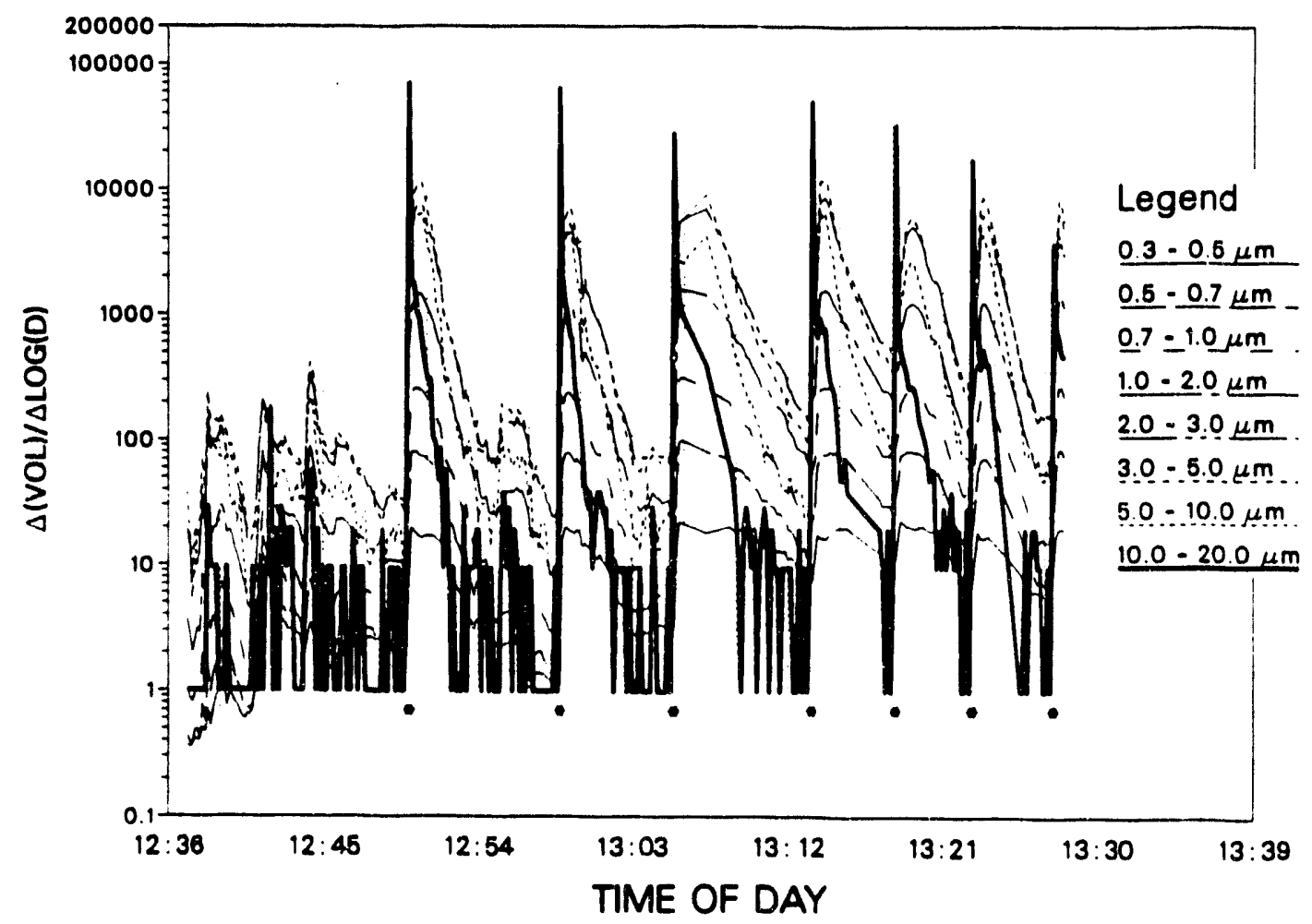

b)

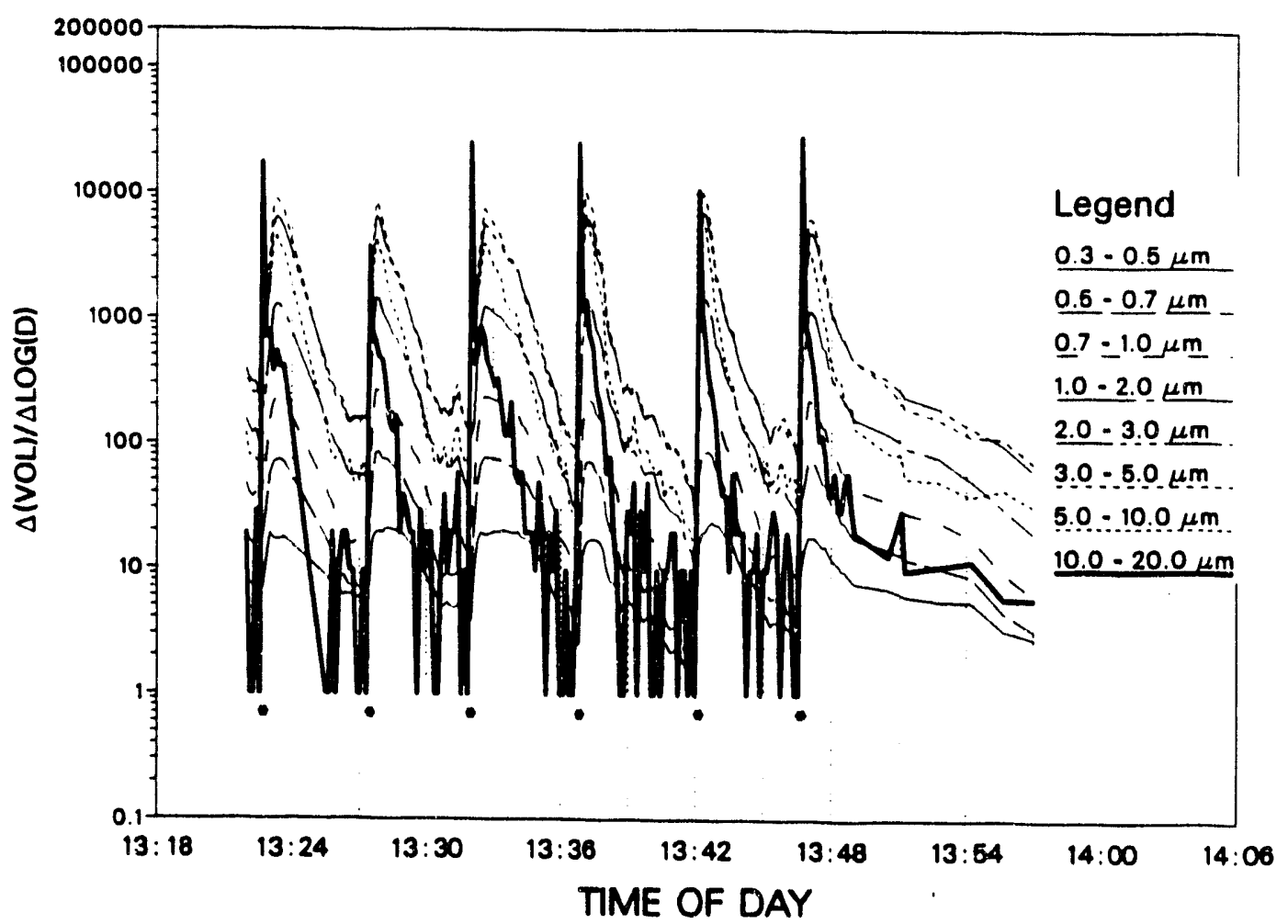

FIGURE 20 Climet Optical Particle Counter data from the 155-mm/M109A3E2 HIP howitzer at YPG on September 1, 1988.

Asterisks indicate the time of firing. Figure $20 \mathrm{~b}$ continues the time course (note scale change). 
a)

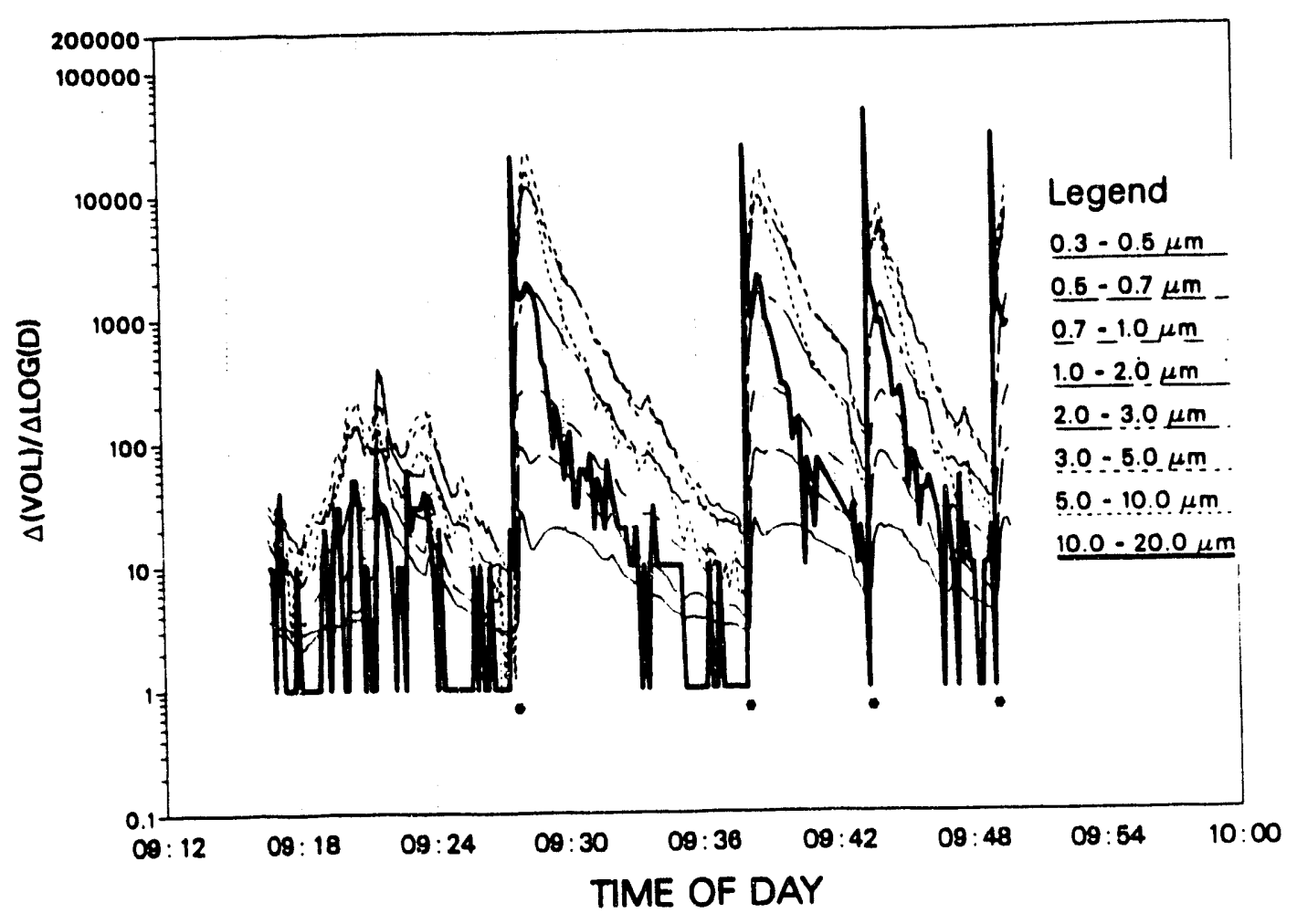

b)

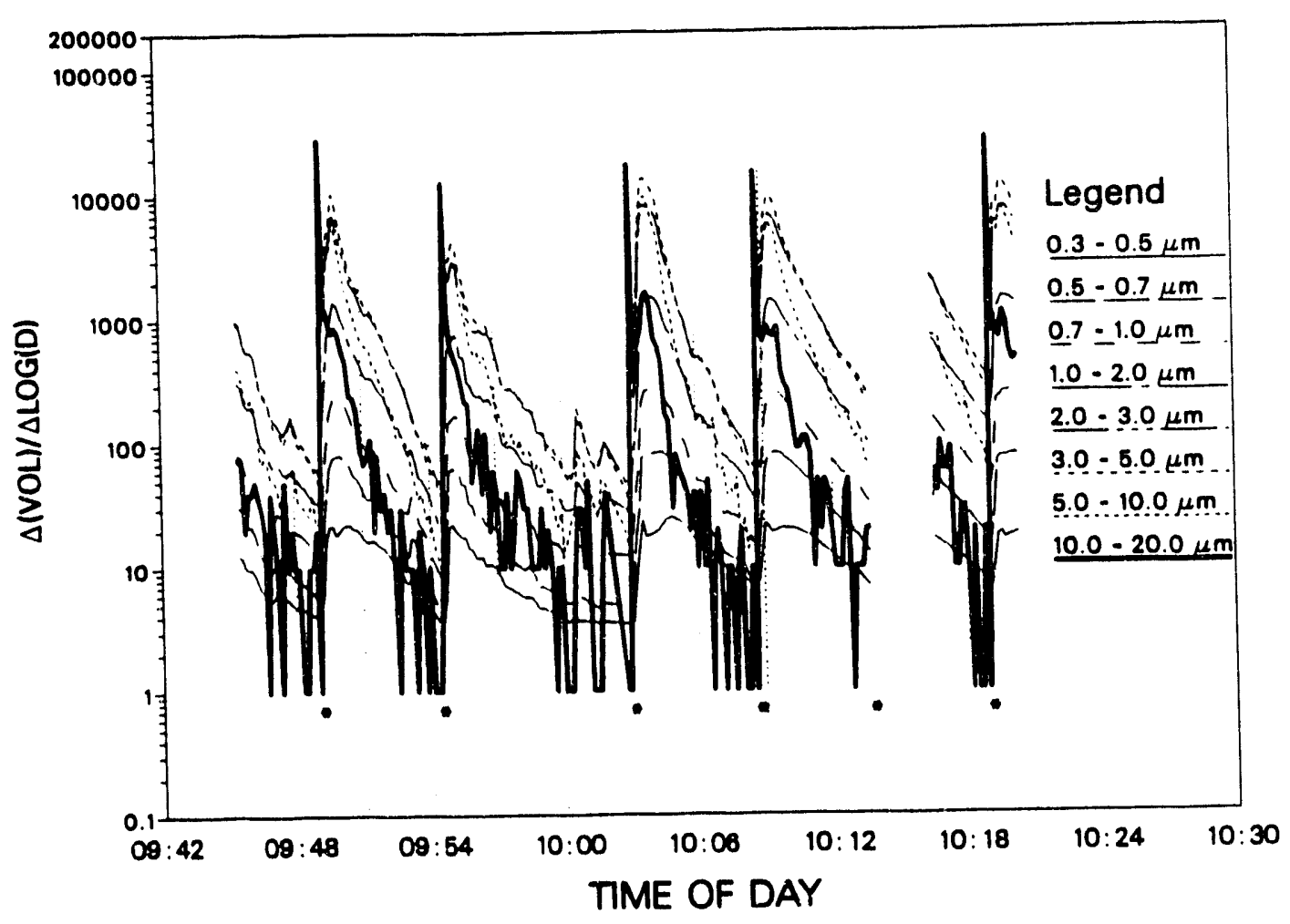

FIGURE 21 Climet Optical Particle Counter data from the 155-mm/M109A3E2 HIP howitzer at YPG on September 2, 1988.

Asterisks indicate the time of firing. The time course from

Fig. 21a is continued in Fig. 21b and 21c (note scale change in 21c). 


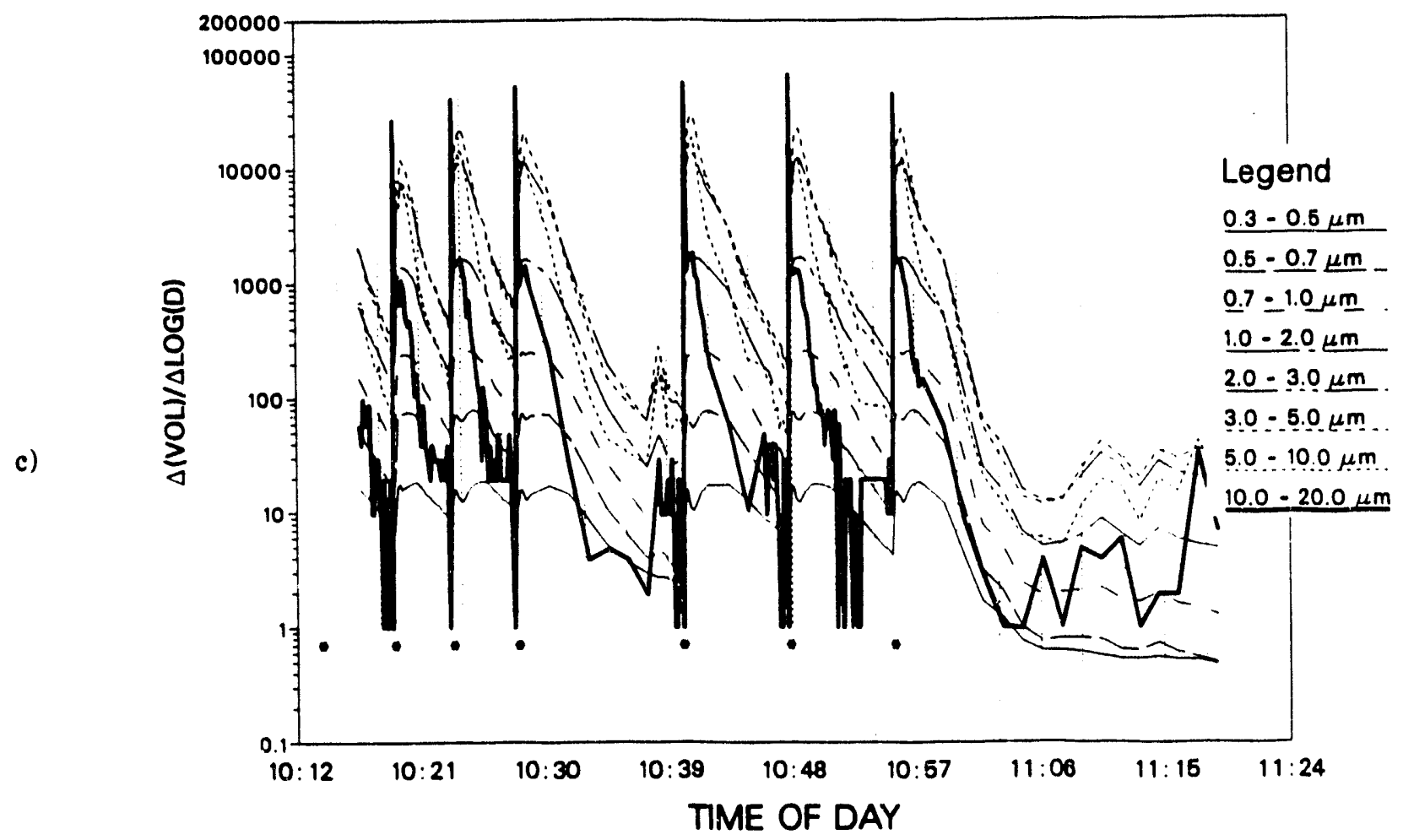

FIGURE 21 (Cont.)

sampler. The fireball from the muzzle reached this sampler; it is therefore possible that the lead found in the liquid was actually in the lead vapor phase that passed through the filter. These filters are considered to be nearly impervious to particulate matter. None of the LMSs inside the cab showed a significant lead content in the nitric acid solution.

Based on the analyses of the LMS prefilters and liquids, no organic lead compounds were expected to be found in the sorption tubes with the solid media; therefore, these sorption substrates were not analyzed.

Results of analyses of the samples collected inside the cab using the Lundgren impactors on September 1-2, 1988, are shown in Table 14, which shows the lead and copper distribution between the different stages of the impactor. The total air lead concentration, calculated by summing the amounts of lead on the four stages and on the after-filter, was very similar to the concentration determined on the total filters collected with the UPASP placed at the same position (Gunner) in the cab. These results indicate that measured air lead concentrations were independent of flow rate from $4 \mathrm{~L} / \mathrm{min}$ for the UPASP samplers to $100 \mathrm{~L} / \mathrm{min}$ for the Lundgren impactor. The analyses also show that the four stages of the impactor collected less than $20 \%$ of the lead in the aerosol, while the after-filter, which collects particles less than $0.3 \mu \mathrm{m}$ a.d., collected $80 \%$ or more of the aerosol lead.

A concern with the use of impactors is always whether or not particles bounce from one stage to the following stage. Experience with the Lundgren impactor has taught us that the 
TABLE 13 Data for aerosol samples collected at YPG from August 31 to September 2, 1988 , during firing of the 155-mm/M109A3E2 HIP howitzer ${ }^{a}$

\begin{tabular}{|c|c|c|c|c|c|c|c|c|}
\hline \multirow{2}{*}{$\begin{array}{l}\text { Sample } \\
\text { ID/Locaclonb }\end{array}$} & \multirow[b]{2}{*}{ Date } & \multirow{2}{*}{$\begin{array}{l}\text { Collec- } \\
\text { tion } \\
\text { Time } \\
(m i n)\end{array}$} & \multirow{2}{*}{$\begin{array}{c}\text { Tota } 1 \\
\mathrm{~Pb}^{\mathrm{C}} \\
(\mu \mathrm{g})\end{array}$} & \multirow{2}{*}{$\begin{array}{c}\text { Total } \\
\text { cuce } \\
(\mu g)\end{array}$} & \multicolumn{2}{|c|}{$\begin{array}{c}\text { Air Lodading } \\
\left(\mu \mathrm{g} / \mathrm{m}^{3}\right)\end{array}$} & \multirow{2}{*}{$\begin{array}{l}\text { Ru/ Pl } \\
\text { Ratio }\end{array}$} & \multirow{2}{*}{$\begin{array}{l}\text { Porcent- } \\
\text { oge of } \\
\text { Total Plo } \\
\text { coldected }\end{array}$} \\
\hline & & & & & $\mathrm{Pb}$ & $\mathrm{gu}$ & & \\
\hline $\begin{array}{l}\text { Charcoal pref: lter } \\
\text { (Gunner 2) }\end{array}$ & $9 / 1 / 88$ & 63 & 4.7 & 1.5 & 149 & 48 & 0.32 & - \\
\hline $\begin{array}{l}\text { XAD2 prefilter } \\
\text { (Gunner 2) }\end{array}$ & $9 / 1 / 88$ & 63 & 3.9 & 1.4 & 124 & 44 & 0.35 & - \\
\hline $\begin{array}{c}\text { Tenax prefilter } \\
\text { (Gunner } 2 \text { ) }\end{array}$ & $9 / 1 / 88$ & 63 & 5.8 & 1.5 & 184 & 48 & 0.26 & - \\
\hline $\begin{array}{l}\text { Charcoal prefilter } \\
\text { (Gunner 2) }\end{array}$ & $9 / 2 / 88$ & 94 & 8.1 & 1.4 & 172 & 30) & 0.17 & - \\
\hline $\begin{array}{l}\text { XAD2 prefilter } \\
\text { (Gunner } 2 \text { ) }\end{array}$ & $7 / 2 / 88$ & 94 & 8.9 & 1.0 & 189 & 21 & 0.11 & - \\
\hline $\begin{array}{l}\text { Tenax prefilter } \\
\text { (Gunner 2) }\end{array}$ & $9 / 2 / 88$ & 94 & 9.1 & 1.4 & 194 & 30 & 1). 15 & - \\
\hline $\begin{array}{l}\text { LMSO-F1 } \\
\text { (1eft side) }\end{array}$ & $8 / 31 / 88$ & 87 & 15.4 & 5.7 & 354 & 131 & 0.37 & 99.7 \\
\hline $\begin{array}{l}\text { LMSI-F1 } \\
\text { (Asst, gunner) }\end{array}$ & $8 / 31 / 88$ & 87 & 4.7 & 1.1 & 108 & 25 & 0.23 & $99 . b$ \\
\hline $\begin{array}{l}\text { LMSO-F2 } \\
\quad(\text { left side) }\end{array}$ & $9 / 1 / 88$ & 63 & 11.2 & 4.7 & 355 & 149 & 0.42 & $98 . .8$ \\
\hline $\begin{array}{l}\text { LMSI-F2 } \\
\text { (Asst. gunner) }\end{array}$ & $9 / 1 / 88$ & 63 & 4.2 & 1.2 & 133 & 38 & 0.28 & 79.5 \\
\hline $\begin{array}{l}\text { LMSO-F3 } \\
\text { (Left side) }\end{array}$ & $9 / 2 / 88$ & 94 & 7.1 & 2.7 & $151^{\circ}$ & 57 & 0.38 & 74.2 \\
\hline $\begin{array}{l}\text { LMSI-F3 } \\
\text { (Asst. gunner) }\end{array}$ & $9 / 2 / 99$ & 94 & 1.9 & 0.3 & $40^{\circ}$ & 6 & 0.16 & 98.4 \\
\hline $\begin{array}{l}\text { LMSO-LL } \\
\text { (1eft side) }\end{array}$ & $8 / 31 / 88$ & 87 & 0.04 & - & - & - & - & $0 . ?$ \\
\hline $\begin{array}{l}\text { LMSI-LI } \\
\text { (Asst. gunner) }\end{array}$ & $8 / 31 / 88$ & 87 & 0.02 & - & - & - & - & $1) .4$ \\
\hline $\begin{array}{l}\text { LMSO-L2 } \\
\text { (left side) }\end{array}$ & $9 / 1 / 88$ & 63 & 0.14 & - & - & - & - & 1.2 \\
\hline $\begin{array}{l}\text { LMSI-L2 } \\
\text { (ASSE. gunner) }\end{array}$ & $9 / 1 / 88$ & 53 & 0.02 & - & - & - & - & 11.5 \\
\hline $\begin{array}{l}\text { LMSO-L3 } \\
\text { (1eft side) }\end{array}$ & $9 / 2 / 88$ & 34 & 0.44 & - & - & - & - & 5.8 \\
\hline $\begin{array}{l}\text { LMSI - L3 } \\
\text { (Asst. gunner) }\end{array}$ & $9 / 2 / 88$ & 94 & 0.03 & -. & - & - & - & 1.0 \\
\hline $\begin{array}{l}\text { LMS-Blank } \\
\quad \text { (inside mobile) }\end{array}$ & $8 / 29 / 88$ & 120 & 0.01 & - & - & - & - & - \\
\hline
\end{tabular}

a Flow rates set at $500 \mathrm{~mL} / \mathrm{min}$.

b See Fig. 5. LMSX-Fn and LMSX-Ln: $x=I$ (Inside) or o (outside): $F=f i l t e r, L=1$ Licuidi: $n=$ sample number.

c Determined by AAS.

d Total Pb collected $=\mathrm{Pb}$ on prefilter (LMS-F sample). Pb in liquid medium (LMS-L Samplo).

- Low values indicate pump malfunction. 
TABLE 14 Lead and copper content of samples collected by the Lundgren impactor from firings of the 155-mm/M109A3E2 HIP howitzer on September 1-2, 1988

\begin{tabular}{|c|c|c|c|c|c|c|}
\hline \multirow[b]{2}{*}{ Szinple } & \multirow[b]{2}{*}{$\begin{array}{c}\text { Size } \\
\text { Fraction } \\
(\mu \mathrm{m})\end{array}$} & \multicolumn{2}{|r|}{$\mathrm{Pb}$} & \multicolumn{2}{|r|}{$\mathrm{Cu}$} & \multirow[b]{2}{*}{$\begin{array}{l}\mathrm{Cu} / \mathrm{Pb} \\
\text { Ratio }\end{array}$} \\
\hline & & $\mu \mathrm{g}$ & $\begin{array}{c}\text { Percentage } \\
\text { of } \\
\text { Total } \\
\end{array}$ & $\mu \mathrm{g}$ & $\begin{array}{c}\text { Percentage } \\
\text { of } \\
\text { Total } \\
\end{array}$ & \\
\hline \multicolumn{7}{|l|}{$9 / 1 / 88^{a}$} \\
\hline Stage I & $>10$ & 22 & 2 & 13 & 7 & 0.59 \\
\hline stage II & $3-10$ & 134 & 14 & 89 & 47 & 0.64 \\
\hline Stage III & $1-3$ & 6 & $<1$ & 1 & $\because 1$ & 0.19 \\
\hline stage IV & $0.3-1$ & 19 & 2 & 2 & 1 & 0.11 \\
\hline After-filter & $<0.3$ & 787 & 81 & 85 & 45 & 0.11 \\
\hline \multicolumn{7}{|l|}{$9 / 2 / 88^{b}$} \\
\hline Stage I & $>10$ & 30 & 2 & 17 & 7 & 0.54 \\
\hline Stage II & $3-10$ & 102 & 5 & 71 & 29 & 0.70 \\
\hline Stage III & $1-3$ & 44 & 2 & 16 & 6 & 0.38 \\
\hline stage IV & $0.3-1$ & 80 & 4 & 12 & 5 & 0.15 \\
\hline After-filter & $<0.3$ & 1571 & 86 & 131 & 53 & 0.08 \\
\hline
\end{tabular}

a Total air $\mathrm{Pb}$ concentration $=154 \mu \mathrm{g} / \mathrm{m}^{3}$.

b Total air Pb concentration $=205 \mu \mathrm{g} / \mathrm{m}^{3}$.

first two stages do need to have grease on the Mylar collection substrate to prevent the larger particles ff " $m$ bouncing. We, therefore, used a thin coat of silicone grease on the Mylar for stages I and II. Nevertheless, since this type of aerosol had not been sampled previously, there was some concern as to whether or not particle bounce would occur on stages III and IV. Several aspects of the results give us confidence that particle bounce did not occur and that the results from the Lundgren are valid. First is the fact that a bimodal distribution is evident in both sets of samples for both lead and copper. This is seen by larger amounts of lead ard copper on stage II and on the after-filter. This is supported by the results from the OPC, which show a peak in the size distribution at around $5 \mu \mathrm{m}$ diameter. However, the OPC lower limit of detection is at $0.3 \mu \mathrm{m}$, and therefore it would not detect the large amount of material in the smaller-sized particles collected on the after-filter. Weights for the total amount of material collected in each size fraction were not obtained, but visual examination supports the idea of a distinct bimodal distribution.

Another feature of the Lundgren results is that even though the copper content of the asrosol particles also follows the bimodal distribution, it does not track the lead by the same ratio. The larger particles have a significantly higher copper content than the smaller particles. More work needs to be done to verify and to understand this dependence of the $\mathrm{Cu} / \mathrm{Pb}$ ratio on particle size. This same range of copper-to-lead ratios can be seen in samples from the total filters. Those results indicated that the aerosol particles collected outside of the weapon were enriched in copper while, at least in some cases, the aerosol particles 
collected inside the weapon were depleted in copper (Table 14). It could well be that the inside/outside difference could be due to inside/outside differences in particle size as indicated by the Lundgren results. It should be pointed out that in many inside samples, the $\mathrm{Cu} / \mathrm{Pb}$ ratio is in an intermediate range, from 0.2 to 0.5 , which may be taken to indicate that aerosol from outside has entered the cab and was sampled inside, with a resulting increase in the ratio. Additional support for this interpretation is obtained from the results of the firing of single rounds discussed below. This feature could possibly be very useful in evaluating respirability of the weapons emissions. The $\mathrm{Cu} / \mathrm{Pb}$ ratio could conceivably be used as a marker to determine whether the aerosol originated outside (from the muzzle) or inside (from the breech).

The carbon monoxide concentrations were continuously monitored at the Gunner position inside the cab. The peak $C O$ concentrations were always less than $15 \mathrm{ppm}$ on August 30 and September 1, 1988, and always less than 40 ppm on September 2, 1988. The increase in $\mathrm{CO}$ concentration almost always coincided with the reentry of the cannoneers into the cab in preparation for the next round of firing, rather than with the firing of the round itself.

At the Gunner position, the aerosols produced by the 155-mm/M109A3E2 HIP weapon had the highest lead content. Using data from Tables 8-13, the Gunner position aerosols were $7.4 \pm 0.4 \% \mathrm{~Pb}$ by weight for the $155-\mathrm{mm} / \mathrm{M} 109 \mathrm{~A} 3 \mathrm{E} 2 \mathrm{HIP}$ weapon (mean $\pm \mathrm{SE}$, $n=3$ ) and $3.1 \pm 0.2 \% \mathrm{~Pb}$ by weight for the 155-mm/M109A3E1 $(n=4)$. Using data from all of the crew positions in the cab (excluding the driver's position), we get similar results: for the HIP weapon the value is $6.8 \pm 1.3 \% \mathrm{~Pb}$ by weight $(n=11)$; for the A3E1 weapon the value is $3.6 \pm 0.9 \% \mathrm{~Pb}$ by weight $(n=15)$. It is not clear why the lead content of the aerosol at the Gunner position and in the cab of the HIP weapon was twice as high in lead content as that of the A3E1 weapon. Even though the difference between the two weapons seems to be consistent from these data, there are too many variables to place any great significance on this apparent difference.

Similar to the measurements on the 8-in./M110 howitzer, air copper concentrations ranged from 12-365 $\mu \mathrm{g} / \mathrm{m}^{3}$ during firing of high-lead charges from the $155-\mathrm{mm} / \mathrm{M} 109 \mathrm{~A} 3$ howitzer (see Tables 8-12), below the limit adopted by the American Conference of Government Industrial Hygienists (ACGIH) for copper dust in workplace air (8-h TWA, $\left.1000 \mu \mathrm{g} / \mathrm{m}^{3}\right)$ but at times above the limit for copper fume $\left(100 \mu \mathrm{g} / \mathrm{m}^{3}\right)$.

Results from the Firing of Single Ruunds. The last three rounds fired on September 2, 1988, were timed so that we could change the filters between each firing to provide some single round data. Only the UPASP filters were used for this set of samples. The analytical results from these samples are given in Table 15.

The TWA PbA concentrations agree well with values from samples which were collected over several firings. The TWA for lead was highest in the muzzle blast zone 
TABLE 15 Results from samples collected during single-round firings of the 155-mm/M109A3E2 HIP howitzer on September 2, 1988

\begin{tabular}{|c|c|c|c|c|c|c|}
\hline \multirow[b]{2}{*}{$\begin{array}{l}\text { Filter } \\
\text { ID/Location }\end{array}$} & \multirow{2}{*}{$\begin{array}{c}\text { Collec- } \\
\text { tion } \\
\text { Time } \\
\text { (min) } \\
\end{array}$} & \multirow[b]{2}{*}{$\begin{array}{c}\text { Total } \\
\mathrm{Pb}(\mu \mathrm{g})\end{array}$} & \multirow[b]{2}{*}{$\begin{array}{c}\text { Total } \\
\mathrm{Cu}(\mu \mathrm{g}) \\
\end{array}$} & \multicolumn{2}{|c|}{$\begin{array}{c}\text { Air Loading } \\
\left(\mu \mathrm{g} / \mathrm{m}^{3}\right)\end{array}$} & \multirow[b]{2}{*}{$\begin{array}{l}\mathrm{Cu} / \mathrm{Pk} \\
\mathrm{Ratic}\end{array}$} \\
\hline & & & & $\mathrm{Pb}$ & $\mathrm{Cu}$ & \\
\hline $\begin{array}{l}\mathrm{G} 1-\operatorname{Rd} 12^{\mathrm{b}} \\
\quad \text { (Gunner) }\end{array}$ & - & 0.3 & 0.2 & - & - & - \\
\hline $\begin{array}{l}\text { G1-Rd13 } \\
\text { (Gunner) }\end{array}$ & - & 0.2 & $\mathrm{ND}^{\mathrm{C}}$ & - & - & - \\
\hline $\begin{array}{l}\text { G1-Rd14 } \\
\text { (Gunner) }\end{array}$ & - & ND & ND & - & - & - \\
\hline $\begin{array}{l}\text { G2-Rd12 } \\
\text { (Asst. gunner) }\end{array}$ & 6 & 6.9 & 0.9 & 287 & 37 & 0.13 \\
\hline $\begin{array}{l}\text { G2-Rd13 } \\
\text { (Asst. gunner) }\end{array}$ & 6 & 7.0 & 0.9 & 292 & 37 & 0.13 \\
\hline $\begin{array}{l}\text { G2-Rd14 } \\
\text { (Asst. gunner) }\end{array}$ & 6 & 7.0 & 0.7 & 292 & 29 & 0.10 \\
\hline $\begin{array}{l}\text { L1-Rd12 } \\
\quad(\text { Loader \#1) }\end{array}$ & 6 & 4.5 & 0.7 & 188 & 29 & 0.16 \\
\hline $\begin{array}{l}\text { L1-Rd13 } \\
\quad(\text { Loader \#1) }\end{array}$ & 6 & 5.0 & 0.7 & 208 & 29 & 0.14 \\
\hline $\begin{array}{l}\text { L1-Rd14 } \\
\quad(\text { Loader \#1) }\end{array}$ & 6 & 4.6 & 0.6 & 192 & 25 & 0.13 \\
\hline $\begin{array}{l}\text { ORS-Rd12 } \\
\quad \text { (outside } \\
\text { right side) }\end{array}$ & 6 & 8.7 & 4.9 & 362 & 204 & 0.56 \\
\hline $\begin{array}{l}\text { ORS-Rd13 } \\
\text { (outside } \\
\text { right side) }\end{array}$ & 6 & 6.0 & 3.5 & 250 & 146 & 0.58 \\
\hline $\begin{array}{l}\text { ORS-Rd14 } \\
\text { (outside } \\
\text { right side) }\end{array}$ & 6 & 10.9 & 5.8 & 454 & 242 & 0.53 \\
\hline $\begin{array}{l}\text { ORC-Rd12 } \\
\quad \text { (outside rear) }\end{array}$ & 6 & 1.9 & 0.9 & 79 & 38 & 0.47 \\
\hline $\begin{array}{l}\text { ORC-RdI3 } \\
\text { (outside rear) }\end{array}$ & 6 & 0.3 & 0.2 & 12 & 8 & 0.67 \\
\hline $\begin{array}{l}\text { ORC-Rd14 } \\
\quad \text { (outside rear) }\end{array}$ & 6 & 2.1 & 1.1 & 87 & 46 & 0.52 \\
\hline $\begin{array}{l}\text { Outside Blank } \\
\text { (rear) }\end{array}$ & 117 & ND & ND & - & - & - \\
\hline
\end{tabular}

a Flow rates set at $4.0 \mathrm{~L} / \mathrm{min}$.

$b$ Pump did not run.

C ND $=$ not detectable. 
(outside right side), lower for the two sets of samples from inside the weapon (Assistant Gunner and Loader 1), and lowest for the outside rear sam le, which is consistent with the earlier results.

This data set also supports the hypothesis that there is a difference between the $\mathrm{Cu} / \mathrm{Pb}$ ratio for the inside and the outside aerosol. There have been indications of this difference in other results but not nearly as convincingly as from these short-collection-time, single-round samples. Since the collection time was so short, it seems reasonable that mixing of the two different types of aerosol did not occur. These samples were all collected as total filters with the UPASPs, so no size fractionation data are available, but if we use the information on the $\mathrm{Cu} / \mathrm{Pb}$ ratio from the Lundgren impactor data (see Table 14), a case can be made that the aerosol inside the weapon is very fine, i.e., less than $1.0 \mu \mathrm{m}$ a.d. and has a $\mathrm{Cu} / \mathrm{Pb}$ ratio of about 0.1 , while the outside aerosol from the muzzle is larger than $1.0 \mu \mathrm{m}$ a.d. and has about a 0.5 ratio of $\mathrm{Cu} / \mathrm{Pb}$. This would seem reasonable since the lead is added as a decoppering agent, and these results would indicate that the lead is doing its job of causing the copper to be blown out of the barrel.

The reason for the difference in the $\mathrm{Cu} / \mathrm{Pb}$ ratio is unclear, but there seems to be a dramatic difference related to the size of the aerosol particles and whether the aerosol was emitted from the muzzle blast or from the breech inside the cab.

The consistency of the results from round to round for the inside samples indicates that the results are reliable. The variance for the outside samples can be understood as variation caused by the wind speed and direction.

\subsection{CONCLUSIONS}

- Although the chemical form of the aerosolized lead was not definitively determined, early results with X-ray powder diffraction indicated the presence of specific lead compounds, $\mathrm{KPb}_{2}\left(\mathrm{CO}_{3}\right)_{2} \mathrm{OH}$ and $\left(\mathrm{NH}_{4}\right)_{2} \mathrm{PbCu}\left(\mathrm{NO}_{2}\right)_{6}$. Infrared analyses show the presence of bicarbonate ion in the samples, most of which is probably potassium bicarbonate.

- The PbA concentrations at crew positions inside the vehicle were much more variable and dependent on wind conditions for the 8-in./M110 howitzer with the CBS than for the 155-mm/M109A3 howitzer with cab. The $\mathrm{PbA}$ concentrations at the Gunner position for the 8-in $/ \mathrm{M} 110$ howitzer ranged from a low of $1 \mu \mathrm{g} / \mathrm{m}^{3}$ when firing with a tail wind to a high of $603 \mu \mathrm{g} / \mathrm{m}^{3}$ with a mild head wind (see Table 6). In contrast, at the Gunner position of the $155-\mathrm{mm} / \mathrm{M} 109$ HIP howitzer, the measured $\mathrm{PbA}$ concentrations were $145-180 \mu \mathrm{g} / \mathrm{m}^{3}$ with a tail wind (Tables 10 and 11) and $205 \mu \mathrm{g} / \mathrm{m}^{3}$ with a head wind (Table 12). This may be attributed to the fact that the CBS of the 
8-in./M110 was open in back, whereas the cab of the $155-\mathrm{mm} / \mathrm{M} 109$ was closed except for the low rear hatch.

- For all weapons, $\mathrm{PbA}$ concentrations were high outside the howitzer in the region of the muzzle blast zone when high-lead charges were fired. These values were $309-381 \mu \mathrm{g} / \mathrm{m}^{3}$ for the 8 -in. $/ \mathrm{M} 110$, $109-496 \mu \mathrm{g} / \mathrm{m}^{3}$ for the $155-\mathrm{mm} / \mathrm{M} 109 \mathrm{~A} 3 \mathrm{E} 1 \mathrm{Cobra}$, and $427-627 \mathrm{\mu g} / \mathrm{m}^{3}$ for the $155-\mathrm{mm} / \mathrm{M} 109$ A3E2 HIP weapon. These results indicate that most of the lead in the charge is expelled from the end of the gun barrel as an aerosol when the weapon is fired and some enters the CBS/cab when the breech is opened or as air is taken in from the outside.

- For both M109A3 weapons, the aerosols collected at crew positions inside the CBS/cab were lower in lead content than the aerosols in the muzzle blast zone. The lead content of the aerosol at the Gunner position, averaged for all weapons, was $5.3 \pm 1.0 \%$ by weight (mean $\pm \mathrm{SE}, \mathrm{n}=6$ ), while in the muzzle blast zone (right side, left side) the values were $18.5 \pm 1.6 \%$ by weight of lead $(n=12)$.

- The aerosols in the muzzle blast zone of the 155-mm/M109A3E1 were similar in lead content to those of the 155-mm/M109A3E2 HIP. Muzzle blast aerosol was $19.3 \pm 1.3 \% \mathrm{~Pb}$ by weight (mean $\pm \mathrm{SE}, \mathrm{n}=$ 7) for the former and $17.5 \pm 2.6 \% \mathrm{~Pb}$ by weight $(n=5)$ for the latter.

- Based on the OPC, the size distributions of all particles for aerosols generated during firing were similar for the 8-in./M110 and the 155-mm/M109A3E2 HIP weapon. (No OPC data were taken for the 155-mm/M109A3E1.)

- The decay time for the mid-range sized particles $(2-5 \mu \mathrm{m})$ in the cab of the $155-\mathrm{mm} / \mathrm{M} 109 \mathrm{HIP}$ weapon was appreciably longer than in the CBS of the 8-in./M110 howitzer. It took $1 \mathrm{~min}$ or less for the aerosol in the M110 to decay by two orders of magnitude; it took 3-6 min for the aerosol in the M109 to decay by the same proportion. This longer suspension of particles in the M109 was probably due to its cab being closed, compared to the open CBS of the M110.

- The lead-containing particles from the aerosol in the cab of the $155-\mathrm{mm} / \mathrm{M} 109 \mathrm{HIP}$ weapon appeared to be significantly smaller than those from the aerosol in the CBS of the 8-in./M110 weapon. For the 8-in./M110 howitzer, only $32 \%$ of the lead in the CBS aerosol was present on particles $2.5 \mu \mathrm{m}$ or less in diameter; in contrast, for the $155-\mathrm{mm} / \mathrm{M} 109 \mathrm{HIP}$ weapon, $83-93 \%$ of the lead in the cab aerosol was on particles $3 \mu \mathrm{m}$ or less, and $81-86 \%$ of the lead was on particles $0.3 \mu \mathrm{m}$ or less in aerodynamic diameter. 
- No excessive CO concentrations were found in the cab of the $155-\mathrm{mm} / \mathrm{M} 109 \mathrm{~A} 3 \mathrm{E} 2 \mathrm{HIP}$ weapon as a result of the firings.

- Air $\mathrm{Cu}$ concentrations inside and outside of the weapon during the firing of high-lead charges from the 8-in./M110 howitzer at APG and the $155-\mathrm{mm} / \mathrm{M} 109 \mathrm{~A} 3$ howitzers at YPG ranged from 1 to $365 \mu \mathrm{g} / \mathrm{m}^{3}$ (set Tables 6 and 8-12), lower than the ACGIH standard for Cu dust $\left(1 \mathrm{mg} / \mathrm{m}^{3}\right)$ but at times higher than that for $\mathrm{Cu}$ fume $\left(100 \mu \mathrm{g} / \mathrm{m}^{3}\right)$. 


\section{ACUTE LEAD EFFECTS STUDY}

\subsection{METHODS}

\subsubsection{Overall Study Design}

Lead exposures and responses were studied in 1987 at Fort Sill, Oklahoma, in two groups of U.S. Army artillery crew members: 22 men from C Battery, 4/4 Field Artillery (4/4 FA; group 1) and 23 men from C Battery, 2/18 Field Artillery (2/18 FA; group 2). Each group participated in exercises during which the crew members fired a large number of M188A1 zone 9 charges from an M110A2 (8-in.) howitzer with a crew ballistic shelter. Each of the M188A1 charges contained 10.25 oz of lead foil, forming a lead-rich aerosol during firing. The purpose of this study was to measure individual lead exposures for each crew member during the firing exercises and to determine whether any changes in blood lead concentration, hematocrit, free erythrocyte porphyrin (FEP), or nerve conduction velocity (NCV) occurred as a result of the lead exposures.

Before the firing exercises started, each crew member signed a consent form, answered a questionnaire, provided a blood sample, and had measurements made of the conduction velocities of six nerves. The questionnaire provided information on the nature of the study population; the biological samples and NCV tests provided baseline values to which values obtained during or after the firing exercises could be compared.

The general protocol for the study of artillerymen is shown in Fig. 22. Each group of artillerymen first fired low-zone, low-lead charges from the standard M110A2 howitzer without a CBS uver a four-day firing period (Fig. 22; -CBS). The crew members then attended a two-week school during which they were trained in firing the same howitzer with a CBS. After completing their training, the crew members fired a combination of low-zone (low-lead) and high-zone (high-lead) charges from the howitzer with a CBS over either two (group 1) or three (group 2) four-day firing periods (group 1, +CBS1 and +CBS2 firing periods, Fig. 22; group 2, +CBS1, +CBS2, and +CBS3 firing periods). During all four-day firing periods, each study participant wore an air sampling pump and filter to provide an individual measure of lead exposure; in addition, each participant provided a blood and urine sample at the firing location (Fig. 22).

On the first Monday after the last four-day firing period (the immediate postexposure [IPE] time point, Fig. 22), a blood and urine sample was taken, and each crew member answered the study questionnaire. During that week, a set of NCV measurements was also made.

Finally, 11 weeks after the start of the firing exercises (the delayed post-exposure [DPE] time point, five to six weeks after the IPE measurements, Fig. 22), a final set of blood and urine samples was taken, each crew member answered the study questionnaire, and a final set of NCV measurements was made. 


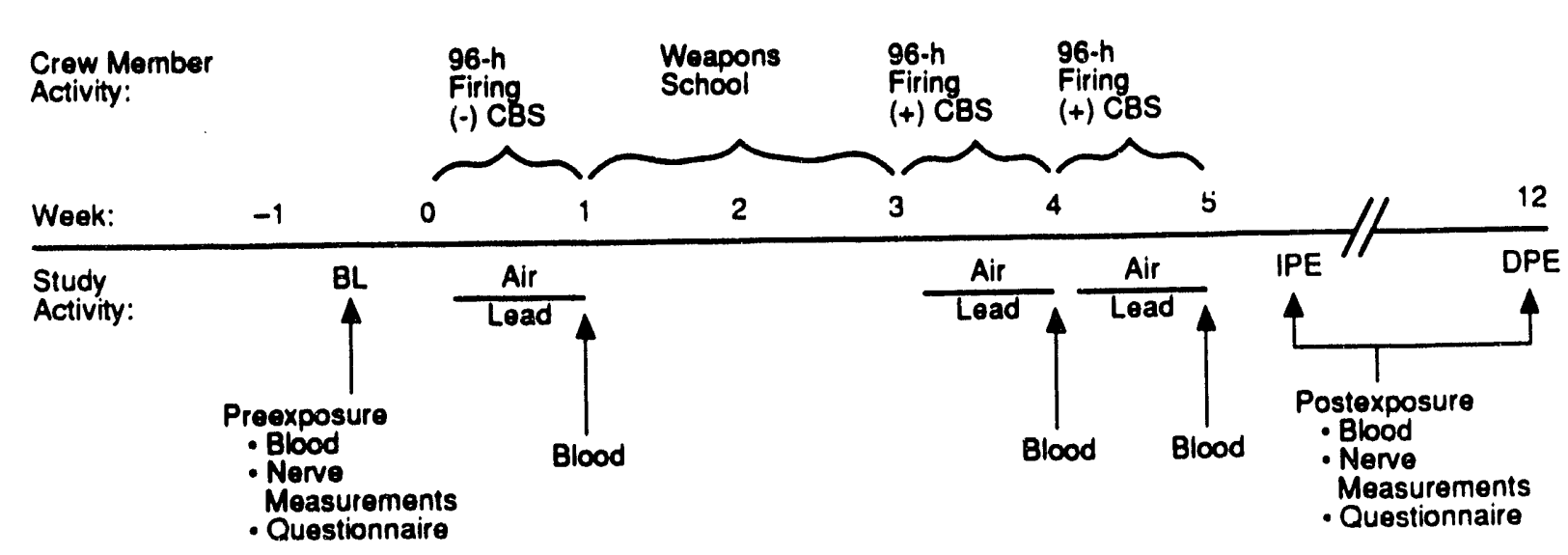

FIGURE 22 Time line for Fort Sill acute lead exposure study: 8-in. howitzer with CBS

\subsubsection{Air Sampling}

Individual lead exposure terms were acquired by sampling air near the breathing zone. Personal air sampling pumps were run at $2.0 \mathrm{~L} / \mathrm{min}$ ( $1 \mathrm{~min}$ on, $1 \mathrm{~min}$ off) for periods ranging from 24 to $48 \mathrm{~h}$ with 0.8- um cellulose acetate aerosol filter cassettes (Millipore Corp., Bedford, Massachusetts) to acquire 24- to 48-h time-weighted-average exposure terms. The $\mathrm{PbA}$ concentrations determined during firing on August 10,1987 , were $34.4 \mu \mathrm{gg} / \mathrm{m}^{3}$ for a pump operating in the $1 \mathrm{~min}$ on, $1 \mathrm{~min}$ off mode, compared to $36.7 \mu \mathrm{g} / \mathrm{m}^{3}$ for a pump operating with continuous air flow. Note that the pumps for the latter determinations were run during the same total time period, but the pump operated in the intermittent mode sampled half as much air as did the pump operated continuously. These results demonstrate that our mode of intermittent air sampling was valid, affording us a longer sampling time for each battery.

\subsubsection{Study Questionnaire}

At the baseline time-point, each study participant was privately interviewed face-toface to obtain data on demographic variables, current general health, current alcohol and smoking behaviors, lifetime injuries to limbs used for nerve conduction velocity testing, and lifetime prior exposure to lead via occupational or hobby exposures. Specific questions in the current health section included probes for symptoms of lead toxicity including weight loss, nausea, diarrhea, abdominal pain, fatigue, and muscular weakness. At the time of each subsequent nerve conduction velocity measurement, each man was privately reinterviewed using a short-form questionnaire regarding recent health, lead toxicity symptoms, and possible lead exposures other than those associated with military weapons firing.

\subsubsection{Blood Sampling}

Blood was sampled in the field as well as in the clinic, according to procedures devised in our laboratory to provide samples uncontaminated by environmental lead. 
Collection of blood in the field was preceded by (1) a thorough soap-and-water washing of both arms of volunteers followed by a water rinse and (2) covering potentially leadcontaminated clothing and hair with a clean surgical gown and shower cap. Prior to the blood drawing, each venipuncture site was wiped down with 70\% ethanol. One 7-mL, EDTAanticoagulant tube (Becton Dickinson Vacutainers Systems, Rutherford, New Jersey) was filled, chilled on ice, and subsequently frozen until analysis. On days when blood was drawn at the clinic, aliquots of approximately $1 \mathrm{~mL}$ of whole blood were removed from the heparinized tubes for determination of hematocrit (in duplicate). Blood samples were collected in the field in order to obtain samples during or immediately after the end of firing. This study design was implemented because several artillerymen whose blood samples were taken just after firing the $155-\mathrm{mm}$ howitzer in the Howitzer Extended Life Program study had much higher blood lead concentrations than men sampled later (As85).

\subsubsection{Nerve Conduction Velocity Measurements}

Training. Dr. Jay V. Subbarao, M.D., was responsible for the development of the electromyography protocol. Dr. Subbarao is a member (by examination) of the American Association of Electromyography and Electrodiagnosis. He lectures on electromyography in the Occupational Medicine Residency Program of the Great Lakes Center for Occupational Safety and Health at the University of Illinois College of Medicine at Chicago. He has been involved for five years in electromyographic diagnosis of occupation-related conditions as a consultant to Carnow and Conibear Associates, a large occupational medicine practice.

To qualify our group members for the NCV measurements, Dr. Subbarao conducted three 2-h, hands-on training sessions. Subsequently, he conducted a written and practical examination of NCV skills. Prior to taking the examination, the group members practiced the techniques and generated data for quality assessment of their skills.

Methods. Baseline (BL), IPE, and DPE measurements of nerve conduction velocity for three motor and three sensory nerves were obtained using a TECA model TD10MK1, Electromyography/Evoked Potential System (TECA Corp., Pleasantville, New York). The motor nerves included the median (MM), ulnar (UM), and peroneal motor nerves (PM). The sensory nerves, measured using antidromic stimulation, were the median (MS), ulnar (US), and sural (SS). Measurement of MM, UM, MS, and US conduction velocities were obtained on the subject's dominant arm from elbow to wrist. Conduction velocities for the PM and SS nerves were measured on the contralateral leg. Skin temperature was monitored on the plantar surface of the hand over the first dorsal interossei muscle for the MM, UM, MS, and US conduction velocity measurements using a skin thermistor connected to a model 5800 electric thermometer (OMEGA Engineering, Inc., Stanford, Connecticut). Skin temperature for the PM and SS nerves was similarly monitored from the medial surface of the foot, approximately $3 \mathrm{~cm}$ distal to the medial malleolus. 
The motor nerves which were surveyed were mixed fast and slow fibers. The conduction velocity of the fast fibers was measured by using supramaximal stimulation, with a stimulus duration between 0.05 and $0.20 \mathrm{~ms}$. The method of de Jesus et al. (De73) was used to adjust the individual NCV values for differences in skin temperature. Arm nerves (MM, UM, MS, US) were adjusted to $34^{\circ} \mathrm{C}$ and leg nerves (PM, SS) were adjusted to $33^{\circ} \mathrm{C}$. The first two arm nerves measured (MM, UM) were adjusted using the beginning hand temperature, while the last two arm nerves measured were adjusted using the final hand temperature. If only one hand temperature was recorded, it was applied to all four arm nerves. Similarly, the beginning foot temperature was applied to the PM nerve, the first leg nerve measured, and the final foot temperature was applied to the SS nerve, the last leg nerve measured. Results are presented for both the original NCV values and the temperature-adjusted data set.

Quality Assessment. Before starting the NCV measurements, the two group members (D.P.P. and B.D.G.) scheduled to make NCV measurements conducted studies at Argonne National Laboratory to determine (1) the variances obtained in repeat measurements on the same individual, (2) the effect of time of day on NCV values, and (3) differences in NCV values between the two NCV measurers.

Whes D.P.P. measured NCVs for a given individual repeatedly on the same day, he obtained a coefficient of variation of $5.2 \%(3.0 \mathrm{~m} / \mathrm{s})(n=4)$ for the MM nerve and $2.1 \%$ $(1.4 \mathrm{~m} / \mathrm{s})(n=5)$ for the US nerve. When D.P.P. measured NCVs for a given individual on nine separate days from December 15, 1986 to March 10, 1987 (the approximate time between BL and DPE in our study), with all measurements started at the same time of day (1500-1600 hours), he obtained a mean coefficient of variation $(n=9)$ for all six nerves of $3.0 \%$, with a range of $1.4 \%$ (US) to $4.2 \%$ (SS). B.D.G. obtained a corresponding mean coefficient of variation for all six nerves $(n=7$ repeat measurements from January 5 to March 11,1987 ) of $3.8 \%$, with a range of $1.5 \%$ (US) to $6.4 \%$ (PM).

Measurements made by D.P.P. on one individual at 9:30 a.m. vs. 4:00 p.m. showed differences of $6.3 \%(\mathrm{MM}), 0.3 \%$ (UM), $1.8 \%$ (MS), $1.4 \%$ (US), $7.9 \%(\mathrm{PM})$, and $5.3 \%(\mathrm{SS})$. The mean difference with time of day was $3.8 \%$.

Measurements made by both D.P.P. and B.D.G. on eight individuals showed mean differences (B.D.G. value minus D.P.P. value) of $2.9 \%(1.8 \mathrm{~m} / \mathrm{s} ; \mathrm{MM}), 1.9 \%(1.3 \mathrm{~m} / \mathrm{s} ; \mathrm{UM})$, $-0.7 \%(-0.5 \mathrm{~m} / \mathrm{s} ; \mathrm{MS}), 0.9 \%(0.6 \mathrm{~m} / \mathrm{s} ; \mathrm{US}),-6.0 \%(-3.0 \mathrm{~m} / \mathrm{s} ; \mathrm{PM})$, and $-1.4 \%(-0.5 \mathrm{~m} / \mathrm{s} ; \mathrm{SS})$. None of these differences were statistically significant at the $p<0.05$ level using the t-test for paired observations. However, the differences between measurers for the MM and PM nerves were borderline in significance $(p<0.1)$.

Results of these studies show that differences between repeat measurements on a given individual were small for both NCV measurers (3-4\%), time of day had little effect on NCV values (4\% difference), and differences between measurements made by our two measurers were small (1-6\%), although somewhat larger than differences for the same measurer making repeat measurements on a given individual (3-4\%). 


\subsubsection{Sample Analyses}

Airborne Lead and Copper. The analysis of personal sampler filters for lead and copper was carried out by electrothermal atomic absorption spectrophotometry on an Instrumentation Laboratory model 951 dual-channel atomic absorption spectrophotometer equipped with a model 655 graphite furnace and a model 254 FASTAC autosampler (Thermo Jarrell Ash Corporation, Franklin, Massachusetts). All glassware was acid-cleaned overnight in $3 \mathrm{~N}$ or $8 \mathrm{~N} \mathrm{HNO}_{3}$, thoroughly rinsed with demineralized/reverse-osmosis water, dried in an oven at $125^{\circ} \mathrm{C}$, and covered with plastic wrap before and during use. The water used for reagent preparation was high resistance (greater than $10^{14}$ megohms) water obtained by passing in-house reverse-osmosis water through a Millipore Milli-Q Water Purification System (Bedford, Massachusetts). The cellulose acetate filters used to collect the $\mathrm{Pb} / \mathrm{Cu}$ aerosol were leached overnight in 50\% Baker Ultrex $\mathrm{HNO}_{3}$ (J. T. Baker Chemical Company, Phillipsburg, New Jersey). If necessary, samples were serially diluted until they were within the linear range of the $\mathrm{Pb} / \mathrm{Cu}$ standard curve.

Blood Lead. Blood lead concentration $(\mathrm{PbB})$ was analyzed by electrothermal atomic absorption using the automated method of Stoeppler et al. (St78). During the period when $\mathrm{PbB}$ values were determined, our laboratory participated in the blood lead proficiency testing programs offered by the Centers for Disease Control (Atlanta, Georgia) or the College of American Pathologists (Skokie, Illinois). During the analysis period, we were on the list of laboratories approved for blood lead analysis by the Occupational Safety and Health Administration, U.S. Department of Labor. From February 1987 to November 1987 (when we analyzed the volunteers' blood for $\mathrm{PbB}$ ), we reported $\mathrm{PbB}$ testing values correctly (in the acceptable range) $100 \%$ of the time. For the three samples in the same low range as our study participants, our analytical values were within $1.3 \pm 0.5 \mu \mathrm{g} / \mathrm{b} / \mathrm{dL}$ (mean $\pm \mathrm{SE}$ ) of the target value.

Hematocrit. Hematocrit samples were prepared from heparinized whole blood by filling duplicate microhematocrit capillary tubes by capillary action. After plugging one end, the tubes were centrifuged for $3 \mathrm{~min}$ on a model MB International microcapillary centrifuge. The samples were read on a hematocrit reader (Damon-IEC Div., International Equipment Company, Needham Heights, Massachusetts).

Free Erythrocyte Porphyrins. Free erythrocyte porphyrins were analyzed using a fluorometric method, which quantitates the fluorescence of FEP after a double extraction procedure (Pi73). (Erythrocyte porphyrins consist mainly of protoporphyrin IX. The words porphyrin and protoporphyrin appear to be used interchangeably in the literature when referring to this assay.) Fluorescence was measured on a Farrand Mark I spectrofluorometer (Farrand Optical Co. Inc., New York). During the period in which our laboratory was involved in FEP analysis, we were enrolled in the Erythrocyte Protoporphyrin Proficiency Testing program sponsored by the U.S. Department of Health and Human Services and 
managed by the Centers for Disease Control (Atlanta, Georgia). From February 1987 to November 1987 (when we analyzed the volunteers' blood for FEP), we reported FEP testing values correctly (in the acceptable range) $95 \%$ of the time. For the nine samples in the same low range as the values of our study participants, our analytical values were within $5.6 \pm$ $2.1 \%$ (mean $\pm \mathrm{SE}$ ) of the target value established by the mean of the reference laboratories. This variation from the target value is the same as that seen among the values of the reference laboratories themselves.

\subsubsection{Dissolution of Aerosol Lead in Simulated Lung Fluid}

Solubility studies were conducted following the method of Eidson and Mewhinney (Ei80, Ei83), by placing a personal sampler filter containing the weapons exhaust aerosol (or a filter spiked with a known salt of lead) between two $0.1-\mu \mathrm{m}$ pore size nylon filters in a Lucite filter holder. The filter holder was submerged in $60 \mathrm{~mL}$ of buffer, and the buffer was then assayed for lead by electrothermal atomic absorption at $0.5,1,2,4,8$, and $24 \mathrm{~h}$.

\subsubsection{Statistical Analyses}

Before subjecting the data set to statistical analyses, an effort was made to identify outliers that should be excluded. A conservative approach was taken such that very few values were excluded. For values of $\mathrm{PbB}$, one baseline value of $19 \mu \mathrm{g} \mathrm{Pb} / \mathrm{dL}$ for study participant 11 was excluded because it was twice as high as any other $\mathrm{PbB}$ value for that person (see Appendix A). No values of FEP or hematocrit were excluded. For the NCV analysis, a careful study of the original data tapes and calculated NCV values identified the following eight measurements (out of a total of 810 ) to be excluded:

subject no.; nerve; time period

34; US; BL

35; SS; DPE

37; MS; BL, IPE, DPE

43; UM, MS, US; BL

For analysis of $\mathrm{PbA}$ values, filters were excluded when the pump period was less than $330 \mathrm{~min}$, which indicated that a flow fault had occurred. In addition, the last filter for participant \#45 was excluded because of the very high $\mathrm{PbA}$ value obtained. All statistical analyses were performed using SAS (SAS85).

Calculation of Cumulative Air Lead Exposures. To obtain a measure of cumulative air lead exposure for each crew member, a value for " $\mu \mathrm{g} \mathrm{Pb}$ " was obtained by summing the amount of lead on each filter from the personal sampling pump worn by that crew member during all firing missions. Filter measurements with pump periods less than $330 \mathrm{~min}$ were excluded from the analysis. If a crew member had three or more missing filters, he was excluded from further analysis, unless the missing filter occurred during the 
first three firing days for the 4/4 FA or the first two firing days for the 2/18 FA (-CBS firing days, when exposures were low). Each time a crew member who was retained in the analysis had a missing filter, the value for the missing day was substituted by the group mean value for that day. Following this procedure, it was possible to obtain individual cumulative air lead exposure values for 19 of the 22 crew members of the 4/4 FA unit and 13 of the 23 crew members of the 2/18 FA unit.

Changes in PbB, FEP, Hematocrit, and NCV. The design of our study was such that each participant served as his own pre-exposure control, i.e., measurements of $\mathrm{PbB}, \mathrm{FEP}$, hematocrit, and NCV were nade at baseline before any firing of high-lead charges; measurements were again made during and after firing to determine changes in each individual. This design potentially allows small responses to lead exposure to be detected that would not be detected in the more customary study design in which a group of leadexposed individuals is compared to a separate group of non-exposed or much less-exposed persons.

To determine whether values changed significantly during a given interval, a change during that interval was calculated for each study participant, and a value for the mean change $\pm \mathrm{SE}$ for the group was calculated as well from the individual values. The Student's t-test for paired observations was then applied to determine whether the mean change for the group was significantly different from zero, with a $p<0.05$ unless noted otherwise.

Relationships to Air Lead Exposures. Standard linear regression analyses were performed to determine whether changes in a given parameter were related to the air lead exposures. For each relationship analyzed (e.g., $\triangle \mathrm{PbB}$ vs. $\mathrm{PbA}$, or $\triangle F E P$ vs. $\triangle \mathrm{PbB}$ ), values of the Pearson correlation coefficient, $p$ value, and number of observations were generated. If a significant correlation with lead exposure was identified, a linear regression analysis was used to provide an equation describing the relationship, along with values of $R^{2}$ and uncertainties in the values of slope and intercept.

\subsection{RESULTS}

\subsubsection{Study Population}

After the study briefings, 22 men from the 4/4 Field Artillery unit and 23 men from the 2/18 Field Artillery unit registered for the study by signing the consent form. During the study, two men from each FA unit dropped out of the study. In addition, two men from the 2/18 FA unit provided blood samples and NCV measurements only at the BL and DPE time points; they did not provide any blood samples in the field or any blood or NCV measurements at the IPE time point. The remaining 39 men (20 from the $4 / 4$ FA unit and 19 from the $2 / 18$ unit) participated in the study throughout. 
As shown in Fig. 23, the men from the two FA units were similar with respect to race (approximately 60\% black), education (approximately $80 \%$ high school graduates), average age (4/4 FA unit $=23.0 \pm 0.9$ years old $[n=21]$; $2 / 18 \mathrm{FA}$ unit $=22.7 \pm 1.0$ years old [ $n=23]$ ), and smoking and drinking habits. Age distributions were such that more of the men from the 2/18 FA unit were in the 18- to 19-year-old range, and, correspondingly, more men from that unit were not married. By way of the questionnaire, no men were identified who had hobbies or second jobs that would have exposed them to lead or who had arm or leg injuries or diseases that might have affected their NCV values. One man from each unit drank heavily both during the week and during the weekend (25-48 drinks during each period), while one additional man from each unit drank heavily during the weekends (25-48 drinks/weekend). The NCV values for these men were still in the normal range, and their values were retained in the analysis.

\subsubsection{Air Lead and Blood Lead Concentrations}

-CBS Firing Periods. During the first firing period (-CBS), when the howitzers were fired without a CBS and no high-lead zone 9 charges were fired, mean TWA PbA concentrations were similar for both FA units and were low, ranging from 0.1 to $0.4 \mu \mathrm{g} / \mathrm{m}^{3}$ (Tables 16 and 17). A number of men in each unit showed no detectable air lead exposure at all during the -CBS period. Correspondingly, there was no rise in the mean $\mathrm{PbB}$ value from the BL to the -CBS time point for either group of men. In fact, there was a slight decrease in the mean $\mathrm{PbB}$ value at -CBS compared to baseline for men of the 2/18 FA unit.

4/4 FA Unit Firing with CBS. When the howitzers were fired with the CBS, mean $\mathrm{PbA}$ values for crew members of the 4/4 FA unit, time-averaged over about $22 \mathrm{~h}$ of collection time, ranged from 1.4 to $6.2 \mu \mathrm{g} / \mathrm{m}^{3}$ during the +CBS1 and +CBS2 firing periods (Table 16).

On June 22 and 23, pumps were placed on the breeches of the guns for the same collection period during which the crew members wore their pumps. On June 22, PbA values for the breech samples were $2.3 \mu \mathrm{g} / \mathrm{m}^{3}$ for gun 1 and $1.2 \mu \mathrm{g} / \mathrm{m}^{3}$ for gun 2 , clearly in range of the mean value for all crew members of $2.1 \pm 0.4 \mu \mathrm{g} / \mathrm{m}^{3}$ (Table 16) obtained for that day. On June 23, $\mathrm{PbA}$ values for the breech samples were $2.4 \mu \mathrm{g} / \mathrm{m}^{3}$ for gun 1 and $2.0 \mu \mathrm{g} / \mathrm{m}^{3}$ for gun 2, similar to the mean value for all crew members of $1.5 \pm 0.2 \mu \mathrm{g} / \mathrm{m}^{3}$ and in range of the minimum and maximum crew member $\mathrm{PbA}$ values obtained for that day (Table 16). These data indicate that $\mathrm{PbA}$ values obtained from a pump placed at the breech of an 8-in. howitzer will provide a reasonable measure of crew member exposure to airborne lead for crew members who spend most of their time on the gun during firing.

On June 29, the first day of the +CBS2 firing period for the 4/4 FA unit, exposures to visible breech exhaust were clearly greater than on other days. As can be seen on our video tape, the wind was light, and the breech and muzzle blast aerosols were denser and stayed for longer periods after firing. Although the maximum number of zone 9 charges was 
not fired during that sample collection period, the mean 24-h TWA PbA concentration was greater than on any other day: $6.2 \pm 0.8 \mu \mathrm{g} / \mathrm{m}^{3}$ (Table 16). The latter value was obtained over a 24-h collection period, during which time the howitzers were not fired continuously.

One feature of the air sampling pump we used was that it would shut down and record the shutdown time whenever the flow rate fell to about $95 \%$ of the set flow rate. Consequently, in case of a flow fault due to crimping of the collection tube (which did happen) or to an overloaded filter (which did not happen in our study), we did not lose data for pumps that shut down. On June 29, the pump of one crew member (study subject \#15, Appendix A) shut down after $0.43 \mathrm{~h}$ ( $26 \mathrm{~min}$ ) due to a flow fault during the first period of continuous firing on that day, having been started at the beginning of that period. The $0.43-\mathrm{h} T W A \mathrm{PbA}$ value for that crew member was $148 \mu \mathrm{g} / \mathrm{m}^{3}$, indicating that the peak air lead concentration to which the crew members were exposed during firing was much higher than the 24-h TWA $\mathrm{PbA}$ concentration of $6.2 \mu \mathrm{g} / \mathrm{m}^{3}$ that was obtained for the entire $24-\mathrm{h}$ collection period. In spite of this fact, the rise in mean blood lead concentration for the group during the +CBS2 firing period was only $1.2 \mu \mathrm{g} / \mathrm{dL}$ blood, from $7.7 \pm 0.4 \mu \mathrm{g} / \mathrm{dL}$ at the end of $+\mathrm{CBS} 1$ to $8.9 \pm$ $0.8 \mu \mathrm{g} / \mathrm{dL}$ at the end of +CBS2 (Table 16). The maximum P'JB value at the end of the +CBS2 firing period was $14 \mu \mathrm{g} / \mathrm{dL}$.

In spite of the fact that crew members of the 4/4 FA unit fired a total of 984 highlead zone 9 charges, the mean rise in $\mathrm{PbB}$ concentration for the group from baseline to the IPE time point was only $1.0 \pm 0.5 \mu \mathrm{g} / \mathrm{dL}$ as a result of their lead exposures (Tables 18 and 19). At the DPE time point, eight weeks after the last firing day, the individual $\mathrm{PbB}$ values fell slightly below the levels measured at baseline, with a mean decrease from BL to DPE of $0.9 \pm 0.3 \mu \mathrm{g} / \mathrm{dL}($ Table $19, p<0.05)$.

2/18 FA Unit Firing with CBS. In contrast, crew members from the 2/18 FA unit fired two to three times more zone 9 charges from the howitzer with CBS than did those from the 4/4 FA unit, a total of 2379 charges (Table 17). During this time, mean values of $\mathrm{PbA}$ for the group ranged from a low of $1.0 \pm 0.2 \mu \mathrm{g} \mathrm{Pb} / \mathrm{m}^{3}$ for the $22-\mathrm{h}$ collection period starting on July 28 , to a high of $27.1 \pm 3.0 \mu \mathrm{g} / \mathrm{m}^{3}$ for the 25 -h collection period starting on August 10 (Table 17). These $\mathrm{PbA}$ values were substantially higher than those of the 4/4 FA unit crew members (see Table 16). For example, on four days, $\mathrm{PbA}$ means for the 2/18 FA unit exceeded all observed means for the 4/4 FA unit; they were 1 13 on July 27, 14.6 on August 5/6, 27.1 on August 10, and 15.6 on August 11 (Table 17). The first three values are significantly different from the highest observed mean value for the 4/4 FA unit according to the modified t-test for the equality of means with unequal variances $(p<0.01)$.

Correspondingly, values of $\mathrm{PbB}$ rose to a greater extent among the $2 / 1.8 \mathrm{FA}$ unit crew members than among the 4/4 FA unit. crew members (Table 17). The mean $\mathrm{PbB}$ value for the $2 / 18 \mathrm{FA}$ group rose from $4.9 \pm 0.3 \mu \mathrm{g} / \mathrm{dL}$ blood at baseline to $11.4 \pm 0.8 \mu \mathrm{g} / \mathrm{dL}$ blood at the IPE time point. The mean rise in $\mathrm{PbB}$ from $\mathrm{BL}$ to IPE, with each man as his own control, 


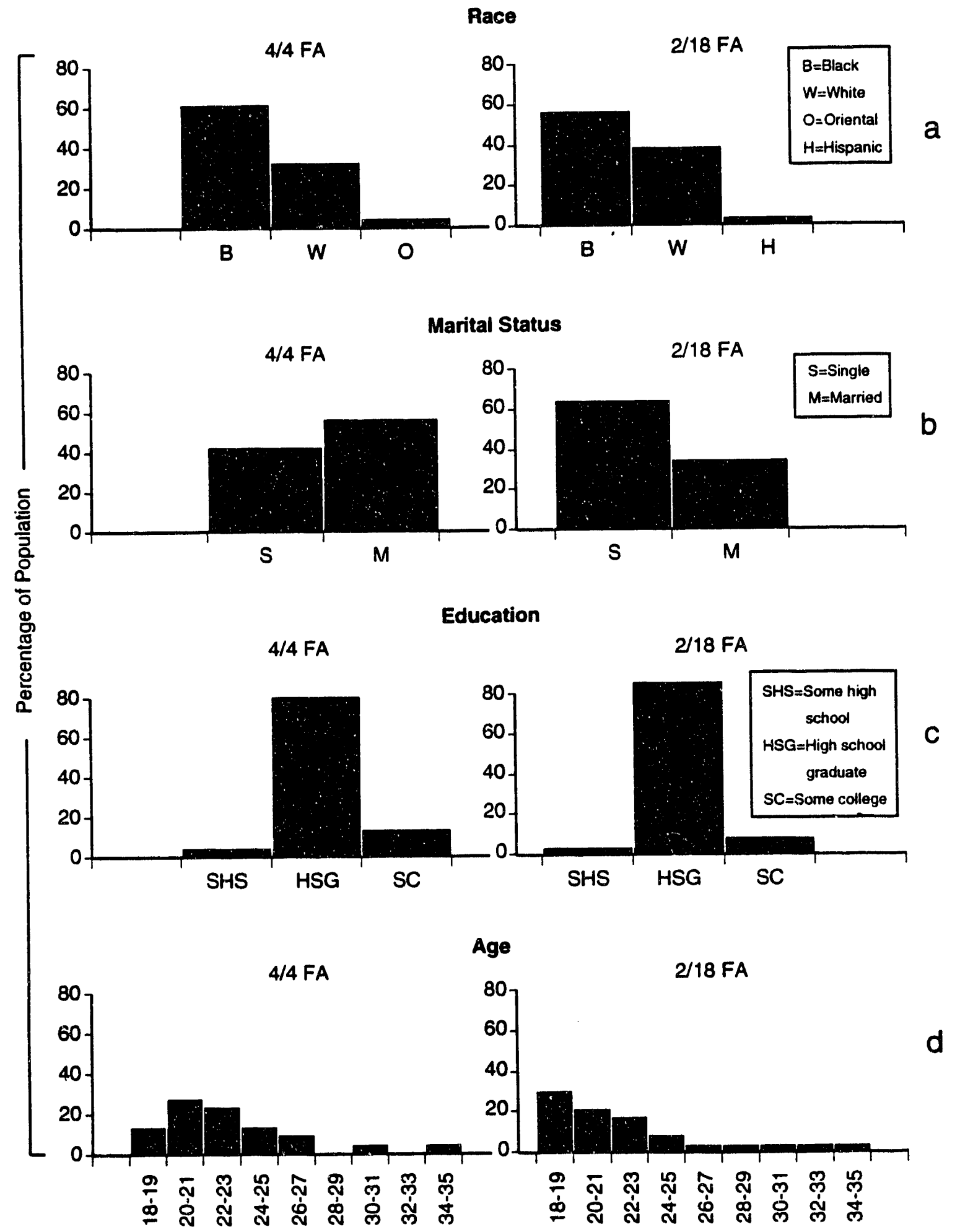

FIGURE 23 Characteristics of the study population (22 crew members of the 4/4 FA unit [group 1] and 23 crew members of the $2 / 18$ FA unit [group 2]) 


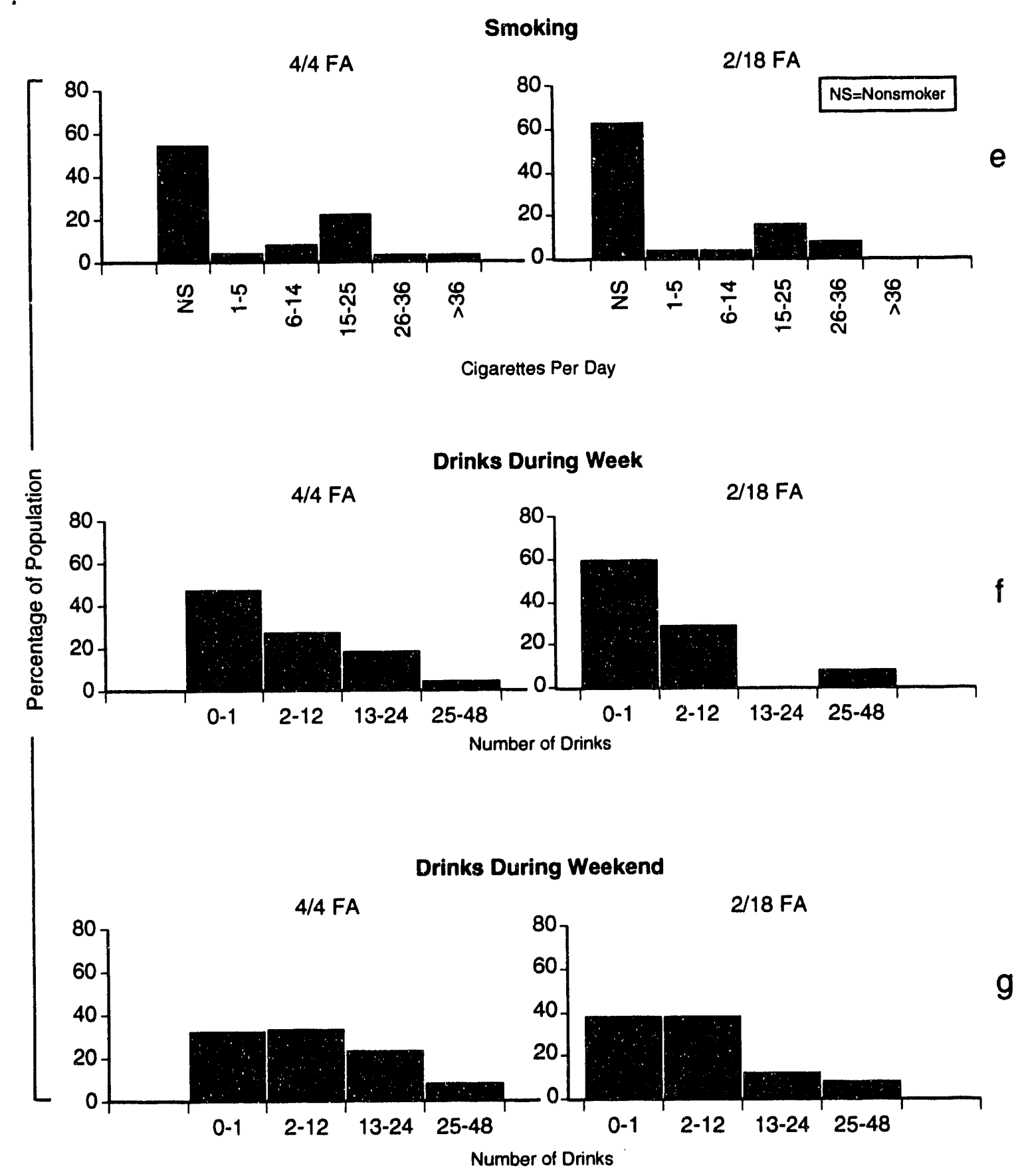

FIGURE 23 (Cont.) 


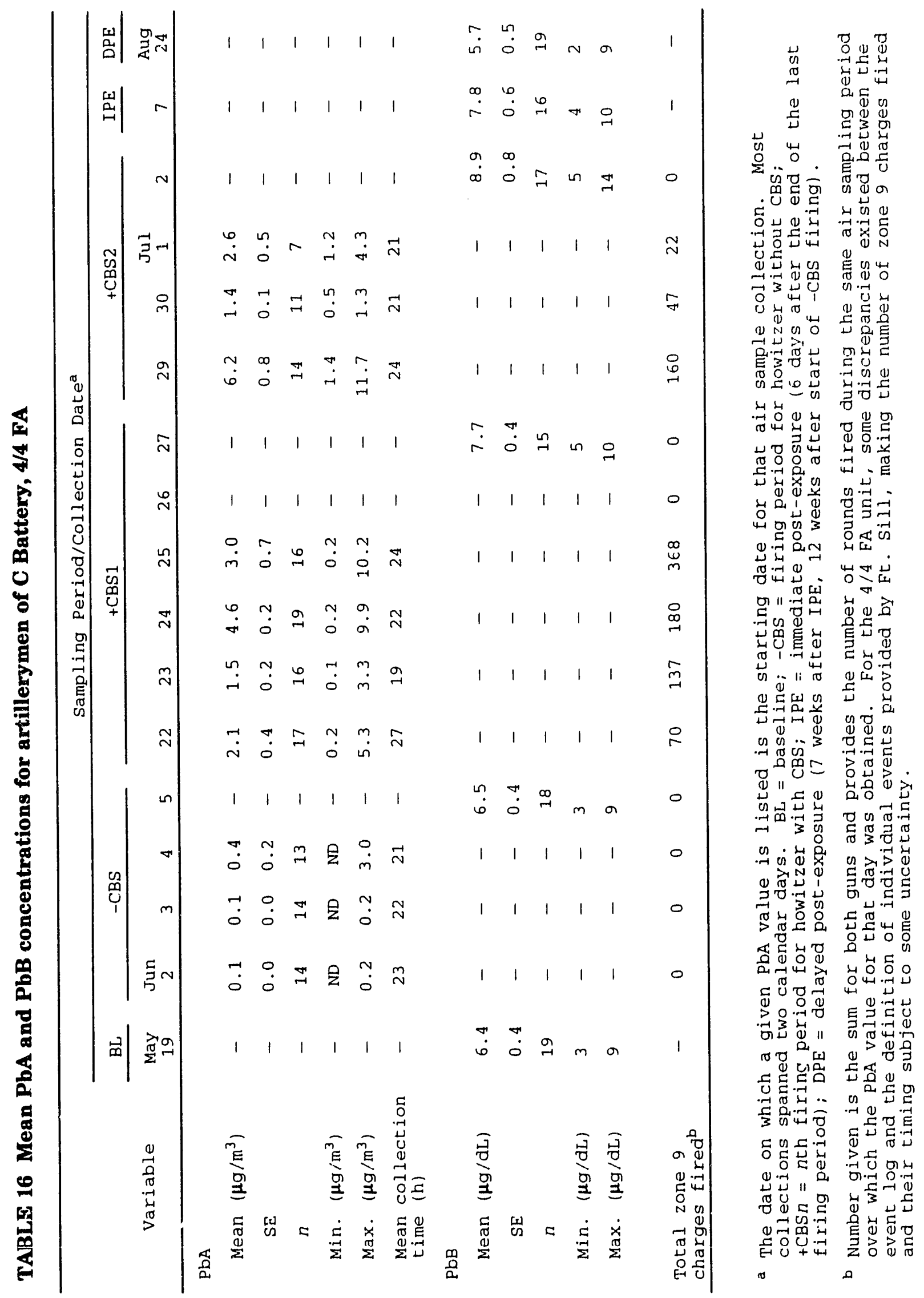




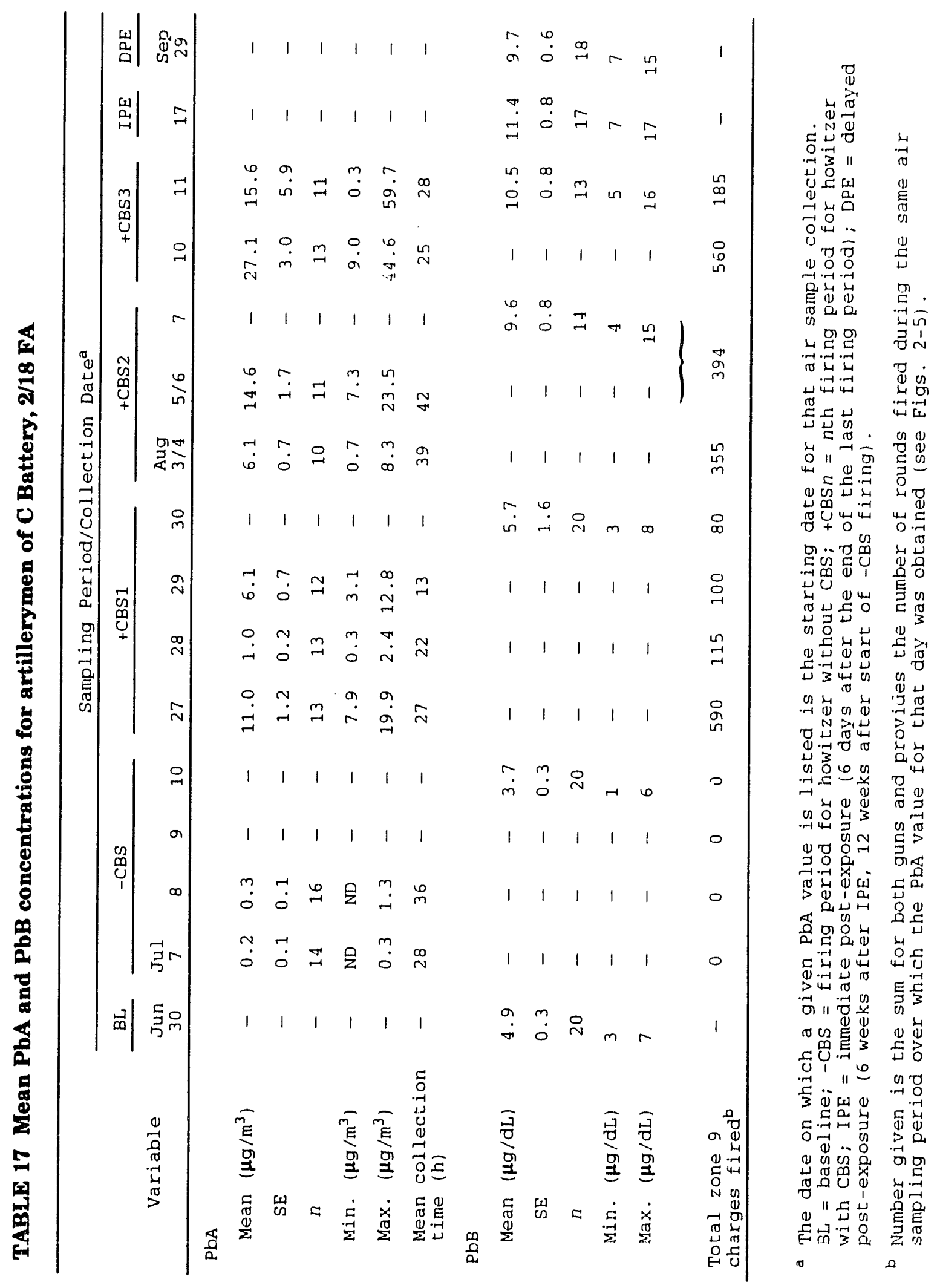


TABLE 18 Values of $\mathrm{PbB}$, hematocrit, and FEP before and after a series of firing exercises

\begin{tabular}{|c|c|c|c|c|c|c|c|c|c|}
\hline Variable & & $\mathrm{BL}^{\mathrm{a}}$ & & & $I P E^{a}$ & & $D P$ & $E^{a}$ & \\
\hline $\begin{array}{c}\mathrm{PbB}(\mu \mathrm{g} / \mathrm{dL}) \\
4 / 4 \mathrm{FA} \\
2 / 18 \mathrm{FA}\end{array}$ & $\begin{array}{l}6.4 \pm \\
4.9 \pm\end{array}$ & $\begin{array}{l} \pm 0.4 \\
\pm 0.3\end{array}$ & $\begin{array}{l}(19) \\
(20)\end{array}$ & $\begin{array}{r}7.8 \pm \\
11.4 \pm\end{array}$ & $\begin{array}{l} \pm 0.6 \\
\pm 0.8\end{array}$ & $\begin{array}{l}(16) \\
(17)\end{array}$ & $\begin{array}{l}5.7 \pm \\
9.7 \pm\end{array}$ & $\begin{array}{l}0.5 \\
0.6\end{array}$ & $\begin{array}{l}(19) \\
(18)\end{array}$ \\
\hline $\begin{array}{l}\text { Hematocrit (o) } \\
4 / 4 \mathrm{FA} \\
2 / 18 \mathrm{FA}\end{array}$ & $\begin{array}{l}43.7 \pm \\
46.0 \pm\end{array}$ & $\begin{array}{l} \pm 0.5 \\
\pm 0.6\end{array}$ & $\begin{array}{l}(19) \\
(22)\end{array}$ & $\begin{array}{l}44.0 \pm \\
44.9=\end{array}$ & $\begin{array}{l} \pm 0.6 \\
\pm 0.6\end{array}$ & $\begin{array}{l}(14) \\
(18)\end{array}$ & $\begin{array}{l}45.2 \pm \\
46.4 \pm\end{array}$ & $\begin{array}{l}0.6 \\
0.5\end{array}$ & $\begin{array}{l}(18) \\
(18)\end{array}$ \\
\hline $\begin{array}{c}\mathrm{FEP}(\mu \mathrm{g} / \mathrm{dL}) \\
4 / 4 \mathrm{FA} \\
2 / 18 \mathrm{FA}\end{array}$ & $\begin{array}{l}19.0 \\
18.9\end{array}$ & $\begin{array}{l} \pm 0.6 \\
\pm 1.3\end{array}$ & $\begin{array}{l}(18) \\
(21)\end{array}$ & $\begin{array}{l}18.2= \\
21.8=\end{array}$ & $\begin{array}{l} \pm 0.6 \\
\pm 1.1\end{array}$ & $\begin{array}{l}(16) \\
(18)\end{array}$ & $\begin{array}{l}20.0 \pm \\
16.2 \pm\end{array}$ & $\begin{array}{l}0.7 \\
0.8\end{array}$ & $\begin{array}{l}(18) \\
(18)\end{array}$ \\
\hline
\end{tabular}

a $B L=$ before first firing mission; IPE = within 1 week after last firing mission; $D P E=6$ weeks after last firing mission. Values are means $\pm \mathrm{SE}$, with the number of individuals in parentheses.

TABLE 19 Mean changes in values of $\mathrm{PbB}$, hematocrit, and FEP for three time intervals ${ }^{\mathrm{a}}$

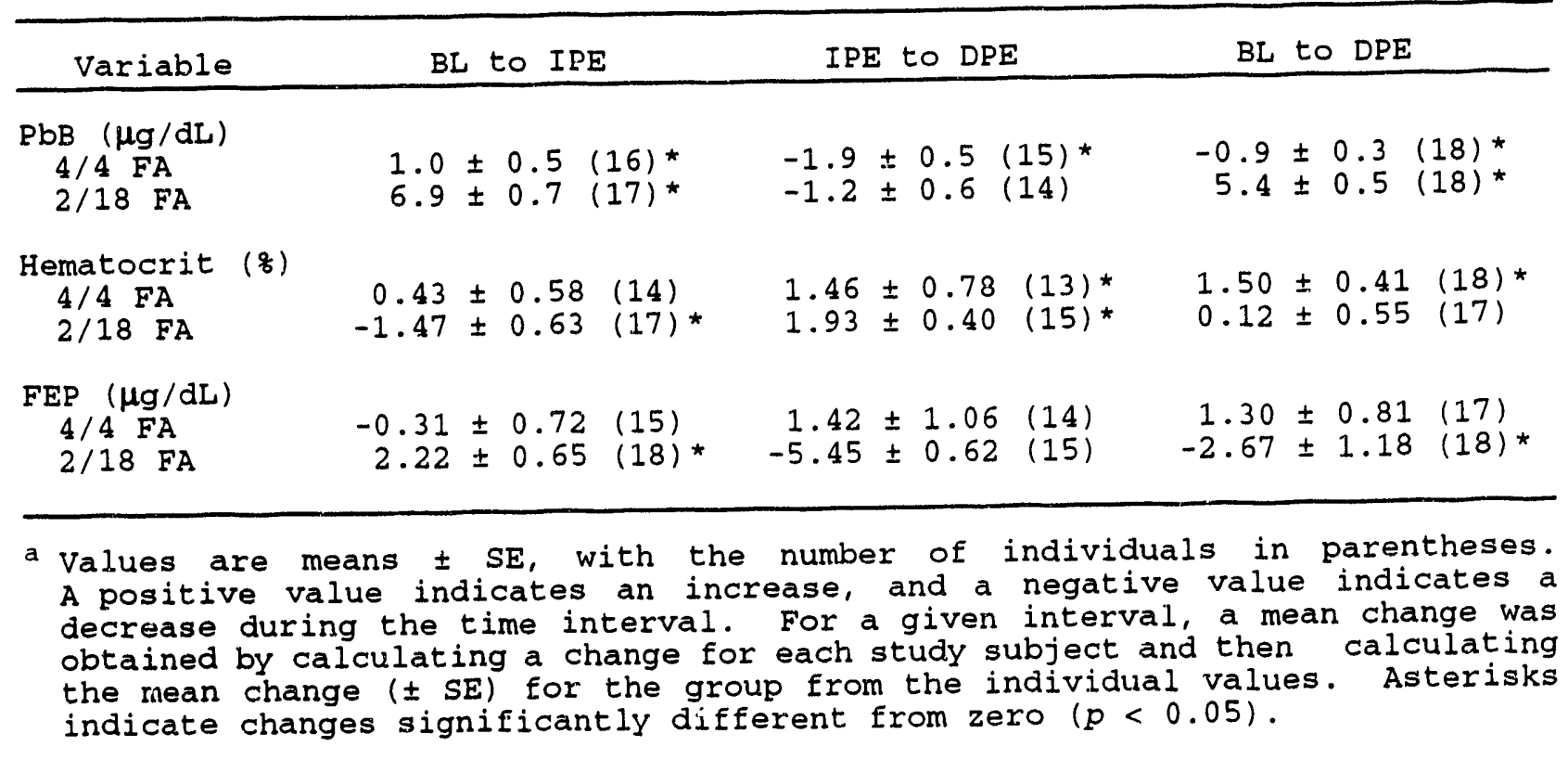


was $6.9 \pm 0.7 \mu \mathrm{g} / \mathrm{dL}$ blood (Table $19, p<0.05$ ), with a maximum $\mathrm{PbB}$ value of $17 \mu \mathrm{g} / \mathrm{dL}$ blood (Table 1.7); the corresponding rise for the $4 / 4 \mathrm{FA}$ was $1.0 \pm 0.5 \mu \mathrm{g} / \mathrm{dL}$ (mean $\pm \mathrm{SE}, n=16$ ) (Table 19, $p<0.05$ ).

The time course of the rise in $\mathrm{PbB}$ for the five most highly exposed crew members of the 2/18 FA unit is shown in Fig. 24. The data for these men are shown in more detail because their individual rises in $\mathrm{PbB}$ were high enough to provide meaningful time-course information. As indicated, the largest rise in $\mathrm{PbB}$ for these five men occurred during the +CBS2 firing period, consistent with the data for the whole group shown in Table 17. In addition, the rise in $\mathrm{PbB}$ for both these men (Fig. 24) and the whole group (Table 19) was sustained for at least seven weeks, in that no substantial decrease in mean $\mathrm{PbB}$ value occurred after the last firing period, from the IPE to the DPE time points (Table 19, $p>0.05$ ).

Figures 25-28 were devised to show the detailed firing schedules, air sampling protocols, wind conditions, and $\mathrm{PbA} / \mathrm{PbB}$ results during each 96 -h firing period for the 2/18 FA unit, among whose crew members a significant increase in $\mathrm{PbB}$ values occurred during firing. As shown in Fig. 25, firing was intermittent during the -CBS firing period from July 7-10, and no zone 9 charges were fired. Wind speeds were quite high, $\mathrm{PbA}$ concentrations were low, and there was no increase in mean $\mathrm{PbB}$ value from $\mathrm{BL}$ to the -CBS blood sampling in the field on July 10 (Table 17).

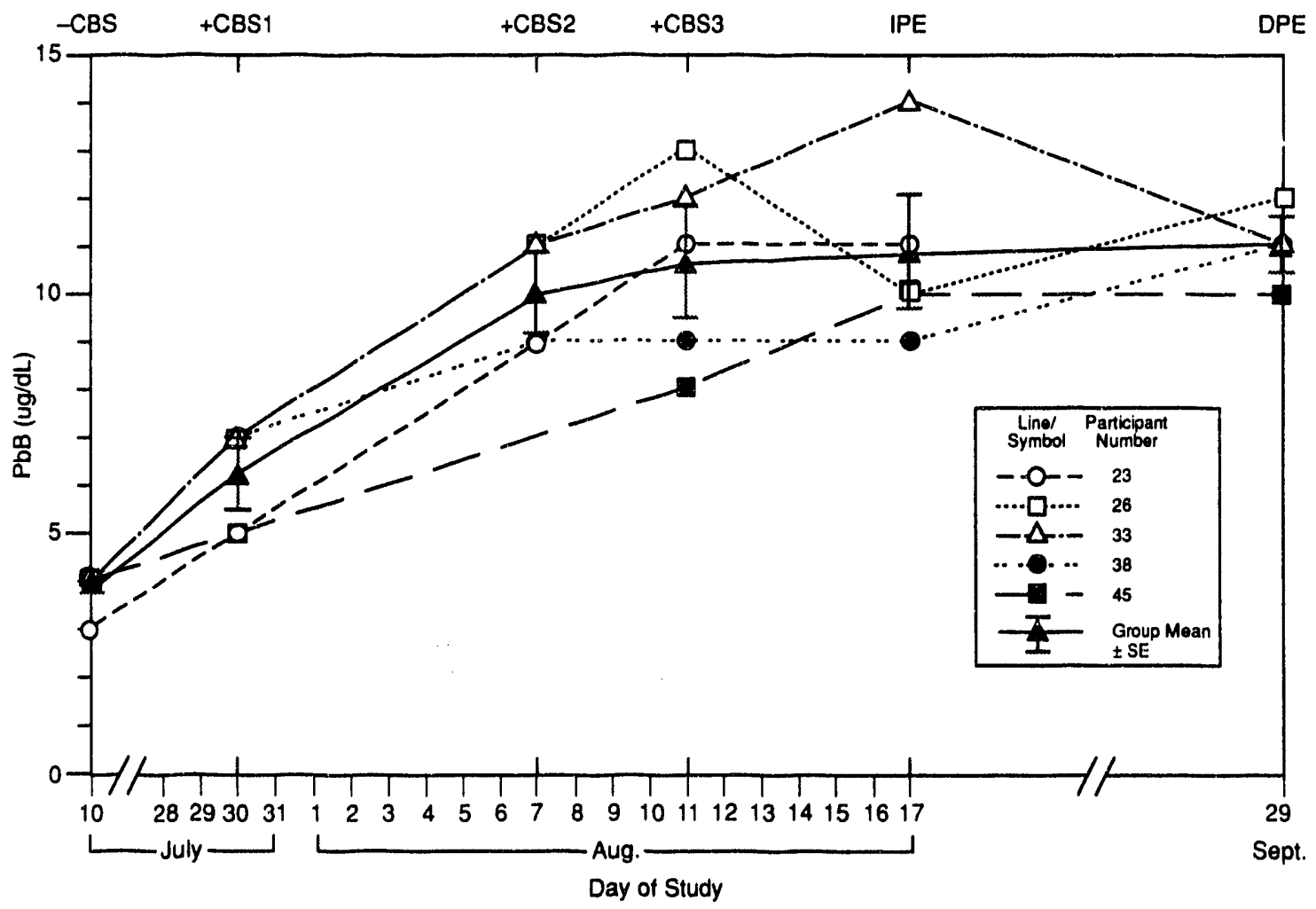

FIGURE 24 Time course of rise in blood lead concentration among five 2/18 FA crew members 


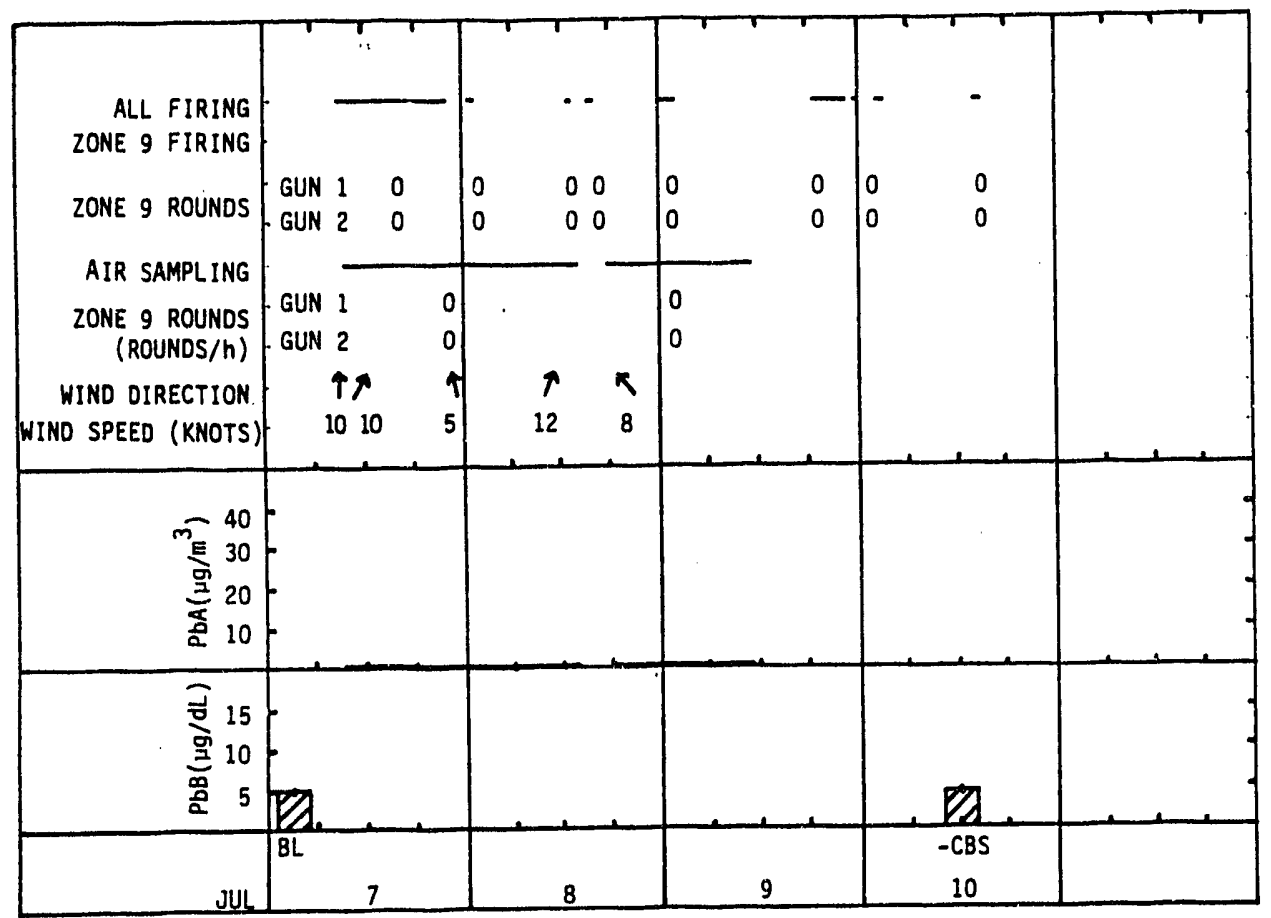

FIGURE 25 Firing course and lead values during the -CBS firing period for the 2/18 FA crew members. Each firing day is shown as a 24-h period from 0000 to 2400 hours. Lines opposite "All firing" show the time periods during which howitzers were fired fairly steadily. Lines opposite "Zone 9 Firing" show the number of zone 9 rounds fired (none during this period). Wind conditions are given as arrows placed at the time a measurement was made. North corresponds to a vertical arrow; wind speed is given below the arrow. The height of each $\mathrm{PbA}$ bar gives the mean time-weighted average value for the group; the width of the bar corresponds to the time period during which the air sample was collected. Values for $\mathrm{PbB}$ are given for the baseline (BL; before firing was started) and for the -CBS blood sample taken in the field on July 10, 1987.

During the + CBS1 firing period, firing was much more continuous than during the -CBS period, and most of the total rounds fired were zone 9 charges (Fig. 26). In addition, except for short periods of time, both guns were functioning. Wind speeds were lower than during the -CBS period, but most of the time the winds had only a small head-wind component. Lack of a steady head-wind component may account for the fairly low mean $\mathrm{PbA}$ value of $11 \pm 1.2 \mu \mathrm{g} / \mathrm{m}^{3}$ obtained for the 27 -h collection period starting on July 27 , during which each gun steadily fired 295 zone 9 charges, an average of 13 rounds per hour for $27 \mathrm{~h}$ (Fig. 26). During this +CBS1 firing period, mean $\mathrm{PbB}$ values rose from $3.7 \pm 0.3$ to $5.7 \pm$ $1.6 \mu \mathrm{g} / \mathrm{dL}$ (Table 17).

To evaluate reasons for changes in :'bA values from one day to another at Fort Sill or from one firing location to another (e.g., Fort Sill vs. APG), account was taken of differences in firing rate, wind conditions, and firing vs. air sampling periods. (Air sampled 


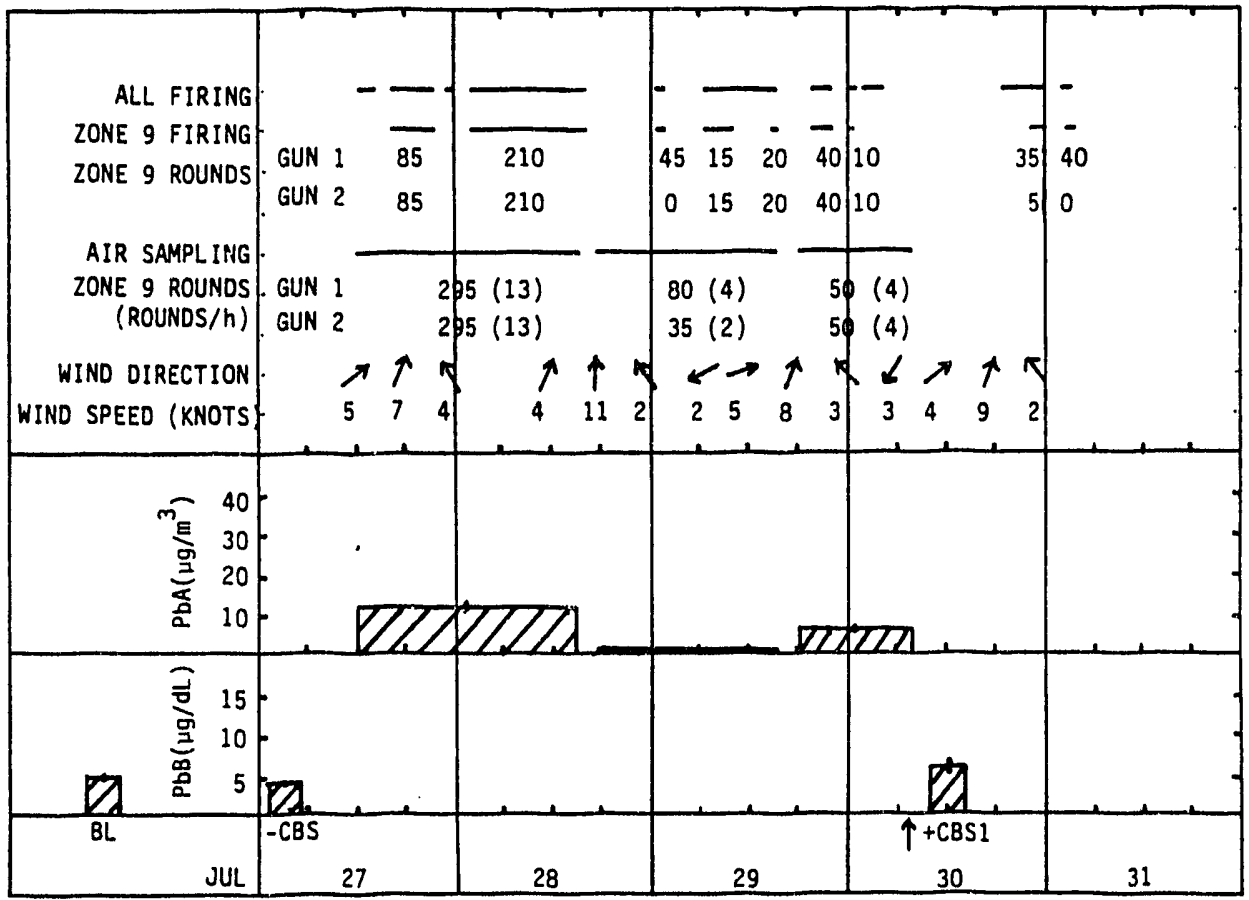

FIGURE 26 Firing course and lead values during the +CBS1 firing period for the 2/18 FA crew members. See Fig. 25 caption for explanation of the figure layout. The numbers of zone 9 rounds fired are given for each gun below the "Zone 9 Firing" lines. The number of zone 9 rounds fired and the rounds per hour value (in parentheses) are given for each gun below the air sampling lines. Zone 9 charges were always fired from west to east, so winds with an east wind component $(\leftarrow)$ provided a head wind. Values of $\mathrm{PbB}$ are given for the baseline ( $\mathrm{BL}$ ), -CBS (at the start of the +CBS1 firing period), and July 30, 1987 (at the end of the +CBS1 period). The arrow on July 30 shows the time of day at which the blood sample was taken in the field.

when the gun was inactive would result in a low TWA PbA for the entire sampling period). Values for PbA obtained at Fort Sill were recalculated to what they would have been if air were sampled only whén the howitzers were being fired, and attention was given to firing rate and weather conditions.

Both weather and firing rate conditions were such that high $\mathrm{PbA}$ values would be expected for the air sample collection period from August 10-11 (+CBS3, Fig. 28). During this 25-h collection period, each gun, with CBS, fired 265-295 zone 9 charges at an average rate for the entire period of 10-11 rounds per hour. In addition, wind speeds were generally low (1-5 knots), and wind directions had strong head-wind components throughout the firing period (Fig. 28). The mean 25-h TWA PbA value for the group was $27 \pm 3 \mu \mathrm{g} / \mathrm{m}^{3}$, with a maximum value of $45 \mu \mathrm{g} / \mathrm{m}^{3}$ (Table 17). Because active firing occurred during only approximately one-half of the air sample collection period (Fig. 28), each 25-h TWA PbA value 


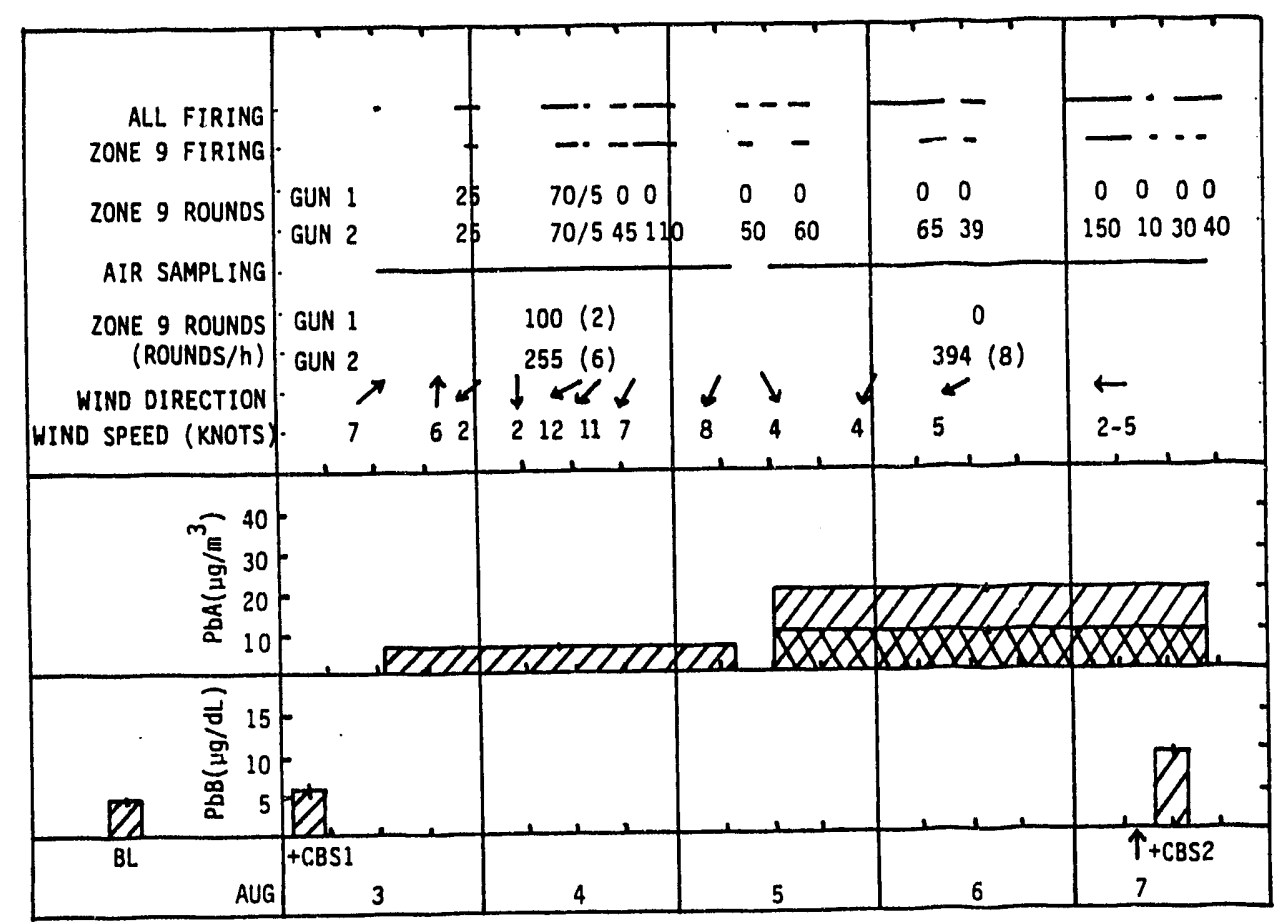

FIGURE 27 Firing course and lead values during the +CBS2 firing period for the $2 / 18$ FA crew members. Figure layout is explained in the captions to Figs. 25 and 26. For the air samples collected on August 5-7, two bars are given because the $\mathrm{PbA}$ values for the 11 crew members who provided samples fell into two separate ranges, with five crew members at about $20 \mu \mathrm{g} \mathrm{Pb} / \mathrm{m}^{3}$ and six at about $10 \mu \mathrm{g} \mathrm{Pb} / \mathrm{m}^{3}$.

would double if it were averaged only over the period of active firing. Consequently, a reasonable mean $\mathrm{PbA}$ value for this period of firing zone 9 charges from the 8 -in. howitzer at a rate of 20 rounds per hour (one round every $3 \mathrm{~min}$ ) for $12 \mathrm{~h}$ is $60 \mu \mathrm{g} / \mathrm{m}^{3}$. This value is approximately tenfold lower than the value of approximately $600 \mu \mathrm{g} / \mathrm{m}^{3}$ obtained with the same weapon at APG under similar conditions of firing, i.e., rapid fire with a light head wind (see Table 6). Our best explanation for the lower value of $\mathrm{PbA}$ at Fort Sill is that the elevation of the barrel during firing was very high at Fort Sill, while firing at APG was carried out in the loading position.

Judging from the high levels of lead on their filters compared to the low levels for the rest of the crew, we identified five crew members who spent the longest time manning the one howitzer that was actively firing during the air sample collection on August 11-12 (Fig. 28). For these five crew members, a 28 -h TWA PbA value of $31 \pm 9 \mu \mathrm{g} / \mathrm{m}^{3}$ (mean $\pm \mathrm{SE}$ ) was obtained; the crew member with the highest 28-h TWA PbA value had an exposure of $60 \mu \mathrm{g} / \mathrm{m}^{3}$ during that firing period (subject 45; see Appendix A). Because active firing occurred during only approximately 6 of the $28 \mathrm{~h}$ of air sampling (Fig. 28), the mean value of $\mathrm{PbA}$ averaged only over the period of active firing is $140 \mu \mathrm{g} / \mathrm{m}^{3}$ for the group of five crew members, about twofold over the corresponding value for the August 10-11 collection period 


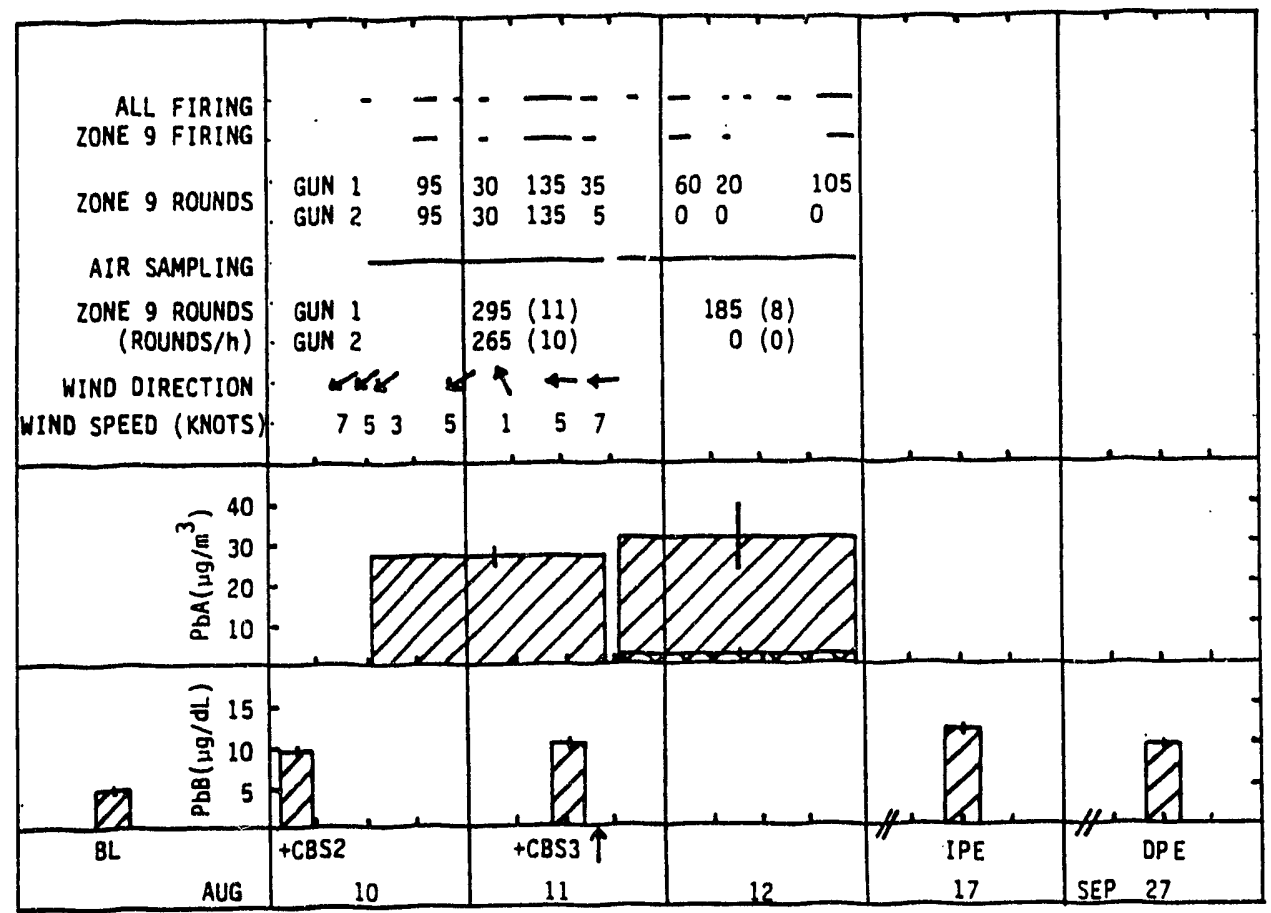

FIGURE 28 Firing course and lead values during the +CBS3 firing period for the 2/18 FA crew members. Figure layout is explained in the captions to Figs. 25 and 26. For the air samples collected on August 11-12, two bars are given because the $\mathrm{PbA}$ values for the 11 crew members who provided samples fell into two separate ranges, with five crew members at about $30 \mu \mathrm{g} \mathrm{Pb} / \mathrm{m}^{3}$ and six at about $3 \mu \mathrm{g} \mathrm{Pb} / \mathrm{m}^{3}$. $\mathrm{PbB}$ values are given for the baseline (BL), +CBS2 (before the +CBS3 firing), +CBS3 (taken in the field [arrow] on August 11,1987), IPE (six days after +CBS3), and DPE (six weeks after IPE) time points.

$\left(60 \mu \mathrm{g} / \mathrm{m}^{3}\right)$; the adjusted $\mathrm{PbA}$ value for the crew member with the highest exposure is $270 \mu \mathrm{g} / \mathrm{m}^{3}$. The rate of fire of zone 9 charges averaged over only the period of active firing was 36 rounds per hour (one round every $1.7 \mathrm{~min}$ ), also about twofold greater than the rate of fire on August 10-11. These results indicate that, under similar weather conditions, $\mathrm{PbA}$ values may be directly proportional to firing rate.

In Section 2 (Aerosol Studies), the muzzle blast aerosol was shown to be rich in lead. At Fort Sill, a personal sampler placed in a tree about $20 \mathrm{ft}$ downwind from the muzzle blast confirmed this finding, showing a $\mathrm{PbA}$ value of $59.2 \mu \mathrm{g} / \mathrm{m}^{3}$ during $7.8 \mathrm{~h}$ of sampling on August 10, 1987. 


\subsubsection{Relationship between Airborne Lead Exposures and Blood Lead Responses}

An analysis of the relationship between airborne lead exposure and blood lead levels was conducted. Two approaches yielded statistically significant relationships.

PbA vs. Rise in PbB. Figure 29 shows the relationship between the TWA PbA for each individual crew member on August 10, 1987, and each individual's rise in $\mathrm{PbB}$ from baseline to the end of the +CBS3 firing mission (blood sample taken on August 11, 1987). This relationship was analyzed because August 10 was the day of the highest lead exposure for the greatest number of men in the entire study. As can be seen from Fig. 29, a linear relationship between TWA $\mathrm{PbA}$ and rise in $\mathrm{PbB}$ from baseline was observed. The slope of the line was $0.10 \pm 0.04$ (mean $\pm \mathrm{SE}, p=0.027$ ), indicating that for each rise in TWA $\mathrm{PbA}$ of $10 \mu \mathrm{g} / \mathrm{m}^{3}$, there was a rise in blood lead of only $1 \mu \mathrm{g} / \mathrm{dL}$.

The intercept of our dose-response curve was $3.6 \pm 1.4 \mu \mathrm{g} / \mathrm{dL}$ (mean $\pm \mathrm{SE}, p=0.041$ ) rather than zero, probably indicating that a mean rise of about $3.6 \mu \mathrm{g} / \mathrm{dL}$ could be attributed to exposures prior to August 10,1987. The $\mathrm{R}^{2}$ value for the fit of the line to the clata points was $0.35(R=0.59)$.

Cumulative Air Lead Exposure vs. Rise in PbB. Our second approach was to analyze the relationship between a measure of cumulative air lead exposure for each individual crew member during all the firing missions and the change in $\mathrm{PbB}$, from baseline to the DPE blood sample taken six to seven weeks after the last firing mission. A linear relationship was obtained between cumulative lead exposure and change in blood lead levels from baseline to the DPE sampling time (Fig. 30). The slope of the linear regression line was $0.065 \pm 0.006$ (mean $\pm \mathrm{SE}, p=0.0001$ ), and the intercept was $-2.07 \pm 0.43$ (mean $\pm \mathrm{SE}$, $p=0.0001$ ). The value of $R^{2}$ was 0.85 . The negative value of the intercept is a reflection of the fact that some of the 4/4 FA unit crew members, whose exposures to lead were much less than those of the 2/18 FA unit crew members, had PbB values at DPE that were lower than their values at baseline.

A relationship analogous to that shown in Fig. 30 was also analyzed for the IPE blood samples, which were taken two days after the last firing mission. A relationship between cumulative air lead exposure and rise in PbB from baseline to IPE existed but showed more erratic data points than the relationship shown in Fig. 30. This may be because the IPE values of $\mathrm{PbB}$ were a function of both the cumulative air lead exposure and the high lead exposures seen during the last firing mission, whereas the DPE values of $\mathrm{PbB}$ used in Fig. 30 were more clearly a function of cumulative lead exposure.

As a measure of cumulative lead exposure, the abscissa of Fig. 30 gives numerical values expressed both as " $\mu \mathrm{g} \mathrm{Pb}$ " and " $\mathrm{gg} \mathrm{Pb} / \mathrm{m}^{3} \cdot \mathrm{min}$ ". The value for " $\mu \mathrm{g} \mathrm{Pb}$ " for each crew member was obtained by summing the amount of lead on all filters from the personal sampling pump worn by that crew member during all firing missions, as described in Methods (Section 3.1). 

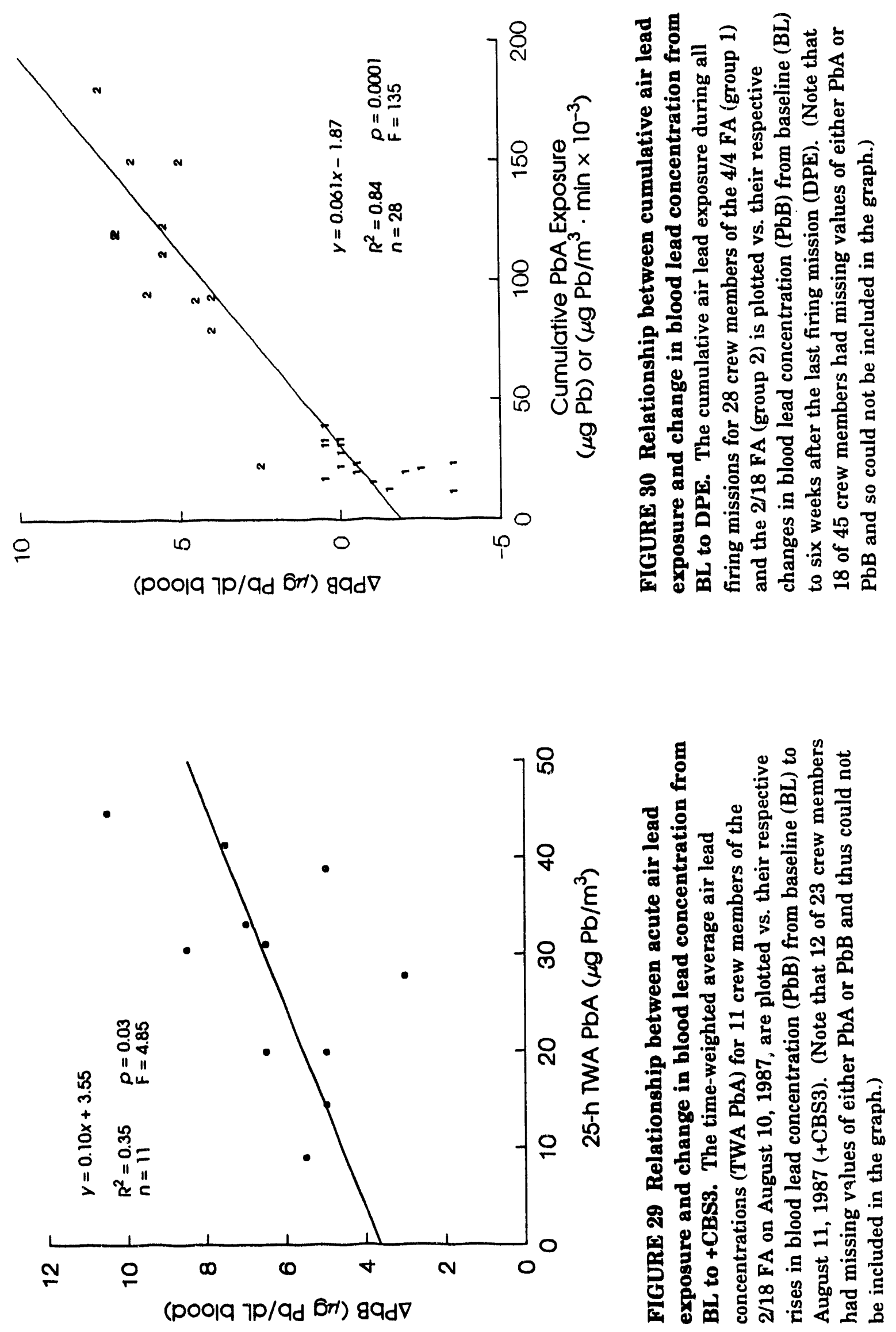
The value for " $\mu \mathrm{g} \mathrm{Pb} / \mathrm{m}^{3} \cdot \min "$ was obtained by using the following:

Definitions:

$\mathrm{A}_{1}=$ amount of $\mathrm{Pb}$ (in $\mu \mathrm{g}$ ) on filter for air sampling period \#1;

$T_{1}=$ time of sampling (min) for air sampling period \#1;

$2 \times 10^{-3}=$ air sampling rate $\left(\mathrm{m}^{3} / \mathrm{min}\right)$.

For sampling period \#1,

$$
\mu \mathrm{gb} / \mathrm{m}^{3} \cdot \min =\frac{2 A_{1}}{T_{1}\left(2 \times 10^{-3}\right)} \cdot T_{1}=A_{1} \times 10^{3}
$$

The multiplier 2 in the numerator is a multiplication factor to account for the air sampling protocol (one minute on, one minute off).

For the sum of all sampling periods (1 through $n$ ),

$$
\text { cumulative lead exposure }=\sum_{1}^{n} A_{n} \times 10^{3}
$$

which is the summation of the amounts of lead on all filters, calculated as described above. Cumulative lead exposure is given as $\mu \mathrm{g} / \mathrm{m}^{3} \cdot \mathrm{min}$ in order to allow a comparison of these values for the crew members with the value of $24,000 \mu \mathrm{g} / \mathrm{m}^{3} \cdot \mathrm{min}$, which is the cumulative air lead exposure of a person occupationally exposed to lead for one 8-h workday at the OSHA permissible exposure limit (PEL) of $50 \mu \mathrm{g} / \mathrm{m}^{3}$. (For an 8-h work day at $50 \mu \mathrm{g} / \mathrm{m}^{3}$, exposure is expressed as $\mu \mathrm{g} / \mathrm{m}^{3} \cdot \mathrm{min}=50 \mu \mathrm{g} / \mathrm{m}^{3} \times 8 \mathrm{~h} \times 60 \mathrm{~min} / \mathrm{h}=24,000 \mu \mathrm{g} \mathrm{Pb} / \mathrm{rn}^{3} \cdot \mathrm{min}$.)

\subsubsection{Hematocrit and Free Erythrocyte Porphyrin Concentrations}

Changes in Hematocrit. Table 18 presents the mean values of blood lead, hematocrit, and FEP for crew members of the 4/4 FA, whose lead exposures during their weapons firing exercises were comparatively low, and those of the $2 / 18 \mathrm{FA}$, whose lead exposures were considerably higher. The individual values for each crew member are presented in Appendix A.

For crew members of the 4/4 FA, the mean hematocrit value did not change from $\mathrm{BL}$ to IPE and increased slightly from IPE to DPE (Table 18). In contrast, for crew member 3 of the 2/18 FA, the mean hematocrit value decreased slightly from BL to IPE and then returned to $B L$ values at the DPE time point.

Table 19 presents the mean changes in blood lead, hematocrit, and FEP during the time intervals shown. To obtain these values, the change in blood lead, hema ${ }^{\prime}$ ocrit, or FEP 
for each crew member was calculated for each time interval. A mean change ( $\pm \mathrm{SE}$ ) for the group was then calculated from the changes for each individual crew member. The Student's t-test for paired observations was employed to determine if the mean change for the group was significantly different from zero $(p<0.05)$. This approach made use of each man as his own control, with the result that small but consistent changes might become significant that would not be significant if mean values for the group (Table 18) were compared.

As shown by the values marked with asterisks in Table 19, during the time interval from BL to IPE, during which time the men were exposed to lead from weapons fire, crew members of the 4/4 FA showed a small but significant rise in $\mathrm{PbB}$ and no significant change in hematocrit; those of the 2/18 FA showed a greater rise in $\mathrm{PbB}$ accompanied by a small decrease in hematocrit that was statistically significant. Because the $2 / 18$ FA crew members were exposed to lead to a greater extent than the 4/4 FA crew members were, the possibility exists that the small decrease in hematocrit from BL to IPE among the 2/18 FA crew members was a response to their lead exposure.

During the interval from IPE to DPE, during which time no significant lead exposures from weapons firing occurred compared with those during the BL to IPE interval, hematocrits for both groups showed small but significant increases. For the 4/4 FA group, this IPE to DPE increase resulted in a significant increase from BL to DPE, while for the 2/18 FA group, the IPE to DPE increase brought their hematocrits back to BL values, with no significant change in hematocrit from BL to DPE.

Changes in FEP. Concentrations of FEP in the blood of crew members of the 4/4 FA did not change significantly during the course of the study (Table 18). However, for crew members of the 2/18 FA, FEP concentrations increased by $15 \%$ from BL to IPE, and this small increase was statistically significant (Table 19). During the IPE to DPE time interval, FEP concentrations in the $2 / 18 \mathrm{FA}$ crew members decreased to a mean that was $14 \%$ below the $\mathrm{BL}$ value. The possibility exists that the small increase in FEP from BL to IPE, corresponding to the small decrease in hematocrit that occurred during this interval, occurred as a result of the higher lead exposures among the $2 / 18 \mathrm{FA}$ crew members. In a study of dietary lead exposure that we conducted in rabbits, FEP concentrations were significantly increased by one week after the start of lead exposure (Bh85). The intervals from BL to IPE and IPE to DPE in the Fort Sill study reported here were each about six weeks.

\subsection{Relationships between Air Lead Exposures and Changes in Hematocrit and FEP Concentrations}

Biolcgical Parameters of Lead Exposure. We first determined Pearson correlation coefficients and $p$ values for the relationships of hematocrit and FEP changes to a number of different biological parameters of lead exposure: change in PbB from BL to IPE, change in $\mathrm{PbB}$ from $\mathrm{BL}$ to $\mathrm{DPE}$, maximum value of $\mathrm{PbB}$ during the study, and maximum rise in $\mathrm{PbB}$ (from $\mathrm{BL}$ ) during the study. We found that the greatest number of significant 
relationships to lead exposure occurred with use of the change in $\mathrm{PbB}$ from $\mathrm{BL}$ to $\mathrm{DPE}$ as the biological measure of lead exposure. We have found that this parameter also shows the strongest correlation to air lead exposure ( $p$ value of 0.03 and a correlation coefficient of 0.60 for $\triangle \mathrm{PbB}$ from $\mathrm{BL}$ to $\mathrm{DPE}$ vs. TWA PbA on August 10, 1987 [Fig. 29]; a $p$ value of 0.0001 and a correlation coefficient of 0.92 for $\triangle \mathrm{PbB}$ from $\mathrm{BL}$ to $\mathrm{DPE}$ vs. total cumulative $\mathrm{PbA}$ exposure during the study [Fig. 30]). Consequently, we present here an analysis of hematocrit and FEP changes as they relate to changes in $\mathrm{PbB}$ from $\mathrm{BL}$ to DPE.

Hematocrit vs. Lead Exposure. Table 20 presents the $p$ values and correlation coefficients for the relationships of change in hematocrit during the indicated time intervals to change in $\mathrm{PbB}$ from $\mathrm{BL}$ to $\mathrm{DPE}$. Considering the combined groups, which gives the greatest spread in lead exposures, it can be seen that both the decrease in hematocrit during the BL to IPE time interval and the following increase in hematocrit from IPE to DPE have $p$ values that indicate a relationship to lead exposure, with the BL to IPE decrease ( $p=$ 0.009) (Fig. 31) showing a much stronger relationship to lead exposure than the IPE to DPE increase $(p=0.08)$ (Fig. 32). The regression equations for the relationships are shown in the figures. The intercept of the equation in Fig. 31 is not different from zero $(0.12 \pm 0.51$, mean $\pm \mathrm{SE}, p=0.82)$, and the slope is $-0.33 \pm 0.12(p=0.009)$. This means that for each rise in $\mathrm{PbB}$ of $1 \mu \mathrm{g} / \mathrm{dL}$, one could expect a decrease in hematocrit of $0.33 \%$. It should be noted that the low value of $R^{2}(0.23)$ for this relationship (Fig. 31) indicates that lead exposure explained only $23 \%$ of the variability in the change in hematocrit values.

TABLE 20 Statistical analysis of relationships between lead exposure and change in hematocrit and FEP during three time intervals ${ }^{\mathrm{a}}$

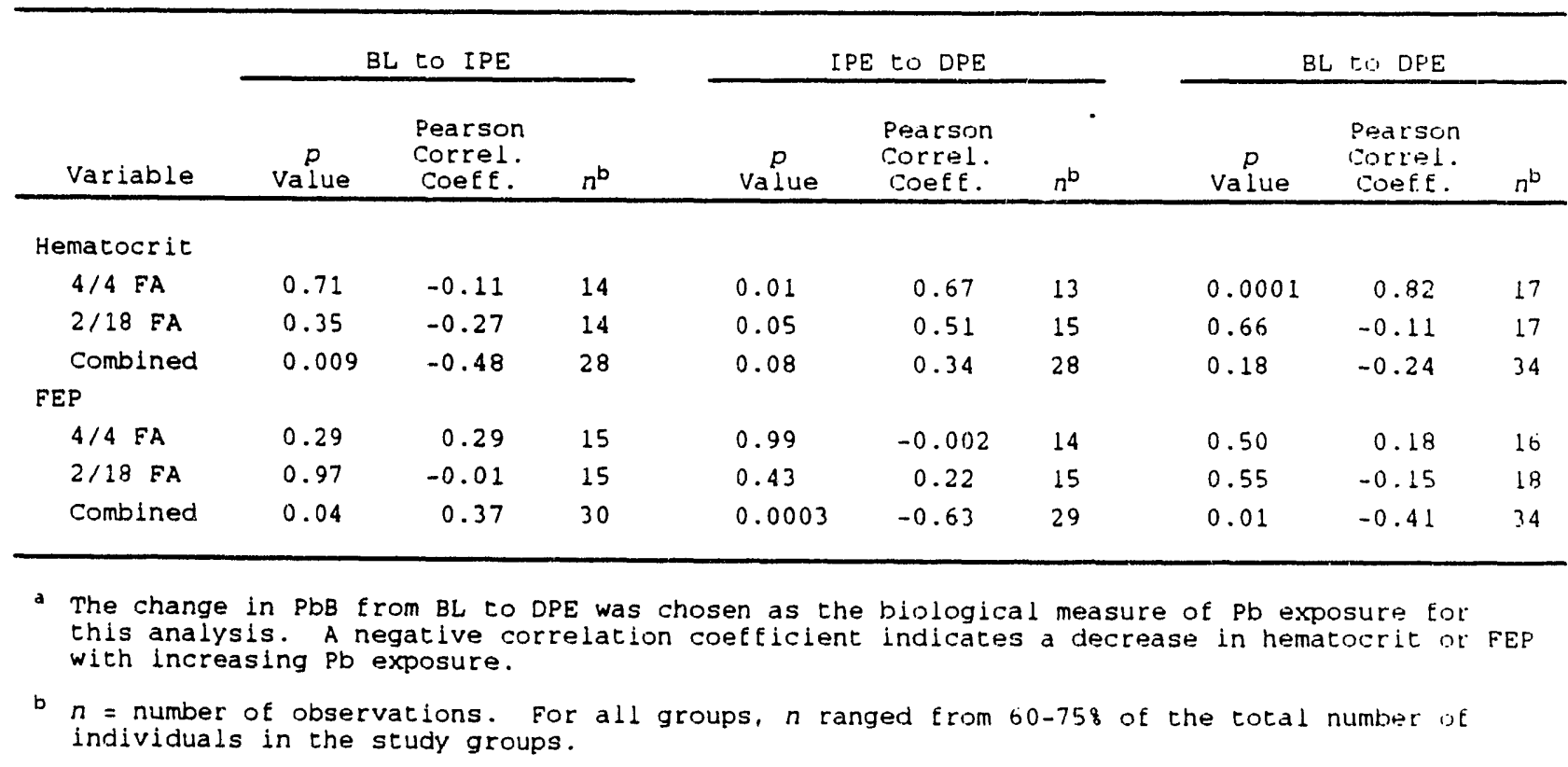



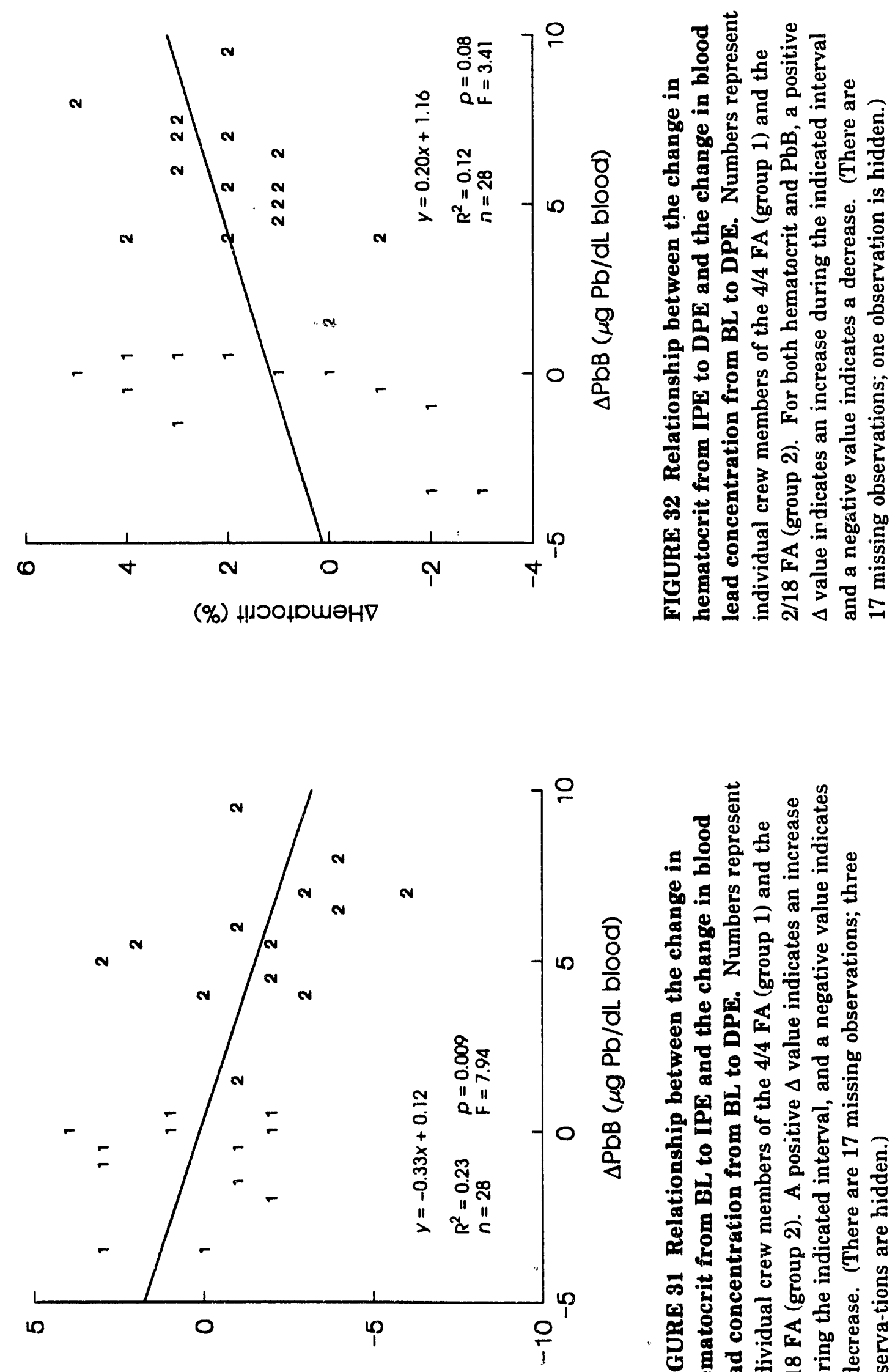

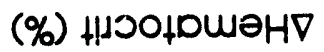

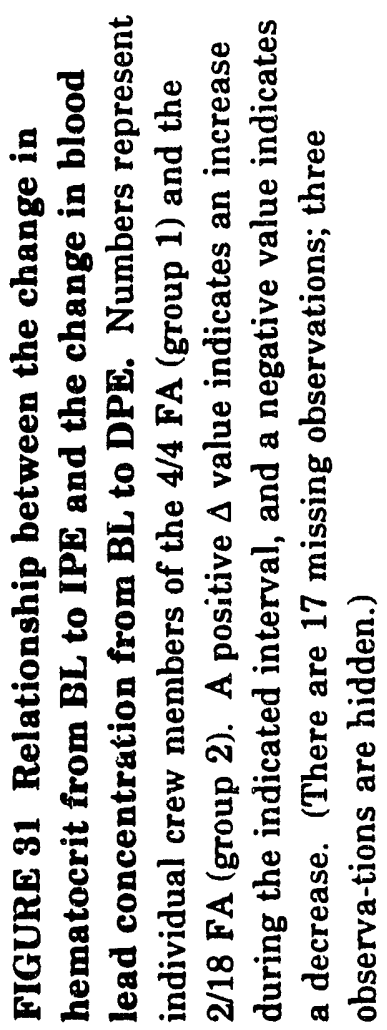


FEP vs. Lead Exposure. As indicated in Table 20, when results of the two groups were analyzed together, changes in FEP during all time intervals showed a relationship to lead exposure with a $p$ value less than 0.05 . These relationships, with their regression equations, are shown in Figs. 33 and 34. As indicated in Fig. 33, the rise in FEP during the BL to IPE time interval was related to the change in $\mathrm{PbB}$ from BL to DPE by an equation with an intercept not different from zero $(-0.02 \pm 0.59, p=0.97)$ and a slope of $0.29 \pm 0.13$ $(p=0.04)$, so that for each rise in $\mathrm{PbB}$ concentration of $1 \mu \mathrm{g} / \mathrm{dL}$ blood, one could expect a rise in FEP of $0.29 \mu \mathrm{g} / \mathrm{dL}$ blood. Again, the low value of $\mathrm{R}^{2}(0.14)$ indicates that lead exposure explains only $14 \%$ of the variability in the $\triangle F E P$ values.

From the relationships shown in Figs. 32 and 34, it appears that both the rise in hematocrit and the fall in FEP during the IPE to DPE time interval (when the men were no longer firing high-lead rounds to the extent that they were during the BL to IPE time interval) occurred to a greater extent in the men with the highest lead exposures.

Overview of Lead Relationships. The mean change in $\mathrm{PbB}$ from $\mathrm{BL}$ to $\mathrm{DPE}$ for the $4 / 4 \mathrm{FA}$ crew members was $-0.9 \pm 0.3 \mu \mathrm{g} / \mathrm{dL}$ (mean $\pm \mathrm{SE}, n=18$ ) (Table 19), indicating that their lead exposures were low enough during the firing exercises (BL to IPE time interval) that, on the average, the $\mathrm{PbB}$ of the men decreased from $\mathrm{BL}$ to $\mathrm{DPE}$ by approximately $1 \mathrm{\mu g} / \mathrm{dL}$.

The mean change in $\mathrm{PbB}$ from $\mathrm{BL}$ to $\mathrm{DPE}$ for the 2/18 FA crew members was $5.4 \pm$ $0.5 \mu \mathrm{g} / \mathrm{dL}$ (mean $\pm \mathrm{SE}, n=18$ ) (Table 19), indicating that their lead exposures were substantially greater than those of the $4 / 4$ FA crew members, high enough to produce an average increase in $\mathrm{PbB}$ from $\mathrm{BL}$ of approximately $5 \mu \mathrm{g} / \mathrm{dL}$ at the DPE time point, six weeks after the end of the firing exercises.

Because of this large difference in lead exposures between the two groups, any parameter that was significantly different between the two groups would most likely come out with a significant relationship to lead exposure when the data for the two groups were considered together, even if some difference between the groups other than lead exposure were the cause of the change in the parameter. The fact remains, however, that when the data from both groups are considered together, hematocrit decreased slightly and FEP increased slightly in the crew members who were more highly exposed to lead, and the reverse occurred when lead exposure was stopped. The direction of the changes are as would be expected for a response to lead exposure. We were able to detect these small changes with statistical significance because of the unusual nature of our study design in which each man was his own control. 

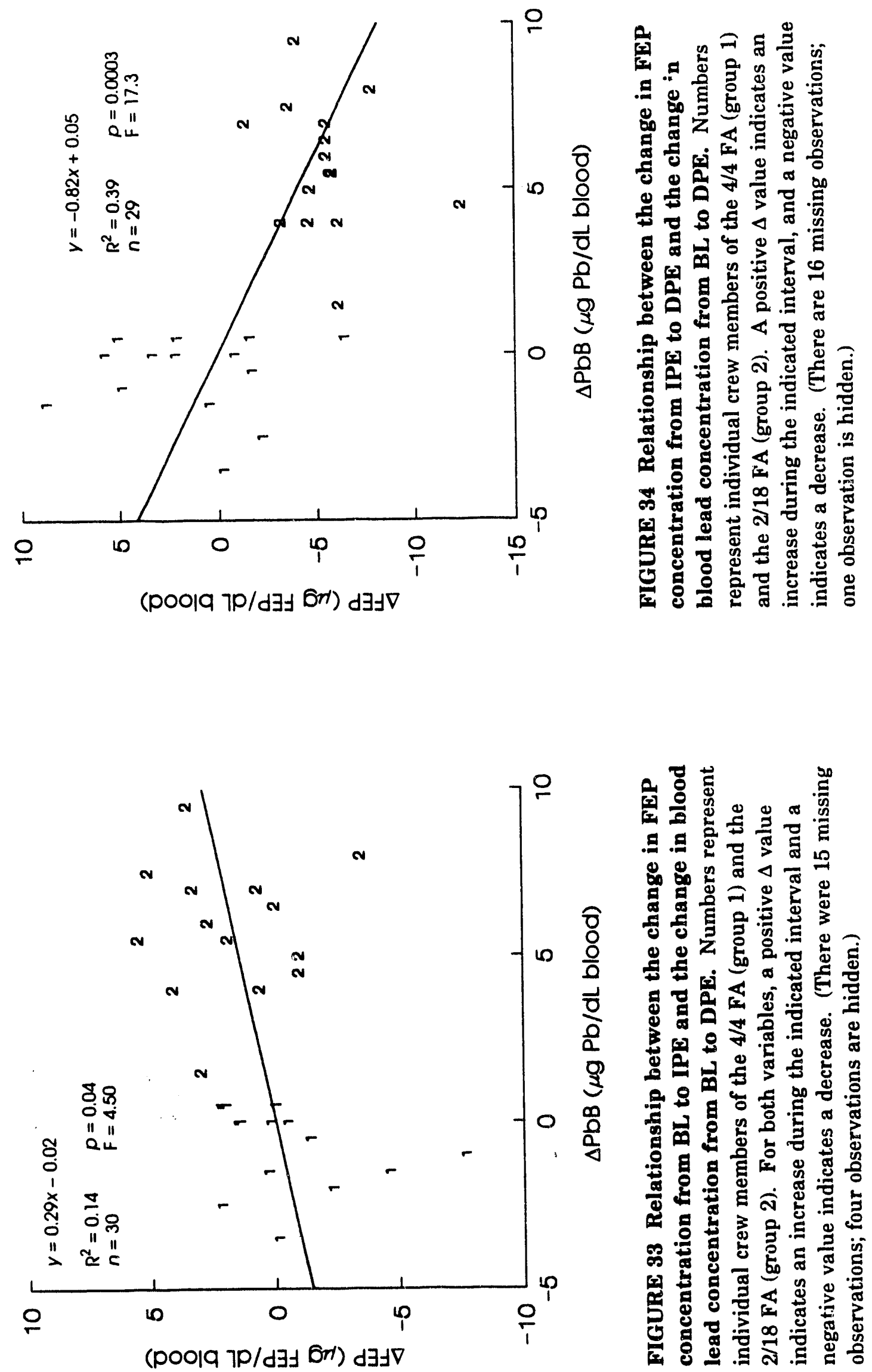


\subsubsection{Nerve Conduction Velocities}

Changes in Nerve Conduction Velocity without Temperature Adjustment. Because the adjustments in NCV values for differences in skin temperature significantly affected the results, and because the appropriateness of the temperature correction procedure could not be well evaluated, the results of our study are presented both with and without adjustment of the NCV values for skin temperature.

The mean NCV values for each group, unadjusted for skin temperature, are presented in Table 21 for each of the six nerves that we measured. (The individual NCV values for each crew member in the $\mathrm{C}$ Batteries of the 4/4 FA and 2/18 FA and their skin temperatures are presented in Appendix B.) The uncertainties in the mean NCV values were very small (SE values of $1.4 \mathrm{~m} / \mathrm{s}$ or less, $2 \%$ of the mean), indicating that small differences in NCVs, if they occurred, could be measured. The results expressed as mean NCV values indicate that changes from baseline to the IPE or DPE points were very small.

Because each crew member was measured at each time point, the differences in NCV from BL to IPE, IPE to DPE, and BL to DPE could be calculated for each individual. The mean differences for each time interval and group are presented in Table 22 . These differences were used to determine if a significant change in nerve conduction velocity occurred for the three time intervals shown in Table 21. The starred values in Table 22 show differences that approach ( $p<0.1$, one asterisk) or are statistically significant ( $p<0.05$, two asterisks) by Student's t-test for paired observations.

4/4 FA. For crew members from the 4/4 FA, whose cumulative lead exposures were substantially lower than for the $2 / 18 \mathrm{FA}$, no nerve showed a significant increase in NCV during the BL to IPE interval; only one nerve, the ulnar sensory nerve, showed a decrease that approached significance $(2.1 \%[1.40 \mathrm{~m} / \mathrm{s}]$ mean decrease, $p<0.1$; Table 22$)$. These results indicate that the firing exercises caused little change in the NCV values during the course of the exercises themselves.

At the DPE time point, three nerves showed small decreases from baseline values that were borderline in significance $(p<0.1): 2.03,1.34$, and $1.76 \mathrm{~m} / \mathrm{s}$ decreases for the ulnar motor (3.1\%), ulnar sensory (2.0\%), and sural sensory (4.0\%) nerves, respectively (Table 22 ). The mean decreases for these nerves were very small.

2/18 FA. For crew members of the 2/18 FA during the BL to IPE interval, one nerve showed a statistically significant increase $(3.50 \mathrm{~m} / \mathrm{s}[8.9 \%]$ for the sural sensory nerve; $p<0.05)$, and one nerve showed an increase with borderline significance $(1.32 \mathrm{~m} / \mathrm{s}[2.2 \%]$ for the median motor nerve; $p<0.1$; Table 22). Two factors may have influenced the BL to IPE differences for the 2/18 FA. First is that the mean skin temperatures were lower at the time of the baseline measurements than at IPE: $31.0^{\circ} \mathrm{C}$ vs. $32.6^{\circ} \mathrm{C}$ at $\mathrm{BL}$ vs. IPE for the feet and 
TABLE 21 Mean NCV before and after a series of firing exercises ${ }^{a}(\mathrm{~m} / \mathrm{s})$

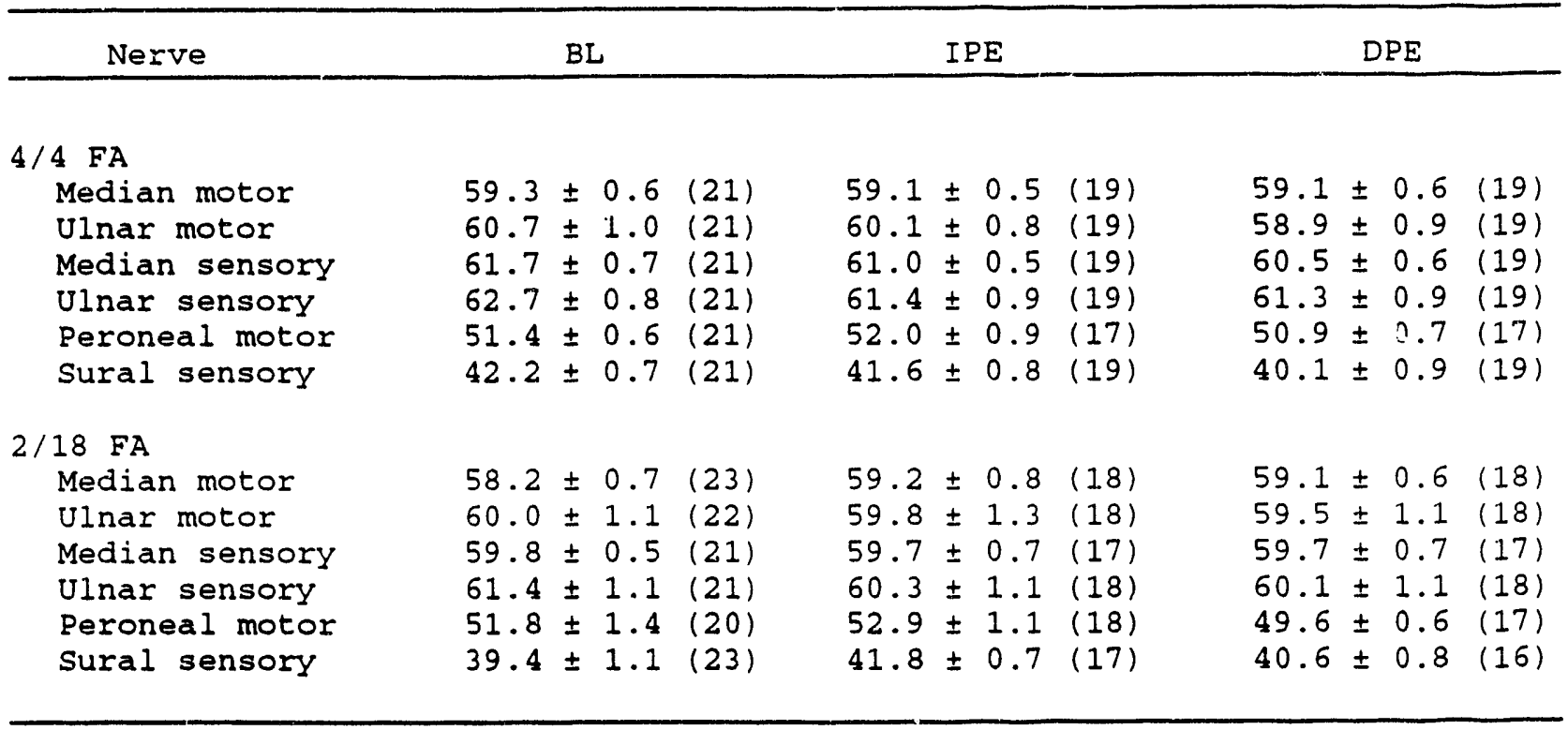

a Baseline = before first firing mission; IPE = within 1 week after last firing mission; $D P E=6$ weeks after last firing mission. Values are means $\pm S E$, with the number of individuals in parentheses. Values have not been adjusted for skin temperature. Measurements were all made by D.P.P., except those at BL for the $2 / 18$ FA, which were made by B.D.G.

TABLE 22 Mean differences in NCV before and after a series of firing exercises ${ }^{a}(\mathrm{~m} / \mathrm{s})$

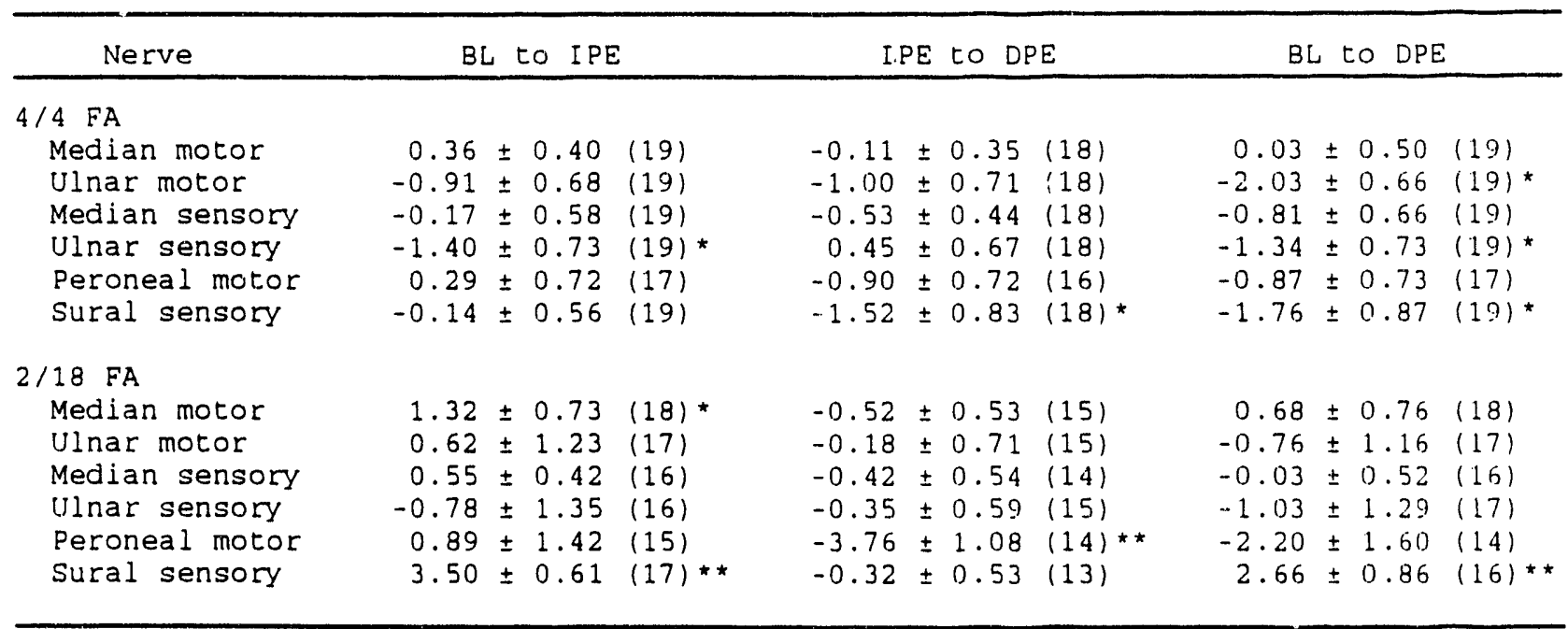

a Values are means $\pm S E$, with the number of individuals in parentheses. A negative value indicates a decrease in NCV during the time interval. Asterisks indicate values that are significantly different from zero according to the paired $t \cdot t e s t(*=p \cdot 0.1$; ** $=p<0.051$. Values are for data not adjusted for skin temperature. 
$31.9^{\circ} \mathrm{C}$ vs. $33.6^{\circ} \mathrm{C}$ at $\mathrm{BL}$ vs. IPE for the hands. Although some authors report no effects of temperature on NCVs for temperatures above $31.0^{\circ} \mathrm{C}$, others report substantial increases in NCV with increasing temperature for skin temperatures below $34{ }^{\circ} \mathrm{C}$ (e.g., a $5 \%$ [2-3 m/s] increase per degree Celsius). A second factor is that different operators made the measurements at $\mathrm{BL}$ and IPE for the 2/18 FA crew members. Our current evaluation indicates that, although the increases from BL to IPE may have been due in part to a change of operator, the effects of the lower skin temperatures at BL, especially in the case of the sural sensory nerve which is just below the surface of the calf to ankle skin, probably played a bigger role. Consequently, effects of skin temperature on NCV values are further evaluated later in this section. Except for the peroneal motor nerve, all mean baseline values for the 2/18 FA crew members were lower than those of the 4/4 FA crew members (Table 21).

During the six-week period from IPE to DPE, only the peroneal nerve showed a statistically significant change in NCV. The NCV of the peroneal nerve showed a decrease during this time interval that was greater than any other decrease observed in the study $(3.76 \mathrm{~m} / \mathrm{s}, 7.1 \%$; Table 22$)$. Because the decrease occurred in the $2 / 18 \mathrm{FA}$ crew members and not the 4/4 FA, the possibility needs to be investigated that the decrease was a result of the greater lead exposure of the 2/18 FA crew members.

Relationship of NCV Changes to Lead Exposure. The question was asked whether there was any correlation between the changes in blood lead concentration from $\mathrm{BL}$ to DPE measured for a given crew member and his change in NCV during the time intervals $\mathrm{BL}$ to IPE, IPE to DPE, or BL to DPE. In this analysis, change in PbB from BL to DPE was used as the measure of biological exposure to lead during the firing exercises.

In Table 23 are presented the $p$ values and Pearson correlation coefficients from the analysis of potential relationships between lead exposure and change in NCV $(\triangle N C V)$. For the individual analyses of the 4/4 FA and 2/18 FA units, only one nerve showed a significant relationship of $\triangle N C V$ to lead exposure: the ulnar sensory nerve in measurements of the 2/18 FA unit during the IPE to DPE interval, for which $p<0.03$ and the correlation coefficient was 0.56 (Table 23). However, the probability is high that this relationship appeared by chance alone, because calculations show that each time we test for a relationship to lead six independent times at a level of $\alpha=0.05$, the probability is $26.5 \%$ that one result will come up significant by chance alone.

Results of the analysis for the combined groups show a significant positive correlation between lead exposure and $\triangle N C V$ for the sural sensory nerve during both the BL to IPF, and BL to DPE time intervals. These relationships to lead exposure may stem from the low NCV values for the sural sensory nerve at baseline due to low skin temperatures for the more highly exposed 2/18 FA crew members. The peroneal nerve for the combined groups was the only nerve for which a decrease in NCV with increased lead exposure (indicated by a negative correlation coefficient) approached statistical significance $(p=0.08$, IPE to DPE time 


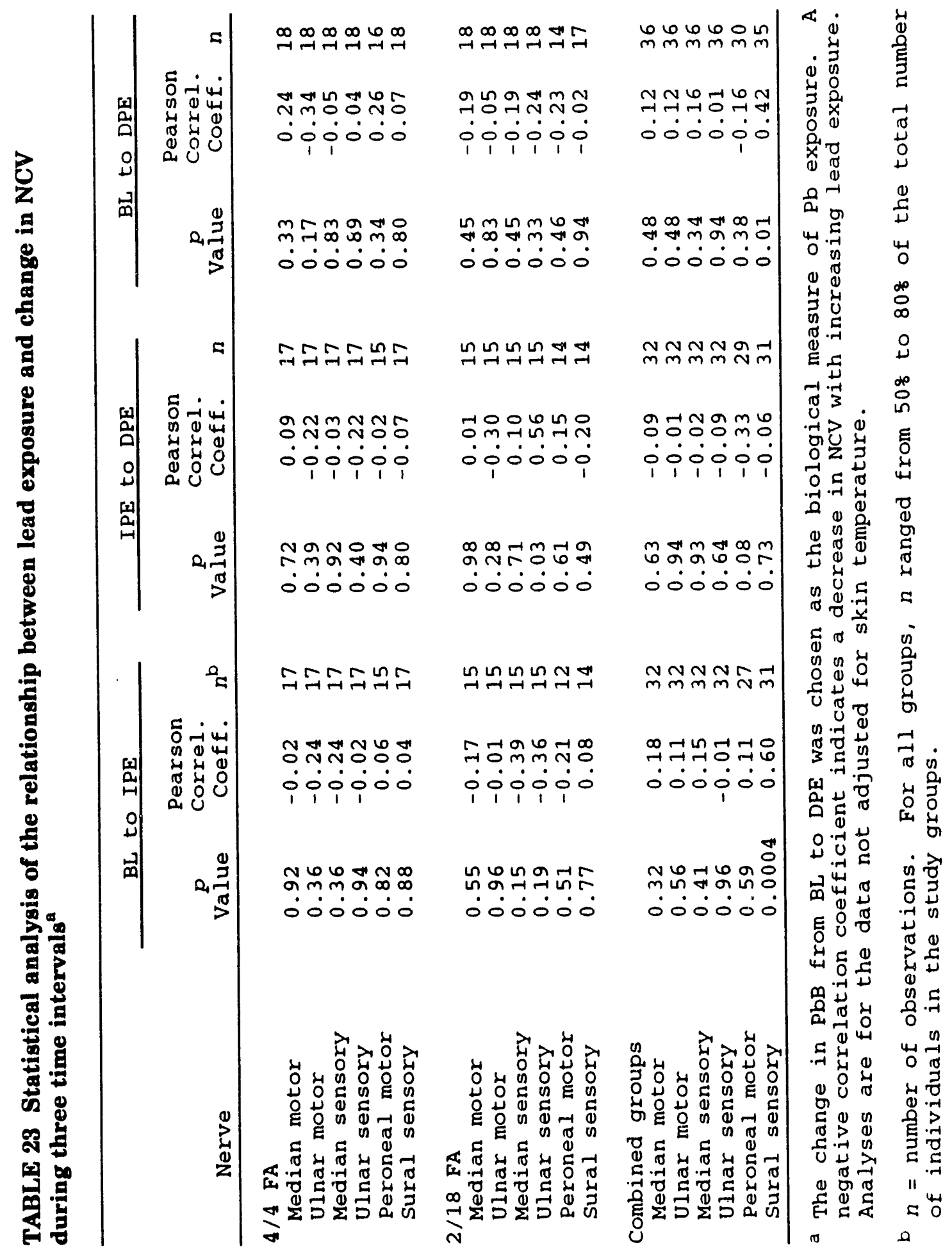


interval). This relationship is plotted in Fig. 35, where it can be seen that 12 of $14 \mathrm{crew}$ members from the 2/18 FA (group 2) showed a decrease in NCV for the peroneal nerve from IPE to DPE (indicated by a negative $\triangle \mathrm{NCV}$ ), while only 9 of 14 in group 1 (4/4 FA) showed a decrease. In addition, most of the individual decreases for the $4 / 4 \mathrm{FA}$ unit were smaller than those seen in the 2/18 FA unit.

Changes in Nerve Conduction Velocity with Temperature Adjustment. The mean NCV values for each group, adjusted to $34^{\circ} \mathrm{C}$ for arm nerves and $33{ }^{\circ} \mathrm{C}$ for leg nerves according to the method of de Jesus et al. (De73), are presented in Table 24 for each of the six nerves measured. (Individual skin temperatures are presented in Appendix B.) The latter adjustment temperatures were chosen as the lowest temperatures at which the test NCV values of de Jesus et al. appeared to become independent of skin temperature. Because most skin temperatures were below the adjustment temperatures, the mean values of all nerves rose after adjustment (Table 24 vs. Table 21), especially at baseline for the 2/18 FA crew members, who had lower skin temperatures at BL than at other NCV measurement times. Another characteristic of the temperature-adjusted data set is the somewhat lower values of $n$ for the 2/18 FA at baseline, when a number of skin temperatures were not obtained because of a discharged battery on the temperature probe.

4/4 FA. The small, borderline-significant decrease in the NCV value of the ulnar sensory nerve from BL to IPE in the 4/4 FA crew members shown in Table 22 persisted after temperature adjustment (Table 25). However, in the temperature-adjusted data set, the decrease from BL to IPE was countered by a similar increase from IPE to DPE, such that no net change occurred from BL to DPE for the ulnar sensory nerve. The small decrease in the sural sensory nerve from IPE to DPE that was observed in the Table 22 data set also persisted after temperature correction and achieved $p<0.05$ in significance level. These NCV changes, 1.3 to $1.4 \mathrm{~m} / \mathrm{s}$, however, are very small and may have appeared by chance alone.

2/18 FA. For crew members of the 2/18 FA, the NCV increases in the median motor and sural sensory nerves that appeared during the BL to IPE (MM and SS) and BL to DPE (SS) periods in the absence of temperature adjustment (Table 22) were no longer present after temperature adjustment (Table 25). In addition, all nerves except the SS nerve showed decreases in NCV values during both the BL to IPE and the IPE to DPE time periods, resulting in statistically significant decreases in three of these five nerves during the entire period from BL to DPE (Table 25). These decreases, 2.4 to $6.6 \mathrm{~m} / \mathrm{s}$, are larger than any that appeared in the 4/4 FA crew members; however, the decreases appeared only after adjustment of the NCV values for skin temperature, making the validity of the temperature correction an important issue.

Relationship of NCV Changes to Lead Exposure. When the temperatureadjusted data from 2/18 FA crew members were analyzed alone, five nerves showed statistically significant increases in NCV with increasing lead exposure: UM, MS, US, PM, 


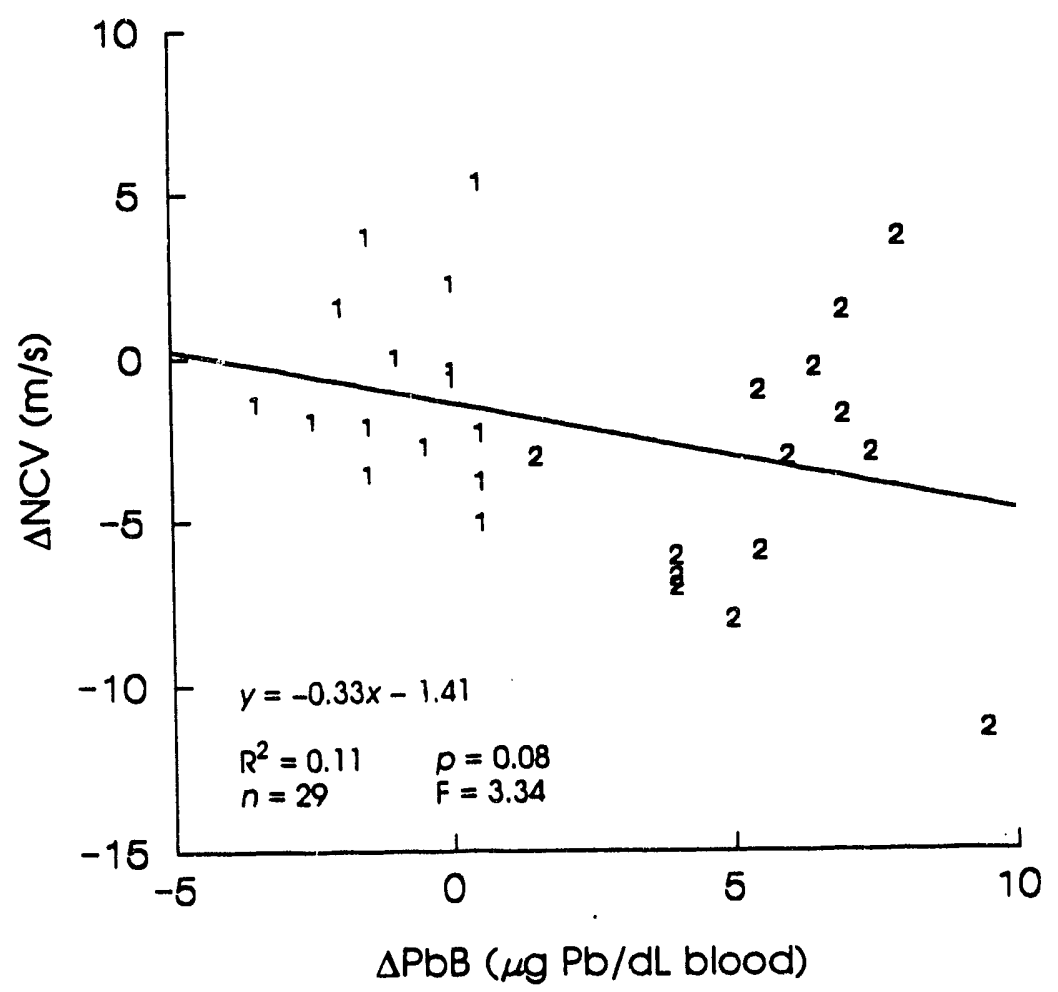

FIGURE 35 Change in peroneal nerve conduction velocity from IPE to DPE vs. the change in blood lead concentration from BL to DPE. Numbers represent crew members of the 4/4 FA (group 1) or the 2/18 FA (group 2). (There are 16 missing observations; one observation is hidden.)

and SS, $p=0.03-0.07, \mathrm{R}=0.54-0.77$ (Table 26). These relationships did not persist when values for both the $4 / 4$ and the $2 / 18 \mathrm{FA}$ units were considered together (combined groups), except in the case of the sural sensory nerve. In fact, except for the increase in the sural sensory NCV with lead exposure, no significant relationship to lead exposure was identified for the combined groups. However, all four arm nerves showed similar negative correlation coefficients (approximately -0.2 ), with $p$ values of about 0.3 , perhaps indicating a trend that might have become significant if lead exposures had been higher (Table 26).

Summary. In spite of fairly high lead exposures among crew members of the $2 / 18$ FA unit, blood lead concentrations among the crew members did not rise above $17 \mu \mathrm{g} / \mathrm{dL}$, a concentration lower than those that might be expected to result in decreases in NCV values. Here we have demonstrated that our measurement technique is very reproducible and would allow us to measure even small lead-dependent NCV changes were they to occur. We have also learned that the effect of temperature adjustment on an NCV data set is potentially large, and in our future measurements, we plan to bring each crew member to the same skin temperature each time we repeat a measurement on him, such that no temperature adjustment will be necessary. 
TABLE 24 Mean NCV before and after a series of firing exercises temperature-adjusted data $\operatorname{set}^{\mathrm{a}}(\mathrm{m} / \mathrm{s})$

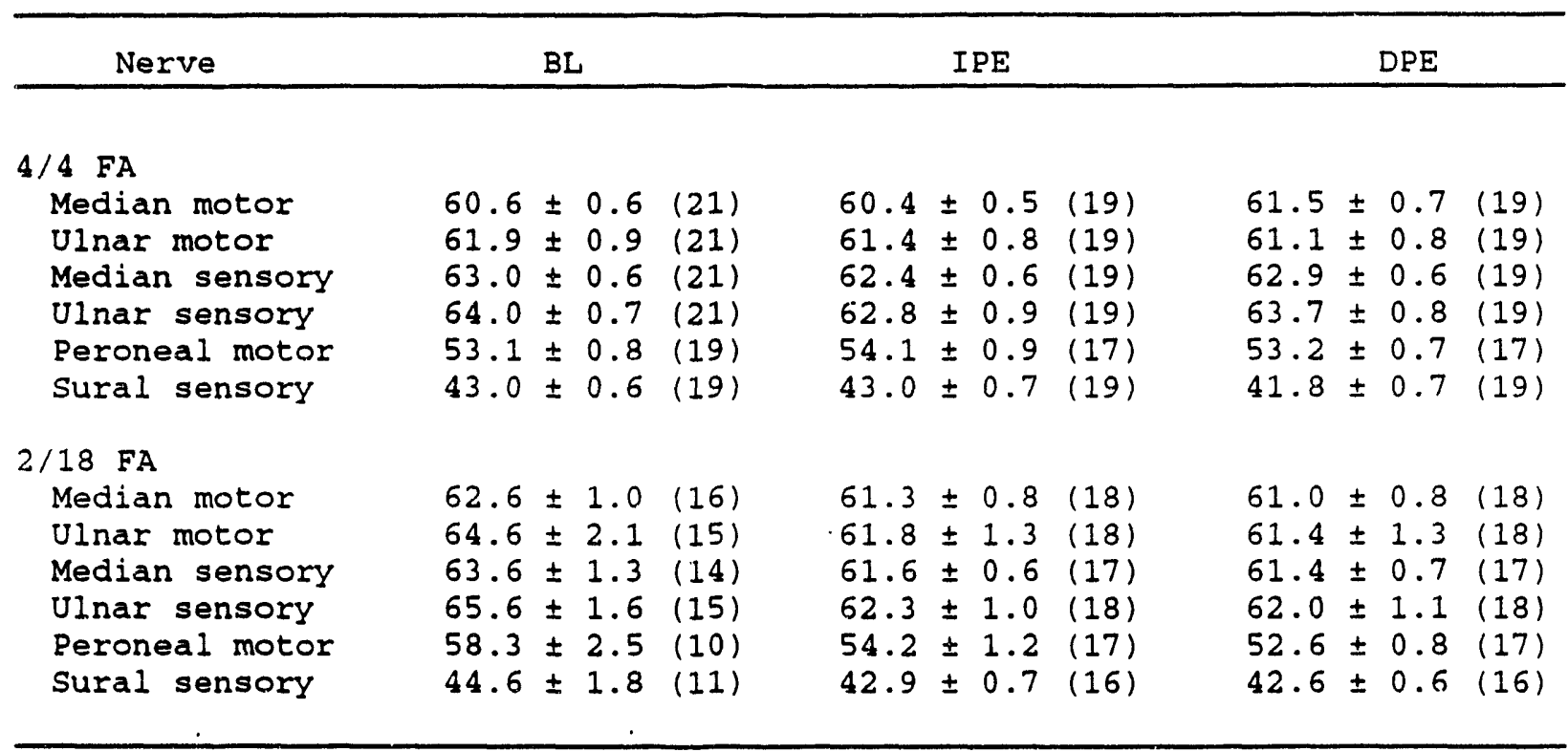

a NCV values have been adjusted to $34^{\circ} \mathrm{C}$ for arm nerves (MM, UM, MS, US) and to $33^{\circ} \mathrm{C}$ for leg nerves (PM, SS) according to the method of de Jesus et al. (as described in section 3.1).

TABLE 25 Mean differences in NCV before and after a series of firing exercises temperature-adjusted data $\operatorname{set}^{\mathrm{a}}(\mathrm{m} / \mathrm{s})$

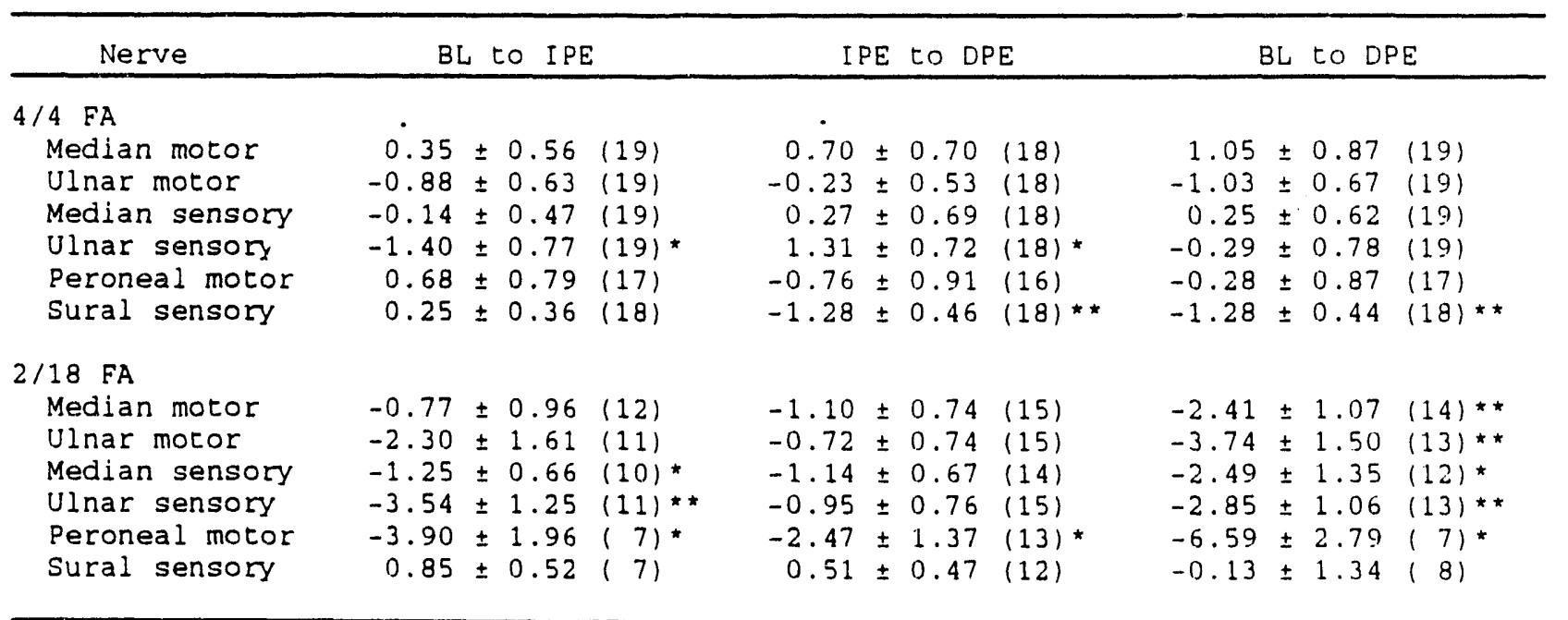

a Values are means $\pm S E$, with the number of individuals in parentheses. A negative value indicates a decrease in NCV during the time interval. Asterisks indicate values that are different from zero at a borderline (*) or significant (**) level according to the paired $t$-test $(*=p<0.1 ; * *=p<0.05)$. All NCV values were adjusted for temperature as described in section 3.1 before $\triangle \mathrm{NCV}$ values were calculated. 


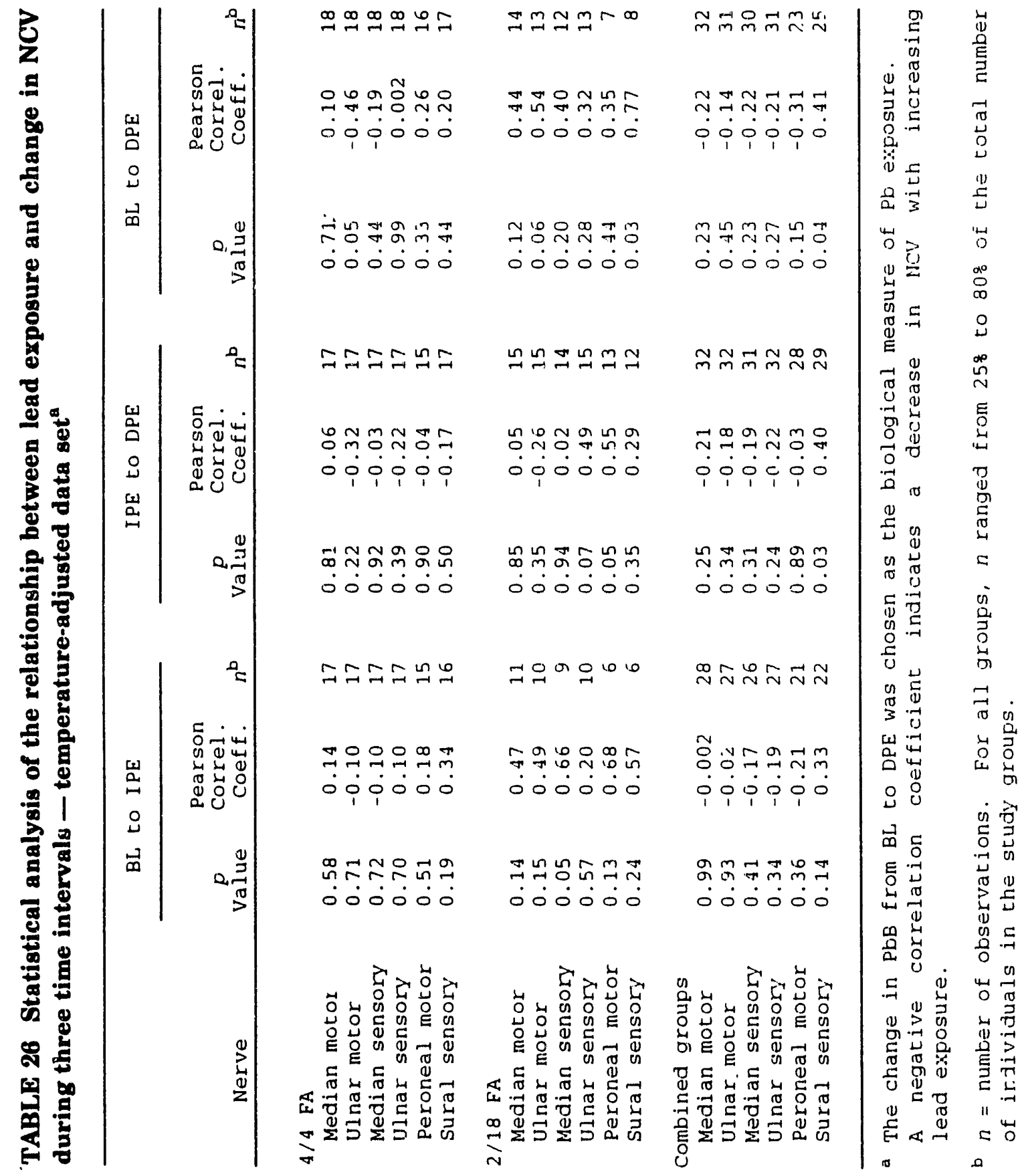


One aspect of our results indicates that we may have been on the edge of an effect of lead on nerve conduction velocity: person \#27 of FA 2/18 had the greatest number of NCV decreases of anyone in our study (five of the six nerves decreased in NCV from BL to IPE and these decreases remained at DPE [see Appendix B]; person \#27 also had blood lead concentrations that were steadily higher than any other individual in the study [see Appendix B]). The possibility exists that if exposures had been higher, as our aerosol study indicates could occur for crew members firing high-lead charges from the 155-mm howitzer, a spectrum of responses showing an effect of lead on NCVs might be seen.

\subsubsection{Dissolution of Aerosol Lead in Simulated Lung Fluid}

Initial solubility tests of known lead salts in simulated lung fluid demonstrated that this fluid was not adequate on its own for realistically studying the lung solubility of lead compounds present in weapons exhaust aerosols. Because simulated lung fluid is buffered with a bicarbonate salt at $\mathrm{pH} 7.4$, relatively high concentrations of carbonate anion, $\mathrm{CO}_{3}{ }^{2-}$, prevented the dissolution of even a soluble salt of lead, such as lead nitrate, $\mathrm{Pb}\left(\mathrm{NO}_{3}\right)_{2}$. Only $1-2 \%$ of $50 \mu \mathrm{g}$ of lead as $\mathrm{Pb}\left(\mathrm{NO}_{3}\right)_{2}$ dried onto a personnel sampler filter went into solution after $72 \mathrm{~h}$ of incubation in simulated lung fluid at room temperature (approximately $23^{\circ} \mathrm{C}$ ). In contrast, we know that persons exposed by inhalation to lead oxide aerosol have shown dissolution and movement into blood of about $50 \%$ of the lead initially deposited in the lung (Ch75).

Respirable particles are normally cleared from the lung by two methods: (1) particles that impact on the bronchi are worked up by ciliary action and swallowed; (2) particles that are entrapped in the alveoli are removed mainly by pulmonary macrophages. Particles that are phagocytized by pulmonary macrophages eventually end up in intracellular lysosomes. Intralysosomal $\mathrm{pH}$ has been measured and has been reported to be approximately 4.8 (Ma87). Because even soluble salts of lead were shown to be insoluble in simulated lung fluid, and because many of the respirable particles would be taken up by pulmonary macrophages, subsequent solubility tests were conducted at $\mathrm{pH} 4.8$ to gain insight into the kinetics of solubility after phagocytosis by pulmonary macrophages. Sodium acetate was chosen as the buffer because it has a carboxyl group with a $\mathrm{pK}_{\mathrm{a}}$ near $\mathrm{pH} 4.8$.

The initial solubility studies were conducted with known salts of lead of different solubilities. Figure 36 shows the dissolution of $\mathrm{Pb}\left(\mathrm{NO}_{3}\right)_{2}$ and lead carbonate $\left(\mathrm{PbCO}_{3}\right)$ in $200 \mathrm{mM}$ acetate buffer, $\mathrm{pH}$ 4.8. In contrast to the data obtained with simulated lung fluid at $\mathrm{pH} 7.4, \mathrm{~Pb}\left(\mathrm{NO}_{3}\right)_{2}$ was relatively soluble, and its dissolution in the buffer was rapid. At the first sampling period of $0.5 \mathrm{~h}, 67 \%$ of the recovered lead had dissolved in the buffer. This curve can be compared with the one obtained with a suspension of $\mathrm{PbCO}_{3}$ (a relatively insoluble salt of lead). By $0.5 \mathrm{~h}$, only $15 \%$ of the recovered lead had dissolved in the buffer. The curve labeled "free filter" shows the dissolution of a $\mathrm{Pb}\left(\mathrm{NO}_{3}\right)_{2}$-spiked filter which was not sandwiched between two 0.1-um nylon filters. The curves "free filter" and "Pb( $\left.\mathrm{NO}_{3}\right)_{2}$ demonstrate that the dissolution rate of a soluble salt of lead was not affected by separating the solute and solvent by the $0.1-\mu \mathrm{m}$-pore nylon filters. 


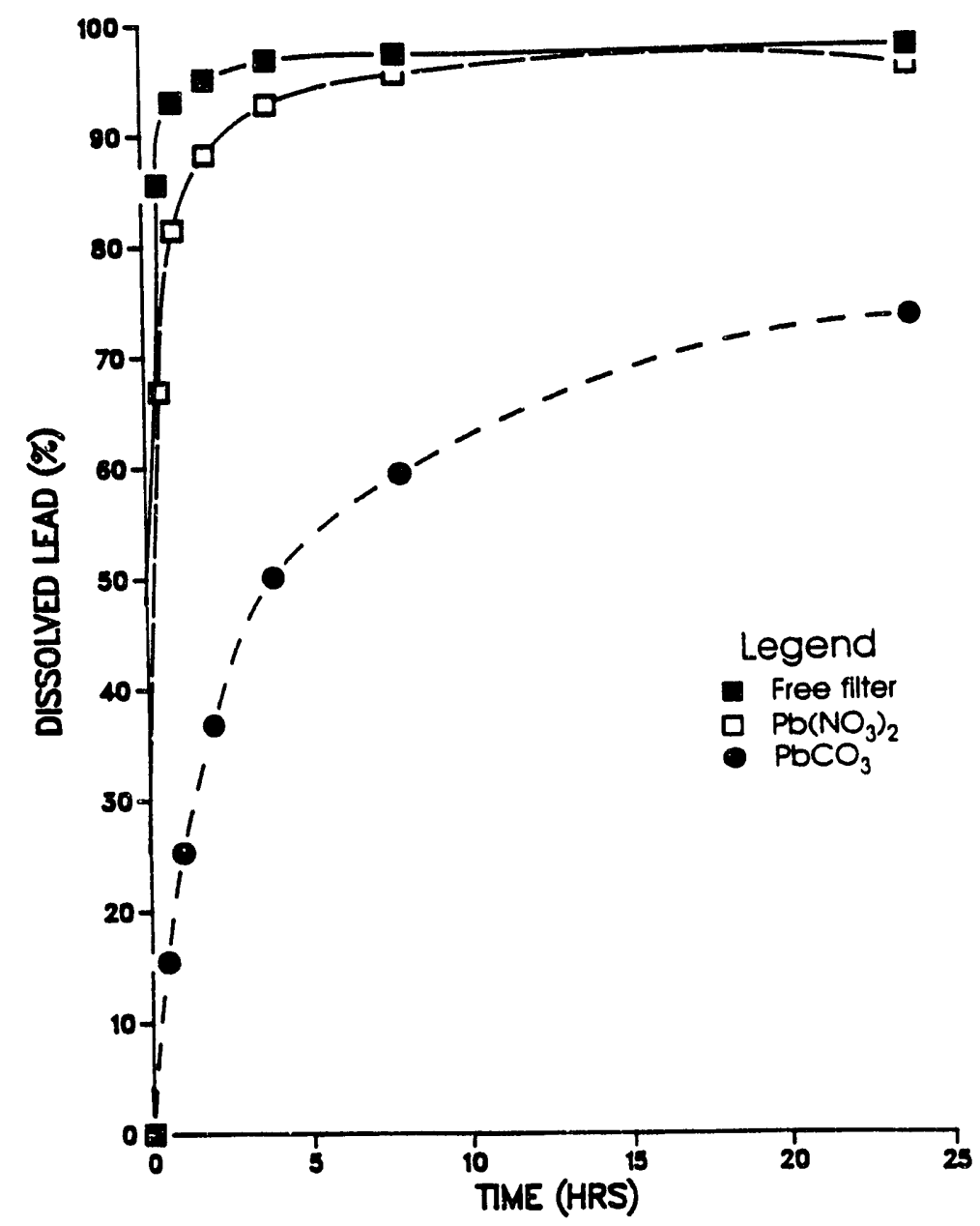

FIGURE 36 Dissolution of lead nitrate and lead carbonate over time in $200 \mathrm{mM}$ acetate buffer, pH 4.8. The lead compounds were dried onto a cellulose acetate filter. $\mathrm{Pb}\left(\mathrm{NO}_{3}\right)_{2}$ dissolution was tested for a filter placed directly in solution (free filter) as well as for a filter sandwiched between two $0.1-\mu \mathrm{m}$-pore nylon filters in a filter holder.

Figures 37 and 38 show the dissolution of three different forms of lead in $50 \mathrm{mM}$ acetate buffer, $\mathrm{pH}$ 4.8. The two previous salts of lead are compared with lead in actual weapons aerosol collected during the acute lead effects study at Fort Sill, Oklahoma. The weapons aerosol depicted in Figure 37 was collected over the breech of the 8-in. howitzer on August 10 , a day on which the $\mathrm{Cu} / \mathrm{Pb}$ ratios were low. Ratios as low as those observed on August 10 were found when the air was sampled over a period of time when high-lead charges (zone 9) were being used. Results show that initial dissolution of 50-60\% of the lead from the weapons aerosol occurred by $4 \mathrm{~h}$. The relative order of solubility for this dissolution was $\mathrm{PbCO}_{3}>\mathrm{Pb}\left(\mathrm{NO}_{3}\right)_{2}>$ weapons $\mathrm{Pb}$, with $20-30 \%$ of the $\mathrm{Pb}\left(\mathrm{NO}_{3}\right)_{2}$ and weapons $\mathrm{Pb}$ 

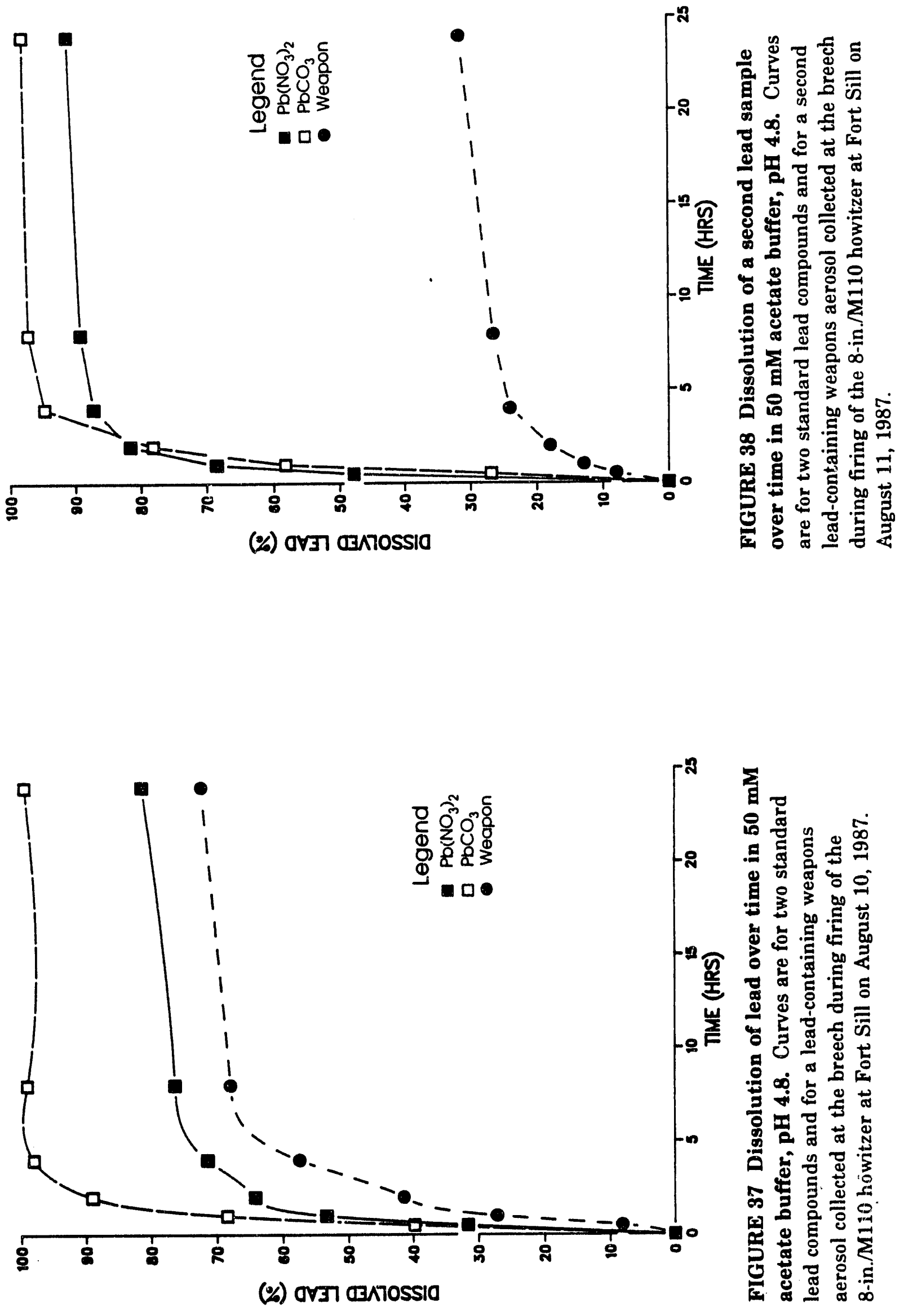
remaining undissolved after $24 \mathrm{~h}$. Figure 38 shows results of a dissolution study repeating the $\mathrm{Pb}\left(\mathrm{NO}_{3}\right)_{2}$ and $\mathrm{PbCO}_{3}$ salts along with a second breech sample collected on August 11 , 1987, at Fort Sill. This particular breech sample had a much lower amount of lead on it (10\% of the previous breech filter) but was quite heavily loaded with organic material (i.e., carbonaceous combustion material). In this dissolution, both the $\mathrm{Pb}\left(\mathrm{NO}_{3}\right)_{2}$ and $\mathrm{PbCO}_{3}$ were rapidly dissolved, with 87 and $95 \%$ of the recovered lead accounted for by $4 \mathrm{~h}$. The weapons $\mathrm{Pb}$ dissolved much more slowly - only $24 \%$ dissolved by $4 \mathrm{~h}$. In addition, after $24 \mathrm{~h}, 68 \%$ of the weapons $\mathrm{Pb}$ remained undissolved. Similar to the previous dissolution (Fig. 37), the relative order of final solubility was $\mathrm{PbCO}_{3}>\mathrm{Pb}\left(\mathrm{NO}_{3}\right)_{2}>$ weapons $\mathrm{Pb}$.

\subsection{DISCUSSION}

\subsubsection{Study Population and Study Design}

Our study of lead exposure in an occupational setting, compared to others in the literature, has certain advantages with respect to detecting a response to lead. One advantage is the small age range among the study participants (40 of 45 were 18-2.6 years old; total age range, 18-35 years). Studies of persons exposed to lead in a battery plant, for example, usually include a much larger age range, typically 22-60 years old. Because NCV values decrease with age, determining whether lead alters NCV values is more difficult in a group with a large age range.

Another advantage is the low values and small range of $\mathrm{PbB}$ concentrations among the participants at baseline $(3-9 \mu \mathrm{g} / \mathrm{dL})$. These values are well below the mean value of $16.9 \pm 0.3 \mu \mathrm{g} / \mathrm{dL}$ for men 18-74 years old in the general U.S. population (Ma82). Persons working in the same occupational setting often have different lengths of employment, resulting in the potential for differences in lead responses to a given work environment because of differences in prior exposure. The low $\mathrm{PbB}$ values and small range at baseline among our participants indicates that their prior exposure, at least in the recent past, was not great and did not differ drastically between participants.

A third advantage is that each study participant served as his own control, with measurements made on each participant before, during, and after his participation in the set of firing exercises. Furthermore, an individual exposure term for each participant was obtained by way of a personal air sampling device, and the crew members fired more highlead charges in a shorter period of time during the monitored exercises than they ever had before. Responses to a known lead exposure could thus be measured with greater sensitivity than is possibie with most study designs. If the crew members were adversely affected by an acute exposure to lead aerosols generated during 8-in. howitzer firing, our results should clearly identify those effects. 


\subsubsection{Air Lead and Blood Lead Concentrations}

When low-zone charges were fired from the 8-in. howitzer without the crew ballistic shelter (-CBS periods), 24-h TWA air lead concentrations averaged $0.1-0.4 \mu \mathrm{g} / \mathrm{m}^{3}$ (see Tables 16 and 17). These concentrations are similar to the low values found in the outdoor air of rural communities (Az75, EPA84a). During this firing period, $\mathrm{PbB}$ concentrations did not rise from the low values present in the crew members at baseline. A small but statistically significant difference in $\mathrm{PbB}$ values at baseline was observed between the crew members of the 4/4 FA and the 2/18 FA units (see Table 18); this difference persisted after the -CBS firing period, and so was probably real, rather than due to a systematic difference in the assay for the two groups at baseline.

As shown in Tables 16 and $17, \mathrm{PbA}$ concentrations were clearly elevated when highzone, high-lead charges were fired from the howitzer with crew ballistic shelter. Consistent with the results of the aerosol studies portion of this program, air lead concentrations did not always predictably correspond to the rate of fire of high-lead charges. For example, the rate of fire was similar on July 27 and August 10, but $\mathrm{PbA}$ values were nearly three times higher on August 10 than on July 27, most likely due to low wind speeds with a significant head wind component during the August 10 collection (see Fig. 28).

It is clear that conditions of low wind speed, head wind direction, and rapid rate of fire existed during the firing at Fort Sill on August 10, 1987. These conditions appear to have been similar to those present at Aberdeen on August 20,1986, when PbA concentrations were tenfold higher than those seen at Fort Sill. Our best explanation for the difference in $\mathrm{PbA}$ values for the two locations is the high elevation of the weapon at Fort Sill, shown in Fig. $6 \mathrm{~b}$. At APG, the howitzer was fired into Chesapeake Bay in the loading position (position is shown in Fig. 6c). The potential for muvement of the lead-rich aerosol from the muzzle blast into the breathing zones of the crew members would be much greater if the muzzle blast were produced at ground level. Substantiating this interpretation are results of Herud and Brown (He82) on $\mathrm{PbA}$ values in the crew compartment of the M109A2 howitzer during firing. Their results showed that a mean $\mathrm{PbA}$ value of $1470 \pm 223 \mu \mathrm{g} / \mathrm{m}^{3}$ (mean $\pm \mathrm{SE}, n=7$ ) was obtained at the Gunner position during firing of 12 high-lead charges at a weapon elevation of 40 mils, while a mean $\mathrm{PbA}$ value of $300 \pm 135 \mu \mathrm{g} / \mathrm{m}^{3}(n=3)$ was obtained while firing the same number of charges at 880 mils of elevation. (At both elevations, firing was conducted with the bore evacuator not working).

For our study, $\mathrm{PbA}$ values were measured over approximately a 24-h period because the firing schedule of the crew members spanned all hours in the day, instead of only the customary 8-h workday of industrial workers. The OSHA PEL of $50 \mu \mathrm{g} \mathrm{Pb} / \mathrm{m}^{3}$ for an $8-\mathrm{h}$ workday is reduced to $17 \mu \mathrm{g} / \mathrm{m}^{3}$ when applied to a 24-h day. From Tables 16 and 17 , it can be seen that the 24-h OSHA PEL was not exceeded during any of the sampling periods for

members of the $4 / 4 \mathrm{FA}$ (maximum $\mathrm{PbA}=11.7 \mu \mathrm{g} / \mathrm{m}^{3}$ on June 29). For the $2 / 18 \mathrm{FA}$, the mean $\mathrm{PbA}$ for all crew members was higher than the 24-h OSHA PEL on one day, August 10, when the mean TWA PbA was $27 \mu \mathrm{g} / \mathrm{m}^{3}$; the $\mathrm{PbA}$ for the most highly exposed individual (max $\mathrm{PbA}$ ) 
was higher than the 24-h OSHA PEL on five days: July 27 and August 5, 6, 10, and 11 (see Table 17).

The highest $\mathrm{PbA}$ concentration experienced by the $2 / 18 \mathrm{FA}$ crew members, even when averaged over only the period of active firing $\left(140 \mu \mathrm{g} / \mathrm{m}^{3}\right)$, was much lower than those measured during firing at some indoor firing ranges $\left(1500-5500 \mu \mathrm{g} / \mathrm{m}^{3}\right)(\mathrm{La} 75, \mathrm{Fi} 79, \mathrm{Da} 88$, $\mathrm{Br} 89$ ). In addition, the $\mathrm{PbB}$ concentrations among the howitzer crew members after firing (4-17 $\mu \mathrm{g} / \mathrm{dL})$ were much lower than among firing range personnel $(40-140 \mu \mathrm{g} / \mathrm{dL})(\mathrm{La} 75$, Fi79, No87, Br89).

For crew members of the 4/4 FA unit, 24-h TWA PbA values did not rise above 24-h TWA PbA values measured by Azar et al. (Az75) for taxicab drivers in Los Angeles. However, exposures among the crew members differed strikingly from those of the cab drivers in that $\mathrm{PbA}$ values rose very high compared to the TWA values during active howitzer firing, as high as $150 \mu \mathrm{g} \mathrm{Pb} / \mathrm{m}^{3}$, as shown by the pump that experienced a flow-fault during a period of continuous firing on a day when the 24-h TWA PbA was $6.2 \mu \mathrm{g} / \mathrm{m}^{3}$. An important aspect of our study was to try to evaluate whether the acute rises in $\mathrm{PbA}$ experienced by the howitzer crew members might have caused a greater or lesser response to lead than would have been anticipated from the 24-h TWA $\mathrm{PbA}$ values.

Several studies of exposure of humans to airborne lead have been conducted that may provide information relevant to our exposures at Fort Sill. Chamberlain et al. (Ch75) exposed a number of people for 5-30 min to a high concentration of lead oxide aerosol that was labeled with ${ }^{203} \mathrm{~Pb}$. He showed that, after these brief high-level exposures, blood lead concentrations rose to a maximum $20 \mathrm{~h}$ later and stayed at this plateau until 100-150 $\mathrm{h}$. The $\mathrm{PbB}$ concentrations fell with a half-life of 16 days, a value very close to the half-life for blood lead determined in humans by Rabinowitz after oral exposure to lead (Ra73, Ra74). Chamberlain et al. found that $30-50 \%$ of the inspired lead was deposited in the lungs and that the lead cleared from the lungs with a half-life of $6.6 \mathrm{~h}(\mathrm{Ch} 75)$. These data indicate that $\mathrm{PbB}$ concentrations may continue to rise for a number of hours after a period of brief highlevel exposures during firing and may decrease very slowly after that.

Concerning the time-course of $\mathrm{PbB}$ rise after airborne lead exposure, Griffin et al. (Gr75a, Gr75b) continuously exposed rats and monkeys to $21.5 \mu \mathrm{g} / \mathrm{m}^{3}$ of lead in the form of lead oxide for one year and continuously exposed humans to either $3.2 \mu \mathrm{g} / \mathrm{m}^{3}$ or $10 \mu \mathrm{g} / \mathrm{m}^{3}$ of lead for extended periods of time. In both studies, $\mathrm{PbB}$ concentrations rose to a first plateau by two weeks after the start of exposure. This first plateau persisted for 2-3 months, at which time a second plateau was established that had a blood lead concentration that was twice as high as the first plateau. In our study at Fort Sill, the crew members from the $2 / 18$ FA unit appeared to have reached a plateau in blood lead concentration by two weeks after the start of exposure (see Table 17 and Fig. 24), and even though exposures were significant after the two-week point, $\mathrm{PbB}$ concentrations did not continue to rise above that plateau. The 2/18 FA crew members at Fort Sill were exposed to airborne lead over a three-week period. The results of Griffin et al. imply that the $\mathrm{PbB}$ values of the crew members might have also risen to a second, higher plateau had they been exposed for a longer period of time. 
It appears that $\mathrm{PbB}$ values fell more slowly after cessation of exposure in the $2 / 18 \mathrm{FA}$ crew members (see Table 17 and Fig. 24) than we expected they would frum the literature. Landrigan et al. (La75) showed that $\mathrm{PbB}$ values fell to about half by five weeks after cessation of exposure among three persons exposed to airborne lead at a firing range. In the study of Griffin et al. (Gr75b), three of four men who were continuously exposed to $10 \mu \mathrm{g} / \mathrm{m}^{3}$ of lead for four weeks had returned to baseline values of $\mathrm{PbB}$ by two weeks after the end of their exposures, and all four were at baseline by six weeks. In addition, except for two of the most highly exposed men, the crew members of the M109A3 howitzer in the Howitzer Extended Life Program study were back to baseline PbB concentrations by 10 weeks after the end of firing (As85). In contrast, the crew members of the 2/18 FA unit showed no significant decrease in $\mathrm{PbB}$ from the end of the firing exercises to six weeks later (see Table 19, IPE to DPE).

A number of investigators have shown that lead workers who smoke have higher $\mathrm{PbB}$ concentrations than do their nonsmoking peers (Ne83, La85). Increased hand-to-mouth transfer of lead and decreased clearance of lead by lung macrophages are thought to account for this effect of smoking. We looked for an effect of smoking among the 2/18 FA crew members to see whether evidence existed for increased hand-to-mouth transfer of weapons exhaust components among crew members who smoked heavily. As shown in Table 27, the rise in $\mathrm{PbB}$ from baseline to $\mathrm{DPE}$ was $5.7 \mu \mathrm{g} / \mathrm{dL}$, independent of whether the men were heavy smokers or not. Even though the crew members did smoke during break times between firing, their smoking did not detectably increase their exposures to lead.

TABLE 27 Effect of smoking on $\mathrm{PbB}$ response to $\mathrm{PbA}$ exposures among crew members firing the 8-in. howitzer ${ }^{\mathrm{a}}$

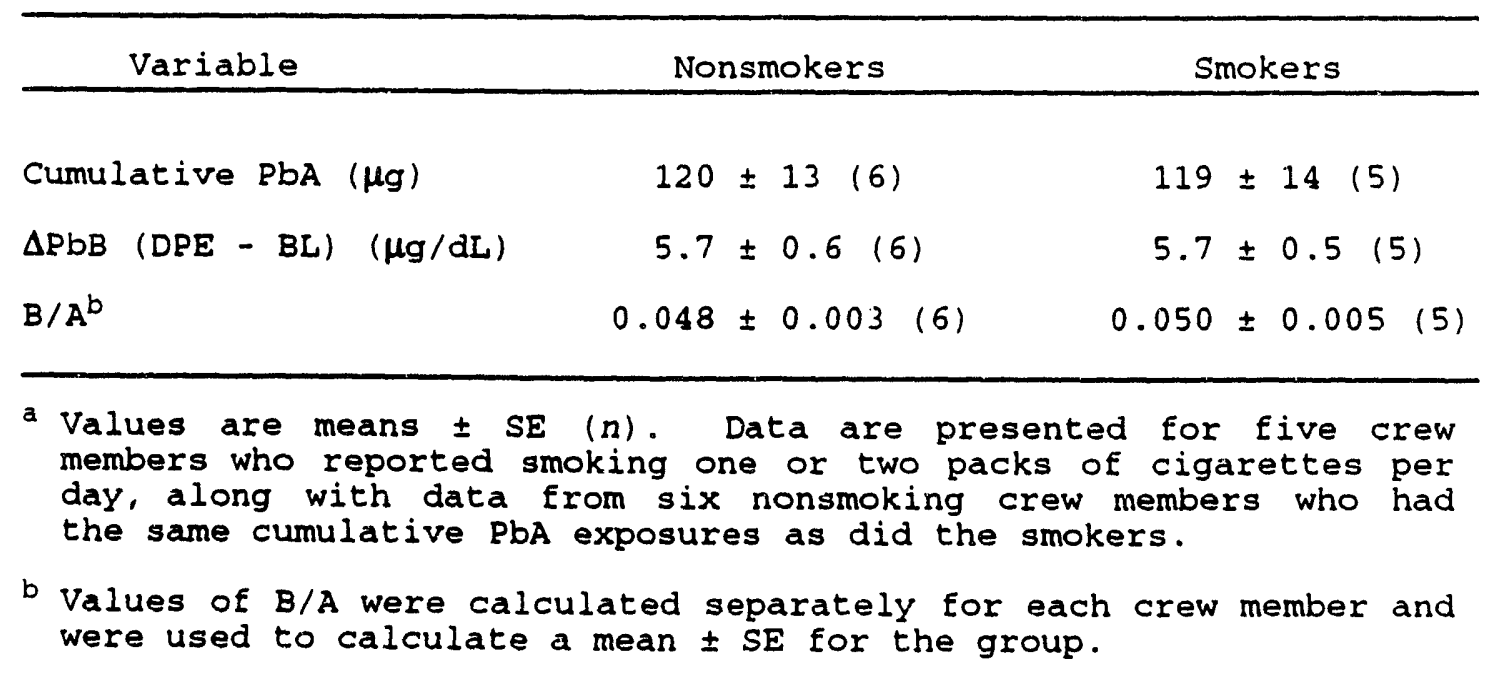




\subsubsection{Relationship of Air Lead to Blood Lead}

Figure 29 shows a significant relationship between airborne lead exposure on August 10,1987, and the rise in blood lead for each man from baseline to August 11, 1987. The slope of the line is small $\left(0.1 \mu \mathrm{g} / \mathrm{dL}\right.$ per $\left.1 \mu \mathrm{g} / \mathrm{m}^{3}\right)$, indicating that the blood lead response to that day's air lead exposure was also small. The fact that the men did not respond very strongly to exposures during the last week of the three weeks of high-lead firing is also shown in Fig. 24 and Table 17, in which very little increase in blood lead occurred from the +CBS2 to the +CBS3 time point, in spite of significant exposures during that time interval. It appears, as in the study of Griffin et al. (Gr75b), that the men had reached a plateau in blood lead during the first two weeks and were no longer showing as striking increases in blood lead in response to air lead exposures as previously. The reason for this plateau is not clear.

In order to evaluate the magnitude of the overall increase in $\mathrm{PbB}$ concentration compared to an overall view of the air lead exposures, we assigned a mean $\mathrm{PbA}$ concentration to each day during the +CBS firing periods based on the personal sampling pump data plotted for the five crew members in Fig. 24. These values ranged from $2 \mu \mathrm{g} / \mathrm{m}^{3}$ on August 3 to $35 \mu \mathrm{g} / \mathrm{m}^{3}$ on August 11, with values of $0.2 \mu \mathrm{g} / \mathrm{m}^{3}$ assigned to days when no high-lead charges were fired (see Fig. 24). (A lead level of $0.2 \mu \mathrm{g} / \mathrm{m}^{3}$ is typical of rural settings in the United States [Az75, EPA84a] and is in range of the mean values for the -CBS firing periods, when no high-lead charges were fired.) From these values, a mean 24-h TWA PbA for all + CBS days (until the day of +CBS3 blood sampling on August 11, 1987) was calculated to be $7.9 \pm 2.3 \mu \mathrm{g} / \mathrm{m}^{3}$ (mean $\pm \mathrm{SE}, n=16$ days). The corresponding mean rise in $\mathrm{PbB}$ from $\mathrm{BL}$ to the + CBS3 sampling point for the same five crew members was $6.8 \pm 1.0 \mu \mathrm{g} / \mathrm{dL}(n=5)$. From this analysis, we obtained a value of $\beta$ of $0.86 \mu \mathrm{g} / \mathrm{dL}$ per $\mu \mathrm{g} / \mathrm{m}^{3}$, where $\beta$ is the ratio $\triangle \mathrm{PbB}: \triangle \mathrm{PbA}$. This analysis implies that the rise in $\mathrm{PbB}$ for the crew members might be predictable from their average $\mathrm{PbA}$ exposure, irrespective of the fact that some exposure days were high and some were low and, in fact, that during some exposure days, there were high and low periods of exposure.

The above value of $\beta$ for our study was obtained according to the approach taken by many investigators of lead exposure in humans (Wi69, Go67, Gr75b, Gr81, EPA84b). Our value can be compared to ones obtained from the study of Griffin et al., in which men were continuously exposed ( $23 \mathrm{~h} /$ day) to either $3.2 \mu \mathrm{g} / \mathrm{m}^{3}$ or $10 \mu \mathrm{g} / \mathrm{m}^{3}$ of lead oxide $(\mathrm{Gr} 75 \mathrm{~b})$. For 13 men exposed to $3.2 \mu \mathrm{g} / \mathrm{m}^{3}$, the mean rise in $\mathrm{PbB}$ values at three weeks was $3.6 \pm 0.6 \mu \mathrm{g} / \mathrm{dL}$ (mean $\pm \mathrm{SE}$ ), yielding a $\beta$ of 1.1 for this first plateau. The plateau at final equilibrium had a rise in $\mathrm{PbB}$ of $6.2 \pm 1.1 \mu \mathrm{g} / \mathrm{dL}$, for $\mathrm{a} \beta$ of 1.9 .

At two and four weeks after continuous exposure to $10 \mu \mathrm{g} / \mathrm{m}^{3}$, the rises in $\mathrm{PbB}$ values were $7.2 \pm 0.6 \mu \mathrm{g} / \mathrm{m}^{3}$ (mean $\left.\pm \mathrm{SE}, n=12\right)$ and $8.3 \pm 0.7 \mu \mathrm{g} / \mathrm{dL}(n=13)$, respectively, for a $\beta$ of 0.65 . After 12 weeks of exposure, the mean rise in $\mathrm{PbB}$ value was $16.0 \pm 1.0(n=8)$ and was steady until the end of exposure at 18 weeks, with a final $\beta$ of 1.6 .

At four weeks of exposure to $10 \mu \mathrm{g} / \mathrm{m}^{3}$, the rise in $\mathrm{PbB}$ concentration $(8.3 \mu \mathrm{g} / \mathrm{dL}$ ) for the men in the study of Griffin et al. is similar to the rise that we observed in the five above 
crew members $(6.8 \mu \mathrm{g} / \mathrm{dL})$ after three weeks of exposure to a mean $24-\mathrm{h}$ TWA PbA concentration of $8 \mu \mathrm{g} / \mathrm{m}^{3}$. These results again indicate that the rise in $\mathrm{PbB}$ among the crew members in some way may correspond to the mean $\mathrm{PbA}$ value for the entire exposure time rather than to the days of high exposure.

In a sense, the strong relationship between cumulative airborne lead exposure and rise in $\mathrm{PbB}$ shown in Fig. 30 supports the above analysis. The results indicate that the rise in $\mathrm{PbB}$ is predictable based on the total amount of lead breathed, without consideration of the peaks and valleys of the exposure profile in time.

In Fig. 30, the abscissa is expressed as both " $\mu$ g $\mathrm{Pb}$ " and " $\mu \mathrm{g} \mathrm{Pb} / \mathrm{m}^{3} \cdot \mathrm{min}^{\prime}$ (see Section 3.2.3 for the mathematical relationship between " $\mu \mathrm{g} \mathrm{Pb}^{\prime \prime}\left[\mathrm{A}_{1}\right]$ and $\mu \mathrm{g} \mathrm{Pb} / \mathrm{m}^{3} \cdot \min$ ). As shown, the crew members were exposed to $10,000-40,000 \mu \mathrm{g} / \mathrm{m}^{3} \cdot \mathrm{min}$ (group 1) and 80,000-180,000 $\mu \mathrm{g} \mathrm{Pb} / \mathrm{m}^{3} \cdot \mathrm{min}$ (group 2) during their entire periods of exposure. For the 4/4 FA (group 1) crew members, the number of +CBS exposure days was seven (see Table 16), corresponding to $168,000 \mu \mathrm{g} / \mathrm{m}^{3} \cdot \mathrm{min}$ if they had been exposed to seven days of $8-\mathrm{h} /$ day at the OSHA PEL of $50 \mu \mathrm{g} / \mathrm{m}^{3}$ of lead. For the $2 / 18 \mathrm{FA}$ (group 2) crew members, who were exposed during nine days of +CBS exposure (see Table 17), total exposure would have been $216,000 \mu \mathrm{g} / \mathrm{m}^{3} \cdot \mathrm{min}$ for nine working days at the OSHA PEL. Results indicate, therefore, that cumulative exposures among the crew members at Fort Sill were, on the average, not greater than they would have experienced in the workplace at the OSHA PEL.

\subsubsection{Hematopoietic Response to Lead}

During the M109A3 Howitzer Extended Life Program Operational Test II conducted by the Army from June 3, 1985 through July 26, 1985, 12-h TWA PbA values averaged

30-50 $\mu \mathrm{g} / \mathrm{m}^{3}$ during the firing of an average of eight M119 charges per hour (As85). During six weeks of firing, the average rise in blood lead concentration among the 19 crew members monitored was $9 \mu \mathrm{g} / \mathrm{m}^{3}$, and the maximum rise was $27 \mu \mathrm{g} / \mathrm{m}^{3}$. Zinc protoporphyrin concentrations during that time rose from about 20 to about $30 \mu \mathrm{g} / \mathrm{dL}$. (Zinc protoporphyrin measurements provide values that are directly comparable to FEP and EP [erythrocyte porphyrin] values.) Although $\mathrm{PbB}$ concentrations fell to prefiring baseline values by 11 weeks later, the zinc protoporphyrin levels remained at 25-30 $\mu \mathrm{g} / \mathrm{dL}$. In our study of the 8-in. howitzer, $\mathrm{PbA}$ concentrations during firing were lower and more variable than in the $155-\mathrm{mm}$ M109A3 howitzer, and the rises in blood lead and FEP were also lower (see Table 19).

The FEP concentrations of the crew members in our study (see Table 18) are very similar to the mean value for the U.S. population, $21.6 \pm 0.28 \mu \mathrm{g} / \mathrm{dL}$ of blood, determined in the NHANES II study (Ma86). A number of investigators have used their data to generate a relationship of $\mathrm{PbB}$ to $\mathrm{EP}$ concentrations in large groups of children and to determine a threshold $\mathrm{PbB}$ concentration below which $\mathrm{EP}$ concentrations appear to be independent of $\mathrm{PbB}$ concentration. Threshold values obtained so far range from 12 to $16 \mu \mathrm{g} / \mathrm{dL}$ (Pi82, Ha85).

The $\mathrm{PbB}$ concentrations among the crew members in our study ranged from 4 to $17 \mu \mathrm{g} / \mathrm{dL}$ at the IPE sampling time, and so were in range of the threshold values for an EP 
response to lead. In spite of this, we saw a small but, significant increase in FEP concentration in our more highly exposed crew members (see Table 19) and found a statistically significant correlation between FEP increase and rise in $\mathrm{PbB}$ (see Fig. 33). We applied the equation of Piomelli et al. (Pi82) to calculate the expected increase in FEP for crew members of the $2 / 18 \mathrm{FA}$ unit, who experienced a rise in mean blood lead value from $4.9 \mu \mathrm{g} / \mathrm{dL}$ at $\mathrm{BL}$ to $11.4 \mu \mathrm{g} / \mathrm{dL}$ at the IPE sampling time. Independent of whether we used the Piomelli equation based on his whole population of 2004 children $\left(\log _{10} \mathrm{EP}=1.099+0.016 \mathrm{PbB}\right.$; $\mathbf{R}=0.51)$ or the one for children with $\mathrm{PbB}$ values greater than $20\left(\log _{10} \mathrm{EP}=\right.$ $0.910+0.022 \mathrm{PbB} ; \mathrm{R}=0.60$ ), the expected rise in FEP was $4.1 \mu \mathrm{g} / \mathrm{dL}$ for a rise in $\mathrm{PbB}$ from 4.9 to $11.4 \mu \mathrm{g} \mathrm{Pb} / \mathrm{dL}$. The $2 / 18 \mathrm{crew}$ members actually showed a mean rise of $2.2 \mu \mathrm{g} \mathrm{FEP} / \mathrm{dL}$, not very different from that anticipated from the Piomelli equations considering the age difference between the two exposed populations (children vs. adults).

Coutselinis et al. (Co79) reported a significant inverse relationship between $\mathrm{PbB}$ concentration and hematocrit in both Iowa residents and plant workers with $\mathrm{PbB}$ values ranging from 10 to $37 \mu \mathrm{g} / \mathrm{dL}$. The slope of the linear regression equation from their data was -0.2 . This value is similar to the slope of -0.3 obtained from our regression analysis shown in Fig. 31.

Results of our study therefore suggest that lead may have influenced heme metabolism at $\mathrm{PbB}$ concentrations in adults below the currently reported threshold values for children. Again, these effects are small enough that they could have become detectable only with the type of design employed in our study.

\subsubsection{Peripheral Nervous System Response to Lead}

One striking feature of the NCV data set obtained in this study is the extremely reproducible nature of the NCV values. Few biological parameters show mean values for groups of individuals that have standard errors in the range of $2 \%$ of the mean. A power calculation based on our test measurements made prior to the Fort Sill study indicates that a difference in NCV of approximately $3 \mathrm{~m} / \mathrm{s}$ would be needed to achieve statistical significance. This difference is similar in magnitude to the decreases reported in the literature in response to lead exposure. We, therefore, have achieved a level of competence in making NCV measurements that would allow us to detect decreases in NCV in response to lead exposure were they to occur in our study population.

One aspect of the NCV measurements that we became more aware of during the course of this study is the relatively large adjustment in NCV that some investigators recommend be made for differences in skin temperature (at about $2 \mathrm{~m} / \mathrm{s}$ per degree Celsius). Investigators differ, however, on the skin temperature above which they assume no need for temperature adjustment, with values ranging from $27^{\circ} \mathrm{C}$ to $35^{\circ} \mathrm{C}$ (As80, Se83, Si83, De73), depending on measurement location, etc. Because the magnitude of the recommended adjustment is in the range of the magnitude of the lead-induced differences that have been reported, any adjustment for skin temperature could significantly affect the nature of the changes observed if there were individuals with low skin temperatures. Because we 
encountered a number of low skin temperatures (27-29 ${ }^{\circ} \mathrm{C}$, Appendix B) during the baseline measurements of the 2/18 FA unit, we applied the best-documented method of adjusting for skin temperature available and considered our data set with and without the applied temperature adjustment.

Without temperature adjustment, only the peroneal nerve showed a statistically significant decrease in NCV for the 2/18 FA unit that was borderline in its inverse relationship to lead exposure (see Table 22; Table 23, combined groups; and Fig. 35). This nerve is one that has been shown by others to decrease in lead-exposed workers (Fe77, Bu79, Co84). The other nerves showed no inverse relationship to lead exposure.

With the temperature-adjusted data set, additional nerves showed NCV decreases in the 2/18 FA unit. However, except for the peroneal nerve, these decreases, although possibly indicative of a small effect of the increased lead exposures among the 2/18 FA unit, rely too heavily on temperature adjustment methods to be convincing.

Many industrial exposures to lead involve simultaneous exposure to additional metals such as zinc or copper. In the studies of Araki et al. (Ar87, Mu87), there was some indication that simultaneous exposure to copper might counteract $\mathrm{Pb}$-induced NCV decreases. Because crew members firing high-lead charges are exposed to both lead and copper, these observations should be kept in mind. The air copper concentrations in the study of Araki et al. were in the range of those measured at YPG for the 155-mm howitzer but were much higher than those measured at Fort Sill for the 155-mm howitzer fired at high barrel elevation (see Appendix A).

We currently have the unusual opportunity to apply what we have learned about conducting NCV measurements to a study of lead exposures among crew members firing the 155-mm howitzer. We anticipate that lead exposures will be higher with this weapon system, with its more enclosed cab, than in the 8-in. howitzer study reported here. For the $155-\mathrm{mm}$ howitzer study, we are using a heated water bath when necessary to bring arm and leg skin temperatures to $34^{\circ} \mathrm{C}$ at the hand and $33^{\circ} \mathrm{C}$ at the foot prior to making the measurements. Consequently, no adjustments for skin temperature should be necessary. If, indeed, we are on the edge of an effect of lead on peripheral nerve conduction velocities in this 8-in. howitzer study, these results should be confirmed and seen more clearly in the follow-up study of crew members tiring the $155-\mathrm{mm}$ howitzer.

\subsubsection{Solubility Studies of the Lead Aerosol}

We measured the rate of dissolution of the aerosol lead in an acetate buffer adjusted to $\mathrm{pH} 4.8$ in order to reproduce the $\mathrm{pH}$ within the lysosomes of the lung macrophages. At the neutral $\mathrm{pH}$ of the extracellular lung fluid, we found that even a relatively soluble salt of lead dissolved only to an extent of $1-2 \%$ in $72 \mathrm{~h}$, indicating that uptake of the particles by macrophages would be necessary to effect the dissolution of lead aerosol in the lung. 
At $\mathrm{pH} 4.8$, we found that, when the filter was rich in lead and not heavily deposited with carbonaceous material, the aerosol lead dissolved at approximately the same rate as the model compounds, $\mathrm{Pb}\left(\mathrm{NO}_{3}\right)_{2}$ and $\mathrm{PbCO}_{3}$, with $50-60 \%$ of the lead dissolved by $4 \mathrm{~h}$ (Fig. 37). These results indicate that, once particles of weapons aerosol are taken up by lung macrophages, the lead present on those particles should dissolve readily. The lead on the filter dissolved less readily when the filter was lower in lead and had heavy deposits of black carbonaceous material from the firing. This decrease in solubility would probably not happen in the lungs, where the particles are not packed together as on the filter.

\subsection{CONCLUSIONS}

A summary of the results of the acute lead effects study was presented in the Summary. Here we present the conclusions that we came to as a result of that study.

- Wind direction and speed had a measurable effect on airborne lead concentrations at crew member positions during the firing of high-lead charges from the 8-in. howitzer with CBS.

- Acute exposures to elevated concentrations of airborne lead during the firing of high-lead charges produced rises in $\mathrm{PbB}$ values that corresponded to those expected from the 24-h TWA values of $\mathrm{PbA}$; the acutely elevated $\mathrm{PbA}$ values that occurred during firing did not enhance the $\mathrm{PbB}$ response to airborne lead.

- For $2 / 18$ crew members, mean $\mathrm{PbB}$ concentrations rose during the first 12 days of exposure to elevated $\mathrm{PbA}$ concentrations (July 27 to August 11). They then appeared to reach a steady state in which $\mathrm{PbB}$ values did not continue to rise, even during periods of high airborne lead exposure compared to those earlier in the study.

- Values of $\beta(\triangle \mathrm{PbB} / \Delta \mathrm{PbA})$ were approximately $1 \mu \mathrm{g} \mathrm{Pb} / \mathrm{dL}$ per $\mu \mathrm{g} \mathrm{Pb} / \mathrm{m}^{3}$ $\left(1 \mathrm{~m}^{3} / \mathrm{dL}\right.$ ) for crew members of the $2 / 18 \mathrm{FA}$. The values we obtained are similar to those reported by other investigators who have studied $\mathrm{PbB}$ responses of humans to various forms of airborne lead at levels in the range of those found in our study (24-h TWA PbA $=2-35 \mu \mathrm{g} / \mathrm{m}^{3}$ for 2/18 FA).

- Mean $\mathrm{PbB}$ concentrations for blood samples taken in the field during the last firing exercise (+CBS3 for the 2/18 FA) were the same as those determined six days later at IPE; no rapid fall in $\mathrm{PbB}$ occurred shortly after cessation of firing, as was suspected might have occurred among several men in the previous Howitzer Extended Life Program study conducted by the Army. 
- For members of the $2 / 18 \mathrm{FA}$, whose mean rise in $\mathrm{PbB}$ during firing was $6.9 \pm 0.7 \mu \mathrm{g} / \mathrm{dL}, \mathrm{PbB}$ concentrations did not decrease significantly during the six to seven weeks after cessation of the firing exercises.

- Small decreases in hematocrit and small increases in FEP that occurred during the firing exercises were significantly correlated with increasing airborne lead exposure. These changes appeared to reverse themselves during the six to seven weeks after cessation of the firing exercises.

- Considering the temperature-adjusted data set, small decreases in NCV values occurred during the $B L$ to DPE interval that appeared to be borderline in relationship to increasing airborne lead exposures. Results of the current study that the Army is conducting on lead exposures among crew members firing high-lead charges from the $155-\mathrm{mm}$ howitzer, in which $\mathrm{PbB}$ values rose substantially more than in this study with the 8-in. howitzer, may confirm or negate the borderline NCV relationship to lead exposure reported here.

- Adjustments of NCV values for differences in skin temperature can be potentially large. The need for such adjustments should clearly be minimized in any future studies by carefully warming the limbs of each study participant to the same temperature for each repeat measurement.

- All changes that appeared to be related to airborne lead exposure among the crew members firing high-lead charges from the 8-in. howitzer with CBS were small (3\% mean decrease in hematocrit, $12 \%$ mean increase in FEP, 6\% mean decrease in NCV among $2 / 18 \mathrm{FA}$ crew members).

- In spite of the small changes that occurred during the firing mission, all group mean values of $\mathrm{PbB}, \mathrm{FEP}$, hematocrit, and $\mathrm{NCV}$ remained within the normal ranges for persons not occupationally exposed to lead (Ma82, Ki83). 


\section{RECOMMENDATIONS}

\subsection{APPROACH TO MONITORING EXPOSURE TO LEAD}

Our study has demonstrated that the extreme peaks of air lead concentration that follow firing of high-lead charges from the 8-in. howitzer with crew ballistic shelter do not cause greater rises in blood lead than would be expected from exposures to the same total amount of air lead at a single, constant concentration. In addition, the extremes in $\mathrm{PbA}$ concentration do not cause enhanced responses in the hematopoietic system but, in our study, produced small changes in free erythrocyte protoporphyrin and hematocrit consistent with those reported in the literature for similar rises in $\mathrm{PbB}$ concentration. Consequently, it seems reasonable to apply OSHA standards to crew members firing high-lead charges, bearing in mind that the OSHA permissible exposure limit of $50 \mu \mathrm{g} \mathrm{Pb} / \mathrm{m}^{3}$ for an $8 \mathrm{~h}$ workday (8. $\mathrm{h}$ TWA) falls to a FEL of only $17 \mu \mathrm{g} / \mathrm{m}^{3}$ when the crew members are on duty for a $24-\mathrm{h}$ period during prolonged firing exercises (24-h TWA). The 24-h TWA PEL, $17 \mu \mathrm{g} / \mathrm{m}^{3}$, was exceened on six of the 12 days of firng high-lead charges by the 2/18 FA unit; it was not exceeded on any of the eight days of firing high-lead charges by the 4/4 FA unit.

The question remains as to how many high-lead rounds need to be fired to produce a day on which the PEL might be exceeded. At Fort Sill, a mean 12-h TWA PbA of $60 \mu \mathrm{g} / \mathrm{m}^{3}$ resulted from firing an average of one round every $3 \mathrm{~min}$ for $12 \mathrm{~h}$ under light head wind conditions. This corresponds to breathing about $690 \mu \mathrm{g}$ of lead in $12 \mathrm{~h}$ (assuming $23 \mathrm{~m}^{3}$ are inhaled per day), or about $3 \mu \mathrm{g}$ of lead per round fired. At the same rate of breathing, a person at the OSHA PEL would breathe $383 \mu \mathrm{g}$ of lead per 8-h day. Consequently, on a day sirilar in wind conditions to August 10 at Fort Sill, crew members who fire 130 rounds in a 24-h day would be expected to breathe an amount of lead similar to that breathed at the OSHA PEL during an 8-h work day. Therefore, a reasonable guideline might be that if crew members fire more than 100 high-lead rounds in a day from the 8-in. howitzer in an elevated position as at Fort Sill, that day should be counted as a day when exposures could reach the OSHA PEL. Correspondirgly, at more than 60 high-lead rounds per day, exposures could reach the OSHA action level of $30 \mu \mathrm{g} \mathrm{Pb} / \mathrm{m}^{3}$. In contrast, if the 8-in. howitzer is fired in the loading position under adverse vind conditions, $\mathrm{PbA}$ concentrations tenfold higher $\left(600 \mu \mathrm{g} / \mathrm{m}^{3}\right)$ can be expected, in which case firing of only 10 high-lead charges in a day would provide enough lead to have the day count as one on which the PEL might be exceeded. Clearly, these estimations apply to the 8-in. howitzer and would be expected to be different for the 155-mm howitzer.

The OSHA guidelines for $\mathrm{PbA}$ are set on the basis of anticipated levels of $\mathrm{PbB}$ at final equilibrium. Consequently, it is possible, on the basis of our results, that some excursions above the 24-h OSHA PEL might be permitted for 8-in. howitzer crew members when exposure periods are short enough that final equilibrium is not reached. Until additional data are collected that provide a higher degree of confidence in the air-lead to blood-lead relationship for artillery firing, monitoring blcod lead levels would seem to be indicated. 
In keeping with the OSHA guidelines, a policy of requiring showers and a change of clothes before crew members return home from an exercise of high-lead firing might be instituted (OSHA requires that showers be taken if persons work at a level above the PEL). Such a policy would assure that lead is not brought back to homes in which small children reside. Also consistent with OSHA policy would be medical surveillance by sampling for blood lead and zinc protoporphyrin levels for those artillerymen who fire high-lead charges at a level that would approximate the PEL for more than 30 days in a year. For these men, it would be especially important to confirm whether a second higher plateau in $\mathrm{PbB}$ concentration is reached after 60 days of exposure, as expected from the studies of Griffin et al. (Gr75a, Gr75b).

A second insight gained by our study is the high lead content of the muzzle blast aerosol - an insight which provides a rational basis both for predicting and for remedying conditions of high crew member exposure to lead during firing. When the muzzle blast aerosol hangs in the area of the crew members under conditions of low or no wind, and when it. is released near ground level during firing in the loading position, maximum air lead exposures occur - exposures that could result in crew members inhaling the same amount of lead after only six rounds of high-lead charges as they would during $8 \mathrm{~h}$ at the OSHA action level $\left(30 \mu \mathrm{g} / \mathrm{m}^{3}\right)$. The high lead content of the muzzle blast aerosol outside of the weapon may explain past data on the lack of decrease in $\mathrm{PbA}$ concentrations by changing ventilation conditions in the CBS to draw in outside air. It identifies a disadvantage with respect to the muzzle brake on the $155-\mathrm{mm}$ howitzer, which directs the muzzle blast back in two streams, each at a $45^{\circ}$ angle from the barrel, to the rear of the weapon where the crew members operate. For this reason, one could predict that weapon elevation on the $155-\mathrm{mm}$ howitzer might have a smaller effect on lead exposures than on the 8-in. howitzer, in which firing at high elevations directs the muzzle blast up and away from crew member positions (see Fig. 6b).

Two questions arose from our study that relate to concern for exposures under combat conditions. One is the lack of decrease in $\mathrm{PbB}$ levels after the end of the firing exercises, and the second is the possibility of a borderline decrease in NCVs related to the crew members' lead exposures. The follow-up study being conducted by the Army of crew members firing the $155-\mathrm{mm}$ howitzer is important, because it appears that $\mathrm{PbA}$ concentrations will be higher than in our study of the 8-in. howitzer. If the NCV response appears more clearly in the $155-\mathrm{mm}$ howitzer crew members, an evaluation could be made of the importance of that response to the effective performance of tasks required of artillery crew members under combat conditions. However, such an evaluation would be premature at this time based solely on the results of our study. 


\subsection{RECOMMENDATIONS FOR RESEARCH}

\subsubsection{Aerosol Studies}

At least two aspects of the aerosol study should be pursued further. First, the size of the lead-containing particles from the 8-in. howitzer should be determined with the Lundgren impactor to provide data comparable to that obtained from the 155-mm howitzer. Such measurements would answer the question of whether the aerosols from the two weapon systems truly differ in the sizes of airborne lead particles that they produce during firing.

Second, the chemical nature of the lead in the small-size (less than $0.3 \mu \mathrm{m}$ ) aerosol fraction from the $155-\mathrm{mm}$ howitzer should be determined. We have now collected large amounts of this small particle fraction during our most recent trip to YPG, providing enough samples to do a reliable analysis of the chemical nature of the lead present. The opportunity to do this should not be passed up.

The observation was also made that the $\mathrm{Cu} / \mathrm{Pb}$ ratios of aerosols collected at positions inside the 155-mm/M109A3E2 HIP weapon were consistently lower than the ratios for aerasols collected outside the weapon (see Tables 10-12 and Table 15). A study designed to determine the reasons for this difference might provide insight into the sources of the $\mathrm{Cu}$ and $\mathrm{Pb}$ components of the aerosols.

\subsubsection{Epidemiological Studies}

The study of crew members firing the $155-\mathrm{mm}$ howitzer now being conducted at Fort Sill is an important one. The higher lead exposures anticipated for that weapon system will demonstrate whether the borderline NCV response that may have occurred in the 8-in. howitzer crew members appears with more certainty at higher PbA levels. The 155-mm howitzer study will also provide the opportunity to apply what we learned about the importance of adjusting skin temperatures before making NCV measurements rather than adjusting the data for differences in skin temperature afterwards.

If NCVs decrease among the 155-mm howitzer crew members, a follow-up study should be conducted to determine whether the NCVs return to pre-exposure levels in several months to a year later. An attempt should also be made, possibly experimentally, to evaluate the importance of small decreases in NCV to the conduct of artilleryman duties. The Unit Conduct of Fire Trainer (U/COFT) that is used to simultaneously train tank commanders and gunners could potentially be used to determine whether the ability of military personnel to perform a complex task requiring mental and physical coordination can be correlated with their exposure to lead. The U/COFT measures total length of engagement from target appearance, lay of the gun (aim), indexing of ammunition, and range-finding abilities.

A second approach to evaluating lead exposures in artillerymen is to study the potential consequences of long-term exposures among career personnel. Along these lines, 
we have proposed to evaluate NCVs, blood pressure, and the hematopoietic system in persons with various lengths of service in the artillery to determine whether any changes have occurred that are related to lead exposure. As a measure of cumulative exposure to lead, we have proposed to determine lead concentrations in the skeletons using an instrument for measuring in vivo bone lead concentrations.

Finally, with respect to metabolic aspects of lead exposures, research could be conducted to study the source of lead in the aerosol and in the blood of artillerymen. Preparation of lead foil enriched with a stable isotope of lead, such as ${ }^{204} \mathrm{~Pb}$, would allow us to measure the fraction of total airborne lead that is derived from the lead foil. It would also allow us to measure the contribution of lead in lead foil to total lead in blood and urine of the exposed troops, allowing measurement of fractions derived from current and past exposures.

\subsubsection{Animal Studies}

Effects of sporadic, short-term exposure to high levels of airborne lead could best be studied in an animal system. Once the chemical forms of lead during weapons firing have been identified, one could generate aerosols of the relevant chemical forms of lead and study toxic responses in animals exposed under conditions similar to the military weapons exposures. 


\section{REFERENCES}

Ar87 Araki, S., K. Murata, and H. Aono. Central and peripheral nervous system dysfunction in workers exposed to lead, zinc and copper: a follow-up study of visual and somatosensory evoked potentials. International Archives of Occupational and Environmental Health 59:177-187 (1987).

As80 Ashby, J.A.S. A neurological and biochemi'val study of early lead poisoning. British Journal of Industrial Medicine 37:133-140 (1980).

As85 Astley, C. Medical and Health Surveillance for M109A3 Howitzer Extended Life Program (HELP) Operational Test II, 3 June $1985^{\circ}$ through 26 July 1985, U.S. Army Report (1985).

Az75 Azar, A., R.D. Snee, and K. Habibi. An epidemiologic approach to community air lead exposure using personal air samplers. In: Lead: Environmental Quality and Safety Supplement, Vol. II (Griffin, T.B., and J.H. Knelson, eds.), Academic Press, New York, pp. 255-290 (1975).

Bh85 Bhattacharyya, M.H., R.P. Larsen, B.D. Whelton, E.S. Moretti, D.P. Peterson, and R.D. Oldhm. Influence of Exposure to Lead on Vitamin D Metabolite Concentrations in Young, Growing Rabbits. Argonne National Laboratory Report No. ANL-85-30, pp. 109-110 (1985).

Bo86 Boeckx, R.L. Lead poisoning in children. Analytic Chemistry 58:274A-287A (1986).

Br89 Brewer, F. Lead exposure in an indoor firing range. Journal of Occupational Medicine 31:409-410 (1989).

Bu79 Buchthal, F., and F. Behse. Electrophysiology and nerve biopsy in men exposed to lead. British Journal of Industrial Medicine 36:135-147 (1979).

Ch75. Chamberlain, A.C., W.S. Clough, M.J. Heard, D. Newton, A.N.B. Stott, and A.C. Wells. Uptake of lead by inhalation of motor exhaust. Proceedings of the Royal Society of London B 192:77-110 (1975).

Co84 Corsi, G., G.B. Bartolucci, P. Fardin, P. Negrin, and S. Manzoni. Biochemical and electrophysiological study of subjects with a history of past lead exposure. American Journal of Industrial Medicine 6:281-290 (1984).

Co79 Coutselinis, A., D. Trichopoulos, and X. Zavitsianos. Low blood lead concentrations and hemopoiesis. Clinical Chemistry 25:1339 (1979).

Da88 Dams, R., C. Vandecasteele, B. Desmet, M. Helsen, M. Nagels, G. Vermeir, and Z.Q. Yu. Element concentrations in the air of an indoor shooting range. The Science of the Total Environment 77:1-13 (1988). 
De73 de Jesus, Jr., P.V., I. Hausmanowa-Petrusewicz, and R.L. Barchi. The effect of cold on nerve conduction of human slow and fast nerve fibers. Neurology (Minneapolis) 23:1182-1189 (1973).

Ei80 Eidson, A.F., and J.A. Mewhinney. In vitro solubility of yellowcake samples from four uranium mills and the implications for bioassay interpretation. Health Physics 39:893-902 (1980).

Ei83 Eidson, A.F., and J.A. Mewhinney. In vitro dissolution of respirable aerosols of industrial uranium and plutonium mixed-oxide nuclear fuels. Health Physics 45:1023-1037 (1983).

EPA84a Air Quality Criteria for Lead, Vol. I, U.S. Environmental Protection Agency Report No. EPA-600/8-83-028B, pp. 1-33 (1984).

EPA84b Air Quality Criteria for Lead, Vol. IV, U.S. Environmental Protection Agency Report No. EPA-600/8-83-028B, pp. 11-185 (1984).

Fe77 Feldman, R.F., M.K. Hayes, R. Tounes, and F.D. Aldrich. Lead neuropathy in adults and children. Archives of Neurology 34:481-488 (1977).

Fi79 Fischbein, A., C. Rice, L. Sarkozi, S.H. Kon, M. Petrocci, and I.J. Selikoff. Exposure to lead in firing ranges. Journal of the American Medical Association 241:1141-1144 (1979).

Go67 Goldsmith, J.R., and A.C. Hexter. Respiratory exposure to lead: epidemiological and experimental dose-response relationships. Science 158:132-134 (1967).

Gr75a Griffin, T.B., F. Coulston, H. Wills, and J.C. Russell. Biologic effects of airborne particulate lead on continuously exposed rats and rhesus monkeys. In: Lead: Environmental Quality and Safety Supplement, Vol. II (Griffin, T.B., and J.H. Knelson, eds.), Academic Press, New York, pp. 202-220 (1975).

Gr75b Griffin, T.B., F. Coulston, H. Wills, and J.C. Russell. Clinical studies on men continuously exposed to airborne particulate lead. In Lead: Environmental Quality and Safety Supplement, Vol. II (Griffin, T.B., and J.H. Knelson, eds.), Academic Press, New York, pp. 221-240 (1975).

Gr81 Gross, S.B. Human oral and inhalation exposures to lead: summary of kehoe balance experiments. Journal of Toxicology and Environmental Health 8:333-377 (1981).

Ha85 Hammond, P.B., R.L. Bornschein, and P. Succop. Dose-effect and dose-response relationships of blood lead to erythrocytic protoporphyrin in young children. Environmental Research 38:187-196 (1985). 
He82 Herud, C. and L.C. Brown. Determination of Airborne Lead Concentrations in the Crew Compartment of a M109A2 Self-Propelled Howitzer during Firing. U.S. Army Report No. 83-CC-69 (1982).

Ki83 Kimura, J. Principles of nerve conduction studies. In: Electrodiagnosis in Diseases of Nerve and Muscle: Principles and Practice, F.A. Davis, Philadelphia, pp. 83-104 (1983).

La75 Landrigan, P.J., A.S. McKinney, L.C. Hopkins, W.W. Rhodes, W.A. Price, and D.H. Cox. Chronic lead absorption: result of poor ventilation in an indoor pistol range. Journal of the American Medical Association 234:394-397 (1975).

La85 Landrigan, P.J., and W.E. Straub. Occupational lead exposure aboard a tall ship. American Journal of Industrial Medicine 8:233-239 (1985).

Ma82 Mahaffey, K.R., J.L. Annest, J. Roberts, and R.S. Murphy. National estimates of blood lead levels: United States, 1976-1980: association with selected demographic and socioeconomic factors. New England Journal of Medicine 307:573-579 (1982).

Ma86 Mahaffey, K.R., and J.L. Annest. Association of erythrocyte protoporphyrin with blood lead level and iron status in the second national health and nutrition examination survey, 1976-1980. Environmental Research 41:327-338 (1986).

Ma87 Marafante, E., M. Lundborg, M. Vahter, and P. Camner. Dissolution of two arsenic compounds by rabbit alveolar macrophages in vitro. Fundamental and Applied Toxicology 8:382-388 (1987).

Mu87 Murata, K, S. Araki, and H. Aono. Effects of lead, zinc and copper absorption on peripheral nerve conduction in metal workers. International Archives of Occupational and Environmental Health 59:11-20 (1987).

Ne83 Neri, L.C., H. Johansen, and D. Hewitt. Health effects of low level occupational exposure to lead: the Trail, British Columbia, study. Archives of Environmental Health 38:180-189 (1983).

No87 Novotny, T., M. Cook, J. Hughes, and S.A. Lee. Lead exposure in a firing range. American Journal of Public Health 77:1225-1226 (1987).

Pi73 Piomelli, S. A micromethod for free erythrocytic porphyrins: the FEP test. Journal of Laboratory and Clinical Medicine 81:932-940 (1973).

Pi82 Piomelli, S., C. Seaman, D. Zullow, A. Curran, and B. Davidow. Threshold for lead damage to heme synthesis in urban children. Proceedings of the National Academy of Science USA 79:3335-3339 (1982).

Ra73 Rabinowitz, M.N., G.W. Wetherill, and J.D. Kopple. Lead metabolism in the normal human: stable isotope studies. Science 182:725-727 (1973). 
Ra74 Rabinowitz, M. Lead contamination of the biosphere by human activity: a stable isotope study. Ph.D. Thesis, University of Los Angeles (1974).

SAS85 SAS for Personal Computers, Version 6, SAS Institute, Inc., Cary, NC (1985).

Se83 Seppäläinen A.M., S. Hernberg, R. Vesanto, and B. Kock. Early neurotoxic effects of occupational lead exposure: a prospective study. Neurotoxicology 4:181-192 (1983)

Si83 Singer, R., J.A. Valciukas, and R. Lilis. Lead exposure and nerve conduction velocity: the differential time course of sensory and motor nerve effects. Neurotoxicology 4:193-202 (1983).

St78 Stoeppler, M., K. Brandt, and T.C. Rains. Contributions to automated trace analysis. 2. Rabbit method for automated determination of lead in whole blood by electrothermal atomic absorption spectrophotometry. Analyst 103:714-722 (1978).

Wi69 Williams, M.K, E. King, and J. Walford. An investigation of lead absorption in an electric accumulator factory with the use of personal samplers. British Journal of Industrial Medicine 26:202-216 (1969). 


\section{APPENDIX A:}

\section{INDIVIDUAL VALUES OF PbA, CuA, PbB, HEMATOCRIT, AND FEP}

In this appendix are the following tables of individual values:

Table A.1 Time-weighted-average air lead concentrations for individual crew members of the $4 / 4 \mathrm{FA}\left(\mu \mathrm{g} / \mathrm{m}^{3}\right)$

Table A.2 Copper concentrations for aerosol samples listed in Table A.1

- Table A.3 Time-weighted-average air lead concentrations for individual crew members of the $2 / 18 \mathrm{FA}\left(\mu \mathrm{g} / \mathrm{m}^{3}\right)$

Table A.4 Copper concentrations for aerosol samples listed in Table A.3

Table A.5 Blood lead, hematocrit, and FEP results for crew members of the 4/4 FA

Table A.6 Blood lead; hematocrit, and FEP results for crew members of the 2/18 FA 
TABLE A.1 Time-weighted-average air lead concentrations for individual crew members of the $4 / 4 \mathrm{FA}^{\mathrm{a}}\left(\mu \mathrm{g} / \mathrm{m}^{3}\right)$

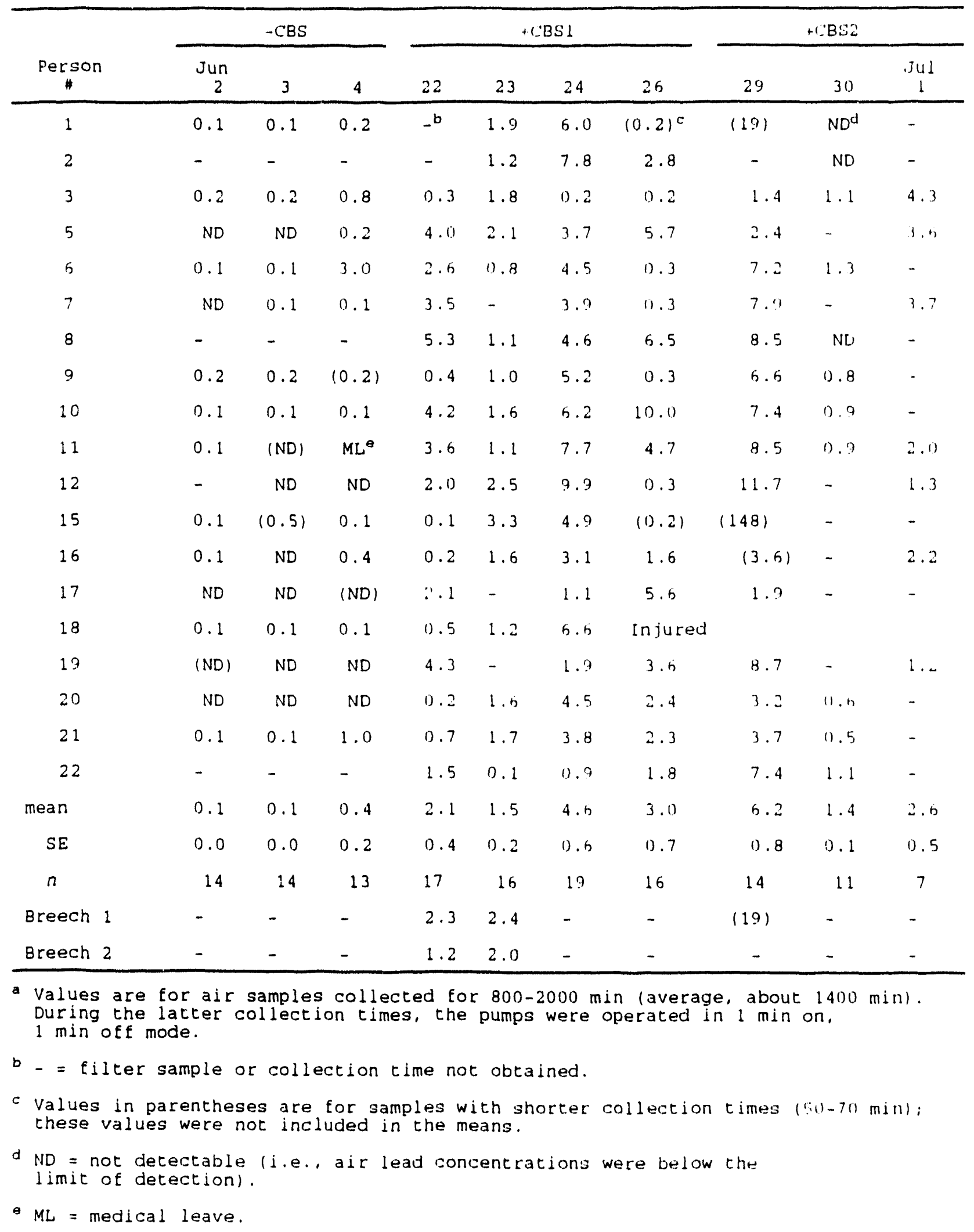


TABLE A.2 Copper concentrations for aerosol samples listed in Table A.1 $\left(\mu \mathrm{g} / \mathrm{m}^{3}\right)$

\begin{tabular}{|c|c|c|c|c|c|c|c|c|c|c|}
\hline \multirow[b]{2}{*}{$\underset{\#}{\text { Person }}$} & \multicolumn{3}{|c|}{$-\mathrm{CBS}$} & \multicolumn{4}{|c|}{$+\mathrm{CBS} 1$} & \multicolumn{3}{|c|}{$+\angle B S 2$} \\
\hline & $\begin{array}{c}\text { Jun } \\
2 \\
\end{array}$ & 3 & 4 & 22 & 23 & 24 & 26 & 29 & 30 & $\begin{array}{c}341 \\
1\end{array}$ \\
\hline 1 & $N D^{a}$ & 0.5 & 2.5 & $-b$ & 11.2 & 2.1 & $(7.5)^{c}$ & $(2.8)$ & ND & - \\
\hline 2 & - & - & - & - & 3.9 & 6.9 & 9.4 & - & $\mathrm{ND}$ & - \\
\hline 3 & ND & ND & 1.0 & 3.0 & 3.7 & ND & 2.6 & 0.7 & $N D$ & 0.4 \\
\hline 5 & ND & 0.7 & 2.1 & 3.6 & 7.9 & 1.2 & 7.1 & 0.8 & ND & 1.2 \\
\hline 6 & ND & 0.5 & 4.9 & 0.5 & 4.5 & 1.6 & 0.3 & 3.9 & 11.1 & . \\
\hline 7 & 0.2 & 1.1 & 2.4 & 2.5 & - & 2.7 & 12.11 & 1.7 & - & $\therefore$. \\
\hline 8 & - & - & - & 1.3 & 6.3 & 2.1 & 13.9 & 2.2 & $N[1$ & .- \\
\hline 9 & 0.7 & 1.4 & $(9.8)$ & 6.8 & 5.3 & 5.6 & 0.8 & 1.5 & ND & - \\
\hline 10 & 0.1 & 0.8 & 2.5 & 4.3 & 8.1 & 3.7 & 20.2 & 2.3 & 2.5 & - \\
\hline 11 & ND & (ND) & - & 1.0 & 5.1 & 2.3 & 7.9 & 1.2 & ND & 0.4 \\
\hline 12 & ND & 0.2 & 0.4 & 2.3 & 12.4 & 7.8 & 8.9 & 3.9 & ND & ND \\
\hline 15 & 0.3 & (ND) & 0.2 & 3.7 & 5.2 & 4.5 & $(23.7)$ & $(38.3)$ & - & - \\
\hline 16 & 1.0 & 1.3 & 2.1 & 4.0 & 7.9 & 3.3 & 5.1 & $(3.6)$ & - & 0.4 \\
\hline 17 & ND & 0.3 & ND & 0.5 & - & 1.7 & 6.1 & 0.7 & - & - \\
\hline 18 & 0.2 & 1.0 & 2.4 & 3.0 & 2.9 & 1.8 & Injured & & & \\
\hline 19 & (ND) & 0.2 & 4.8 & 5.0 & - & 0.8 & h.t & 1.8 & - & 11.4 \\
\hline 20 & ND & 0.8 & 0.6 & 4.2 & 5.3 & 2.4 & 12.1 & $1 . t$ & - & - \\
\hline 21 & 0.8 & 1.3 & 1.3 & 5.8 & 5.5 & 3.8 & 5.9 & 1.3 & $N[1$ & - \\
\hline 22 & - & - & - & 0.4 & ND & 0.1. & 10.5 & 1.8 & ND & - \\
\hline mean & 0.5 & 0.8 & 2.1 & 3.1 & 6.3 & 2.9 & 8.0 & $2.1)$ & - & $0 . n$ \\
\hline$S E$ & 0.1 & 0.1 & 0.4 & 0.5 & 0.7 & 0.5 & 1.2 & 0.3 & - & 11.1 \\
\hline$n$ & 7 & 13 & 13 & 17 & 15 & 18 & 17 & 16 & - & $n$ \\
\hline Breech 1 & - & - & - & 3.5 & 8.4 & - & - & $(4.2)$ & - & - \\
\hline Breech 2 & - & - & - & 1.6 & 6.8 & - & - & - & - & - \\
\hline
\end{tabular}

a $N D=$ not detectable.

b - = filter sample or collection time not obtained.

c Values in parentheses are for samples with short collection times, as indicated in Table A.1. 
TABLE An3 Time-wieghted-average air lead concentrations for individual crew members of the $2 / 18 \mathrm{FA}^{\mathrm{a}}\left(\mu \mathrm{g} / \mathrm{m}^{3}\right)$

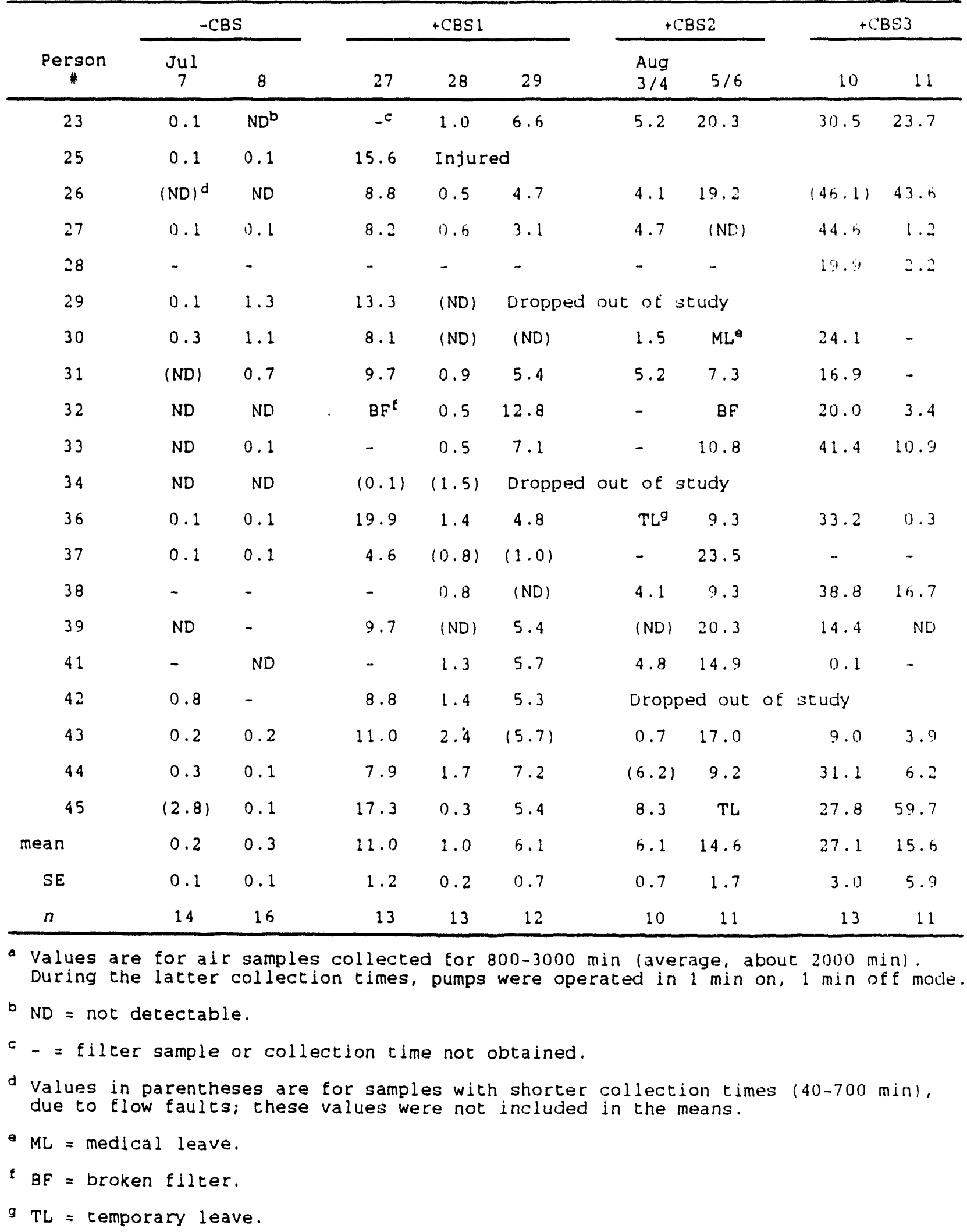


TABLE A.4 Copper concentration for aerosol samples in Table A.3 $\left(\boldsymbol{\mu g} / \mathrm{m}^{3}\right)$

\begin{tabular}{|c|c|c|c|c|c|c|c|c|c|}
\hline \multirow[b]{2}{*}{$\begin{array}{c}\text { Person } \\
\quad \#\end{array}$} & \multicolumn{2}{|c|}{- CBS } & \multicolumn{3}{|c|}{$+C B S 1$} & \multicolumn{2}{|c|}{$+\mathrm{CBS} 2$} & \multicolumn{2}{|c|}{$+\mathrm{CBS3}$} \\
\hline & $\begin{array}{c}\mathrm{Jul} \\
7\end{array}$ & 8 & 27 & 28 & 29 & $\begin{array}{l}\text { Aug } \\
3 / 4\end{array}$ & $5 / 6$ & 11) & 11 \\
\hline 23 & $\mathrm{ND}^{\mathrm{a}}$ & ND & $-b$ & 5.4 & 2.2 & 6.6 & 12.2 & 14.6 & 15.0 \\
\hline 24 & ND & 0.6 & 5.0 & - & - & - & - & - & - \\
\hline 26 & ND & 1.3 & 4.2 & 11.5 & 1.4 & 3.7 & 11.8 & 27.4 & 36.8 \\
\hline 27 & ND & 0.4 & 4.0 & 8.7 & 1.1 & 5.6 & $(N D)^{c}$ & 18.5 & 1.5 \\
\hline 28 & - & - & - & - & - & - & - & 10.5 & 1.5 \\
\hline 29 & ND & 2.4 & 7.4 & (ND) & Dropped & out of at & cudy & & \\
\hline 30 & ND & 1.3 & 1.3 & (ND) & $(N D)$ & 2.6 & $M L^{d}$ & 15.3 & - \\
\hline 31 & (ND) & 0.8 & 4.4 & 12.1 & 2.1 & 7.3 & 1.9 & 9.1 & - \\
\hline 32 & ND & 1.1 & $B F^{e}$ & 8.9 & 5.8 & - & 0.7 & 11.9 & 2.1 \\
\hline 33 & ND & 0.4 & - & 10.0 & 3.2 & - & 5.7 & 31.1 & 9.2 \\
\hline 34 & ND & 0.2 & (ND) & $(41.3)$ & Dropped & out of 3 & cudy & & \\
\hline 36 & ND & 1.2 & 8.6 & 23.4 & 2.3 & $T L^{\mathrm{E}}$ & 3.4 & 21.2 & 1.4 \\
\hline 37 & ND & ND & 0.9 & $(33.5)$ & $(3.4)$ & - & 13.1 & 10.5 & 1.4 \\
\hline 38 & ND & - & (ND) & 1.7 & (ND) & 3.3 & 2.3 & 21.0 & 10.4 \\
\hline 39 & ND & ND & 4.5 & (ND) & 1.7 & (ND) & 17.3 & 7.6 & ND \\
\hline 41 & ND & ND & - & 8.6 & 2.4 & 6.5 & 5.7 & ND & - \\
\hline 42 & ND & - & 4.4 & 18.1 & 4.4 & Droppe & d out & of study & \\
\hline 43 & ND & 1.9 & 2.8 & 0.6 & $(2.5)$ & 0.5 & 8.7 & 3.2 & 3.1 \\
\hline 44 & 0.04 & 0.8 & 1.9 & 1.4 & 2.1 & $(5.3)$ & 3.8 & 19.8 & 4.0 \\
\hline 45 & (ND) & ND & 5.7 & 6.2 & 2.9 & 6.2 & $\mathrm{TL}$ & 13.5 & 39.7 \\
\hline mean & ND & 1.0 & 4.2 & 10.3 & 2.6 & 4.7 & 7.2 & 16.1 & 11.3 \\
\hline SE & - & 0.2 & 0.6 & 1.9 & 0.4 & 0.8 & 1.5 & $2.1)$ & 4.2 \\
\hline$n$ & - & 12 & 13 & 13 & 12 & 9 & 12 & 14 & 11 \\
\hline
\end{tabular}

a ND $=$ not detectable.

$b-=$ filter or collection time not obtained.

c Values in parentheses are from aerosol samples with shorter collection times, as indicated in Table A.3.

$d M L=$ medical leave.

Q $B F=$ broken filter.

f TL - temporary leave. 
TABLE A.5 Blood lead, hematocrit, and FEP results for crew members of the $4 / 4 \mathrm{FA}^{\mathrm{a}}$

\begin{tabular}{|c|c|c|c|c|c|c|c|c|c|c|c|c|c|}
\hline \multirow{2}{*}{$\begin{array}{c}\text { Person } \\
\#\end{array}$} & \multicolumn{7}{|c|}{ Blood lead $(\mu \mathrm{g} / \mathrm{dL})$} & \multicolumn{3}{|c|}{$\begin{array}{c}\text { Hematoorit } \\
\text { (8) }\end{array}$} & \multicolumn{3}{|c|}{ FEP $(\mu \mathrm{g} / \mathrm{dL})$} \\
\hline & & $B L$ & $-C B S$ & $+\mathrm{CBS} 1$ & $+C B S 2$ & IPE & DPE & BL & I PE & DPE & BL & I PE & DPE \\
\hline 1 & & 8 & 5 & 7 & 9 & 7 & 6 & 41 & 44 & 43 & 20 & 18 & 16 \\
\hline 2 & & 9 & - & 10 & 17 & 8 & 9 & 46 & 44 & 49 & 18 & 18 & 24 \\
\hline 3 & & 5 & 4 & - & 5 & - & 3 & 39 & - & 40 & 19 & - & 21 \\
\hline 4 & & 8 & 7 & - & 8 & 7 & 6 & 44 & 43 & 46 & 17 & 17 & 18 \\
\hline 5 & & 6 & 8 & 9 & 10 & 10 & 7 & 43 & 41 & $4 h$ & 15 & In & 19 \\
\hline 6 & & 8 & 8 & 9 & 9 & 10 & 8 & 43 & 47 & 47 & It & 16 & 18 \\
\hline 7 & & 6 & 8 & 7 & 7 & 9 & 7 & 46 & 47 & 48 & 17 & 18 & 17 \\
\hline 8 & & 6 & 7 & 8 & - & 9 & 7 & 44 & 45 & 48 & 22 & 24 & 17 \\
\hline 9 & & 7 & 6 & - & 6 & 10 & 3 & 44 & 47 & 44 & 18 & 18 & 18 \\
\hline 10 & & 5 & 6 & 6 & 8 & 9 & 6 & 46 & - & 47 & 20 & 20 & 18 \\
\hline 11 & & 19 & - & 10 & 10 & - & 6 & 46 & - & 45 & 20 & - & 19 \\
\hline 12 & & 6 & 4 & - & 14 & 4 & - & 45 & 43 & - & 21 & 19 & - \\
\hline 15 & & 8 & 8 & 10 & - & 9 & 6 & 43 & 46 & 44 & 24 & 19 & 22 \\
\hline 16 & & 3 & 3 & 5 & 5 & 4 & 2 & 44 & - & 44 & 23 & 17 & 27 \\
\hline 17 & & 6 & 9 & 6 & 8 & 6 & 6 & 41 & 41 & 39 & - & 18 & 18 \\
\hline $18^{b}$ & & 6 & 5 & - & - & - & 2 & 46 & - & 50 & - & - & 19 \\
\hline 19 & & 7 & 8 & 8 & 14 & 11 & 8 & 43 & 44 & 46 & 17 & 19 & 24 \\
\hline 20 & & 4 & 7 & 6 & 7 & 4 & 6 & 42 & 40 & 44 & 22 & 24 & 27 \\
\hline 21 & & 8 & 7 & 7 & 8 & 7 & 5 & 46 & - & 45 & 19 & 21 & 19 \\
\hline 22 & & 6 & 7 & 7 & 7 & - & 5 & 45 & 44 & 48 & 16 & - & 19 \\
\hline $\begin{array}{ll}\text { a } & \text { BL } \\
\text {-CBS } \\
+ \text { +CSS1 } \\
+ \text { CBS2 } \\
\text { IPE } \\
\text { DPE }\end{array}$ & $\begin{array}{l}= \\
= \\
= \\
= \\
= \\
=\end{array}$ & $\begin{array}{l}\text { bas } \\
\text { dur } \\
\text { dur } \\
\text { dur } \\
\text { imm } \\
\text { del }\end{array}$ & $\begin{array}{l}\text { eline } \\
\text { ing } \mathrm{fi} \\
\text { ing } \mathrm{f} \\
\text { ing se } \\
\text { ediate } \\
\text { ayed } \mathrm{p}\end{array}$ & $\begin{array}{l}t \text { firi } \\
t \text { firi } \\
\text { nd } f \text { ir } \\
\text { ost-ex } \\
t-\operatorname{expo}\end{array}$ & $\begin{array}{l}\text { irst f } \\
\text { g miss } \\
g \text { miss } \\
\text { ng miss } \\
\text { osure } \\
\text { ure } 16\end{array}$ & $\begin{array}{l}\text { ing } \\
n \text { wi } \\
n \text { wit } \\
\text { on w } \\
\text { mmed. } \\
\text { eeks }\end{array}$ & $\begin{array}{l}\text { ssion) } \\
\text { out crew } \\
\text { CBS } \\
\text { h CBS } \\
\text { tiely after } \\
\text { fter last }\end{array}$ & $r$ las & $=\begin{array}{l}=\mathrm{fir} \\
\mathrm{ig} \mathrm{mi}\end{array}$ & $\begin{array}{l}\text { shelter } \\
\text { ing miss } \\
\text { ssion). }\end{array}$ & $\begin{array}{l}\text { (CBS) } \\
\text { ion) }\end{array}$ & & \\
\hline
\end{tabular}


TABLE A.6 Blood lead, hematocrit, and FEP results for crew members of the $2 / 18 \mathrm{FA}^{\mathrm{a}}$

\begin{tabular}{|c|c|c|c|c|c|c|c|c|c|c|c|c|c|}
\hline \multirow[b]{2}{*}{$\begin{array}{c}\text { Eerson } \\
*\end{array}$} & \multicolumn{7}{|c|}{ Blood lead $(\mu g / d L)$} & \multicolumn{3}{|c|}{$\begin{array}{c}\text { Hematocrit } \\
\left(\begin{array}{l}0 \\
0\end{array}\right)\end{array}$} & \multicolumn{3}{|c|}{$\operatorname{FEP} \quad(\mu g / d L)$} \\
\hline & BL & $-\mathrm{CBS}$ & $\begin{array}{c}+\mathrm{CBS} \\
1\end{array}$ & $\begin{array}{c}+C B S \\
2\end{array}$ & $\begin{array}{c}+\mathrm{CBS} \\
3\end{array}$ & IPE & DPE & $B L$ & IPE & DPE & $\mathrm{BL}$ & I PE & DPE \\
\hline 23 & 2 & 3 & 5 & 9 & 11 & 11 & - & 47 & 44 & - & 27 & 28 & - \\
\hline $24^{b}$ & 3 & - & - & - & - & - & - & 48 & - & - & - & - & - \\
\hline $25^{c}$ & 4 & 5 & - & - & - & - & 7 & 41 & - & 45 & 11 & - & 21 \\
\hline 26 & 5 & 4 & 7 & 11 & 13 & 10 & 12 & - & 46 & 49 & 13 & 18 & 14 \\
\hline 27 & 7 & 4 & 3 & 15 & 15 & 17 & 11 & 43 & 45 & $4 h$ & 22 & 24 & 18 \\
\hline 28 & 5 & 3 & - & 7 & 9 & 12 & 8 & 44 & 44 & 43 & 15 & 15 & 12 \\
\hline $29^{b}$ & 4 & 4 & 6 & - & - & - & 10 & 48 & - & 46 & 19 & - & 19 \\
\hline 30 & 6 & 5 & 6 & - & - & 16 & 15 & 43 & 42 & 44 & 11 & 15 & 11 \\
\hline 31 & 3 & 3 & 7 & 11 & - & 12 & 9 & 42 & 41 & 44 & 17 & 19 & 14 \\
\hline 32 & 7 & 6 & 9 & 13 & 13 & 16 & - & 42 & 46 & - & 17 & 24 & - \\
\hline 33 & 5 & 4 & 7 & 11 & 12 & 14 & 11 & 50 & 46 & 47 & 19 & 19 & 14 \\
\hline $34^{\mathrm{k}}$ & 6 & 5 & 5 & - & - & 9 & - & 48 & 47 & - & 13 & 20 & - \\
\hline 35 & 5 & 3 & 6 & 8 & - & 11 & 12 & 48 & 44 & 49 & 30 & 26 & 19 \\
\hline 36 & 3 & 3 & 5 & 8 & 10 & - & 10 & 49 & 43 & 45 & 19 & 19 & 14 \\
\hline 37 & 3 & 2 & 3 & - & - & 4 & 4 & 47 & 46 & 46 & 26 & 29 & 23 \\
\hline 38 & $-d$ & 4 & 7 & 9 & 3 & 9 & 11 & 49 & $4 n$ & 49 & 18 & 21 & 20 \\
\hline 39 & 5 & - & 6 & 13 & 11 & 11 & 10 & 48 & 45 & 49 & 19 & 20 & 15 \\
\hline .40 & 3 & 1 & 3 & 4 & 5 & - & 6 & 46 & - & 45 & 15 & - & 13 \\
\hline 41 & 6 & - & 6 & 8 & - & 13 & 10 & 47 & 44 & 46 & 21 & 25 & 19 \\
\hline $42^{\circ}$ & 4 & 5 & 6 & - & - & - & - & 42 & - & - & - & - & - \\
\hline 43 & 4 & 3 & 3 & - & 9 & 7 & 8 & 45 & 43 & 44 & 32 & 31 & 19 \\
\hline 44 & 6 & 3 & 4 & 7 & 11 & 12 & 10 & 48 & 46 & 48 & 14 & 20 & 14 \\
\hline 45 & 6 & 4 & 5 & - & 8 & 10 & 10 & 4.7 & 50 & 51 & 21 & 20 & In \\
\hline
\end{tabular}

a $B L=$ baseline (before first firing mission)

-CBS = during first firing mission without crew ballistia shelter (CBS)

+CBS1 = during first firing mission with CBS

+ CBS2 = during second firing mission with CBS

$+\mathrm{CBS} 3$ = during third firing mission with CBS

IPE = irmediate post-exposure (immediately after last firing mission)

DPE = delayed post-exposure ( 6 weeks after last firing mission)

b Drupped out of study.

c Injured.

d Blood clotted - unable to take suitable sample. 


\section{APPENDIX B: \\ INDIVIDUAL VALUES OF NERVE CONDUCTION VELOCITY AND SKIN TEMPERATURE}

In this appendix are listings of the individual values of nerve conduction velocity and skin temperature. For nerve conduction velocity listings, Table B.1,

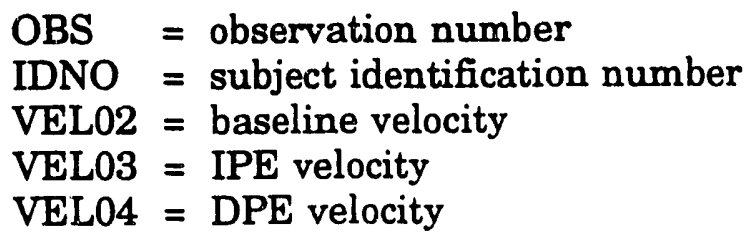

For skin temperature listings, Tables B.2 through B.4,

Tech = technician

Hand = right (R) or left (L)

Room = room temperature $\left({ }^{\circ} \mathrm{C}\right)$

HSTs = hand skin temperature at start of NCV measurement period (nerves MM, UM, MS, US)

HSTe = hand skin temperature at end of NCV measurement period

LSTs = leg skin temperature at start of NCV measurement period (nerves PM, SS)

LSTe = leg skin temperature at end of NCV measurement period 
TABLE B.1 Individual values of nerve conduction velocity $(\mathrm{m} / \mathrm{s})$

\begin{tabular}{|c|c|c|c|c|c|}
\hline OBS & IDNO & NERVE & VELO2 & VELO3 & VELO4 \\
\hline 1 & 1 & MM & 56.92 & 56.03 & 56.03 \\
\hline 2 & 2 & MM & 61.42 & 62.50 & 63.64 \\
\hline 3 & 3 & MM & 61.40 & 62.50 & 62.50 \\
\hline 4 & 4 & MM & 55.92 & 56.82 & 56.92 \\
\hline 5 & 5 & MM & 57.38 & 57.38 & 54.44 \\
\hline 6 & 6 & MM & 57.95 & 58.96 & 59.09 \\
\hline 7 & 7 & MM & 59.27 & 57.20 & 60.14 \\
\hline 8 & 8 & MM & 59.15 & 60.19 & 61.32 \\
\hline 9 & 9 & MM & 58.33 & 60.38 & 60.38 \\
\hline 10 & 10 & MM & 60.05 & 60.00 & 59.90 \\
\hline 11 & 11 & MM & 54.82 & 59.09 & 59.09 \\
\hline 12 & 12 & MM & 58.40 & 59.37 & • \\
\hline 13 & 13 & MM & 64.32 & - & - \\
\hline 14 & 14 & MM & - & - & - \\
\hline 15 & 15 & MM & 58.11 & 58.11 & 59.21 \\
\hline 16 & 16 & $\mathbf{M M}$ & 58.19 & 56.35 & 57.29 \\
\hline 17 & 17 & MIM & 60.23 & 62.50 & 60.05 \\
\hline 18 & 18 & MM & 64.77 & - & 61.40 \\
\hline 19 & 19 & $\mathbf{M M}$ & 60.31 & 61.40 & 59.38 \\
\hline 20 & 20 & $\mathbf{M M}$ & 59.82 & 59.15 & 60.14 \\
\hline 21 & 21 & $\mathbf{M M}$ & 63.73 & 60.23 & 59.09 \\
\hline 22 & 22 & MM & 55.44 & 55.44 & 53.71 \\
\hline 23 & 23 & $\mathbf{M M}$ & 56.82 & 55.92 & - \\
\hline 24 & 24 & MM & 55.56 & - & - \\
\hline 25 & 25 & $\mathbf{M M}$ & 56.82 & - & 61.30 \\
\hline 26 & 26 & $\mathbf{M M}$ & 64.95 & 64.86 & 64.90 \\
\hline 27 & 27 & $\mathbf{M M}$ & 59.32 & 54.92 & 55.44 \\
\hline 28 & 28 & MM & 61.40 & 59.43 & 58.26 \\
\hline 29 & 29 & MM & 58.96 & - & 56.92 \\
\hline 30 & 30 & $\mathbf{M M}$ & 59.09 & 62.50 & 62.50 \\
\hline 31 & 31 & $\mathbf{M M}$ & 56.03 & 56.25 & 54.30 \\
\hline 32 & 32 & $\mathbf{M M}$ & 56.71 & 60.19 & - \\
\hline 33 & 33 & $\mathbf{M M}$ & 61.30 & 63.73 & 60.00 \\
\hline 34 & 34 & $\mathbf{M M}$ & 56.45 & 56.45 & - \\
\hline 35 & 35 & $\mathbf{M M}$ & 58.40 & 56.55 & 56.45 \\
\hline 36 & 36 & $\mathbf{M M}$ & 56.73 & 60.42 & 58.47 \\
\hline 37 & 37 & $\mathbf{M M}$ & 53.88 & 59.03 & 57.87 \\
\hline 38 & 38 & $\mathbf{M M}$ & 60.19 & 60.10 & 60.46 \\
\hline 39 & 39 & $\mathbf{M M}$ & 61.22 & 62.50 & 60.00 \\
\hline 40 & 40 & $\mathbf{M} \mathbf{M}$ & 63.73 & - & $60 \cdot 1.4$ \\
\hline 41 & 41 & MM & 54.82 & 60.10 & 59.03 \\
\hline 42 & 42 & $\mathbf{M M}$ & 60.19 & - & - \\
\hline 43 & 43 & MM & 52.54 & 53.57 & 57.62 \\
\hline 44 & 44 & MaM & 54.44 & 62.50 & 60.27 \\
\hline 45 & 45 & $\mathbf{M M}$ & 58.04 & 57.11 & 60.23 \\
\hline
\end{tabular}


TABLE B.1 (Cont)

\begin{tabular}{|c|c|c|c|c|c|}
\hline OBS & IDNO & NERVE & VELO2 & VELO3 & VELO4 \\
\hline 46 & 1 & UM & 60.69 & 60.66 & 61.57 \\
\hline 47 & 2 & UM & 65.14 & 64.29 & 62.50 \\
\hline 48 & 3 & UM & 62.50 & 62.50 & 60.66 \\
\hline 49 & 4 & UM & 50.78 & 52.88 & 52.76 \\
\hline 50 & 5 & UM & 61.59 & 59.90 & 56.89 \\
\hline 51 & 6 & $\mathbf{U M}$ & 62.50 & 61.55 & 54.79 \\
\hline 52 & 7 & $\mathbf{U M}$ & 64.34 & 59.93 & 61.59 \\
\hline 53 & 8 & UM & 63.49 & 64.42 & 60.71 \\
\hline 54 & 9 & UM & 52.59 & 57.69 & 56.25 \\
\hline 55 & 10 & UM & 64.58 & 61.55 & 65.57 \\
\hline 56 & 11 & UM & 52.21 & 57.29 & 52.59 \\
\hline 57 & 12 & UM & 60.81 & 60.83 & • \\
\hline 58 & 13 & $\mathbf{U M}$ & 56.34 & - & • \\
\hline 59 & 14 & UM & - & - & - \\
\hline 60 & 15 & UM & 60.71 & 58.16 & 61.62 \\
\hline 61 & 16 & UM & 61.57 & 55.74 & 57.43 \\
\hline 62 & 17 & $\mathbf{U M}$ & 65.57 & 64.55 & 61.52 \\
\hline 63 & 18 & UM & 57.63 & - & 54.51 \\
\hline 64 & 19 & UM & 69.23 & $68 \cdot 10$ & 64.26 \\
\hline 65 & 20 & $\mathbf{U M}$ & 59.08 & 57.50 & 58.33 \\
\hline 66 & 21 & UM & 61.61 & 55.83 & 58.33 \\
\hline 67 & 22 & UM & 60.83 & 59.08 & 56.25 \\
\hline 68 & 23 & UM & 59.57 & 59.03 & - \\
\hline 69 & 24 & UM & 54.22 & - & - \\
\hline 70 & 25 & $\mathbf{U M}$ & 65.22 & - & 62.50 \\
\hline 71 & 26 & UM & 64.29 & 65.43 & 62.50 \\
\hline 72 & 27 & UM & 57.16 & 46.20 & 46.54 \\
\hline 73 & 28 & UM & 60.88 & 60.83 & 58.39 \\
\hline 74 & 29 & $\mathbf{U M}$ & 59.03 & - & 61.57 \\
\hline 75 & 30 & UM & 62.50 & 60.63 & 59.66 \\
\hline 76 & 31 & UM & 59.08 & 59.74 & 59.74 \\
\hline 77 & 32 & UM & 57.57 & 66.53 & • \\
\hline 78 & 33 & UM & 65.48 & 65.57 & 63.49 \\
\hline 79 & 34 & $\mathbf{U M}$ & 63.32 & 61.64 & - \\
\hline 80 & 35 & UM & 58.54 & 61.62 & 58.33 \\
\hline 81 & 36 & UM & 46.41 & 52.31 & 50.95 \\
\hline 82 & 37 & UM & 63.42 & 63.46 & 62.50 \\
\hline 83 & 38 & $\mathbf{U M}$ & 64.37 & 58.82 & 58.71 \\
\hline 84 & 39 & UM & 63.45 & 68.29 & 69.20 \\
\hline 85 & 40 & $\mathbf{U M}$ & 66.29 & $\bullet$ & 60.61 \\
\hline 86 & 41 & UM & 57.14 & 61.55 & 60.58 \\
\hline 87 & 42 & UM & 60.76 & $\cdot$ & $\cdot$ \\
\hline 88 & 43 & $\mathbf{U}$ & 56.55 & $51 \cdot 14$ & 59.34 \\
\hline 89 & 44 & UM & 49.31 & 56.96 & 58.39 \\
\hline 90 & 45 & UM & 61.63 & 56.01 & 57.57 \\
\hline
\end{tabular}


TABLE B.1 (Cont.)

\begin{tabular}{|c|c|c|c|c|c|}
\hline OBS & IDNO & NERVE & VELO2 & VELO3 & VELO4 \\
\hline 91 & 1 & MS & 59.03 & 60.14 & 60.14 \\
\hline 92 & 2 & MS & 67.22 & 63.64 & 62.50 \\
\hline 93 & 3 & MS & 60.34 & 62.50 & $61 \cdot 34$ \\
\hline 94 & 4 & MS & 53.42 & 58.89 & 58.89 \\
\hline 95 & 5 & MS & 61.38 & 58.26 & 56.35 \\
\hline 96 & 6 & MS & 61.34 & 58.96 & 56.82 \\
\hline 97 & 7 & MS & 59.15 & 58.19 & 62.50 \\
\hline 98 & 8 & MS & 60.27 & 60.19 & 58.96 \\
\hline 99 & 9 & MS & 63.62 & 64.77 & 64.77 \\
\hline 100 & 10 & MS & 63.83 & 61.17 & 62.50 \\
\hline 101 & 11 & MS & 57.02 & 60.19 & 59.03 \\
\hline 102 & 12 & MS & 65.32 & 63.64 & - \\
\hline 103 & 13 & MS & 65.10 & - & • \\
\hline 104 & 14 & MS & - & - & - \\
\hline 105 & 15 & MS & 61.32 & 59.21 & 59.27 \\
\hline 106 & 16 & MS & 61.90 & 64.86 & 60.31 \\
\hline 107 & 17 & MS & 63.70 & 64.95 & 63.80 \\
\hline 108 & 18 & MS & 67.86 & - & 63.68 \\
\hline 109 & 19 & MS & 60.34 & 61.38 & 59.38 \\
\hline 110 & 20 & MS & 60.19 & 60.23 & 61.36 \\
\hline 111 & 21 & MS & 63.73 & 60.23 & $61 \cdot 34$ \\
\hline 112 & 22 & MS & 59.92 & 58.40 & 57.29 \\
\hline 113 & 23 & MS & 58.89 & 57.87 & - \\
\hline 114 & 24 & MS & 59.32 & - & - \\
\hline 115 & 25 & MS & 62.50 & - & 63.73 \\
\hline 116 & 26 & MS & 64.86 & 64.77 & 63.68 \\
\hline 117 & 27 & MS & 54.69 & 52.54 & 52.88 \\
\hline 118 & 28 & MS & 61.38 & 61.44 & 61.38 \\
\hline 119 & 29 & MS & 56.60 & - & 57.78 \\
\hline 120 & 30 & MS & 60.19 & 61.38 & 60.27 \\
\hline 121 & 31 & MS & 59.09 & 60.31 & 59.09 \\
\hline 122 & 32 & MS & 58.89 & 59.03 & - \\
\hline 123 & 33 & MS & 62.50 & 63.83 & 61.22 \\
\hline 124 & 34 & MS & 59.27 & 60.34 & - \\
\hline 125 & 35 & MS & 60.38 & 60.31 & 59.32 \\
\hline 126 & 36 & MS & 59.57 & 59.43 & 57.46 \\
\hline 127 & 37 & MS & 53.12 & 57.95 & 53.88 \\
\hline 128 & 38 & MS & 59.03 & 59.41 & 59.95 \\
\hline 129 & 39 & MS & 58.89 & 60.10 & 57.69 \\
\hline 130 & 40 & MS & 62.50 & - & 61.78 \\
\hline 131 & 41 & MS & 58.89 & 62.50 & 60.19 \\
\hline 132 & 42 & MS & 63.70 & • & • \\
\hline 133 & 43 & MS & 44.21 & 54.23 & 59.07 \\
\hline 134 & 44 & MS & 56.14 & 60.23 & 62.50 \\
\hline 135 & 45 & MS & 59.15 & 57.20 & 57.02 \\
\hline
\end{tabular}


TABLE B.1 (Cont)

\begin{tabular}{|c|c|c|c|c|c|}
\hline OBS & IDNO & NERVE & VELO2 & VELO3 & VELO4 \\
\hline 136 & 1 & US & 62.50 & 61.57 & 61.59 \\
\hline 137 & 2 & US & 64.75 & 67.16 & 65.30 \\
\hline 138 & 3 & US & 65.48 & 63.51 & 64.39 \\
\hline 139 & 4 & US & 52.88 & 53.21 & 55.5 \\
\hline 140 & 5 & US & 64.37 & 60.69 & 63.3 \\
\hline 141 & 6 & US & 63.46 & 63.48 & 57.2 \\
\hline 142 & 7 & US & 66.35 & 61.59 & 65.3 \\
\hline 143 & 8 & US & 59.62 & 60.61 & 61.5 \\
\hline 144 & 9 & US & 60.03 & 63.39 & 64.2 \\
\hline 145 & 10 & US & 65.68 & 66.60 & 66.8 \\
\hline 146 & 11 & US & 58.49 & 58.04 & 55.9 \\
\hline 147 & 12 & US & 64.24 & 64.29 & . \\
\hline 148 & 13 & US & 62.50 & - & - \\
\hline 149 & 14 & US & - & • & - \\
\hline 150 & 15 & US & 62.96 & 60.66 & 61.5 \\
\hline 151 & 16 & US & 70.97 & 62.50 & 63.4 \\
\hline 152 & 17 & US & 62.50 & 63.46 & 64.4 \\
\hline 153 & 18 & US & 61.62 & - & 54.6 \\
\hline 154 & 19 & US & 65.30 & 67.10 & 61.6 \\
\hline 155 & 20 & US & 60.71 & 57.36 & 60.0 \\
\hline 156 & 21 & US & 58.93 & 54.28 & 55.8 \\
\hline 157 & 22 & US & 64.29 & 57.43 & 62.5 \\
\hline 158 & 23 & US & 64.58 & 62.50 & 。 \\
\hline 159 & 24 & US & 58.44 & - & - \\
\hline 160 & 25 & US & 59.17 & . & 66.6 \\
\hline 161 & 26 & US & 67.31 & 64.52 & 62.5 \\
\hline 162 & 27 & US & 53.05 & 49.06 & 50.6 \\
\hline 163 & 28 & US & 68.01 & 64.37 & 60.7 \\
\hline 164 & 29 & US & 67.16 & $\cdot$ & 66 \\
\hline 165 & 30 & US & 63.43 & 56.16 & 61.5 \\
\hline 166 & 31 & US & 62.50 & 60.63 & 60 \\
\hline 167 & 32 & US & 58.44 & 65.57 & - \\
\hline 168 & 33 & US & 65.48 & 63.52 & 65. \\
\hline 169 & 34 & US & 84.09 & 63.37 & - \\
\hline 170 & 35 & US & 59.93 & 62.50 & 61. \\
\hline 171 & 36 & US & 50.43 & 53.37 & 53.8 \\
\hline 172 & 37 & US & 58.10 & 62.50 & 60.6 \\
\hline 173 & 38 & US & 65.48 & 59.57 & 57.8 \\
\hline 174 & 39 & US & 66.53 & 64.62 & 63. \\
\hline 175 & 40 & US & 62.50 & - & 61.5 \\
\hline 176 & 41 & US & 55.56 & 63.49 & 60. \\
\hline 177 & 42 & US & 63.37 & - & - \\
\hline 178 & 43 & US & 44.56 & 55.47 & 56. \\
\hline 179 & 44 & US & 53.05 & 58.44 & 59.1 \\
\hline 180 & 45 & US & 66.23 & 54.88 & 52. \\
\hline
\end{tabular}


TABLE B.1 (Cont.)

\begin{tabular}{|c|c|c|c|c|c|}
\hline OBS & IDNO & NERVE & VELO2 & VELO3 & VELO4 \\
\hline $\begin{array}{l}181 \\
182 \\
183 \\
184 \\
185\end{array}$ & $\begin{array}{l}1 \\
2 \\
3 \\
4 \\
5\end{array}$ & $\begin{array}{l}\text { PM } \\
\text { PM } \\
\text { PM } \\
\text { PM } \\
\text { PM }\end{array}$ & $\begin{array}{l}46.70 \\
51.07 \\
50.56 \\
51.28 \\
51.60\end{array}$ & $\begin{array}{l}. \bullet 47 \\
51.47 .03 \\
46.02 \\
47.87\end{array}$ & $\begin{array}{l}51.08 \\
53.47 \\
49.72 \\
50.14\end{array}$ \\
\hline $\begin{array}{l}186 \\
187\end{array}$ & $\begin{array}{l}6 \\
7\end{array}$ & PM & $\begin{array}{l}47.39 \\
50.60\end{array}$ & $51 \cdot 60$ & 50.95 \\
\hline $\begin{array}{l}187 \\
188\end{array}$ & $\begin{array}{l}7 \\
8\end{array}$ & $\begin{array}{l}\text { PM } \\
\text { PM }\end{array}$ & 52.76 & 57.50 & 52.44 \\
\hline 189 & 9 & PM & 51.01 & 51.39 & 50.00 \\
\hline 190 & 10 & PM & 48.44 & 49.38 & 54.69 \\
\hline 191 & 11 & PM & 50.48 & 51.56 & 48.30 \\
\hline 192 & 12 & PM & 52.08 & 51.60 & • \\
\hline 193 & 13 & PM & 54.46 & • & - \\
\hline 194 & 14 & PM & - & - & $0^{\circ}$ \\
\hline 195 & $\begin{array}{l}15 \\
16\end{array}$ & $\mathbf{P M}$ & 49.24 & 47.22 & 48.76 \\
\hline $\begin{array}{l}196 \\
197\end{array}$ & $\begin{array}{l}16 \\
17\end{array}$ & PM & 52.23 & 51.95 & 51.96 \\
\hline $\begin{array}{l}197 \\
198\end{array}$ & $\begin{array}{l}17 \\
18\end{array}$ & PM & 52.95 & 57.84 & $\begin{array}{l}55.74 \\
46.39\end{array}$ \\
\hline 199 & $\begin{array}{l}10 \\
19\end{array}$ & $\begin{array}{l}\text { PM } \\
\text { PM }\end{array}$ & $\begin{array}{l}52.33 \\
50.56\end{array}$ & 50.87 & $\begin{array}{l}46.39 \\
48.54\end{array}$ \\
\hline 200 & 20 & $\mathrm{PM}$ & 56.42 & 54.59 & 50.78 \\
\hline 201 & 21 & PM & 58.93 & 57.29 & 55.38 \\
\hline 202 & 22 & PM & 49.06 & 49.02 & 46.30 \\
\hline 203 & 23 & PM & 64.45 & 55.46 & - \\
\hline 204 & 24 & PM & 51.83 & - & - \\
\hline 205 & 25 & PM & 39.06 & - & 47.97 \\
\hline 206 & 26 & $\mathbf{P M}$ & 60.61 & 53.57 & 50.60 \\
\hline 207 & 27 & PM & 59.93 & 55.56 & 49.59 \\
\hline 208 & 28 & PM & 50.15 & 49.72 & 42.97 \\
\hline 209 & 29 & PM & 55.65 & - & 49.54 \\
\hline 210 & 30 & PM & - & 62.50 & 51.14 \\
\hline 211 & 31 & $\mathbf{P M}$ & 50.68 & 50.29 & 47.22 \\
\hline 212 & 32 & PM & 46.32 & 50.83 & - \\
\hline 213 & 33 & PM & 49.48 & 53.69 & 53.33 \\
\hline 214 & 34 & PM & 51.63 & 49.45 & - \\
\hline 215 & 35 & PM & - & 43.96 & 47.55 \\
\hline 216 & 36 & PM & - & 48.89 & 50.26 \\
\hline 217 & 37 & $\mathbf{P M}$ & 57.62 & 56.74 & 53.69 \\
\hline 218 & 38 & PM & 46.69 & 51.81 & 50.00 \\
\hline 219 & 39 & PM & 54.79 & 59.66 & 52.63 \\
\hline 220 & 40 & PM & 56.25 & - & 49.16 \\
\hline 221 & 41 & PM & 44.74 & 57.43 & 51.34 \\
\hline 222 & 42 & PM & 50.48 & - & - \\
\hline 223 & 43 & PM & 46.20 & 46.57 & - \\
\hline 224 & 44 & PM & 50.13 & 50.27 & 49.20 \\
\hline 225 & 45 & PM & 49.11 & 54.90 & 46.88 \\
\hline
\end{tabular}


TABLE B.1 (Cont.)

\begin{tabular}{|c|c|c|c|c|c|}
\hline OBS & IDNO & NERVE & VELO2 & VELO3 & VELO4 \\
\hline 226 & 1 & ss & 44.87 & 41.16 & 44.87 \\
\hline 227 & 2 & SS & 46.05 & 47.30 & 42.68 \\
\hline 228 & 3 & SS & 46.05 & 47.30 & 42.68 \\
\hline 229 & 4 & SS & 37.76 & 34.44 & 35.16 \\
\hline 230 & 5 & SS & 46.05 & 43.15 & 39.77 \\
\hline 231 & 6 & SS & 44.87 & 43.75 & 38.89 \\
\hline 232 & 7 & SS & 40.70 & 42.68 & 43.27 \\
\hline 233 & 8 & SS & 38.89 & 42.19 & 43.75 \\
\hline 234 & 9 & SS & 38.89 & 42.68 & 42.19 \\
\hline 235 & 10 & SS & 40.70 & 42.68 & 46.05 \\
\hline 236 & 11 & SS & 38.89 & 42.19 & 34.50 \\
\hline 237 & 12 & SS & 43.75 & 42.68 & . \\
\hline 238 & 13 & ss & 47.30 & - & - \\
\hline 239 & 14 & SS & . & - & - \\
\hline 2.40 & 15 & SS & 40.70 & 39.77 & 38.04 \\
\hline 241 & 16 & SS & 40.18 & 35.54 & 37.23 \\
\hline 242 & 17 & SS & 35.00 & 35.00 & 35.00 \\
\hline 243 & 18 & SS & 45.31 & - & 40.77 \\
\hline 244 & 19 & SS & 42.68 & 43.27 & 36.68 \\
\hline 245 & 20 & SS & 43.75 & 43.75 & 44.87 \\
\hline 246 & 21 & ss & 42.68 & 41.16 & 41.16 \\
\hline 247 & 22 & SS & 40.70 & 39.77 & 33.65 \\
\hline 248 & 23 & SS & 44.41 & 44.87 & . \\
\hline 249 & 24 & SS & 42.23 & • & - \\
\hline 250 & 25 & SS & 37.50 & - & 39.77 \\
\hline 251 & 26 & SS & 34.44 & 40.18 & 41.67 \\
\hline 252 & 27 & SS & 35.71 & 35.90 & 37.50 \\
\hline 253 & 28 & SS & 42.68 & 41.67 & 40.28 \\
\hline 254 & 29 & SS & 35.51 & - & 38.89 \\
\hline 255 & 30 & SS & 40.70 & 42.68 & 41.67 \\
\hline 256 & 31 & SS & 35.26 & 41.67 & 41.77 \\
\hline 257 & 32 & SS & 40.28 & 42.68 & . \\
\hline 258 & 33 & SS & 45.67 & 48.61 & 48.61 \\
\hline 259 & 34 & SS & 40.76 & 43.75 & - \\
\hline 260 & 35 & SS & 32.45 & 40.70 & 28.69 \\
\hline 261 & 36 & SS & 56.64 & - & . \\
\hline 262 & 37 & SS & 36.59 & 41.67 & 40.70 \\
\hline 263 & 38 & SS & 37.50 & 39.77 & 38.89 \\
\hline 264 & 39 & SS & 37.50 & 42.68 & 43.15 \\
\hline 265 & 40 & SS & 40.70 & - & 36.46 \\
\hline 266 & 41 & SS & 39.40 & 44.87 & 41.67 \\
\hline 267 & 42 & SS & 41.19 & - & - \\
\hline 268 & 43 & SS & 38.35 & 39.77 & 40.28 \\
\hline 269 & 44 & SS & 34.57 & 40.70 & 43.75 \\
\hline 270 & 45 & ss & 35.33 & 38.89 & 35.00 \\
\hline
\end{tabular}


TABLE B.2 Individual skin temperature values at baseline $\left({ }^{\circ} \mathrm{C}\right)$

\begin{tabular}{|c|c|c|c|c|c|c|c|c|c|c|}
\hline ID\# & CRD & Date & me $T$ & rech & d) & Dom & 5 & e & $\mathbf{s}$ & \\
\hline $\begin{array}{l}001 \\
002\end{array}$ & 121 & 0519 & $\begin{array}{l}1616 \\
1424\end{array}$ & $\begin{array}{l}\text { DP } \\
\text { DP }\end{array}$ & $\begin{array}{l}R \\
R\end{array}$ & - & & 34.7 & 34.7 & 34.7 \\
\hline $\begin{array}{l}002 \\
003\end{array}$ & $\begin{array}{l}121 \\
121\end{array}$ & $\begin{array}{l}0520 \\
0521\end{array}$ & $\begin{array}{l}1424 \\
1503\end{array}$ & $\begin{array}{l}\text { DP } \\
\text { DP }\end{array}$ & $\begin{array}{l}\mathbf{R} \\
\mathbf{R}\end{array}$ & $\dot{\bullet}$ & $\begin{array}{l}34.7 \\
35.4\end{array}$ & $\begin{array}{l}34.7 \\
33.6\end{array}$ & $\begin{array}{l}34.7 \\
34.0\end{array}$ & $\begin{array}{l}34.7 \\
.\end{array}$ \\
\hline 004 & 121 & 0520 & 1007 & $\mathrm{DP}$ & $\mathbf{R}$ & - & 30.7 & 28.8 & 30.1 & - \\
\hline 005 & 121 & 0521 & 1248 & DP & 7 & • & 34.7 & 34.1 & 34.0 & - \\
\hline 006 & 121 & 0521 & 1404 & DP & $\pi$ & - & 35.9 & 34.4 & 33.0 & - \\
\hline 007 & 121 & 0519 & 1520 & DP & $\mathbf{R}$ & - & 33.0 & 32.4 & 32.3 & - \\
\hline 008 & 121 & 0521 & 1046 & DP & $\mathbf{R}$ & - & 33.9 & 33.4 & 31.0 & 31.0 \\
\hline 009 & 121 & 0521 & 0900 & DP & $\mathbf{R}$ & - & 33.4 & 33.3 & 30.3 & 30.4 \\
\hline 010 & 121 & 0521 & 0807 & DP & $\mathbf{R}$ & - & 33.0 & 32.7 & 31.0 & 31.0 \\
\hline 011 & 121 & 0520 & 0854 & $D P$ & $\mathbf{R}$ & - & 33.0 & 32.9 & 32.1 & 32.1 \\
\hline 012 & 121 & 0520 & 1613 & $D P$ & $\mathbf{R}$ & - & 34.0 & 34.0 & 33.8 & 33.8 \\
\hline 013 & 121 & 0520 & 1108 & DP & $\mathbf{R}$ & - & 33.4 & 32.0 & - & - \\
\hline 014 & 121 & & & DP & - & - & - & 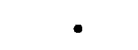 & - & - \\
\hline 015 & 121 & 0519 & 1710 & DP & $\mathbf{R}$ & - & 34.9 & & 32.6 & 32.8 \\
\hline 016 & 121 & 0520 & 1517 & DP & $\mathbf{R}$ & - & 33.4 & 33.9 & 33.0 & 33.1 \\
\hline 017 & 121 & 0521 & 0954 & DP & $\mathbf{R}$ & & 34.3 & 33.7 & 32.8 & - \\
\hline 018 & 121 & 0519 & 1358 & DP & $\mathbf{R}$ & 29.3 & 34.5 & 33.3 & 32.3 & . \\
\hline 019 & 121 & 0520 & 1326 & DP & $\mathbf{R}$ & - & 34.2 & 34.2 & 34.0 & 33.6 \\
\hline 020 & 121 & 0520 & 0757 & DP & $\mathbf{R}$ & - & 32.4 & 33.2 & 32.4 & 32.3 \\
\hline 021 & 121 & 0519 & 1302 & DP & $\mathbf{R}$ & 29.6 & 33.4 & 32.8 & 32.6 & 32.6 \\
\hline 022 & 121 & 0520 & 1150 & DP & R & - & 33.8 & 33.1 & 32.7 & - \\
\hline 023 & 121 & 0630 & 1441 & BG & I & - & 33.7 & 32.6 & - & 33.1 \\
\hline 024 & 121 & 0701 & 1025 & BG & L & • & - & 31.2 & - & 31.0 \\
\hline 025 & 121 & 0701 & 0810 & BG & I & 22.5 & 29.8 & 29.3 & - & 26.8 \\
\hline 026 & 121 & 0701 & 1715 & BG & $\mathbf{R}$ & - & - & - & - & • \\
\hline 027 & 121 & 0701 & 1112 & BG & F & - & 32.9 & 31.7 & - & 33.1 \\
\hline 028 & 121 & 0701 & 1615 & BG & $\mathbf{R}$ & 28.0 & - & • & - & - \\
\hline 029 & 121 & 0630 & 1550 & BG & $=$ & 27.4 & 33.7 & 33.2 & . & . \\
\hline 030 & 121 & 0701 & 1415 & BG & $\mathbf{R}$ & - & 33.2 & 33.1 & • & . \\
\hline 031 & 121 & 0702 & 0810 & BG & $\mathbf{R}$ & 22.6 & 32.1 & 32.2 & - & - \\
\hline 032 & 121 & 0630 & 1040 & BG & L & - & - & . & - & - \\
\hline 033 & 121 & 0701 & 1505 & BG & L & 27.1 & 34.6 & 34.5 & 33.7 & • \\
\hline 034 & 121 & 0630 & 0840 & BG & $\mathbf{R}$ & - & - & • & - & - \\
\hline 035 & 121 & 0701 & 0920 & BG & $\mathbf{R}$ & - & 32.2 & 31.9 & • & . \\
\hline 036 & 121 & 0702 & 1330 & BG & $\mathbf{R}$ & - & • & 32.1 & 32.4 & . \\
\hline 037 & 121 & 0702 & 1010 & BG & $\mathbf{R}$ & 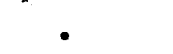 & 28.8 & 26.0 & - & 28.2 \\
\hline 038 & 121 & 0701 & 1325 & BG & $\mathbf{R}$ & 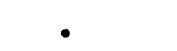 & 34.8 & 33.2 & - & - \\
\hline 039 & 121 & 0702 & 0905 & BG & $\mathbf{R}$ & 26.6 & 29.5 & 28.6 & - & 27.8 \\
\hline 040 & 121 & 0702 & 1555 & BG & $\mathbf{R}$ & - & 33.4 & 33.5 & • & 33.5 \\
\hline 041 & 121 & 0630 & 1145 & BG & $\mathbf{R}$ & $\bullet$ & - & • & . & • \\
\hline 042 & 121 & 0630 & 0952 & BG & $\mathbf{R}$ & 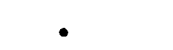 & & - & - & \\
\hline 043 & 121 & 0702 & 1438 & BG & $\mathbf{R}$ & 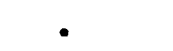 & 31.8 & 31.4 & - & 33.3 \\
\hline 04 & 121 & 0702 & 1120 & BG & $\mathbf{R}$ & $\bullet$ & 31.1 & - & - & 27.9 \\
\hline 045 & 121 & 0630 & 1324 & BG & $\mathbf{R}$ & - & - & - & • & • \\
\hline
\end{tabular}


TABLE B.3 Individual skin temperature values at IPE $\left({ }^{\circ} \mathrm{C}\right)$

\begin{tabular}{|c|c|c|c|c|c|c|c|c|c|c|}
\hline ID\# & CRD & Date & Time & Tech & Hand & Room & HSTS & HSTe & LSTS & LsTe \\
\hline 0 & 131 & 0710 & 1601 & DP & $\mathbf{R}$ & 27.7 & 34.7 & 33.7 & 32.2 & 10 \\
\hline 0 & 131 & 0708 & 1610 & $D P$ & $\mathbf{R}$ & 27.7 & 34.2 & 33.9 & 34.4 & 34.5 \\
\hline 003 & 131 & 0709 & 1040 & DP & $\mathbf{R}$ & 25.2 & 33.9 & 33.9 & 34.4 & 34.6 \\
\hline 004 & 131 & 0710 & 1414 & DP & $\mathbf{R}$ & & 33.4 & 33.0 & 29.0 & 29.2 \\
\hline 005 & 131 & 0710 & 1506 & DP & $\mathbf{R}$ & 25.5 & 33.1 & 32.7 & 32.4 & 32.5 \\
\hline 006 & 131 & 0709 & 1430 & DP & $\mathbf{R}$ & & 34.8 & 34.1 & 34.5 & 34.3 \\
\hline 007 & 131 & 0709 & 0816 & DP & $\mathbf{R}$ & 22.7 & 33.9 & 33.4 & 33.6 & 34.0 \\
\hline 008 & 131 & 0710 & 1318 & DP & $\mathbf{R}$ & 22.0 & 33.3 & 31.9 & 30.9 & 31.0 \\
\hline 009 & 131 & 0708 & 1508 & DP & $\mathbf{R}$ & • & 34.8 & 33.4 & $3<.7$ & 33.4 \\
\hline 010 & 131 & 0708 & 1315 & DP & $\mathbf{R}$ & 21.9 & 32.0 & 31.7 & 31.4 & 31.3 \\
\hline 011 & 131 & 0708 & 1647 & DP & $\mathbf{R}$ & - & 35.0 & 34.1 & .0 & 35.4 \\
\hline 012 & 131 & 0709 & 1130 & DP & $\mathbf{R}$ & . & 34.3 & 33.5 & 33.5 & 34.0 \\
\hline 013 & 131 & . & - & DP & - & - & - & - & - & - \\
\hline 014 & 131 & & - & DP & - & . & - & - & - & - \\
\hline 015 & 131 & 0710 & 0904 & DP & $\mathbf{R}$ & & 33.4 & 32.7 & 31.5 & 31.2 \\
\hline 016 & 131 & 0708 & 0926 & DP & $\mathbf{R}$ & 24.3 & 32.9 & 31.8 & 30.3 & 30.5 \\
\hline 017 & 131 & 0708 & 1420 & DP & $\mathbf{R}$ & . & 34.6 & 34.0 & 34.1 & 34.5 \\
\hline 018 & 131 & & & DP & - & - & - & & • & - \\
\hline 019 & 131 & 0709 & 1600 & DP & $\mathbf{R}$ & 28.3 & 35.0 & 35.0 & 34.8 & 35.2 \\
\hline 020 & 131 & 0710 & 1300 & - & $\mathbf{R}$ & - & 33.0 & 32.5 & 32.1 & 32.1 \\
\hline 021 & 131 & 0708 & 0827 & $\mathrm{DP}$ & $\mathbf{R}$ & 33.0 & 32.7 & 31.7 & 31.8 & 32.4 \\
\hline 022 & 131 & 0710 & 1054 & - & $\mathbf{R}$ & - & 32.4 & 30.5 & 31.7 & 31.7 \\
\hline 023 & 131 & 0820 & 1342 & DP & I & . & 33.8 & 32.3 & 32.5 & 32.4 \\
\hline 024 & 131 & . & - & DP & • & - & - & - & - & - \\
\hline 025 & 131 & 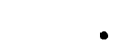 & - & DP & • & - & - & - & - & - \\
\hline 026 & 131 & 0817 & 1500 & - & $\mathbf{R}$ & 27.9 & 34.5 & 34.9 & 32.4 & 32.4 \\
\hline 027 & 131 & 0818 & 0813 & DP & $\mathbf{R}$ & . & 32.6 & 30.6 & 31.6 & 32.4 \\
\hline 028 & 131 & 0817 & 1627 & DP & $\mathbf{R}$ & • & 32.7 & 34.5 & • & 33.9 \\
\hline 029 & 131 & - & - & $D P$ & • & • & - & - & • & - \\
\hline 030 & 131 & 0818 & 1513 & DP & $\mathbf{R}$ & • & 33.6 & 33.9 & - & - \\
\hline 031 & 131 & 0818 & 1322 & DP & $\mathbf{R}$ & • & 33.9 & 33.1 & 31.5 & 32.0 \\
\hline 032 & 131 & 0817 & 1300 & DP & L & • & 34.5 & 33.6 & 34.0 & 34.6 \\
\hline 033 & 131 & 0817 & 1402 & DP & I & • & 35.4 & 34.7 & - & 33.0 \\
\hline 034 & 131 & 0818 & 1650 & DP & $\mathbf{R}$ & • & 35.3 & 34.1 & & 34.5 \\
\hline 035 & 131 & 0819 & 0811 & DP & $\mathbf{R}$ & 24.8 & 32.6 & 32.0 & 31.2 & 31.3 \\
\hline 036 & 131 & 0819 & 1030 & DP & $\mathbf{R}$ & 23.0 & 32.3 & 32.1 & 32.3 & 32.7 \\
\hline 037 & 131 & 0819 & 1416 & DP & $\mathbf{R}$ & . & 32.4 & 32.5 & 31.4 & 31.3 \\
\hline 038 & 131 & 0819 & 1330 & DP & $\mathbf{R}$ & . & 33.8 & 32.2 & 31.5 & 31.5 \\
\hline 039 & 131 & 0818 & 1034 & DP & $\mathbf{R}$ & 25.6 & 32.1 & 32.0 & - & 31.7 \\
\hline 040 & 131 & & . & . & . & • & . & . & • & - \\
\hline 041 & 131 & 0818 & 1610 & DP & $\mathbf{R}$ & - & 34.9 & 32.7 & 33.2 & 33.3 \\
\hline 042 & 131 & & & DP & • & • & - & - & - & - \\
\hline 043 & 131 & 0820 & 1241 & $D P$ & $\mathbf{R}$ & 22.7 & 32.0 & 31.4 & 33.4 & 33.3 \\
\hline 044 & 131 & 0820 & 0904 & DP & $\mathbf{R}$ & 23.9 & 33.2 & 32.5 & 31.5 & 31.7 \\
\hline 045 & 131 & 0818 & 0921 & DP & $\mathbf{R}$ & 24.2 & 32.2 & 32.4 & 30.9 & 32.9 \\
\hline
\end{tabular}


TABLE B.4 Individual skin temperature values at DPE $\left({ }^{\circ} \mathrm{C}\right)$

\begin{tabular}{|c|c|c|c|c|c|c|c|c|c|c|}
\hline D\# & CRD & ate & Time & Tech & Hand & Room & HSTS & HSTe & LSTS & LSTe \\
\hline 001 & 141 & 0825 & 0916 & $D P$ & $\mathbf{R}$ & $\theta^{\circ}$ & 35.1 & 33.9 & - & 34.1 \\
\hline 02 & 141 & 0826 & 1300 & $\mathrm{DP}$ & & 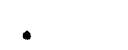 & 33.0 & 32.0 & 32.0 & 33.1 \\
\hline 03 & 141 & 0825 & 1400 & $D P$ & & 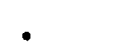 & 34.6 & & & 32.8 \\
\hline 04 & 141 & 0825 & 1317 & DP & & & 33.3 & 33.2 & 30.3 & 30.8 \\
\hline 05 & 141 & 0825 & 1000 & DP & & . & 32.0 & 31.4 & . & 31.8 \\
\hline 06 & 141 & 0825 & 1136 & DP & & & 32.3 & 33.1 & • & 31.2 \\
\hline 07 & 141 & 825 & 1538 & DP & & & 35.2 & 34.6 & • & 35.0 \\
\hline 08 & 141 & 326 & 1328 & $\mathrm{DP}$ & & 25.4 & 34.1 & 32.5 & . & 33.5 \\
\hline 209 & 141 & 25 & 1451 & DP & & & 34.1 & 34.0 & 33.3 & 33.4 \\
\hline 10 & 14 & 25 & 1630 & DP & & & 2 & 34.4 & & .2 \\
\hline 1 & 14 & 0828 & 1015 & DP & & & 30.7 & 30.6 & 30.6 & 30.6 \\
\hline 18 & 14 & . & • & $D P$ & $\cdot$ & - & $\bullet$ & - & - & - \\
\hline 13 & 14 & • & • & DP & . & • & $e^{\circ}$ & • & $\bullet$ & • \\
\hline 14 & 14 & & & DP & . & & . & - & . & . \\
\hline 15 & 141 & 27 & 0950 & DP & $\mathbf{R}$ & 26.9 & 33.2 & 32.3 & 31.6 & 31.5 \\
\hline 1 & 14 & 5 & 1 & DP & $R$ & 23 & 33.2 & 32.4 & 32.0 & 32.0 \\
\hline 1 & 14 & 5 & 30 & DP & $\mathbf{R}$ & 26.8 & 32.9 & 33.1 & 32.9 & 33.2 \\
\hline 18 & 14 & 5 & 40 & DP & $\mathbf{R}$ & . & 32.1 & 31.2 & 31.5 & 31.1 \\
\hline 1 & 14 & 5 & 88 & DP & $\mathbf{R}$ & . & 32.4 & 32.2 & . & 30.5 \\
\hline 120 & 14 & 5 & 34 & DP & $R$ & - & 34.0 & 33.2 & • & 33.2 \\
\hline 121 & 14 & 6 & 0 & DE & $R$ & • & 33.2 & 32.5 & 31.2 & 31.3 \\
\hline 12 & 14 & 27 & 45 & D & $\mathbf{R}$ & - & 32.0 & 31.4 & 29.7 & 30.0 \\
\hline 23 & 14 & • & • & D] & - & - & - & , & - & • \\
\hline 2. & 14 & $\bullet$ & • & DP & 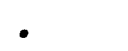 & $\theta^{\circ}$ & • & - & - & - \\
\hline 2 & 14 & 0928 & 1305 & DP & $\mathbf{R}$ & 26.2 & 33.5 & 33.5 & . & 32.3 \\
\hline 2 & 14 & 0928 & 1425 & DP & $\mathbf{R}$ & 27 & 35.0 & 33.9 & • & 32.0 \\
\hline 02 & 14 & 0929 & 0813 & DP & F & 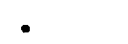 & 33.4 & 32.8 & 31.4 & 32.0 \\
\hline 22 & 14 & 0929 & 0930 & DP & F & 25.0 & 32.7 & 32.6 & 30.9 & 31.1 \\
\hline 2 & 14 & 0930 & 1525 & DP & $\mathbf{R}$ & $\bullet$ & 33.4 & 32.4 & 32.5 & 32.9 \\
\hline 13 & 141 & 0929 & 1145 & DP & F & 24.3 & 33.0 & 32.6 & 31.9 & 32.6 \\
\hline 3 & 147 & 0929 & 1400 & DP & N & 26.3 & 33.9 & 33.6 & 32.6 & 33.2 \\
\hline 3 & 141 & 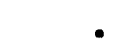 & & DP & • & & . & • & & . \\
\hline $3:$ & 141 & 29 & 1505 & DP & I & & 35.2 & 34.9 & 34.5 & 35.0 \\
\hline 3 & 141 & 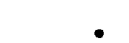 & & DP & • & & . & • & & . \\
\hline $03 !$ & 141 & 0930 & 0930 & DP & $\mathbf{R}$ & & 33.8 & 32.2 & 28.1 & 28.6 \\
\hline 036 & 141 & 0930 & 1315 & DP & $\mathbf{R}$ & $\bullet$ & 33.7 & 33.0 & 32.4 & 32.2 \\
\hline $03^{\circ}$ & 141 & 0930 & 1040 & DP & $\mathbf{R}$ & $\bullet$ & 32.0 & 31.6 & 32.0 & 32.7 \\
\hline 038 & 141 & 0930 & 1145 & DP & $\mathbf{R}$ & & 32.2 & 31.6 & 31.6 & 30.7 \\
\hline 03 & 141 & 0930 & 1430 & $D P$ & $\mathbf{R}$ & 33.5 & 32.5 & 32.6 & 32.5 & \\
\hline 040 & 141 & 0930 & 1240 & $D P$ & $\mathbf{R}$ & • & 32.4 & 32.0 & 30.1 & 30.4 \\
\hline 041 & 141 & 0929 & 1030 & DP & $\mathbf{R}$ & & 34.1 & 31.2 & 30.4 & 30.8 \\
\hline 042 & 141 & & & DP & • & & • & • & & $\bullet$ \\
\hline 043 & 141 & 0930 & 1640 & DP & . & • & 33.9 & 34.2 & 32.8 & 32.6 \\
\hline 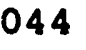 & 141 & 0928 & 1527 & DP & $\mathbf{R}$ & • & 34.4 & 33.9 & & 34.7 \\
\hline 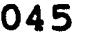 & 141 & 0929 & 1235 & DP & $\mathbf{R}$ & . & 32.0 & 31.9 & 30.0 & 30.4 \\
\hline
\end{tabular}




\section{DISTRIBUTION LIST}

Internal:

M.H. Bhattacharyya (35)

ANL Patent Dept

D.E. Nadziejka (6)

TIS Files

\section{External:}

DOE-OSTI (2)

ANL-E Library (2)

ANL-W Library

Manager, Chicago Field Office (DOE)

Sponsor-required distribution (21)

Commander (1)

U.S. Army Medical Research and Development Command

ATTN: SGRD-RMI-S

Fort Detrick

Frederick, MD 21702-5012

Commander (6)

U.S. Army Biomedical Research and Development Laboratory

ATTN: SGRD-UBZ-RA

Fort Detrick

Frederick, MD 21702-5010

Defense Technical Information Center (2)

ATTN: DTIC-FDAC

Cameron Station

Alexandria, VA 22304-6145

Commandant (1)

Academy of Health Scien :es, U.S. Army

ATTN: HSHA-CDS

Fort Sam Houston, TX 78234-6100

Commandant (1)

Academy of Health Sciences, U.S. Army

ATTN: HSHA-CDC

Fort Sam Houston, TX 78234-6100

President (1)

U.S. Army Field Artillery Board

ATTN: ATZR-BDW

Fort Sill, OK 73503-6100

Commander (1)

U.S. Army Armaments Research, Development and Engineering Center ATTN: SMCAR-FSA-S

Dover, NJ 07801-5001 
Commander (1)

U.S. Army Combat Systems Test Activity

ATTN: STECS-EN-PC

Aberdeen Proving Ground, MD 21005-5059

Commandant (1)

U.S. Army Field Artillery School

ATTN: ATSF-TSM-CN

Fort Sill, OK 73505-5600

Project Manager (1)

Cannon Artillery Weapons System

ATTN: AMCPM-HIP

Dover, NJ 07806-5000

Commander (1)

U.S. Army Operational Test and Evaluation Agency

ATTN: CSTE-TSM

5600 Columbia Pike

Falls Church, VA 22041-5115

Commander (1)

U.S. Army Environmental Hygiene Agency

ATTN: HSHB-MO-A

Aberdeen Proving Ground, MD 21010-5422

Commander (1)

U.S. Army Materiel Command

ATTN: AMCSG

5001 Eisenhower Avenue

Alexandria, VA 22333-0001

Director (1)

Army Materiel Systems Analysis Activity

ATTN: AMXSY-GS

Aberdeen Proving Ground, MD 21005-5071

Commander (1)

U.S. Army Training and Doctrine Command ATTN: ATMD

Fort Monroe, VA 23651-5000 


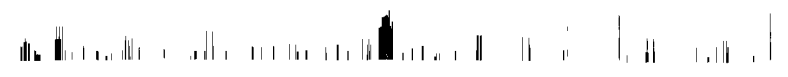

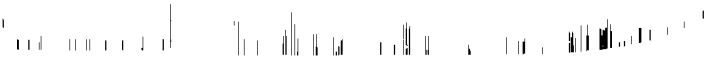
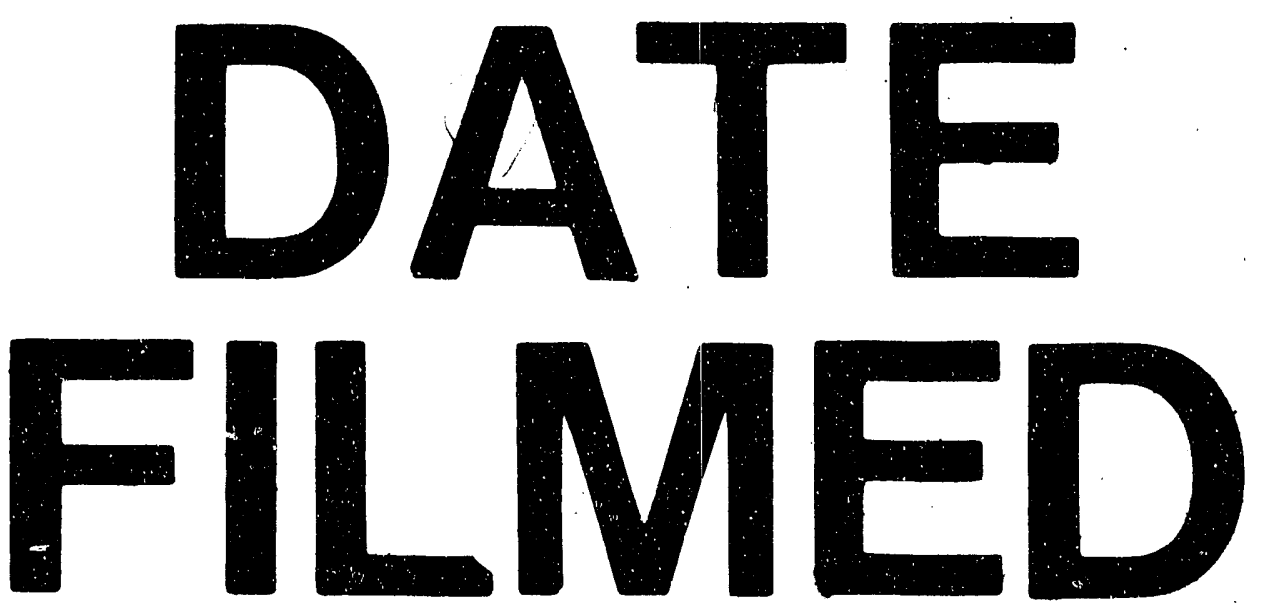

1

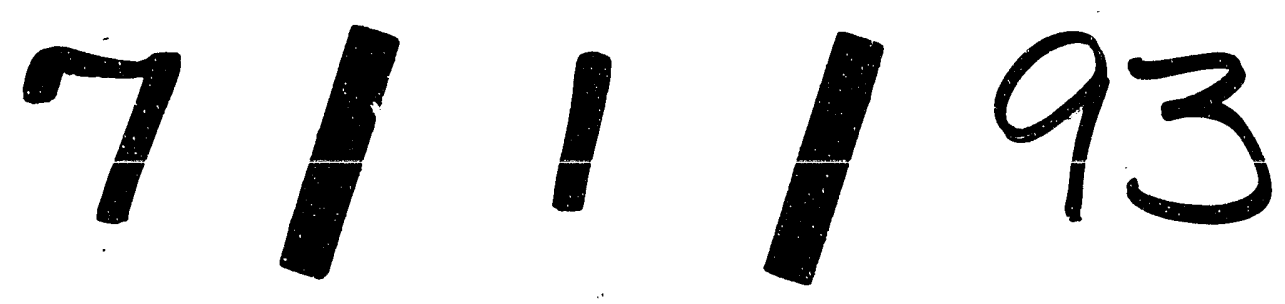


